\title{
AN CORRAN, STAFFIN, SKYE: A ROCKSHELTER WITH MESOLITHIC AND LATER OCCUPATION
}

\author{
Alan Saville, ${ }^{1}$ Karen Hardy, ${ }^{2}$ \\ Roger Miket ${ }^{3}$ and Torben Bjarke Ballin ${ }^{4}$
}

With contributions by

László Bartosiewicz, Clive Bonsall, Margaret Bruce, Stephen Carter, Trevor Cowie, Oliver Craig, Ywonne Hallén, Timothy G. Holden, N.W. Kerr, Jennifer Miller, Nicky Milner, and Catriona Pickard, and with illustrations by

Alan Braby, Marion O’Neil, and Craig Angus

1 Corresponding author. Scottish History and Archaeology Department, National Museums Scotland, Chambers Street, Edinburgh, EH1 1JF, Scotland [email: a.saville@nms.ac.uk] 2 ICREA, Institució Catalana de Recerca I Estudis Avançats, Departament de Prehistòria, Facultat de Filosofia i Lletres, Campus UAB, 08193 Bellaterra, Barcelona, Spain [email: khardy@icrea.cat] 3 The Miller's House, Yearle Mill, Wooler, Northumberland, NE71 6RA, England. [email: yearlemill@yahoo.co.uk] 4 Lithic Research, Banknock Cottage, Denny, Stirlingshire, FK6 5NA, Scotland [email: lithicresearch@btinternet.com] 
Published by the Society of Antiquaries of Scotland, www.socantscot.org.uk with Historic Scotland, www.historic-scotland.gov.uk and the Council for British Archaeology, www.britarch.ac.uk

Editor Helen Bleck

Produced by Archetype Informatique SARL, www.archetype-it.com

ISBN: 978-1-908332-99-8

ISSN: $1773-3803$

Requests for permission to reproduce material from a $S A I R$ report should be sent to the Director of the Society of Antiquaries of Scotland, as well as to the author, illustrator, photographer or other copyright holder.

Copyright in any of the Scottish Archaeological Internet Reports series rests with the SAIR Consortium and the individual authors.

The maps are reproduced from Ordnance Survey material with the permission of Ordnance Survey on behalf of The Controller of Her Majesty's Stationery Office. (C) Crown copyright 2001. Any unauthorised reproduction infringes Crown copyright and may lead to prosecution or civil proceedings. Historic Scotland Licence No. GD 03032G, 2002.

The consent does not extend to copying for general distribution, advertising or promotional purposes, the creation of new collective works or resale. 


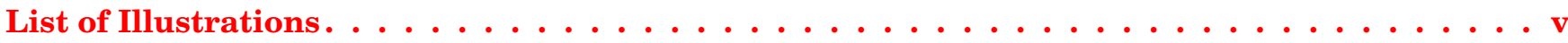

List of Tables $\ldots \ldots \ldots \ldots \ldots \ldots \ldots \ldots \ldots \ldots \ldots \ldots \ldots \ldots \ldots \ldots$

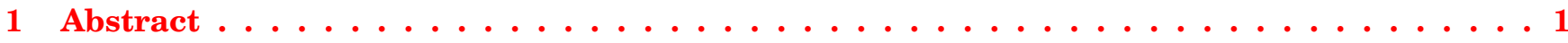

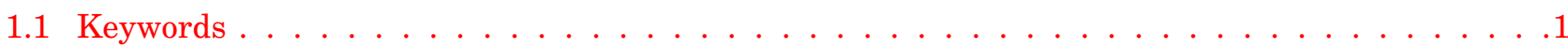

2 Introduction, by Roger Miket, Karen Hardy and Alan Saville . . . . . . . . . . . . . 3

2.1 Discovery and prelude to the excavation $\ldots \ldots \ldots \ldots \ldots \ldots \ldots$

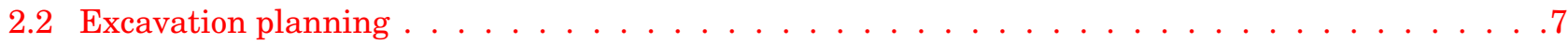

2.3 Excavation strategy $\ldots \ldots \ldots \ldots \ldots \ldots \ldots \ldots \ldots \ldots \ldots$

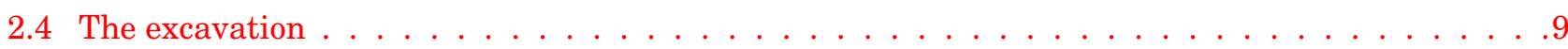

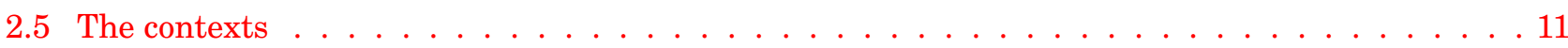

3 Post-excavation Analysis and Specialist Reports, by Karen Hardy,

Alan Saville, Roger Miket and Torben Bjarke Ballin . . . . . . . . . . . . . . . . . 17

4 The Lithic Artefacts, by Karen Hardy, Alan Saville and Torben Bjarke Ballin . . . . . . . 19

4.1 Introduction . . . . . . . . . . . . . . . . . . . . . . 19

4.2 Raw material . . . . . . . . . . . . . . . . . . . . . . . . . 19

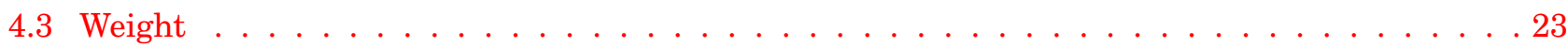

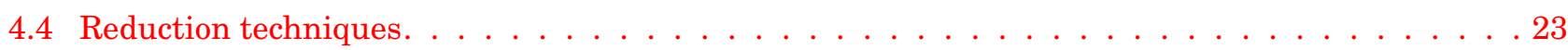

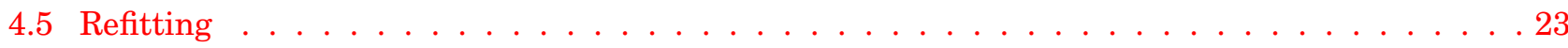

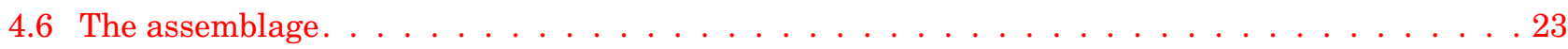

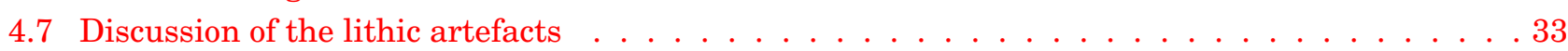

5 Bone and Antler Artefacts, by Alan Saville, with contributions by Ywonne Hallén

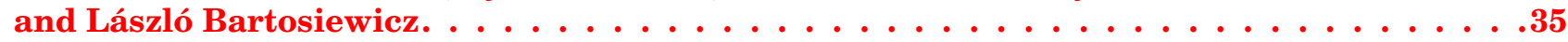

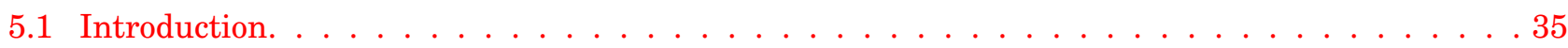

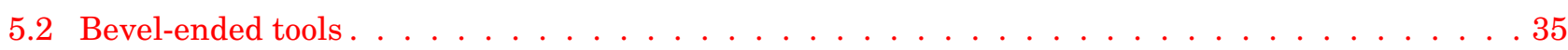

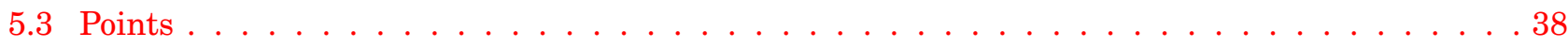

5.4 Miscellaneous/unclassified worked pieces. . . . . . . . . . . . . . . . . . 41

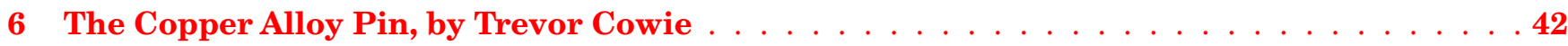

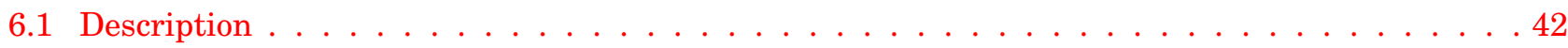

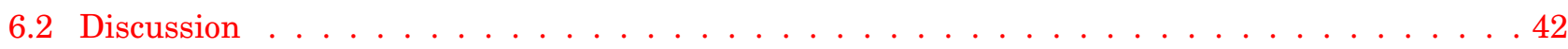

7 Human Bone, by Margaret Bruce (bone) and N W Kerr (teeth) . . . . . . . . . . . . . .44

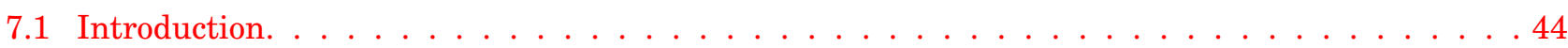

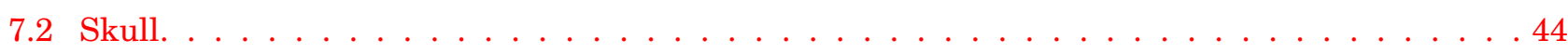

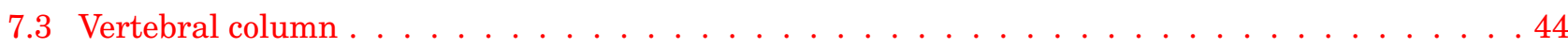




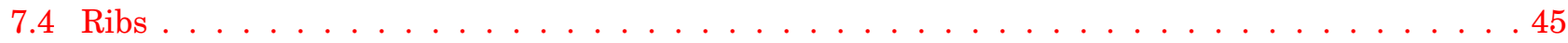

7.5 Upper limb . . . . . . . . . . . . . . . . . . . . . . . . . . . . 45

7.6 Lower limb . . . . . . . . . . . . . . . . . . . . . . . . . . . . . . . 45

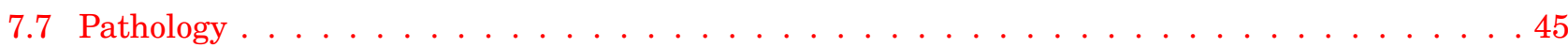

7.8 Number of individuals represented . . . . . . . . . . . . . . . . . . . . . . . . 45

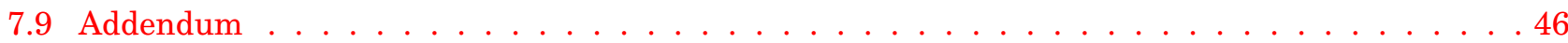

8 Vertebrate Remains, by László Bartosiewicz . . . . . . . . . . . . . . . . . . . . . . . . . . 47

8.1 Introduction. . . . . . . . . . . . . . . . . . . . . . . . 47

8.2 Preservation and recovery . . . . . . . . . . . . . . . . . . . . . . . 4 47

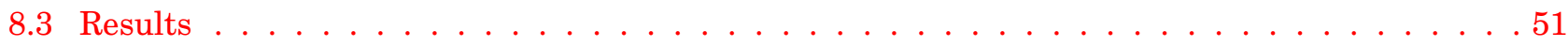

8.4 Discussion. . . . . . . . . . . . . . . . . . . . . . . 59

9 The Marine Molluscs, by Catriona Pickard and Clive Bonsall. . . . . . . . . . . . . . . .62

9.1 Introduction. . . . . . . . . . . . . . . . . . . . . . . . 62

9.2 Procedures . . . . . . . . . . . . . . . . . . . . . . . 62

9.3 Results - discussion and interpretation . . . . . . . . . . . . . . . . . . . 63

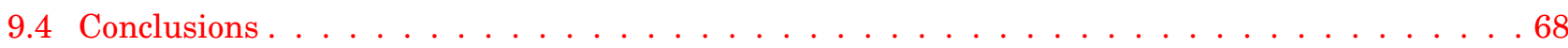

10 Flotation Samples, by Timothy G. Holden, with contributions by Stephen Carter and Jennifer Miller. . . . . . . . . . . . . . . . . . . . . . . . . . . . . . . . .

10.1 Introduction . . . . . . . . . . . . . . . . . . . . . . . . 70

10.2 Uncharred remains . . . . . . . . . . . . . . . . . . . . . . . 70

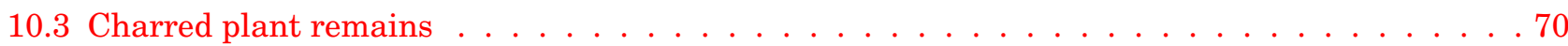

10.4 Terrestrial snail shell . . . . . . . . . . . . . . . . . . . . . . . . . . . 71

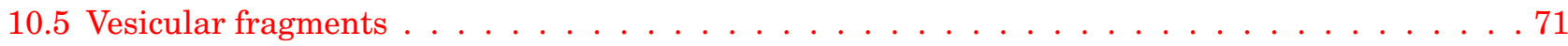

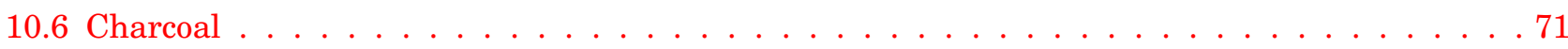

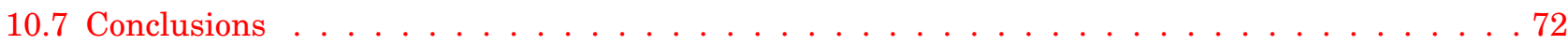

11 Radiocarbon Dates, by Alan Saville and Karen Hardy . . . . . . . . . . . . . . . . 73

12 Isotope Analyses, by Nicky Milner and Oliver Craig . . . . . . . . . . . . . . . . 77

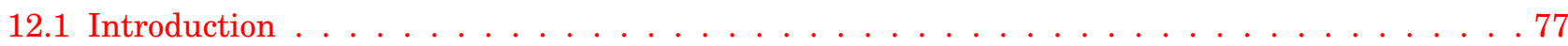

12.2 Sampling and methods . . . . . . . . . . . . . . . . . . . . . . . . . . . . . . . . .

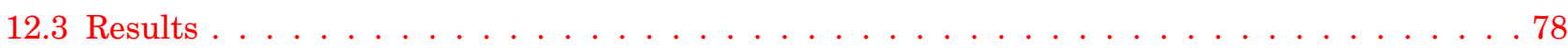

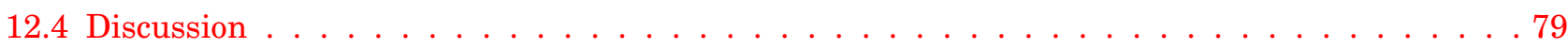

13 General Discussion, by Alan Saville and Karen Hardy . . . . . . . . . . . . . . . . . 80

14 Conclusion, by Alan Saville and Karen Hardy . . . . . . . . . . . . . . . . . . . 82

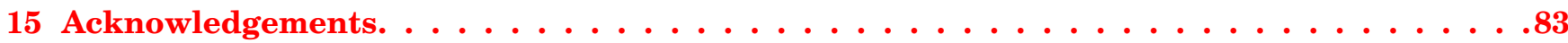

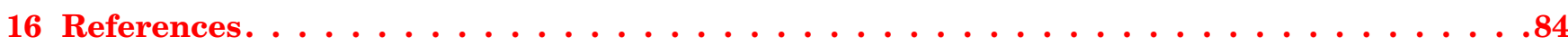

17 Appendix One: Description of the Contexts, by Roger Miket, Karen Hardy

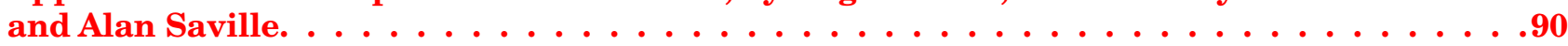

18 Appendix Two: Worked Bone and Antler Artefacts Catalogue, by Alan Saville . . . . . . .95 


\section{LIST OF ILLUSTRATIONS}

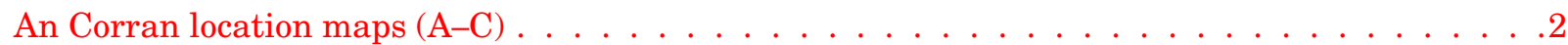

An Corran detailed location map (D) . . . . . . . . . . . . . . . . . . . . . .

Rockshelter ledge in 1988, viewed from the south (photo: Roger Miket) . . . . . . . . . . . . . 3

Rockshelter ledge in 1988, viewed from the north (photo: Roger Miket) . . . . . . . . . . . . .4 Panoramic view of the site and adjacent areas from the ENE prior to the excavation in 1993

(photo: Roger Miket) . . . . . . . . . . . . . . . . . . . . . . . . . . .4

Slope profiles from the rockshelter ledge to the sea. . . . . . . . . . . . . . .5

View from the east after the start of the excavation in 1993 showing the configuration of

the rock-ledges above (photo: Roger Miket) . . . . . . . . . . . . . . . . . . . 6

Plan of the rockshelter ledge showing the position of the 1988 excavation (shaded) . . . . . . . . .6

Plan of the rockshelter ledge showing the position of the 1993-94 excavation area (shaded) . . . . .7

Rock clearance in progress in 1994 viewed from the east following the rockface blasting

(photo: Roger Miket).

Situation in June 1994 subsequent to the rockface blasting, viewed from the north

(photo: Alan Saville) . . . . . . . . . . . . . . . . . . . . . . . . 8

Sketch diagram showing the former and present cliff profile at the site location. . . . . . . . . .9

Excavation in progress in 1993 viewed from the south-east (photo: Roger Miket) . . . . . . . . . 10

Excavation in progress in 1994 viewed from the south (photo: Roger Miket) . . . . . . . . . . . . 10

1993-94 excavation plan showing the location of the recorded sections and selected contexts . . 11

Section D-E at the north edge of the excavation . . . . . . . . . . . . . . . . . 12

Sections $\mathrm{H}-\mathrm{I}$ and $\mathrm{F}-\mathrm{G}$ at the southern limits of the excavation . . . . . . . . . . . . . . . . 12

Section B-C through the basal deposits in the centre of the excavated area . . . . . . . . . . . 14

Burnt deposits (context C8) in upper levels at the rear of the rockshelter (photo: Roger Miket). . 14

Detail of the west end of section B-C showing contexts C35 and C36 (photo: Roger Miket) . . . . 15

Approximate context $\mathrm{C} 17$ horizon viewed from the south . . . . . . . . . . . . . . 15

Stone setting in context C30, viewed from the south (photo: Roger Miket) . . . . . . . . . . 16

Flakes and blades of baked mudstone (photo: NMS) . . . . . . . . . . . . . . . . . 20

Flakes and blades of baked mudstone (photo: NMS) . . . . . . . . . . . . . . . . 20

Large blades of baked mudstone (photo: NMS) . . . . . . . . . . . . . . . . . . . . . . . 21

Flakes and blades of chalcedonic silica (photo: NMS) . . . . . . . . . . . . . . . . . 21

Baked mudstone artefacts with surface alteration, as a percentage of all baked mudstone artefacts in each context. . . . . . . . . . . . . . . . . . . . . . 23

Blades (drawn by Marion O'Neil) . . . . . . . . . . . . . . . . . . . . . . . . . 25

Cores (photo: Alan Saville/NMS) _ . . . . . . . . . . . . . . . . . . . 26

Microliths (photo: NMS) . . . . . . . . . . . . . . . . . . . . . . 27

Microliths, microburins and related forms (drawn by Marion O'Neil) . . . . . . . . . . . . . 28

Scrapers, piercers, edge-trimmed bladelet and miscellaneous retouched piece

(drawn by Marion O'Neil) . . . . . . . . . . . . . . . . . . . . . . . . . . . . . 32

Bevel-ended tools (photo: NMS) . . . . . . . . . . . . . . . . . . . . . . 35

Large bevel-ended tools (photo: NMS) . . . . . . . . . . . . . . . . . . . . . 36

Bevel-ended tools and points (drawn by Marion O'Neil) . . . . . . . . . . . . . . . . . . . . 38

Bevel-ended tools and points (drawn by Marion O'Neil) . . . . . . . . . . . . . . . . . . . 39

Large bevel-ended tools (drawn by Marion O'Neil) . . . . . . . . . . . . . . . . . . . . . 40

Combined bevel-ended tool and point (photo: Alan Saville) . . . . . . . . . . . . . . . . 41

Bone points (photo: NMS) . . . . . . . . . . . . . . . . . . . . . . . . . .41

Copper-alloy pin (photo: NMS) . . . . . . . . . . . . . . . . . . . . . . 42

Copper-alloy pin (drawn by Alan Braby) ． . . . . . . . . . . . . . . . . . . . . 42

The relative abundance of taxa in major wet-sieved samples . . . . . . . . . . . . . . 47

Percentage proportions of fish bone weights recovered by different methods . . . . . . . . . 56

Brown bear phalanx CAT 98 from C34 (photo: NMS) . . . . . . . . . . . . . . . . . . 58

The age distribution of bones from large game . . . . . . . . . . . . . . . . . . . 59

The distribution of size indices calculated from the parameters of red deer measurements

from mainland sites . . . . . . . . . . . . . . . . . . . . . . . . . . 59 
The weight to length distribution of bevel-ended tools ('limpet scoops') and potential raw

materials (refuse bone splinters) . . . . . . . . . . . . . . . . . 60

48 The possible origins of vertebrate remains in the An Corran midden deposits . . . . . . . . . 61

49 Temporal changes in the frequencies of limpets, periwinkles and other shellfish . . . . . . 62

Frequency histograms of length/height ratios $(\mathrm{L} / \mathrm{H})$ of limpet shells from successive phases. . . . 63

Radiocarbon-dated bevel-ended tools (after sampling) (photo: Alan Saville) . . . . . . . . . . .73

Radiocarbon-dated bones (before sampling) (photo: Alan Saville) . . . . . . . . . . . . . . 76

53 Divergent dietary signals from An Corran and other west coast of Scotland

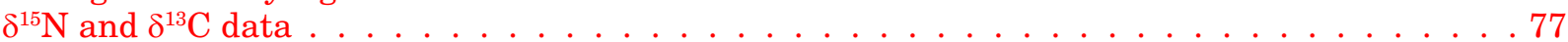




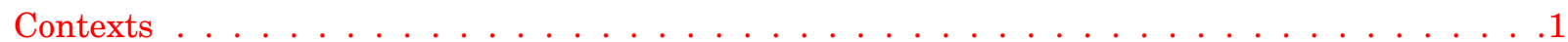

Lithic artefacts by context. . . . . . . . . . . . . . . . . . . . . . . 19

Lithic artefacts by raw material. . . . . . . . . . . . . . . . . . . . . . . 19

Lithic raw materials by main context. . . . . . . . . . . . . . . . . . . . . . . . . . . . . . 22

Baked mudstone artefacts with and without surface alteration, by main context . . . . . . . . 22

Main lithic artefact categories subdivided by main context . . . . . . . . . . . . . . . . . . . . 24

Main lithic artefact categories subdivided by raw material . . . . . . . . . . . . . . . . 24

Typologically classifiable cores by context . . . . . . . . . . . . . . . . . 26

Cores and core fragments by raw material and context . . . . . . . . . . . . . . . . 26

Lithic tools by type and context . . . . . . . . . . . . . . . . . . . . 27

Microliths, microburins and microlith-related forms. . . . . . . . . . . . . . . . 29

Microliths - obliquely blunted point types . . . . . . . . . . . . . . . . . . . 29

Dimensions of complete, and near complete (+), microliths and microburins of chalcedony . . . . 30

Dimensions of complete, and near complete $(+)$, microliths and microburins of

baked mudstone . . . . . . . . . . . . . . . . . . . . . . . . . . . . 30

Microburin types. . . . . . . . . . . . . . . . . . . . . . . . 31

Scrapers by type, context and raw material . . . . . . . . . . . . . . . . . . . 31

Piercers: context and raw material type . . . . . . . . . . . . . . . . . . . . . . 33

Typology and context of bone and antler artefacts . . . . . . . . . . . . . . . . . . 35

Bevel-ended bone tools: length values . . . . . . . . . . . . . . . . . . . . . . 37

Animal taxa identified . . . . . . . . . . . . . . . . . . . . . . . . . 48

The distribution of major types of animal remains by archaeological context . . . . . . . . . 49

The distribution of animal remains by artificial layers in context C31 . . . . . . . . . . . . 50

The distribution of animal remains by $30 \times 30 \mathrm{~cm}$ column samples in context C36 . . . . . . 50

The anatomical distribution of identifiable fish remains. . . . . . . . . . . . . . . . . . . . . 51

The anatomical distribution of bird remains . . . . . . . . . . . . . . . . . . . . . 52

The anatomical distribution of mammalian remains . . . . . . . . . . . . . . . . . . . . . . . . . . . . . . . .

Bone measurements $(\mathrm{mm})$. . . . . . . . . . . . . . . . . . . . . . . . . . . . . . . . . . . 54

Occurrence of marine molluscs in the archaeological contexts sampled . . . . . . . . . . 64

Length measurements of limpet (Patella spp.) shells . . . . . . . . . . . . . . . . . . . . 65

Length measurements of periwinkle (Littorina littorea) shells . . . . . . . . . . . . . . . . 66

Length measurements of dog-whelk (Nucella lapillus) shells . . . . . . . . . . . . . . . . . . 67

Material recovered from the flotation samples . . . . . . . . . . . . . . . . . 70

Terrestrial snail species . . . . . . . . . . . . . . . . . . . . . . . . . . 71

List of charcoal identifications (J. Millar) . . . . . . . . . . . . . . . . . . . . . . 71

Uncalibrated radiocarbon determinations BP in descending 'stratigraphic' order . . . . . . . . 74

Calibrated radiocarbon dates BC in descending chronological sequence. . . . . . . . . . . . 75

Stable isotope data. . . . . . . . . . . . . . . . . . . . . . . . . . . . 78 


\section{ABSTRACT}

The An Corran rockshelter, on the north-east coast of the Trotternish peninsula, Skye, contained a series of shell midden and other deposits with evidence for human occupation from Mesolithic and later periods. A rescue investigation of the site in the winter of 1993-94, immediately prior to anticipated total destruction by rock-blasting for roadworks, included the excavation of a trench dug down to bedrock. A total of 41 separate contexts were identified. Of these, 31 were recent or later prehistoric, the upper levels containing a series of hearths of recent date and an Iron Age copper-alloy pin. The lowest 10 layers were identified initially as Mesolithic on the basis of bone tool and lithic typology, but a series of 18 radiocarbon dates indicates they contain the residues of subsequent prehistoric activity as well. These layers consisted of several distinct areas of midden, below which there were two, possibly three, horizons which probably, based on the presence of broad blade microliths, represent Early Mesolithic activity. The midden layers also contained some human bones radiocarbon-dated to the Neolithic period. The rockshelter was located below an outcrop of baked mudstone and near a source of chalcedonic silica. Both these lithic raw materials were widely used during the Mesolithic as far away as the island of Rùm.

\subsection{Keywords}

Baked mudstone, bevel-ended tools, chalcedonic silica, human remains, Iron Age, Isle of Skye, Mesolithic, Neolithic, rockshelter, shell midden. 

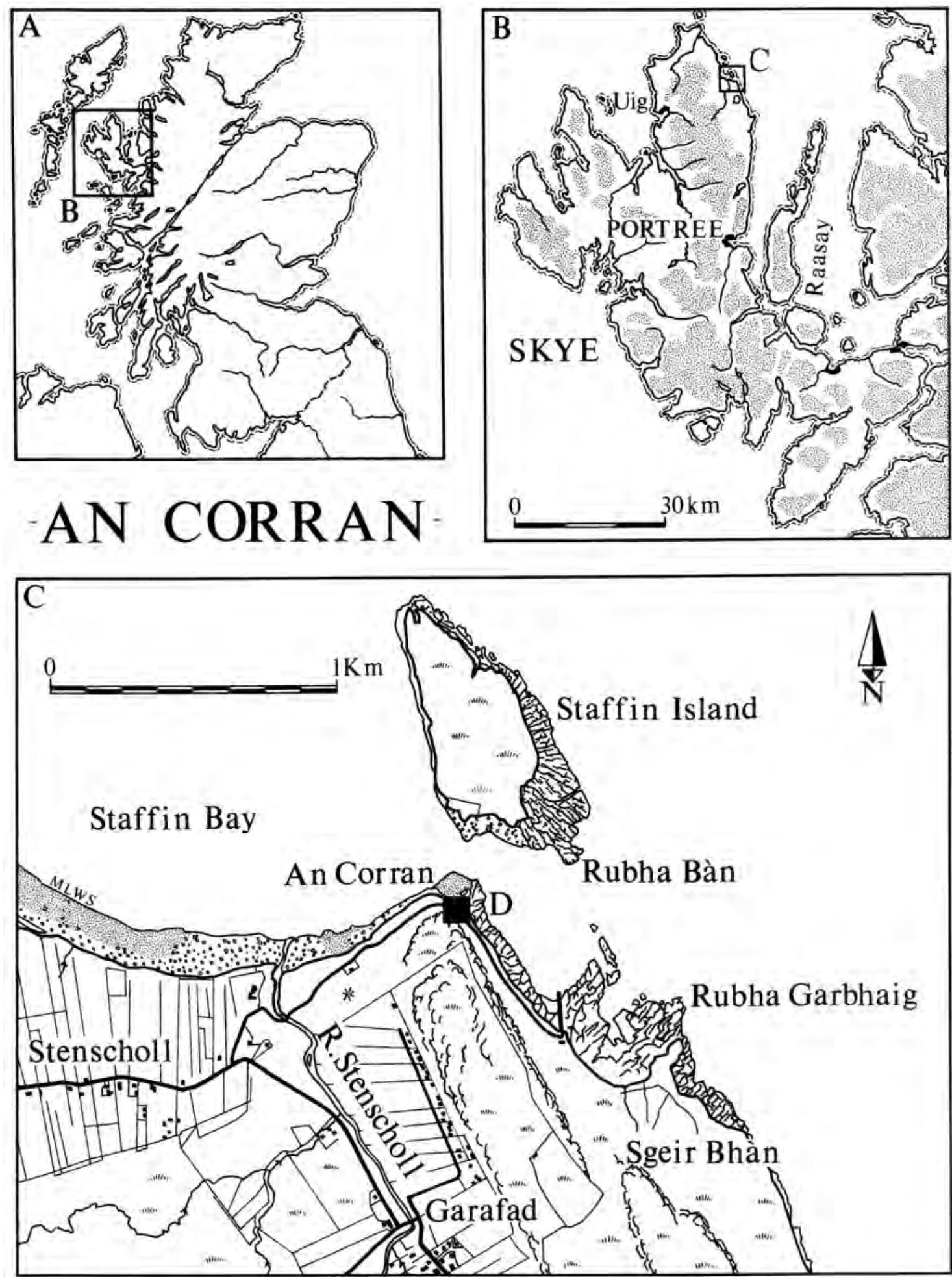

Illus 1 An Corran location maps (A-C) 


\section{INTRODUCTION, by Roger Miket, Karen Hardy and Alan Saville}

The archaeological site referred to here as the An Corran rockshelter is situated in north-east Skye, on the eastern side of the Trotternish peninsula, which is the largest of the three northward projecting headlands of Skye (illus 1 \& 2). Trotternish, the easternmost of the three, is dominated along its length by a north-south trending escarpment, which extends like a raised spine for over $23 \mathrm{~km}$ down the centre of the headland. It is composed of basaltic lavas extruded over softer rocks of Jurassic date, dipping steeply westwards to present a near continuous eastern cliff face, intermittently attaining heights of over $500 \mathrm{~m}$ (Bell \& Harris 1986, 119). To the north of Portree, the coastline is dominated by high cliffs of olivine basalt and dolerite, formed by the intrusion of a sill complex through the Jurassic substrate, and these sea cliffs continue largely unbroken to the southern extremity of Staffin Bay (Anderson \& Dunham 1966, 126; Emeleus \& Bell 2005, 60). Here, at An Corran, the cliffs give way to a broad embayment with a sandy beach, offering the first real opportunity for easy access between sea and land along this whole stretch of coastline and the first landing point north of Portree Bay.

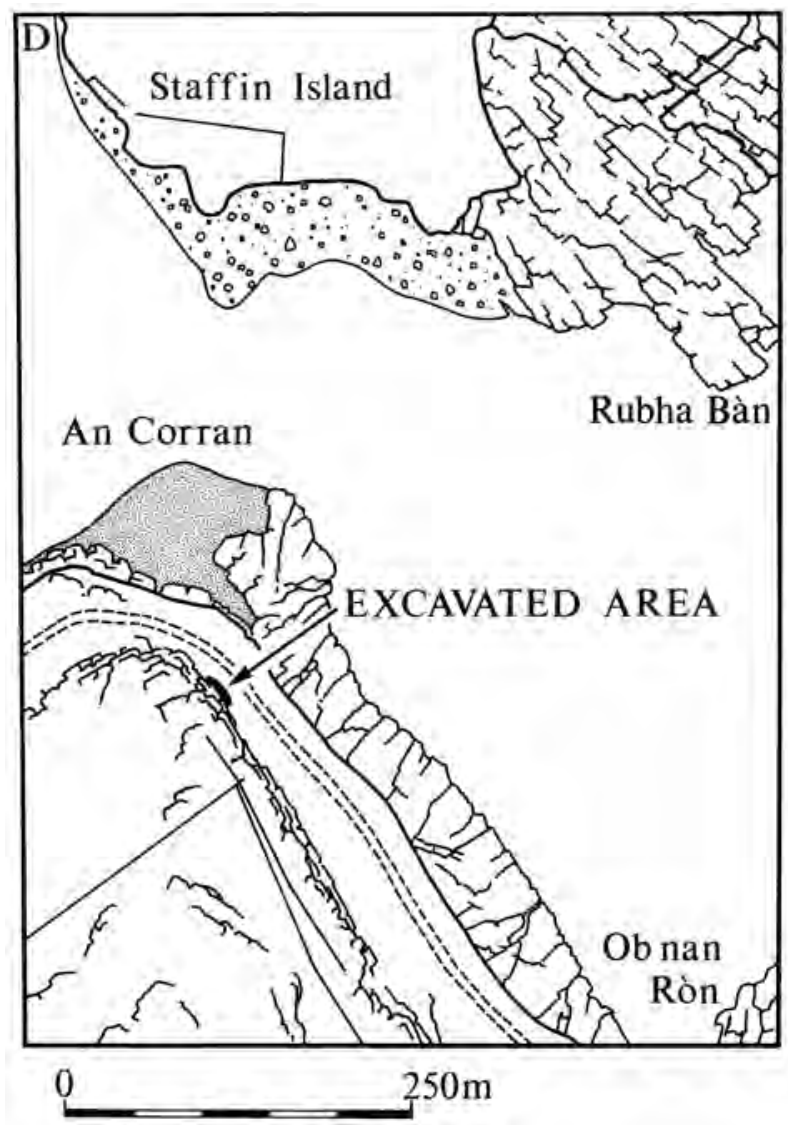

Illus 2 An Corran detailed location map (D)
This embayment is known locally as An Corran (in Gaelic 'the Sickle') after the sweeping curvature of rock partly visible at low-water level and terminating at Staffin Island.

The site (NGR NG 4915 6848) lies on what was a narrow ledge, just south of the An Corran headland, facing eastwards out to sea and towards Staffin Island (illus 3-5). At this point the cliff face and the shore are close, only some 20 metres separating ledge and sea, with the road to Staffin slipway occupying a 'terrace' midway up the slope (illus 6). As elsewhere on this stretch of coast, the lower parts of the cliffs are masked by well-developed scree slopes, composed largely of eroded rock and soil. On the slope immediately below the site the scree has a significant component of blown sand derived from the beach (Anderson \& Dunham 1966, 196). The ledge, with its surface at $c 10 \mathrm{~m}$ above MHWS (Mean High Water Springs), and the rock undercut at its rear, probably

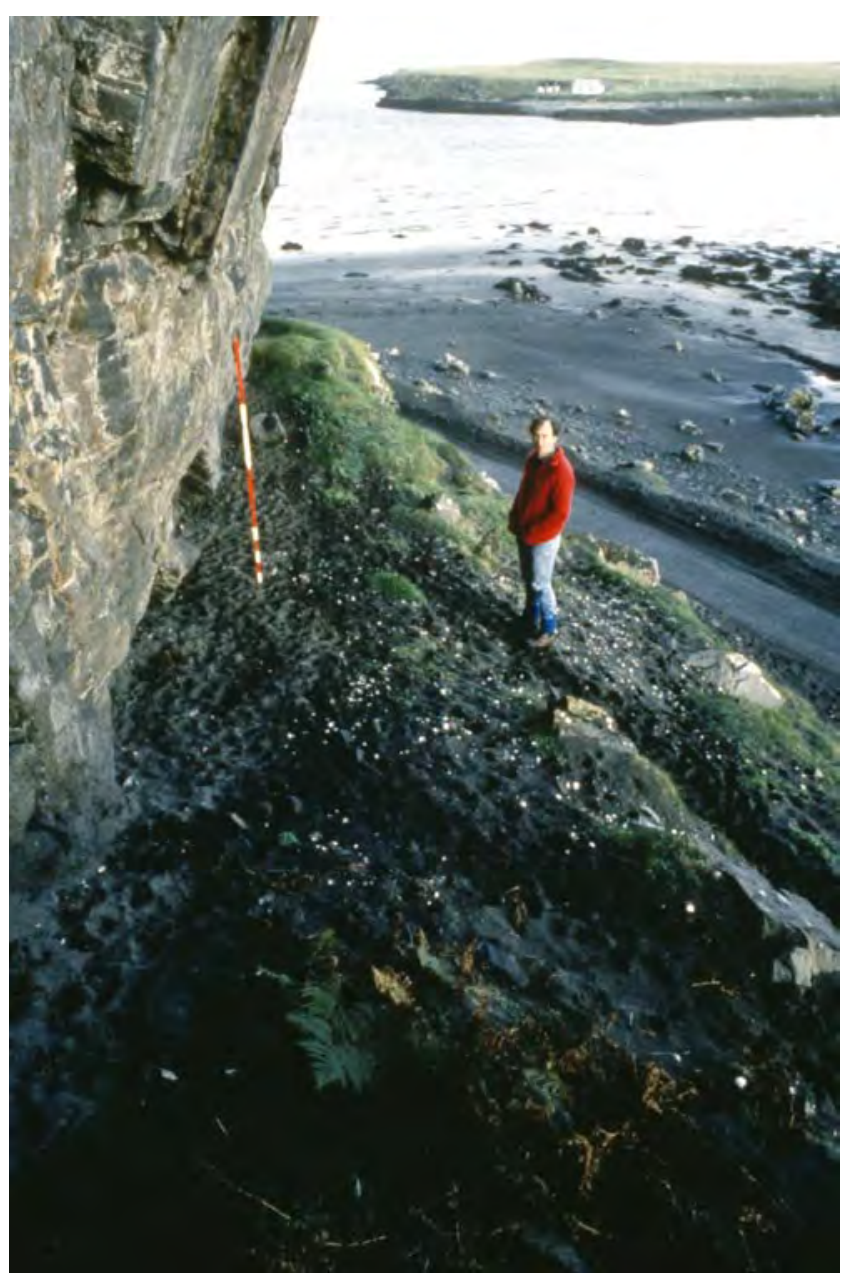

Illus 3 Rockshelter ledge in 1988, viewed from the south (photo: Roger Miket) 


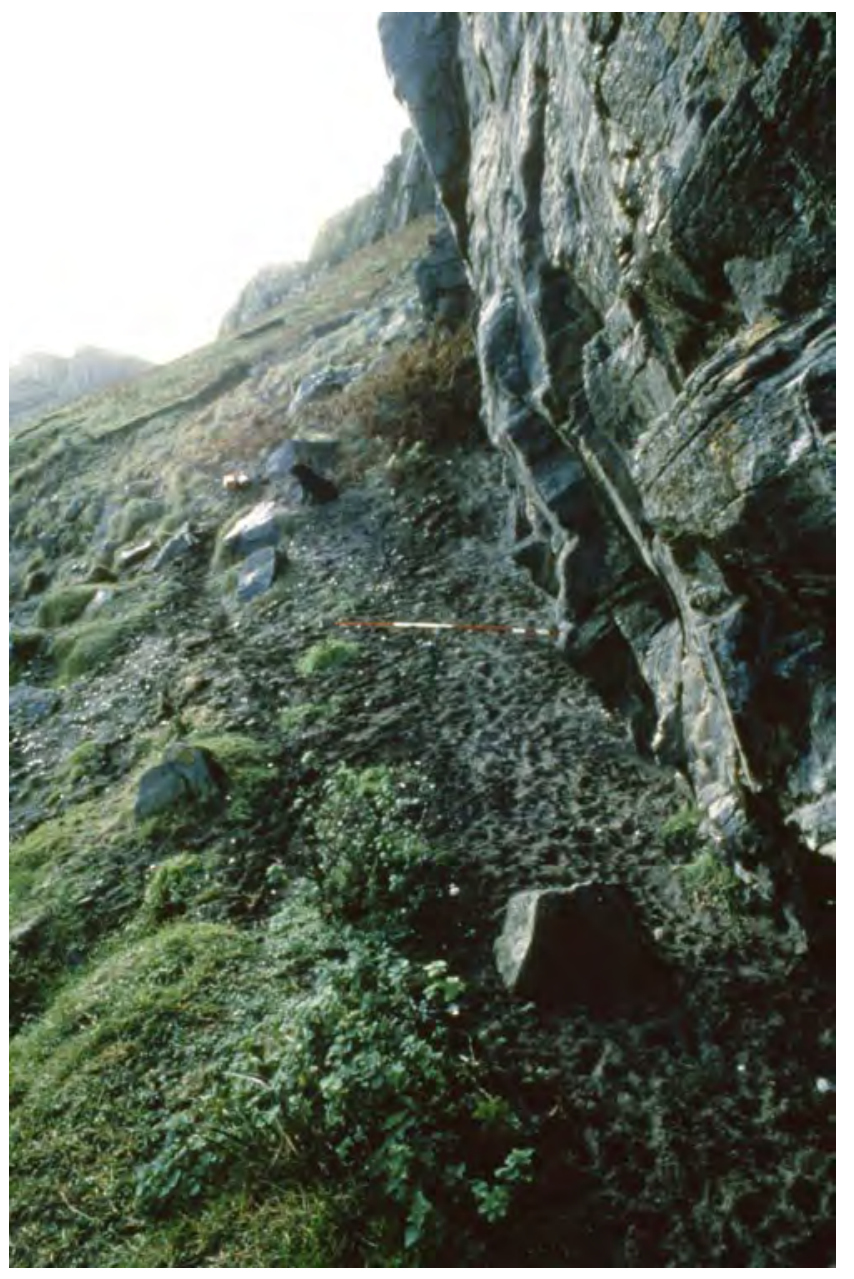

represents an erosional sea 'cave' feature formed at a period of raised shoreline, perhaps during the Devensian glaciation (Benn 1991; Dawson 2007; Richards 1969; Selby et al 2000). However, as Dawson (2007) has recently emphasised, relative postglacial land/sea changes in this location are complex, and the strong effect of glacial isostatic tilt may mean that the sea level was probably much as it is today during the postglacial maximum around 7000 years ago (A. Dawson pers comm). The implication of this is that, during much of the period of human occupation of An Corran, the shoreline and sea level would have been relatively as they are today, thus probably including the offshore status of Staffin Island.

The extent of the ledge, which sloped down from south to north, mirrors the extent of the slight undercutting of the cliff face (illus $3 \& 4$ ). During excavation this undercutting was shown to be more pronounced below the existing surface level, but still insufficient to warrant any description other than 'overhang' for the cliff profile, which creates a classic, albeit relatively shallow, rockshelter situation. Material fallen from above has, over a considerable period of time, created a talus slope, the apex of which lay some metres from the base of the cliff.

Illus 4 (left) Rockshelter ledge in 1988, viewed from the north (photo: Roger Miket)

Illus 5 (below) Panoramic view of the site and adjacent areas from the ENE prior to the excavation in 1993 (photo: Roger Miket)

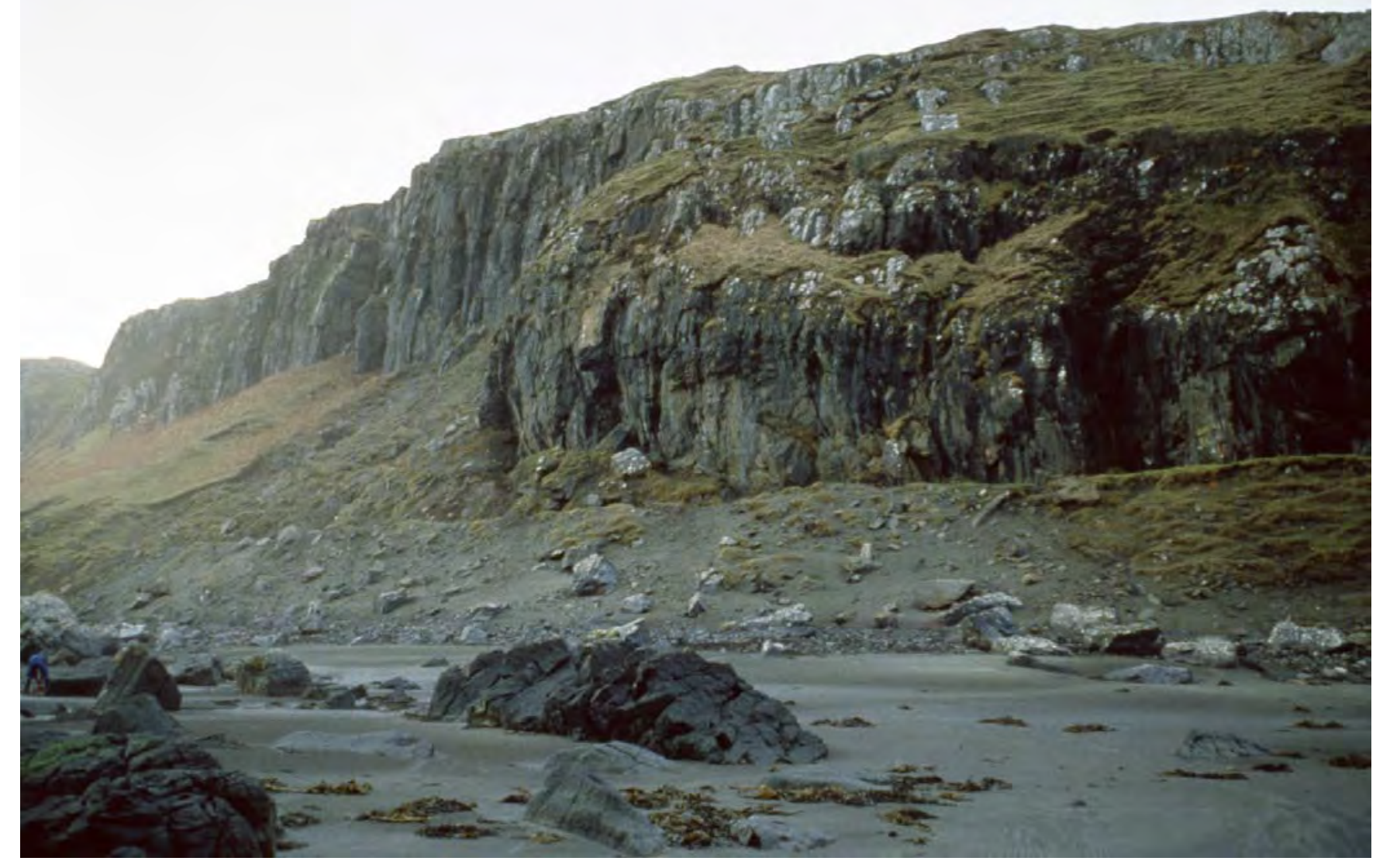




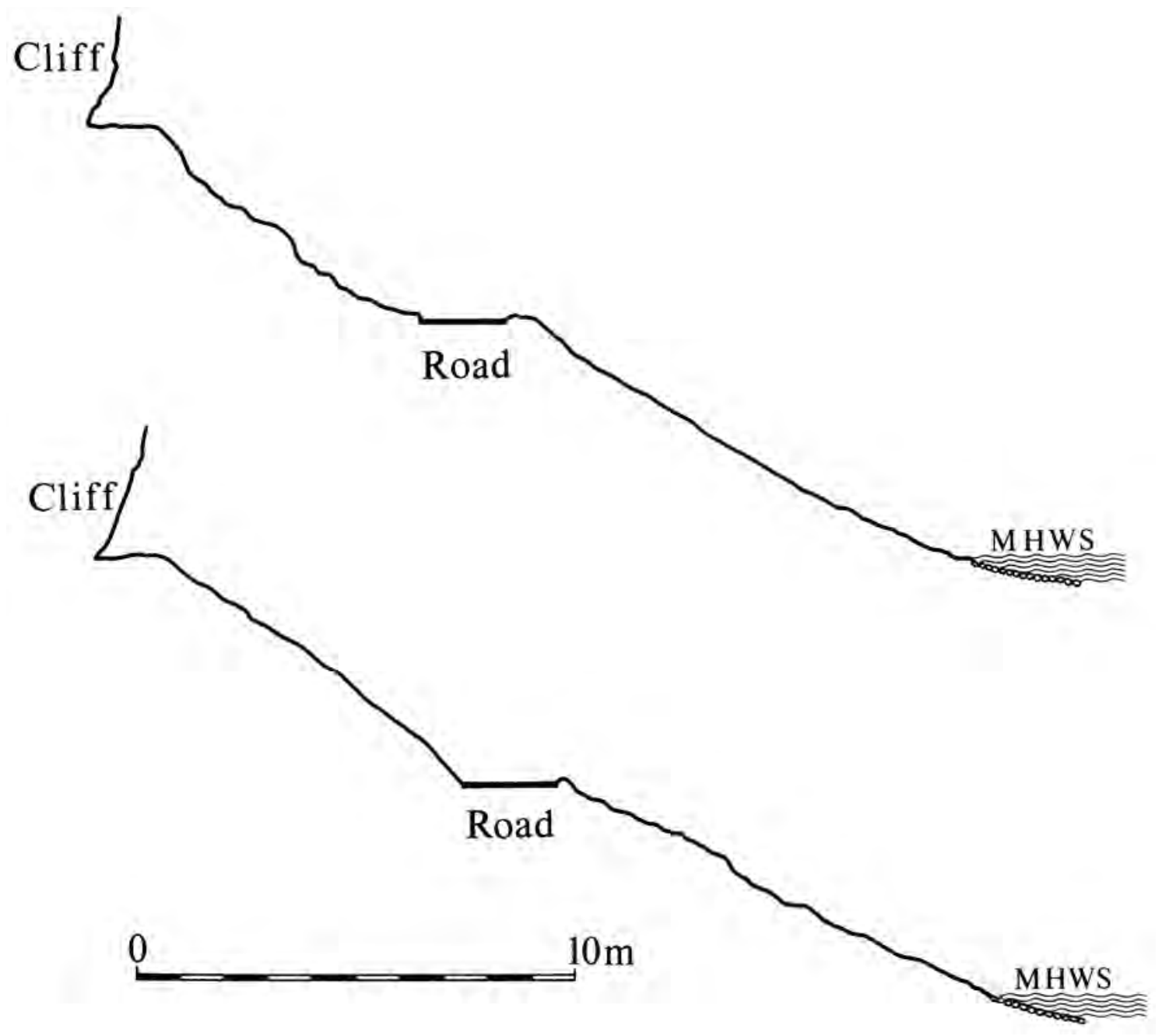

Illus 6 Slope profiles from the rockshelter ledge to the sea. The upper profile is a projection of section $E-D$ at the north edge of the excavation trench (see illus 16); the lower profile is on a parallel alignment $\mathrm{c} 1 \mathrm{~m}$ to the north. The profiles were compiled using tapes and ranging rods.

Directly above the rockshelter lay a second, more extensive ledge (illus 5 \& 7). This ledge, which was accessible from above rather than below, may have been used as a point of lithic exploitation as it lay directly below a band of baked mudstone identical to the lithic raw material found on the site. The implications of this ledge were not recognised at the time of the excavation, and the ledge no longer exists (illus 12).

The rockshelter ledge extended up to $6 \mathrm{~m}$ out from the rock face, but it is thought that some of the width of the ledge may possibly have been removed when the original road was constructed, or may have eroded subsequently. The ledge extended laterally for $16 \mathrm{~m}$ to the north and south. The beach below the site consists of vegetated shingle ridges, and it is one of the few areas of beach sand deposition on Skye.

The nearest freshwater source was a spring, now obscured by rockfall, which emerged on the beach as a stream a few metres to the north of the site, on the headland. Half a kilometre west of An Corran is the mouth of the Stenscholl River (also known locally as the Kilmartin River), which flows into Staffin Bay.

\subsection{Discovery and prelude to the excavation}

The location was first noted as a potential archaeological site by Martin Wildgoose in 1982. A preliminary inspection in May 1988 led to it being added to the local Sites and Monuments Record (NG 46 NE 17) as a rockshelter with shell deposits (Saville \& Miket 1994a; Wildgoose 1988). In September 1988 an assessment of the ledge on behalf of what was then Dualchas (the Skye \& Lochalsh District Council Museum Service), involving a limited examination of the surface sand layers (illus 8), revealed a scattering of shelly material in association with two concentrated patches of burning, as well as fragments of later 19th/early 20th-century pottery. It was concluded that the ledge had been used in a casual manner in relatively recent times, certainly for building a fire, and probably for cooking meals involving shellfish. The sheltered aspect of the site was evident during the assessment and, on the basis that the qualities which attracted activity at one period might equally apply at other times, the Sites and Monuments Record entry made note of 


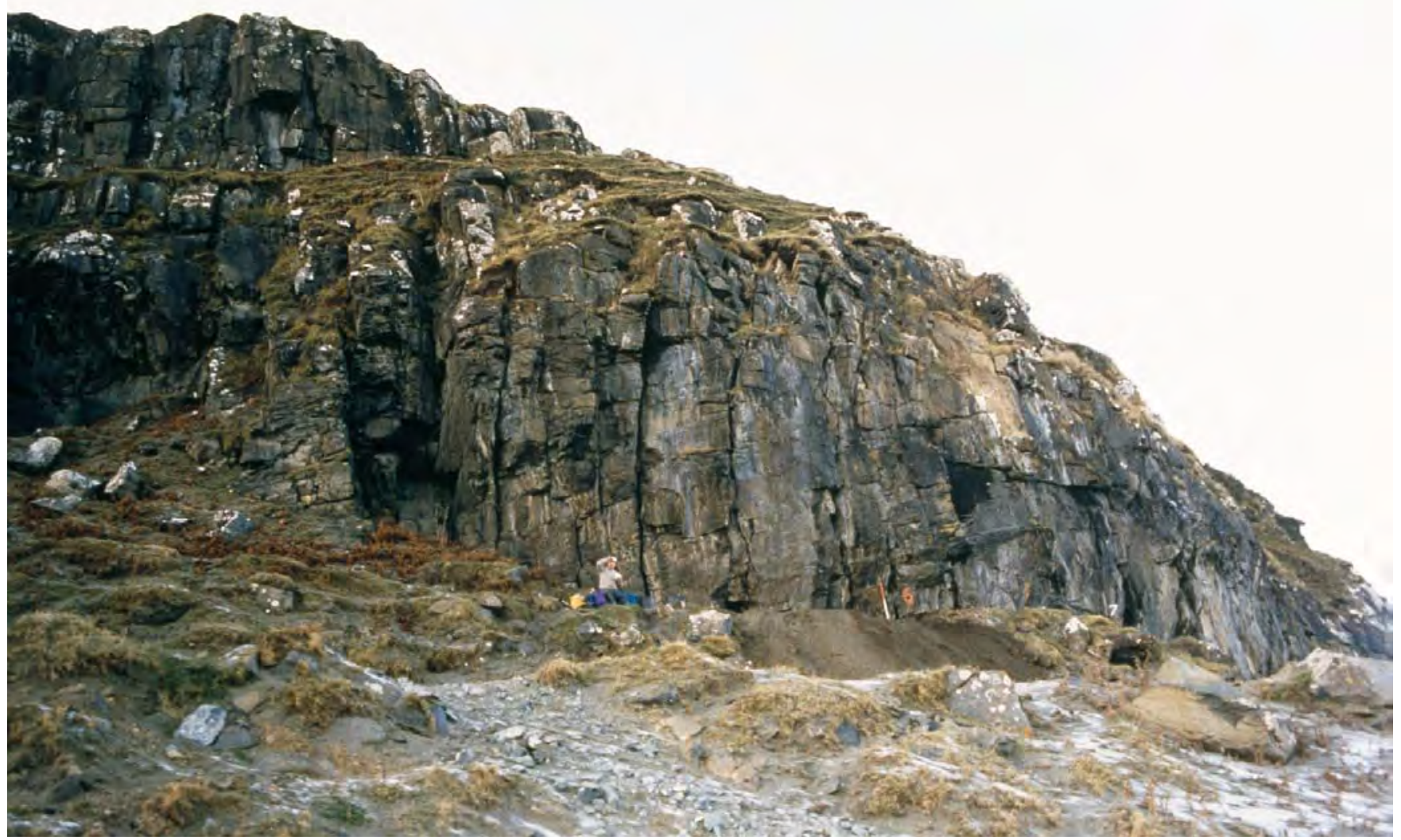

Illus 7 View from the east after the start of the excavation in 1993 showing the configuration of the rockledges above (photo: Roger Miket)

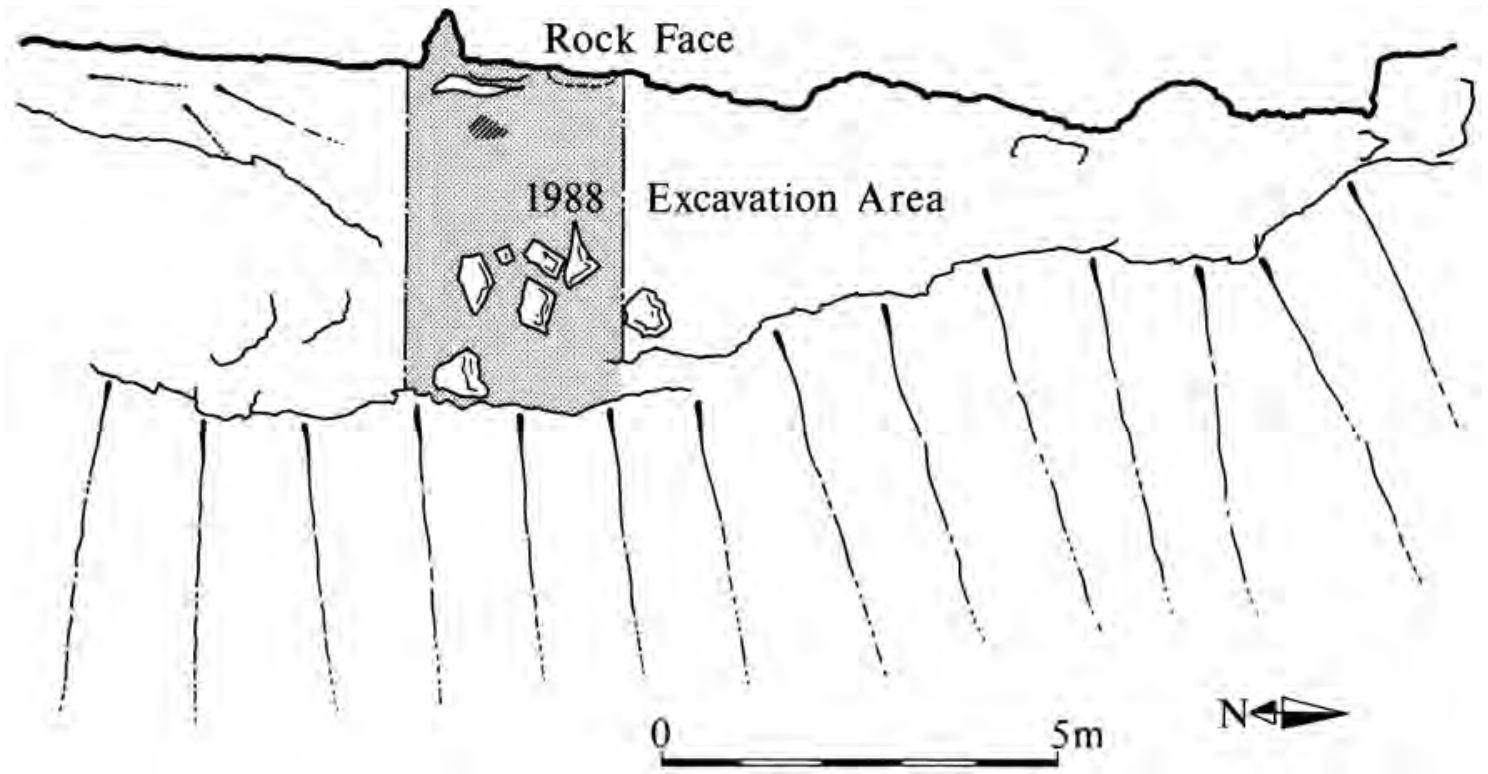

Illus 8 Plan of the rockshelter ledge showing the position of the 1988 excavation (shaded)

the site's potential for the finding of residues from earlier use.

In 1993, the instability of the cliff face adjacent to the access road to Staffin slipway prompted drastic action by Highland Regional Council's Depart- ment of Roads and Transport. The remedy proposed involved cutting back the entire cliff face, including the rockshelter ledge, and utilising the quarried rock as a broad foundation for improved access to the slipway. By the time both the Highland Regional 
Archaeologist and Dualchas learned of this proposal, the contract for demolishing the cliff face, and with it the archaeological site, had been assigned, and commencement of the construction work was said to be absolutely imminent. It is important to note that this happened just before the publication in January 1994 of the National Planning Policy Guideline on Archaeology and Planning (NPPG 5) and the Planning Advice Note on Archaeology (PAN 42 ), when there was still no requirement for developers to engage in any dialogue with archaeologists. Notwithstanding this, the late Bob Gourlay, then the Highland Region Archaeologist, succeeded in last-minute negotiations with both the Roads and Transport Department and the contractors for a three-day window, within which Dualchas might undertake an emergency excavation at the site.

\subsection{Excavation planning}

After four days of working on the site with local volunteers (22-25 November 1993), a clearer picture of its potential began to emerge. An extension to the excavation was granted by the Department of Roads and Transport and a further eight days' work was undertaken (between 29 November and 8 December 1993). At the end of this time, section drawings were made of the upper levels. Contrary to what was expected, however, the demolition work did not begin immediately and a further three days of excavation were carried out in early January 1994. It was at this time that the lowest archaeological layers, C40 and C41, were first identified. The south section of the trench was subsequently cleaned and drawn. In total, some excavation was undertaken on 21 days. Had the excavators known the time which might be available from the start, the excavation could have proceeded in a more planned manner.
As it was, the excavation strategy was adjusted as the length of extensions agreed by Highland Region Roads and Transport emerged. The blasting of the cliff face finally took place in April 1994.

\subsection{Excavation strategy}

The term 'excavation strategy' is perhaps overelaborate for what was intended as little more than an exploration to recover parts of the site's pedigree before its destruction. Yet, before work commenced, five priorities were identified:

- Establishing the site's vertical stratigraphy within the excavated area

- Recovery of material which might indicate the nature of these deposits

- Recovery of material for dating

- Recovery of any environmental data

- Obtaining plans and sections in an attempt to establish a three-dimensional record of the site

The short time-scale and the difficult winter weather conditions allowed only the application of relatively crude approaches. Throughout the 21 days, work proceeded under the expectation that, within a day or two, blasting might begin to remove the entire cliff face, including the rock platform and the archaeological site. Given the small size of the volunteer team assembled and uncertainty about the depths of the deposits, an area of around five square metres, representing approximately onefifth of the extent of the platform, was laid out for investigation over and beyond that of the limited 1988 excavation (illus 9). In the event, the depth of deposits encountered required progressive reductions of the area under excavation.

With a choice between making a detailed record of

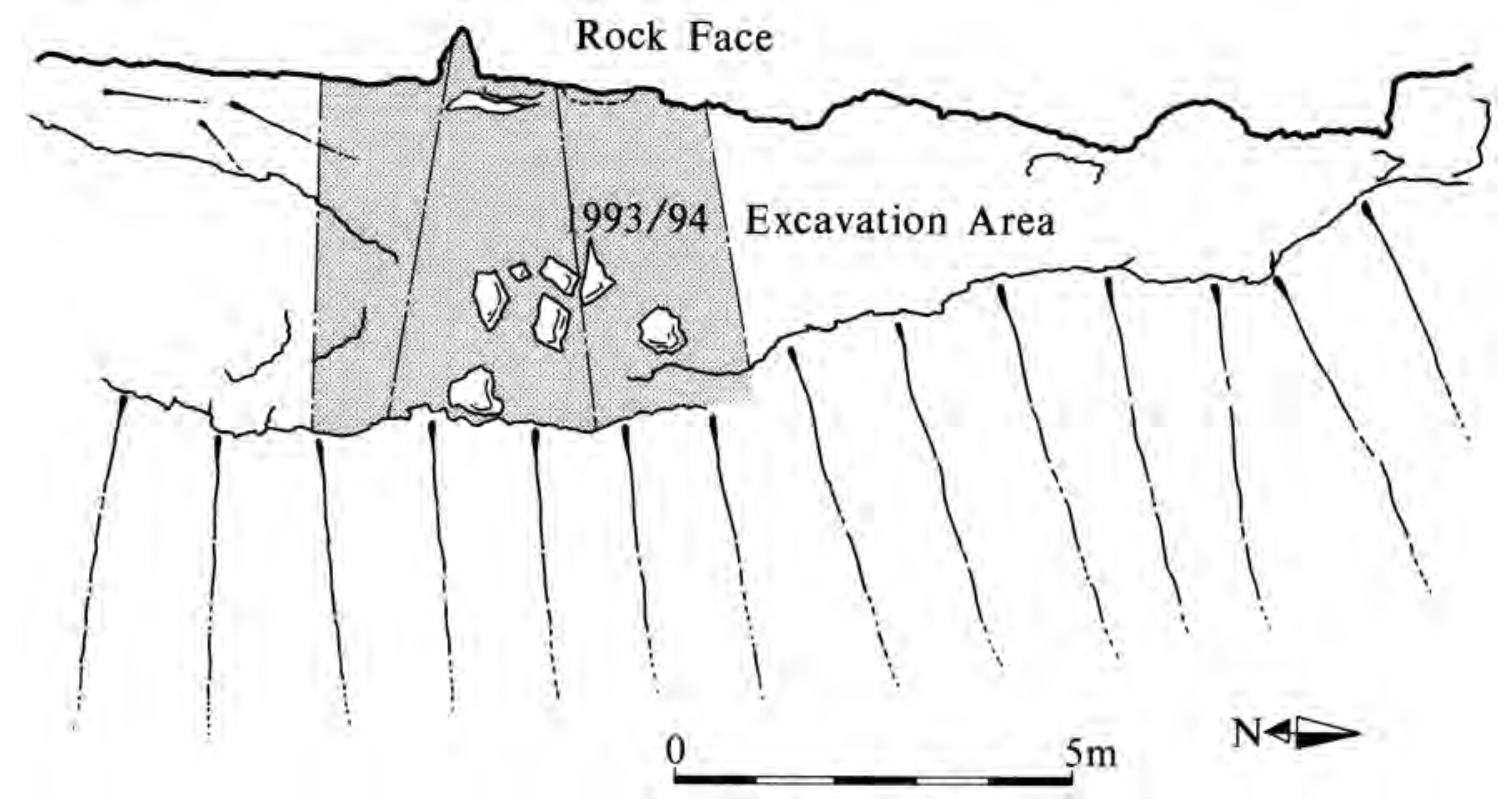

Illus 9 Plan of the rockshelter ledge showing the position of the 1993-94 excavation area (shaded) 


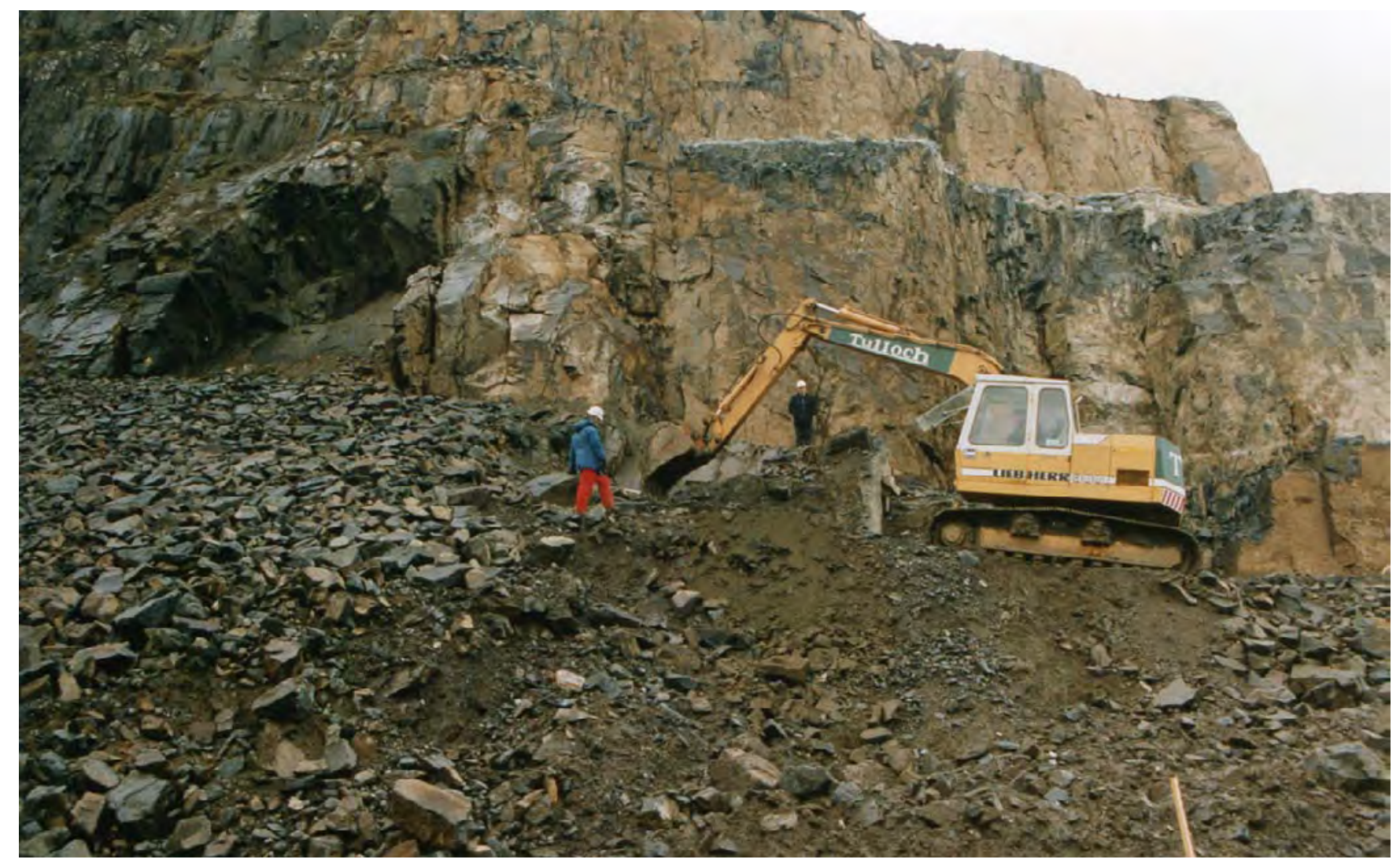

Illus 10 Rock clearance in progress in 1994 viewed from the east following the rockface blasting (photo: Roger Miket)

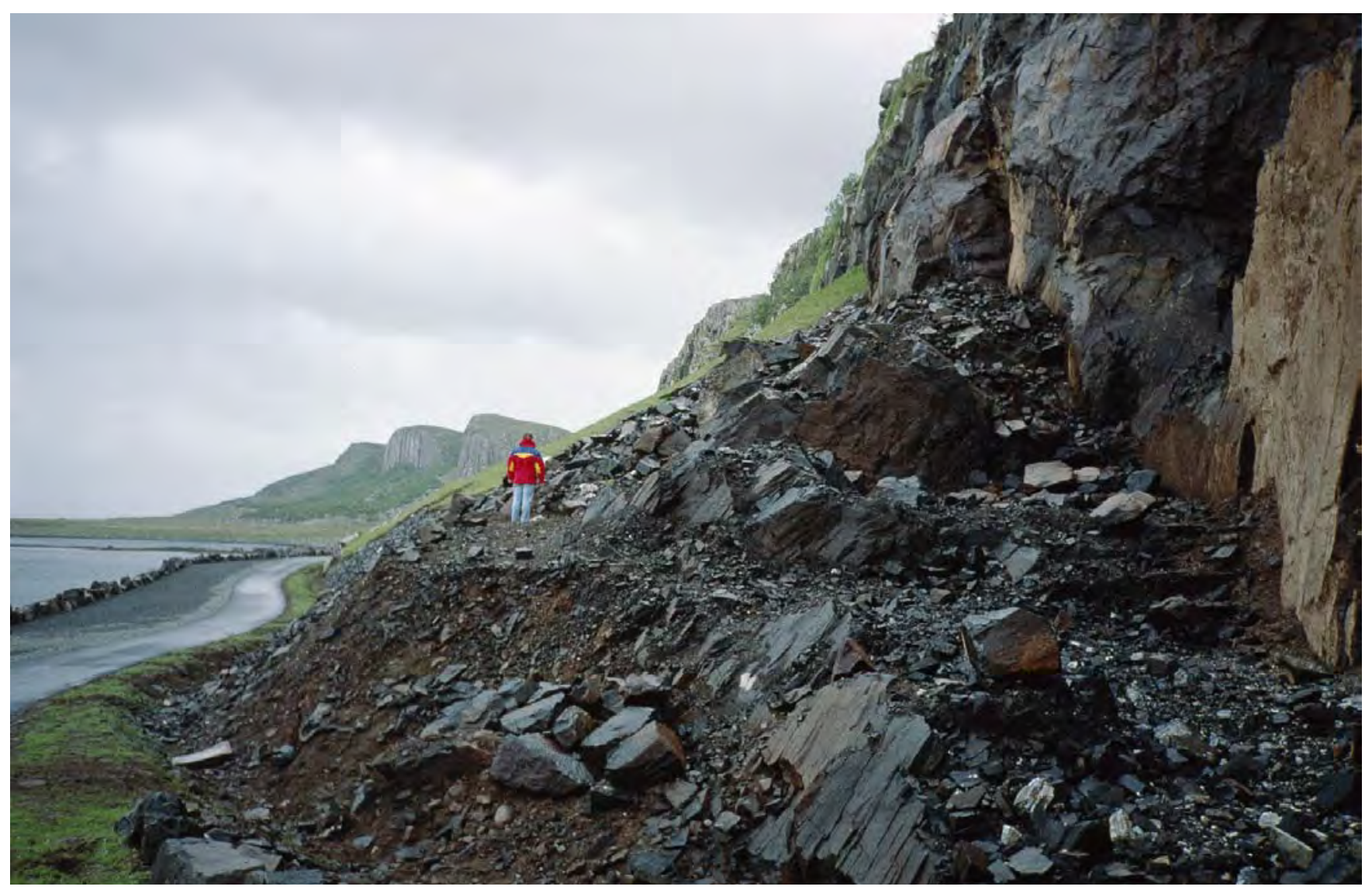

Illus 11 Situation in June 1994 subsequent to the rockface blasting, viewed from the north (photo: Alan Saville) 


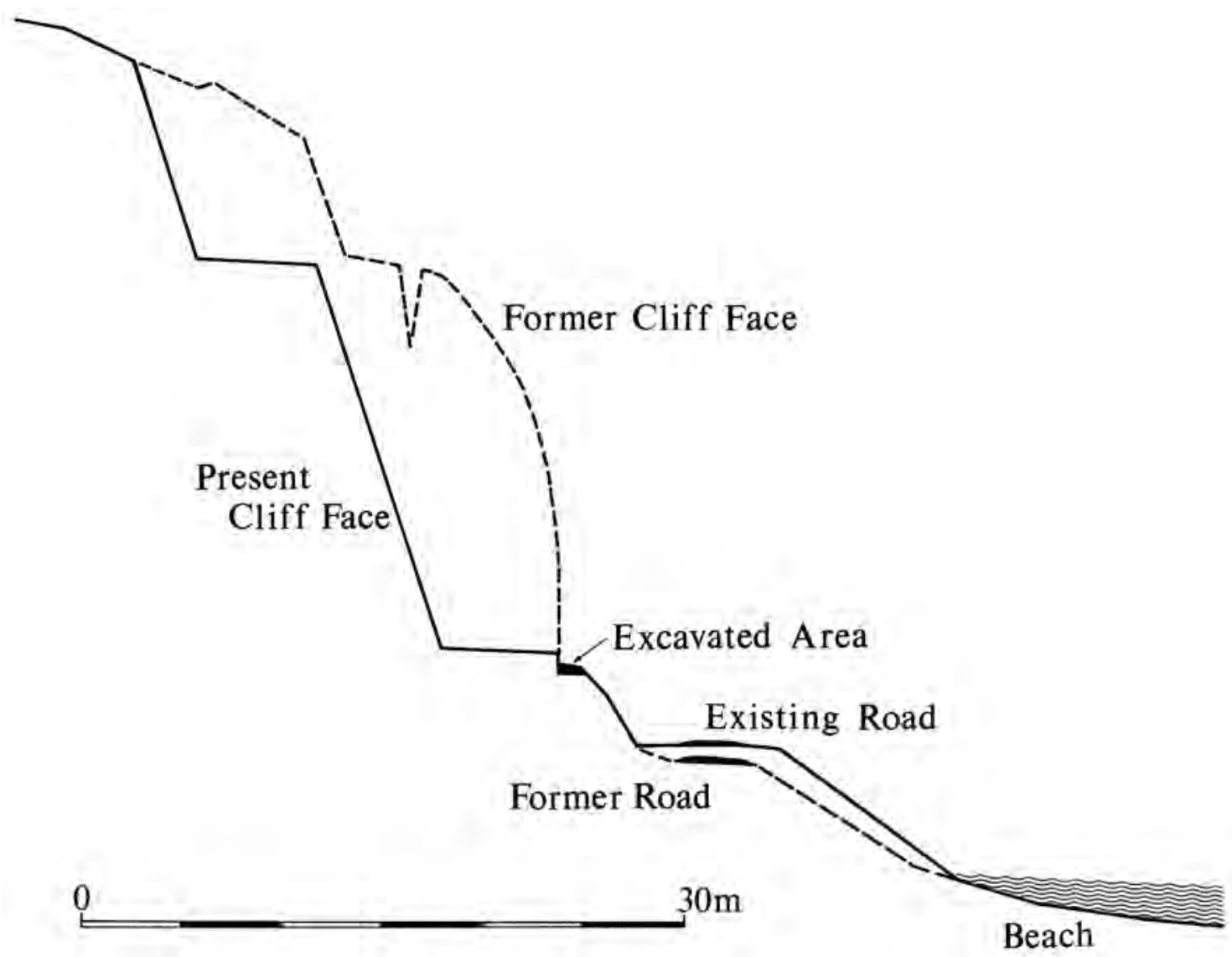

Illus 12 Sketch diagram showing the former and present cliff profile at the site location

the upper strata only and obtaining an impression of the full potential of the site, the decision was taken to opt for the latter. Accordingly, part of a site which might otherwise have justified several seasons of rigorous investigation was hurriedly cut away, with only limited considerations of stratification, recording and sampling procedures. Nevertheless, it was precisely this decision to opt for a sondage which provided the information to justify calling for conservation of the remaining ledge.

Once the nature of the deposits became apparent, discussions opened with Highland Council's Roads and Transport Department as to how the remainder of the platform might be preserved. Demolition of the cliff face above the ledge was inevitable, but agreement was reached over preservation of part of the platform. This was achieved by laying Terram sheeting across the surface of the surviving platform, backfilling the excavated area with sand, and then covering the ledge with a layer of rock to shield it from the impact of falling material. Once the cliff face had been cut back, a skin of smaller stone was added to the slope between the platform and the new road to protect against erosion. Despite the best efforts of all involved, some of the north end of the ledge was lost during the demolition of the cliff face (illus 10-11), and it is important to emphasise that the 'shelter' aspect of the site, that is the original overhanging rock face, has been lost entirely (illus 12).
However, the surviving ledge, now largely covered by rock fall, represents perhaps between two- and threefifths of the original archaeological zone of the ledge prior to excavation and rock-blasting. This surviving section of the ledge, which undoubtedly contains important archaeological remains and could in the future yield a coherent stratigraphic sequence, was scheduled by Historic Scotland in 1999 as an Ancient Monument (No. 7848: 'shell midden 1050m NNE of Staffin House').

\subsection{The excavation}

In attempting to meet the above objectives, a cutting was excavated approximately at the centre of the ledge upon which the site was located (illus 13-14).

Initially the cutting measured $c 6 \times 6 \mathrm{~m}$, abutting the cliff face to the west and expanding slightly eastwards to reach the outer edge of the ledge (illus 15). This contained the area assessed in 1988 (illus 8-9), and the results of the archaeological investigation are included here as if they formed part of a single event. The position of the trench was determined by the following factors:

- The need for the excavation of an area sufficiently large to allow coherent features to be recognisable in plan, either in whole or in part. 


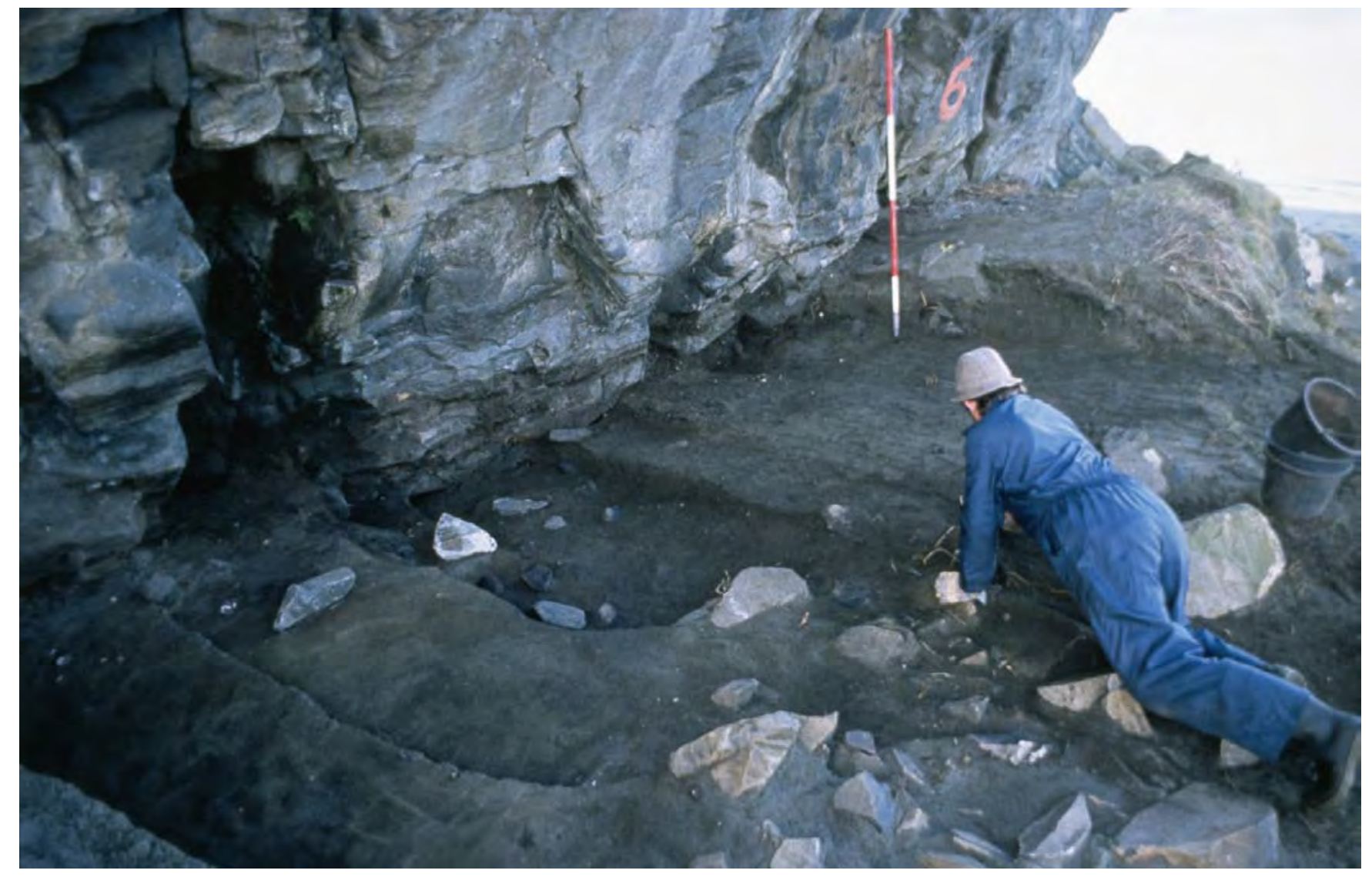

Illus 13 Excavation in progress in 1993 viewed from the south-east (photo: Roger Miket)

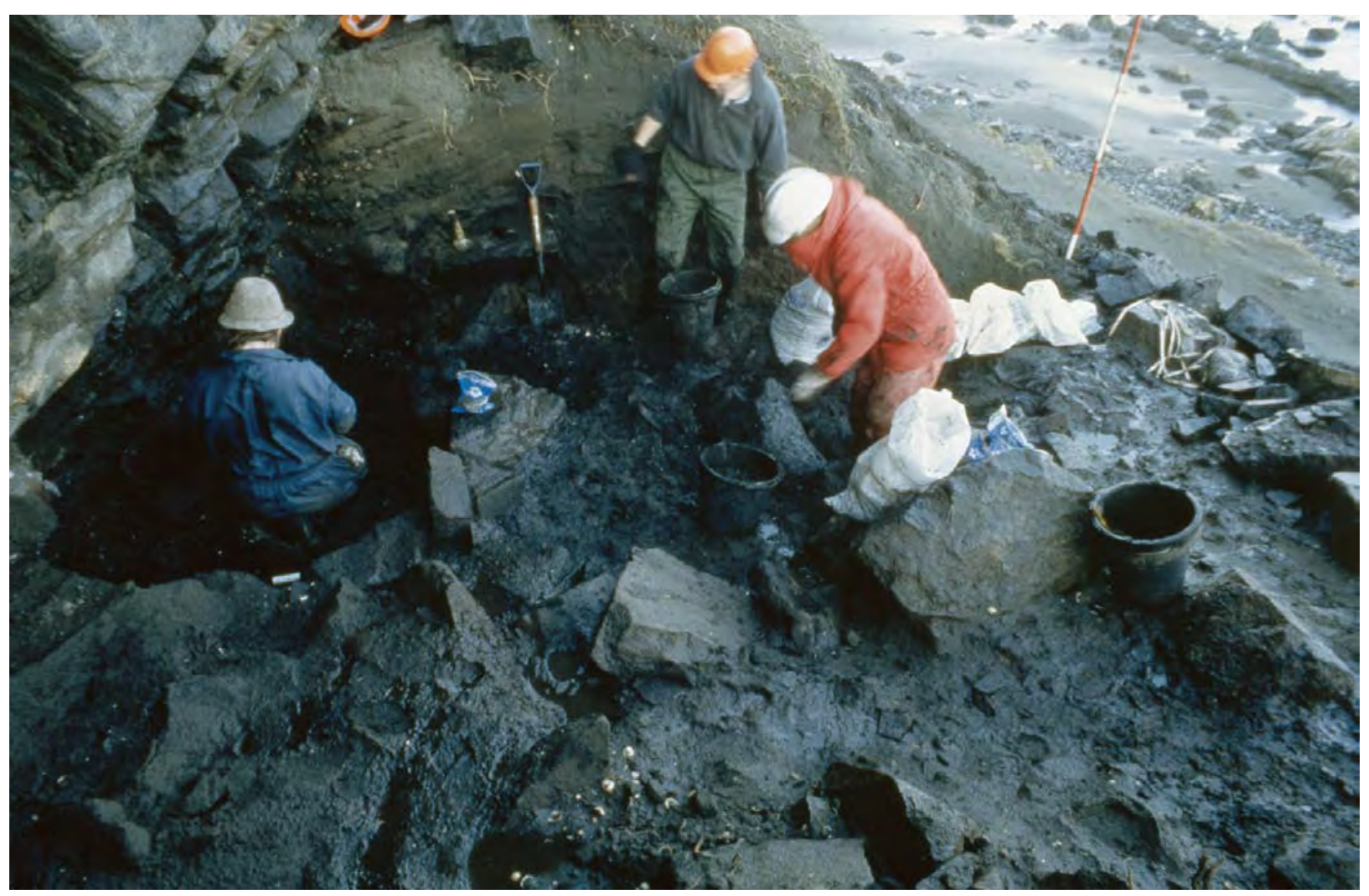

Illus 14 Excavation in progress in 1994 viewed from the south (photo: Roger Miket) 


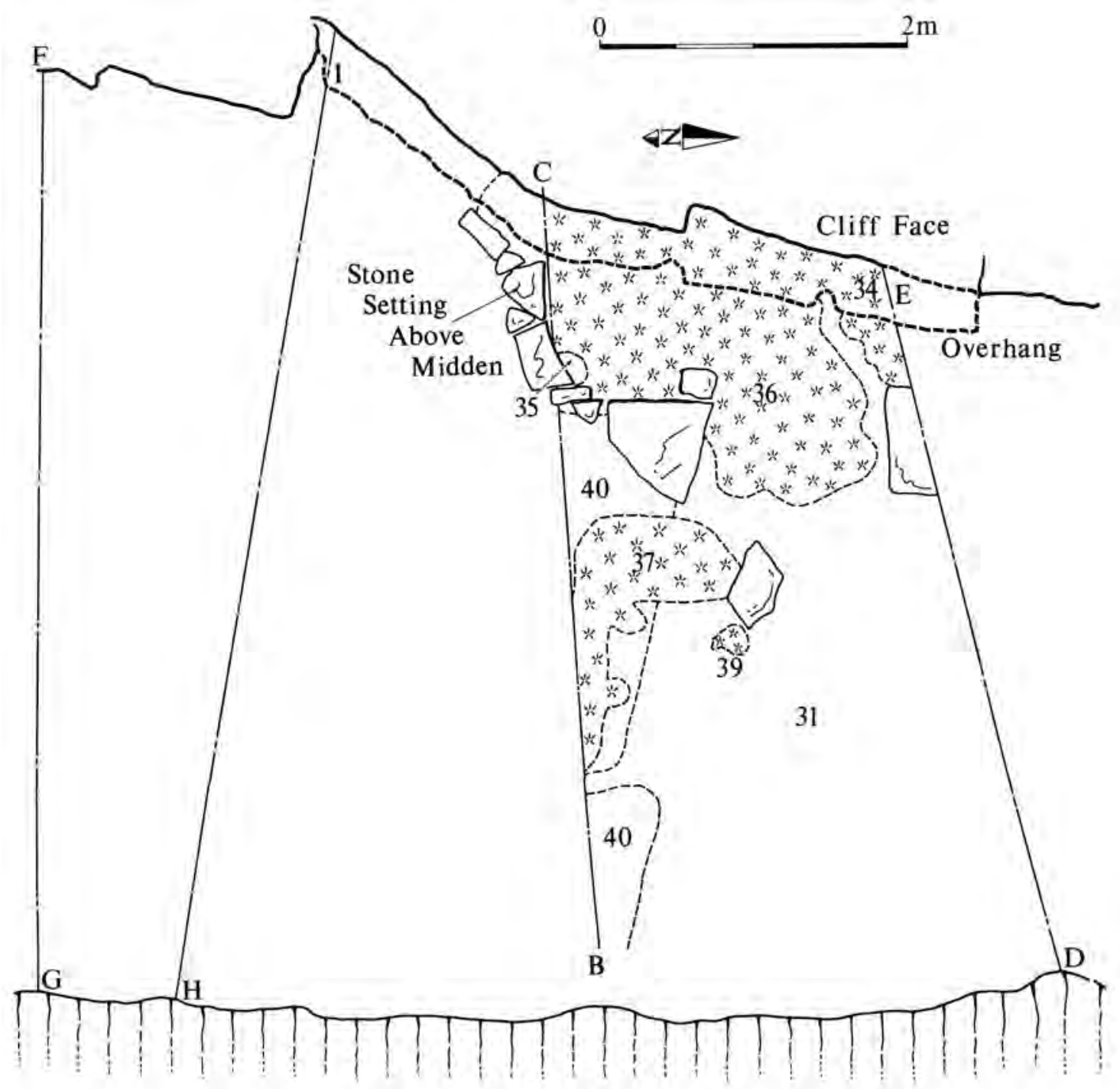

Illus $15 \quad 1993-94$ excavation plan showing the location of the recorded sections and selected contexts

- The nature and character of the underlying deposits were unknown, but surface indications suggested that these might primarily consist of unconsolidated sands and angular boulders. Were this to be the case, the sondage would need to be of a sufficient width to allow the excavation of the site in stratigraphic 'steps' for reasons of safety and accessibility.

- Aneed to match the estimated manpower available to the time-constraint imposed by stratigraphic sequences of unknown extent, horizontally as well as vertically.

Subsequently the extent of the cutting was reduced to a sondage $c 2.5 \mathrm{~m}$ wide between section lines B-C and $\mathrm{D}-\mathrm{E}$ in order to permit some examination of the lower stratigraphy in the time available. As part of this process, substantial volumes of the midden horizons excavated in the sondage were retained as bulk samples.

\subsection{The contexts (see Appendix One)}

In total, 41 different contexts were identified during the excavation and are summarised in Table 1, which also indicates the illustration, if any, on which the context is depicted. They were numbered C1-41, with C1 being uppermost, or most recent, and C41 being immediately on top of the bedrock surface. The sections through the upper layers were D-E (illus 16), F-G and H-I (illus 17), and the only completed deep sondage section was B-C (illus 18). The circumstances and nature of the investigation at this site, as recounted above, preclude a normal full stratigraphic description or the presentation of a meaningful matrix of all the contexts, and in this section it is not possible to maintain an ideal distinction between description and interpretation. The phasing or grouping of the contexts is of necessity 'broad brush', and has been presented slightly differently in some of the specialist reports, 

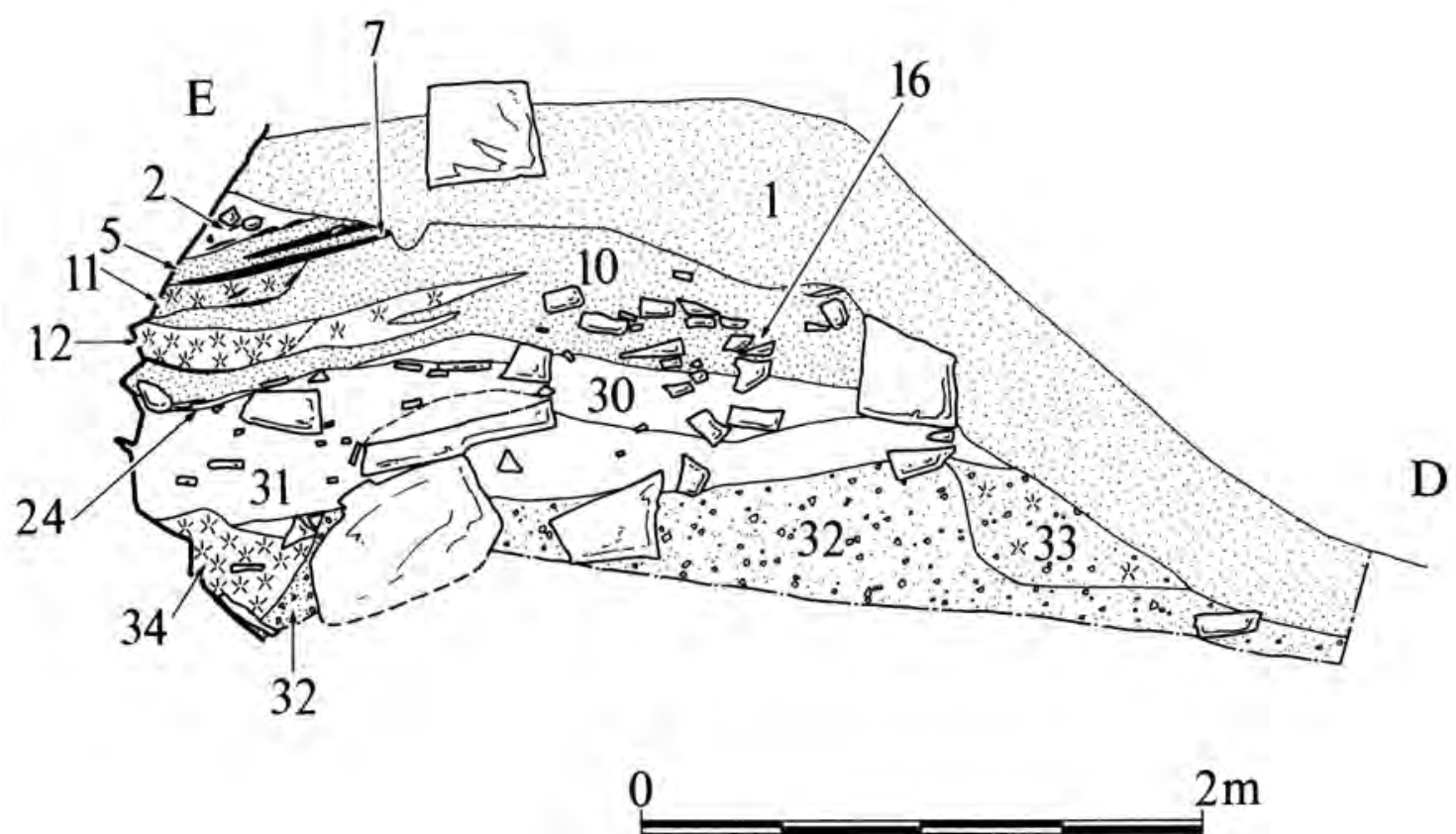

Illus 16 Section $D-E$ at the north edge of the excavation
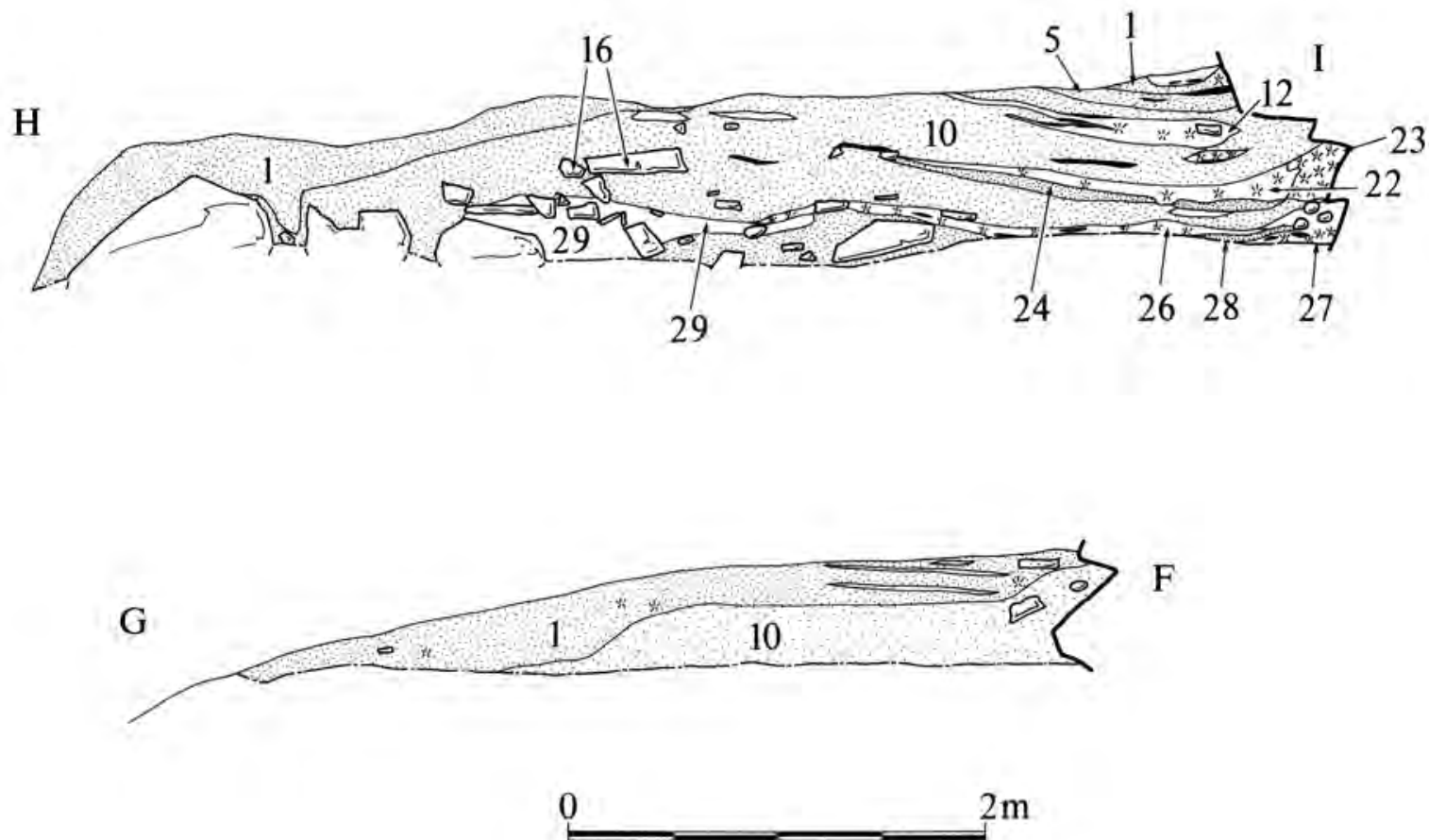

Illus 17 Sections $H-I$ and $F-G$ at the southern limits of the excavation

other than that there is a major division between the uppermost and lowermost context groups.

The uppermost group of contexts (C1-30), appeared as largely comprised of wind-blown sand deposits, interleaved with residues of human activity. This latter took the form of hearths and burnt deposits associated with them (illus 19), as well as lenses of shell deposition. The contexts were characterised by clearly visible lenses that, for the most part, extended across most of the excavated area. As detailed a description as possible for the individual contexts is given at the end of this report (Appendix One).

The lower deposits were mainly formed by a series of human activities taking place on the rock platform, which included aspects of marine and faunal 
Table 1 Contexts

\begin{tabular}{|c|c|c|}
\hline Context & Illus & Description \\
\hline 1 & 16,17 & Light grey/silver fine sand \\
\hline 2 & 16 & Burnt orange/red ash layer with charcoal, crushed shell and stones \\
\hline 3 & & Hearth within $\mathrm{C} 2$ \\
\hline 4 & & Hearth within $\mathrm{C} 2$ \\
\hline 5 & 16,17 & Reddish/brown sand deposit, with some limpet shells \\
\hline 6 & & Thin lens of charcoal and ash within C5 \\
\hline 7 & 16 & Brown ash deposit with charcoal and crushed shell \\
\hline 8 & & Hearth within $\mathrm{C} 7$ \\
\hline 9 & & Hearth within $\mathrm{C} 7$ \\
\hline 10 & $16,17,18$ & Reddish/brown sand with some crushed shell \\
\hline 11 & 16 & Fine sand with uncompacted limpet shell and charcoal \\
\hline 12 & 16,17 & Black/brown ash layer with lenses of charcoal and crushed shell, predominantly limpet \\
\hline 13 & & Hearth with beach cobble pebble base \\
\hline 14 & & Hearth with beach cobble pebble base \\
\hline 15 & & Flagstone hearth \\
\hline 16 & 16,17 & Rock fall \\
\hline 17 & & Beach cobble surface \\
\hline 18 & & Charcoal lens \\
\hline 19 & & Charcoal lens \\
\hline 20 & & Lens of shells \\
\hline 21 & & Lens of shells \\
\hline 22 & 17 & Dark brown layer with dense shell and burning \\
\hline 23 & 17 & Unconsolidated shell deposit \\
\hline 24 & 16 & Lens of red-brown sand \\
\hline 25 & & Lens of shells within $\mathrm{C} 10$ \\
\hline 26 & 17 & Black layer with crushed and whole shells and charcoal patches \\
\hline 27 & 17 & Black layer with crushed and whole shells \\
\hline 28 & 17 & Thin sand with some whole shells \\
\hline 29 & 17 & Brown/orange layer with angular blocks \\
\hline 30 & 16 & Dark brown layer incorporating many large angular blocks \\
\hline 31 & $\begin{array}{l}15,16,18 \\
20\end{array}$ & Black 'claggy' deposit with bone, shell, as well as bone and lithic artefacts \\
\hline 32 & 16 & Red-orange sand \\
\hline 33 & 16 & Brown sand with shell \\
\hline 34 & 15,16 & Unconsolidated shell deposit, partly crushed, with animal bone and lithic artefacts \\
\hline 35 & $15,18,20$ & Intrusive feature, sterile, black, silty fill \\
\hline 36 & 15,20 & $\begin{array}{l}\text { Thick deposit with unconsolidated shell, crushed shell, bone, as well as bone and lithic } \\
\text { artefacts }\end{array}$ \\
\hline 37 & 15,18 & Unconsolidated shell \\
\hline 38 & & Small lens of shell within C31 \\
\hline 39 & 15 & Small lens of shell within C31 \\
\hline 40 & 15,18 & $\begin{array}{l}\text { Dark brown silty deposit with angular stones, bone, fragmented shell, charcoal and lithic } \\
\text { artefacts }\end{array}$ \\
\hline 41 & & $\begin{array}{l}\text { Red clayey deposit present in the cracks in the bedrock, with lithic artefacts, and some burnt } \\
\text { bone }\end{array}$ \\
\hline
\end{tabular}




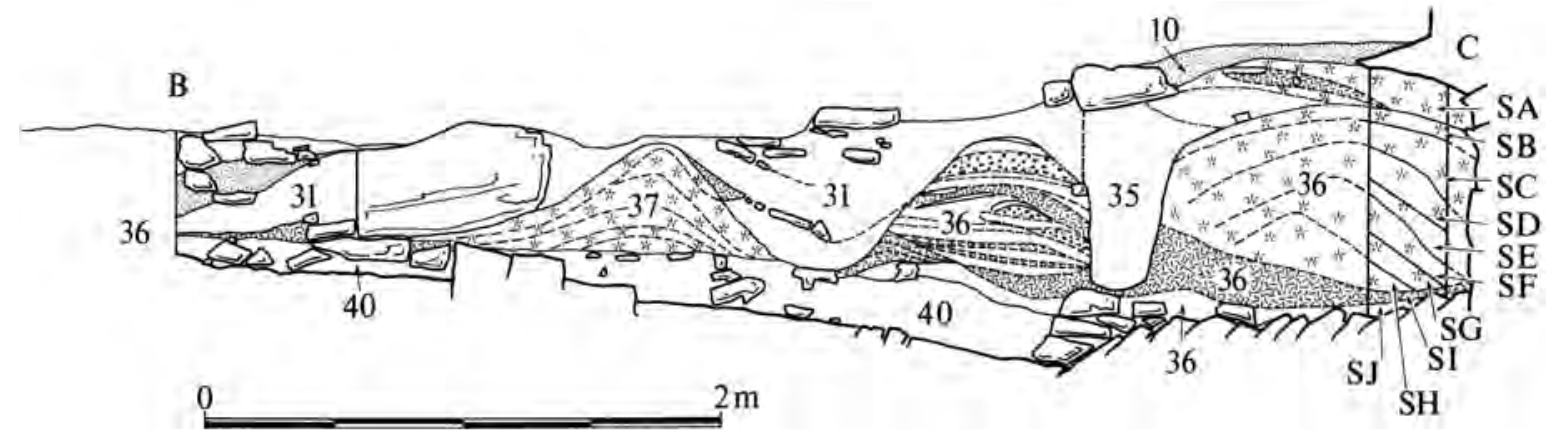

Illus 18 Section B-C through the basal deposits in the centre of the excavated area

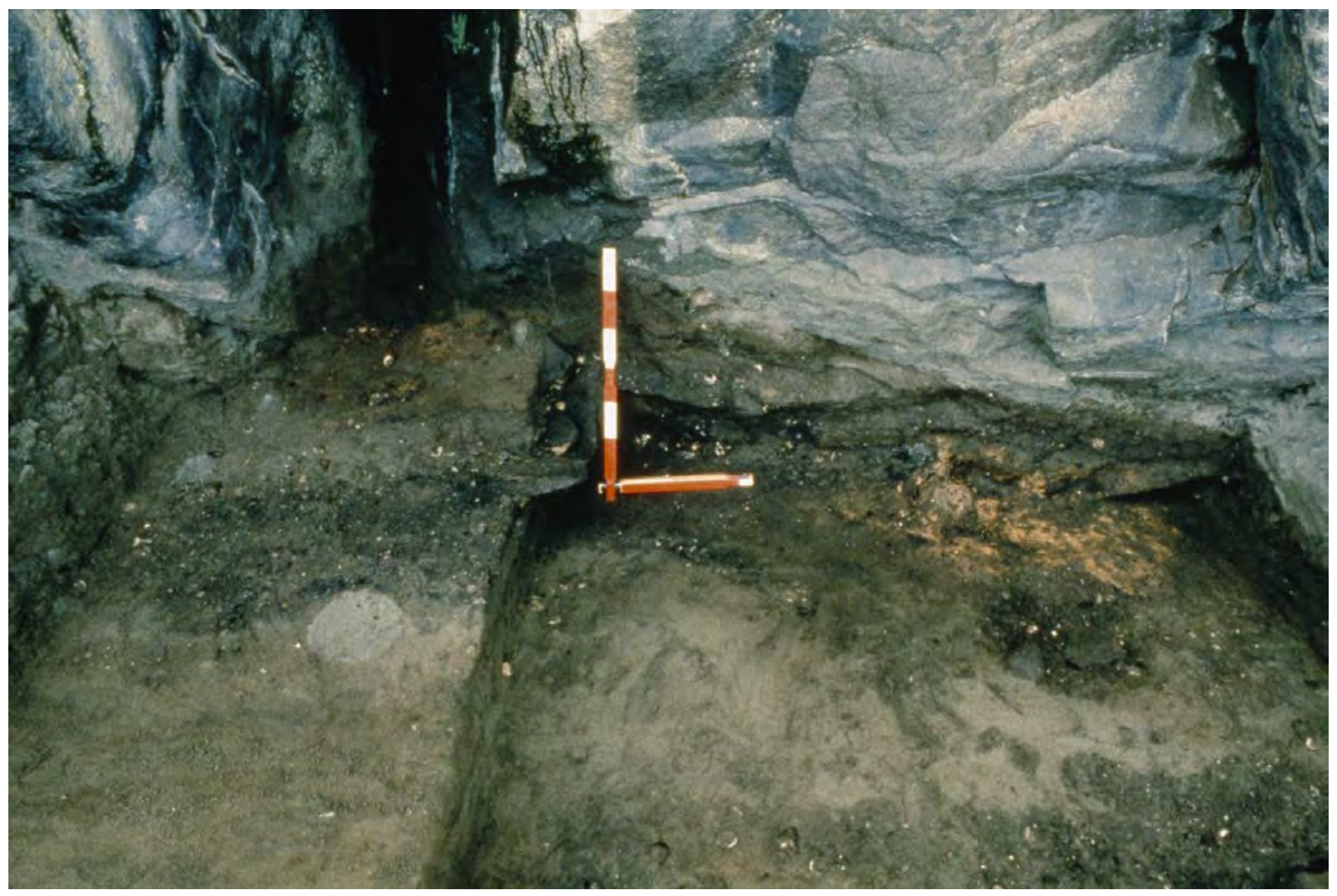

Illus 19 Burnt deposits (context C8) in upper levels at the rear of the rockshelter (photo: Roger Miket)

processing, the deposition of human remains, and the production and use of lithic artefacts. However, it is unlikely that the deposits represent one continuous sequence of events. The 11 lower deposits (C31-41) extending across the area of the trench reached a depth of over $1 \mathrm{~m}$ in places and, with the probable exception of $\mathrm{C} 40$ and $\mathrm{C} 41$ (the original soil and sub-soil?), these deposits were largely anthropogenic in origin. There was an overall tendency for the contexts of this group to appear thicker, more localised in extent, and to contain a higher proportion of angular stone than the higher layers. In particular, there was an absence of the hearths discovered in the earlier group of contexts, although the presence of dispersed burnt residues was pervasive throughout most of these lower deposits.

Although there were no apparent major discontinuities in the sequence, such as the clean wind-blown lenses noted within the first group (possibly indicating periodic human absence from the site), there were indications of different economic strategies or activity regimes through the sequence. The lowest layers (C41, C40 and the lower part of C36), for instance, contained very little shell, and it is likely that the relatively non-calcareous nature of these horizons has prevented the survival of bone, except where burnt or charred. The rest of the lower contexts was dominated by abundant shells, reflect- 


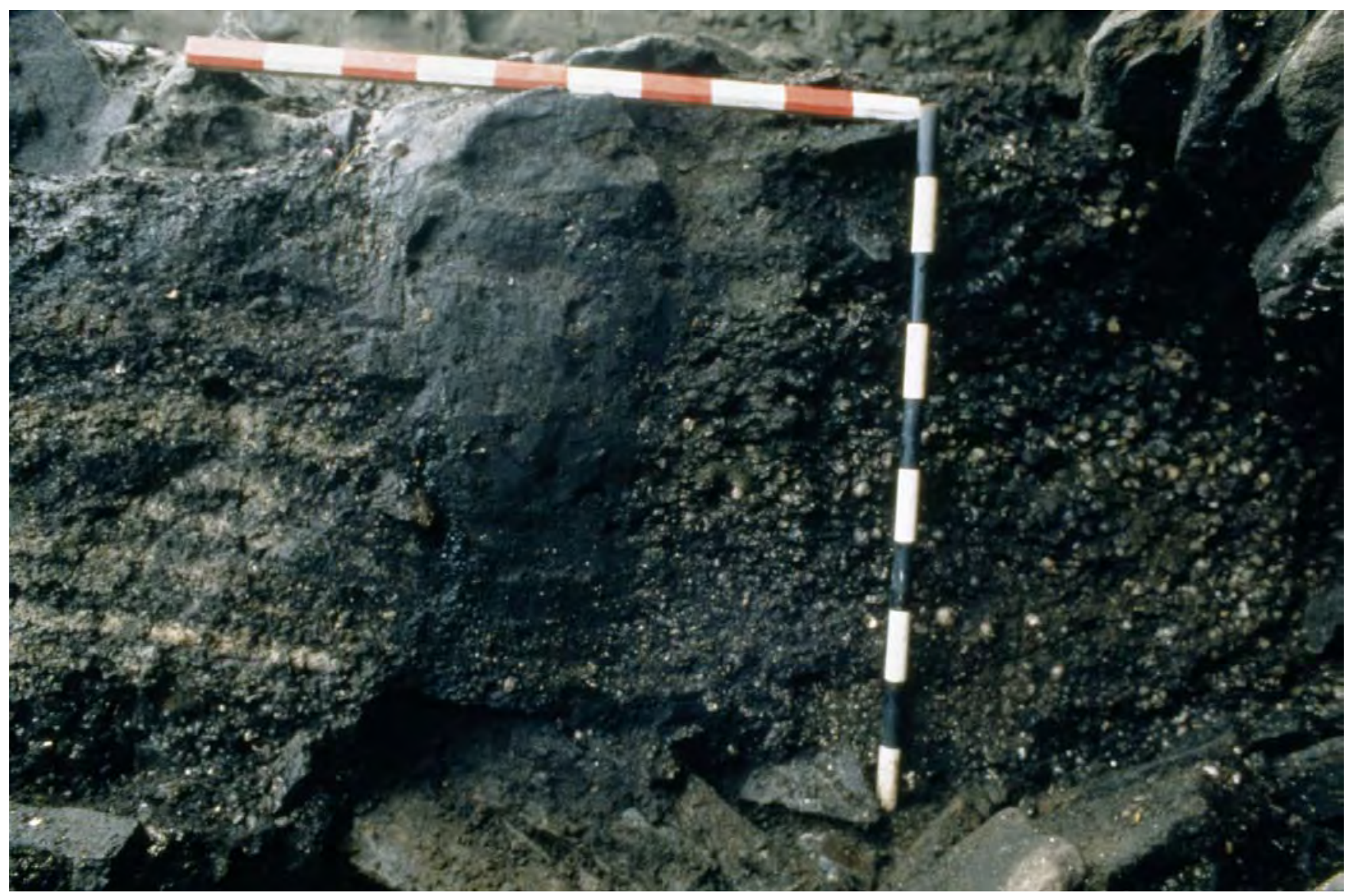

Illus 20 Detail of the west end of section B-C showing contexts C35 and C36 (photo: Roger Miket)

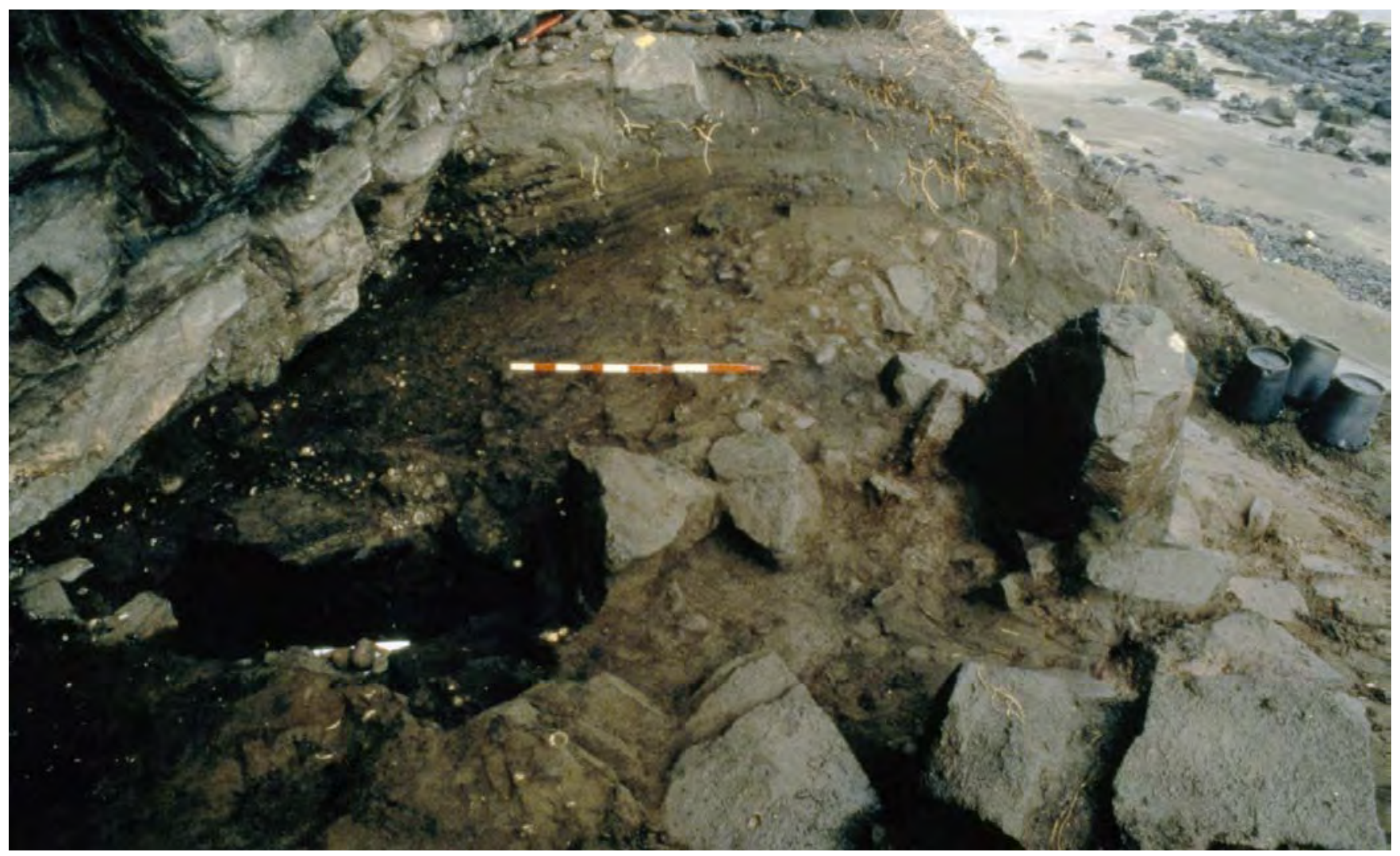

Illus 21 Approximate context C17 horizon viewed from the south. The copper-alloy pin was found to the right of the end of the scale (photo: Roger Miket) 


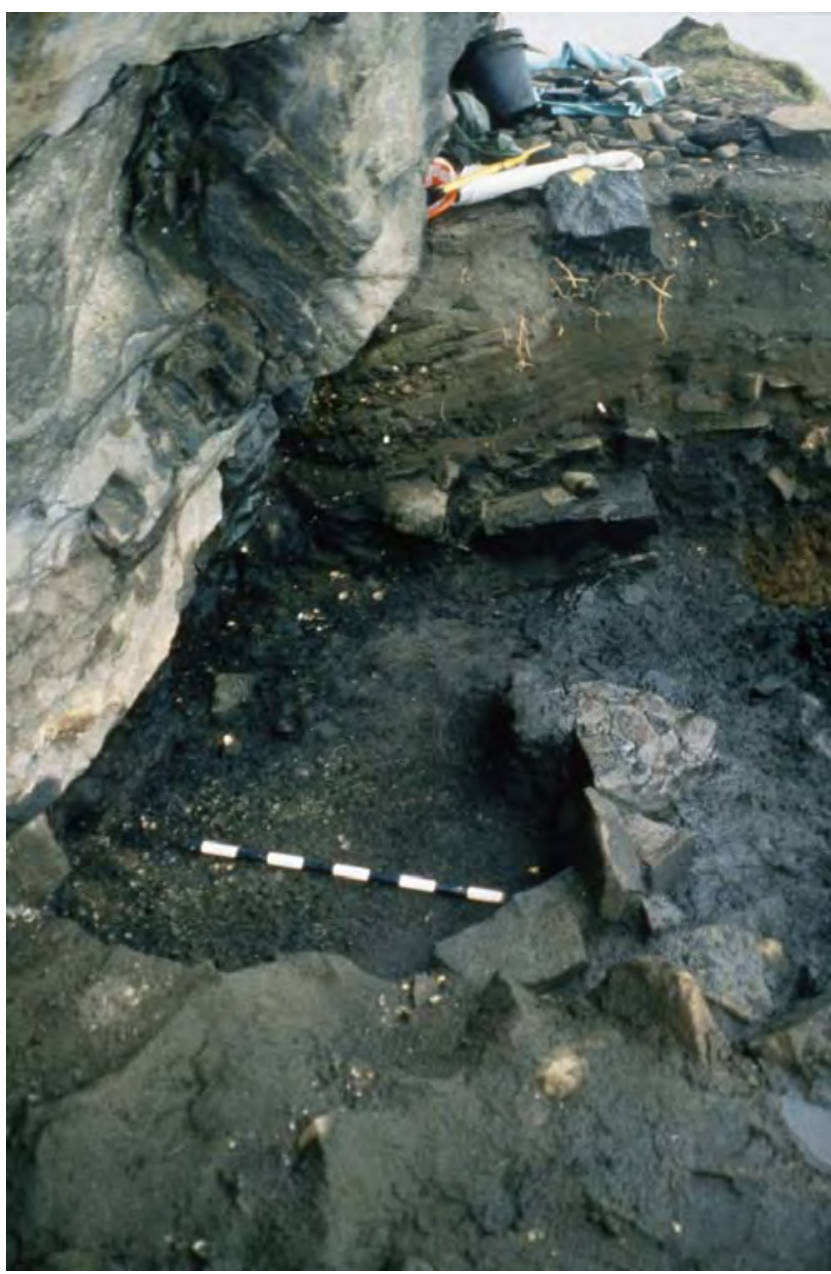

Illus 22 Stone setting in context C30, viewed from the south (photo: Roger Miket)

ing the subsequent importance of shellfish processing activities on or near the ledge. The shells provided the micro-environment which was conducive to the preservation of bone and antler remains, which were extremely common in contexts C31 and C36.

At present, it is impossible to determine with any precision the chronological relationships between many of these layers. C41 and C40 were lower and earlier than the other deposits and preceded midden formation. They extended along most of the trench, and they were not cut by any of the later deposits. The two basal layers of C36, the black silt layer and the layer of crushed shells, were probably also unrelated to the remainder of the deposits.

The significance and configuration of contexts C31 and C35, which appear intrusive, are uncertain Perhaps the most obvious explanation for C35 would be that it was a post-hole or post-pit, but without any record of it in plan or section to the south of section B-C, it could equally well have been a trench-like feature (illus $18 \& 20$ ). Similarly, the western zone of C31 in section (illus 18) looks like the infill of a pit-like feature which has truncated the C36 deposits to the west, although the C37 deposit has a non-truncated character which might imply that in reality it is coeval with C31. These kinds of problems are impossible to resolve on the present evidence.

An important chronological pointer is provided by the copper-alloy pin of Late Bronze Age/Early Iron Age date, found on the surface of $\mathrm{C} 17$ (illus 21). However, the $\mathrm{C} 17$ horizon of beach cobbles, recorded as likely to represent an occupation surface, is unfortunately not represented on any of the sections. From archive photographs, however, it would appear to relate stratigraphically to the $\mathrm{C} 10$ horizon.

The unnumbered, semi- or sub-circular stone setting shown on the plan (illus 15; see also illus 22) and section (illus 18), which overlay C35, appears to predate $\mathrm{C} 10$, as must also be the case with $\mathrm{C} 35$. No further dating evidence for the contexts is available apart from the modern material (19th20th centuries) from $\mathrm{C} 2$. 


\section{POST-EXCAVATION ANALYSIS AND SPECIALIST REPORTS, by Karen Hardy, Alan Saville, Roger Miket and Torben Bjarke Ballin}

The excavation was summarised in an interim report (Rees et al 1994) and some of the handexcavated lithic and bone artefacts were brought to the National Museum's former Artefact Research Unit in Edinburgh. The predominant Mesolithic character of the lithic and bone artefacts from the lower levels at the rockshelter was confirmed by an exploratory radiocarbon date on one of the bone tools (OxA-4994: 7590 \pm 90 BP). Summaries of the excavation and the finds were prepared for publication to bring the site to wider attention (Saville \& Miket 1994a; 1994b), to substantiate and clarify news of the excavation which had already appeared in the national (e.g. The Sunday Times, 20 February 1994) and local press (e.g. The Oban Times, 3 March 1994; Teachd an Tir, spring 1994), and to assist in the necessary fund-raising for post-excavation.

During the excavation, large numbers of finds were recovered from the site, mostly during trowelling, or as a result of dry-sieving some of the deposits through a $2 \mathrm{~mm}$ mesh. In addition, to complement the recovery by hand excavation, substantial bulk sampling was undertaken. Selected blocks and spits of deposit from identifiable contexts (approximately 1.5 tonnes, or $c 11.8 \mathrm{cwt}$, of soil) were transported in fertiliser bags to Edinburgh University's Archaeology Department in the hope of further processing under laboratory conditions. The decision to engage in this form of extensive sampling arose from the time constraints under which the excavation sondage was carried out, as described above.

The ad hoc circumstances of the excavation had precluded making any arrangements in advance for post-excavation or final publication. Roger Miket brought together a small, initially voluntary, working group of specialists from the Archaeology Departments of the University of Edinburgh and the National Museums of Scotland, which began the process of assessing the An Corran finds and estimating the likely costs of producing a report (see various assessment proposals in the project archive by S Boardman et al; P Milburn; and N Murray). Initial grants were obtained in 1996, principally from Historic Scotland and Highland Council, with the National Museum's Artefact Research Unit taking responsibility for the administration of the project. At the end of 1996 Dr Karen Hardy was appointed as part-time An Corran project manager and specialist, and various other specialist reports were commissioned. The initial objective, to produce a final report by the end of 1998, was almost achieved in first draft form, but, as in the case of the Kilellan, Islay, postexcavation project (Ritchie 2005, 5), the An Corran project was put into abeyance by the demise of the
Artefact Research Unit and the activity associated with the creation of the new Museum of Scotland (opened in 1998), and by the other commitments of the main protagonists.

However, references to An Corran in several publications kept the site in the frame as far as its relevance for the Scottish Mesolithic is concerned (e.g. Bonsall 1996; 1997; Mithen 2000; Saville 2003; 2004b; Hardy \& Wickham-Jones 2007). Particular interest in aspects of the human and animal skeletal remains was shown by Dr Nicky Milner, who, together with Dr Oliver Craig, was responsible for obtaining further radiocarbon dates and stable isotope data (Milner \& Craig 2009). Further funding from Historic Scotland became available in 2008-2010 to reignite the project and to allow Dr Torben Bjarke Ballin to collate the archive and bring together all the available material into a draft final report. Alan Saville, as the main stakeholder for the post-excavation project throughout its lengthy gestation, was responsible in 2010-2011 for preparing this final report for publication, but all the main authors have contributed to and signed off on the report as it now stands.

It remains unclear to the main authors of this report how much of the bulk-sampled material referred to above was eventually fully processed. It is the case that some sub-sampling and processing was done and that the residues from this were retained, but there is uncertainty over how much of the total this represents and how much possibly was mislaid. Strenuous efforts were made to clarify the position and to locate any overlooked bulk samples or sub-samples, but without resolving the matter, and it must be concluded that some of the bulksampled material may have been lost. However, 108 small bags of unwashed soil samples which had been intended for insect sampling or reference purposes were available. These were sieved and did produce numerous additional artefacts. There also remains a possibility that a few artefacts which came to light at various stages while the site was partially exposed in 1993-94 have not been traced.

Thus it is necessary to record the fact that the archaeological residues on which this report is based are more in the nature of a grab sample (and one to which limited stratigraphic control can be applied), rather than a controlled sample which can reliably be assessed for its representativeness. Despite this and other difficulties resulting from the emergency nature of the excavation, the An Corran site and its finds are regarded as of considerable significance for Scottish prehistory and well-deserving of the documentation provided here. 
Below, the archaeological residues are presented and interpreted by a number of specialists. The finds include prehistoric artefacts, as well as faunal and botanical material relating to the An Corran site. In total 5184 lithic artefacts were retrieved, in addition to 114 bone tools, two antler tools, and one copper-alloy pin. The faunal and botanical material embraces 46 human bones and teeth, approximately 8000 vertebrate bones and bone fragments (totalling c $4.6 \mathrm{~kg}$ ), and approximately $11 \mathrm{~kg}$ of shell (marine molluscs). Thirty-five flotation samples provided mainly charred hazelnut shells and charcoal, as well as fragments of land snails. Eighteen samples were radiocarbon dated; those samples were based on selected bone tools, as well as human and animal bone.

The specialist contributions were undertaken and completed at different stages during the protracted gestation of this report, and therefore do not necessarily align with all aspects of the final overview as presented here, for example when considering any phasing or grouping of the contexts. This is particularly so since most contributions were completed before all of the radiocarbon dates were available and it has created some inconsistencies, which it is now impossible to resolve for the present report without major reworking of the data. However, all the material from the excavation is held at National Museums Scotland and is available for further study or reanalysis, as has already begun to happen (for $\mathrm{PhD}$ theses at the University of York being undertaken by Ben Elliott and Emily Hellewell).

In this report, all artefacts are referred to by their number (CAT no.) in the individual specialist catalogues, which form part of the site archive (to be deposited with the RCAHMS). In view of the particular importance of the extensive bone artefact assemblage and its relevance for site chronology its catalogue is included with this report (Appendix Two). The An Corran finds are registered at National Museums Scotland with the assemblage designation X.1994.15. 


\section{THE LITHIC ARTEFACTS, by Karen Hardy, Alan Saville and Torben Bjarke Ballin}

\subsection{Introduction}

The lithic assemblage from the excavation includes 5184 artefacts, derived almost entirely from the lower horizons, C31 to C41, with nearly half having been recovered from the lowest two contexts, C40 and C41 (Table 2). The artefacts from the lowest black silty horizon of C36, which represents a discrete stratigraphic context within the main C36 midden, are listed separately as 'the base of C36'.

\subsection{Raw material}

Two main types of raw material are represented (Table 3) and these were identified petrologically in thin-section as baked mudstone and chalcedonic silica. Both materials have excellent flaking properties.

\subsubsection{Baked mudstone}

Baked mudstone is the collection's most common material (3259 pieces, or 63\%). In the Staffin Bay area, it occurs within the local igneous rocks as rafted sediments, which were altered by contact metamorphism. It ranges in colour from dense black through grey to light olive-grey and fawn, and it is always opaque and matt (illus 23-25). Colour and texture relate in part to the extent to which the local mudstone was exposed to heat during its formation process, for which reason a wide range of effects may occur within a single outcrop, with the exterior of the raft being more highly baked than

Table 2 Lithic artefacts by context

\begin{tabular}{lrr}
\hline Context & Number & \% \\
\hline C31 & 1173 & 23 \\
C34 & 23 & $<1$ \\
C35 & 1 & $<1$ \\
C36 & 838 & 16 \\
Base of C36 & 584 & 11 \\
C37 & 9 & $<1$ \\
C38 & 3 & $<1$ \\
C39 & 3 & $<1$ \\
C40 & 1765 & 34 \\
C41 & 713 & 15 \\
Unstratified & 72 & 1 \\
TOTAL & $\mathbf{5 1 8 4}$ & $\mathbf{1 0 0}$ \\
\hline
\end{tabular}

the interior, but also to the effects of weathering on the exterior of individual pieces. Although there are numerous mudstone exposures in the area around An Corran, only one occurrence of an intact baked raft of sediment was noted, and samples taken from this by one of us (Karen Hardy) produced a range of baked mudstone varieties closely similar to those from the archaeological assemblage. This outcrop occurs a few metres above and just north of the now removed rockshelter overhang. Below this still-surviving outcrop there was previously a ledge, accessible from above, which could have been used in connection with the quarrying of baked mudstone. Unfortunately, this ledge was only recognised from photographs after the rock face had been taken back during road construction, and it no longer exists. Samples of baked mudstone collected from the top of the cliff above the site and from the scree produced by blasting of the rock face have been added to the site archive. It is quite likely that the baked mudstone exploited at the site came either from this outcrop, immediately adjacent to the archaeological site, or from eroded blocks scattered in the vicinity. Baked mudstone also occurs as rounded pebbles and cobbles on the beach at An Corran, and some of the collection's artefacts are clearly based on pebbles.

\subsubsection{Chalcedonic silica}

The second most common material (1800 pieces, or $34 \%$ ) exploited at An Corran has an igneous origin, forming as chalcedonic fibres in a dark fine-grained groundmass, and occurring in the assemblage in the form of waterworn pebbles with abraded, sometimes vesicular cortex. The specific source of this raw material (in the following text referred to simply as chalcedony) was not found, but extensive field study (by Karen Hardy) located areas from which it may

Table 3 Lithic artefacts by raw material

\begin{tabular}{lcr}
\hline Raw material & Number & \% \\
\hline Baked mudstone & 3259 & 63 \\
Chalcedony & 1800 & 34 \\
Chert & 71 & 2 \\
Basalt/dolerite & 7 & $<1$ \\
Quartz & 15 & $<1$ \\
Bloodstone & 6 & $<1$ \\
Other & 20 & $<1$ \\
Indeterminate / burnt & 6 & $<1$ \\
TOTAL & $\mathbf{5 1 8 4}$ & $\mathbf{1 0 0}$
\end{tabular}




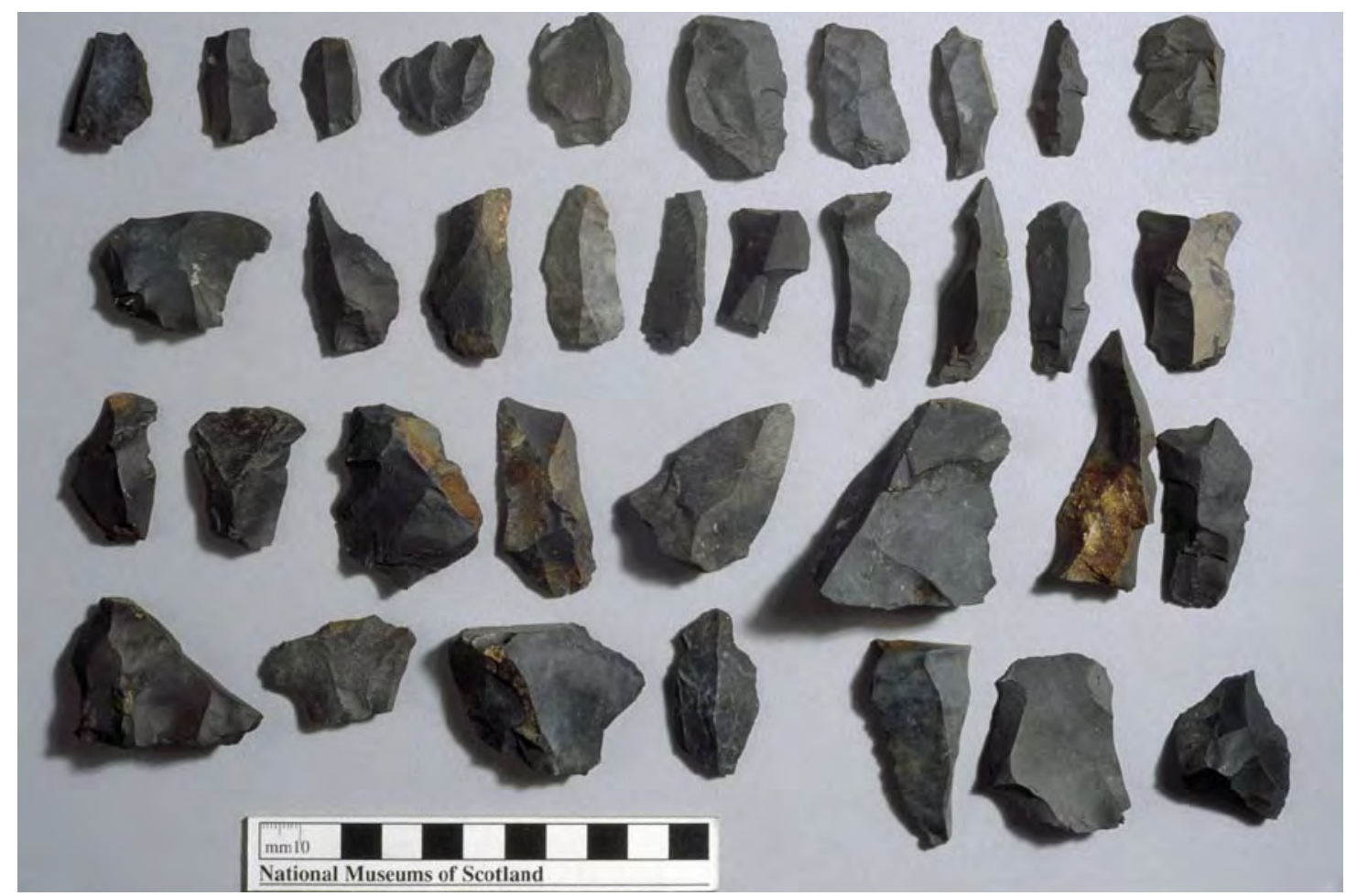

Illus 23 Flakes and blades of baked mudstone (photo: NMS)

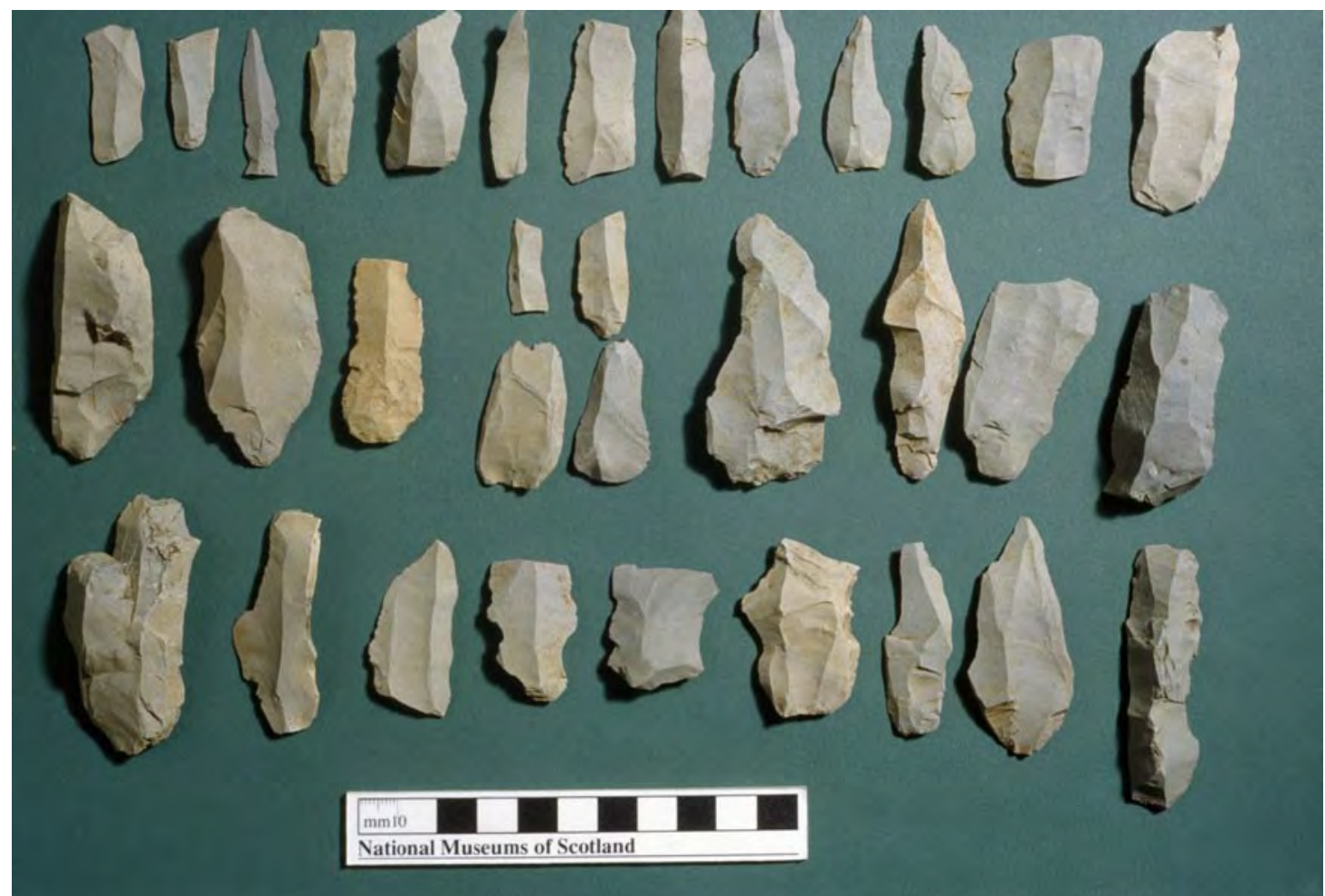

Illus 24 Flakes and blades of baked mudstone (photo: NMS)

possibly have been collected in pebble form. The nearest location was the beach at the mouth of the Stenscholl River, half a kilometre from the site (illus 1, C). Chalcedony occurred sporadically along the beach, but was concentrated at this particular point.
The river was searched upstream for several miles, and chalcedony pebbles were collected from every gravel exposure along it. Other rivers and streams were checked around the Trotternish peninsula, but no pebbles were found in rivers or river mouths 


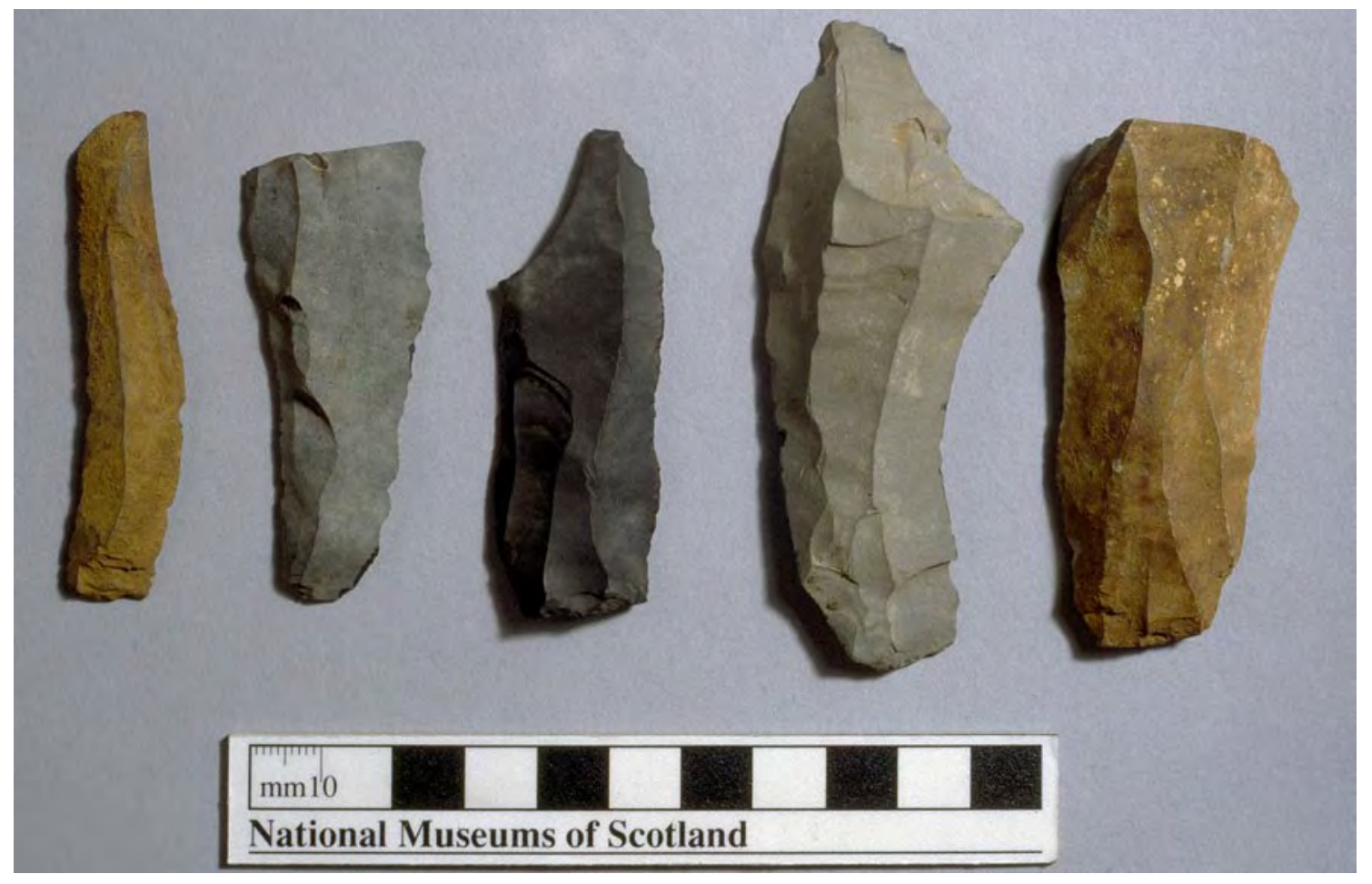

Illus 25 Large blades of baked mudstone (photo: NMS)

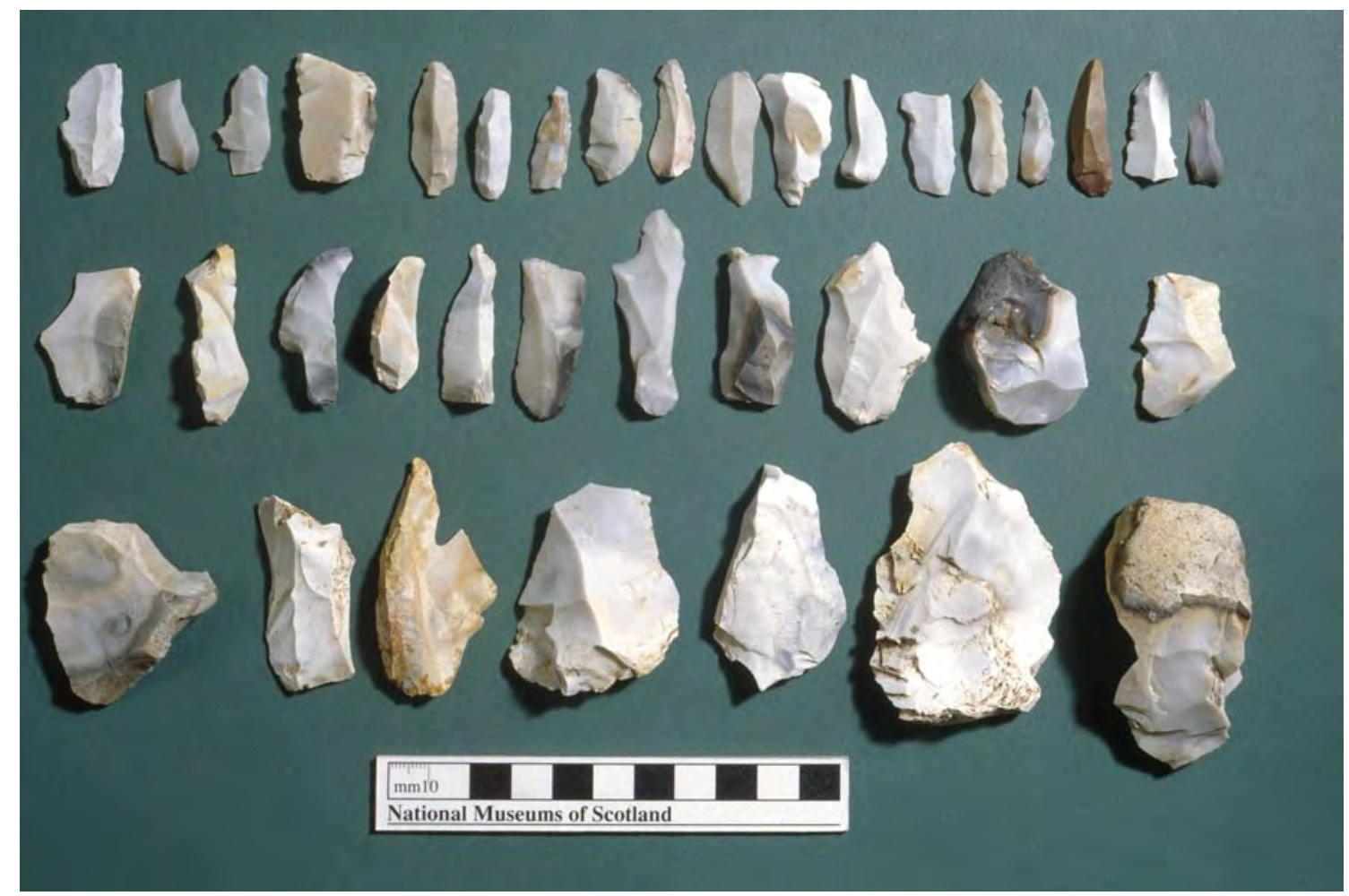

Illus 26 Flakes and blades of chalcedonic silica (Photo: NMS)

anywhere on the western or northern sides. Most likely, the source of this raw material must be found inland, somewhere east of the main escarpment. The chalcedony is translucent, and it displays a wide variety of colours, ranging from black, through light and dark grey, to red, orange and yellow (illus 26). Some pebbles are multi-coloured, and some are banded.

It should be noted that larger artefacts in this material, especially those with cortex, are all 
Table 4 Lithic raw materials by main context

\begin{tabular}{lcccccccc}
\hline & \multicolumn{2}{c}{ Baked mudstone } & \multicolumn{2}{c}{ Chalcedony } & \multicolumn{2}{c}{ The remainder } & \multicolumn{2}{c}{ Total } \\
Context & Number & $\%$ & Number & $\%$ & Number & \% & Number & $\%$ \\
\hline C31 & 798 & 68 & 328 & 28 & 47 & 4 & 1173 & 100 \\
C36 & 528 & 63 & 302 & 36 & 8 & 1 & 838 & 100 \\
Base of C36 & 444 & 76 & 134 & 23 & 6 & 1 & 584 & 100 \\
C40 & 988 & 56 & 741 & 42 & 36 & 2 & 1765 & 100 \\
C41 & 435 & 61 & 250 & 35 & 28 & 4 & 713 & 100 \\
TOTAL & $\mathbf{3 1 9 3}$ & $\mathbf{6 3}$ & $\mathbf{1 7 5 5}$ & $\mathbf{3 5}$ & $\mathbf{1 2 5}$ & $\mathbf{2}$ & $\mathbf{5 0 7 3}$ & $\mathbf{1 0 0}$ \\
\hline
\end{tabular}

Note: as this table does not include finds from insignificant contexts or unstratified finds, its total is lower than that of Table 2

Table 5 Baked mudstone artefacts with and without surface alteration, by main context

\begin{tabular}{|c|c|c|c|c|c|c|}
\hline \multirow[b]{2}{*}{ Context } & \multicolumn{2}{|c|}{ Weathered pieces } & \multicolumn{2}{|c|}{ Unaltered pieces } & \multicolumn{2}{|c|}{ Total } \\
\hline & Number & $\%$ & Number & $\%$ & Number & $\%$ \\
\hline C31 & 391 & 49 & 407 & 51 & 798 & 100 \\
\hline C36 & 153 & 29 & 375 & 71 & 528 & 100 \\
\hline Base of C36 & 160 & 36 & 284 & 64 & 444 & 100 \\
\hline $\mathrm{C} 40$ & 840 & 85 & 148 & 15 & 988 & 100 \\
\hline C41 & 335 & 77 & 100 & 23 & 435 & 100 \\
\hline TOTAL & 1879 & 59 & 1314 & 41 & 3193 & 100 \\
\hline
\end{tabular}

Note: as this table does not include finds from insignificant contexts or unstratified finds, its total is lower than that of Table 2

readily identifiable as chalcedony, but identification of small inner flakes and spalls can be difficult. This is particularly the case with some of the microliths and microburins, some of which are very 'flint-like'. On balance, the absence from the assemblage of any larger implements or waste identifiable as flint, coupled with the absence of flint pebbles from the An Corran beach, argues against the presence of flint at this site, but it cannot be ruled out that a small number of flint artefacts, such as microliths or bladelets, could have been imported.

\subsubsection{Bloodstone and other raw materials}

Seventy-one pieces were defined as chert, probably deriving from the various beds of sediments of the Staffin Bay Formation (Emeleus \& Bell 2005, 35). However, as the colours of these pieces are similar to several of the colours experienced within the baked mudstone continuum, some of them may actually belong to the latter category. Quartz (15 pieces), presumably procured locally, was knapped on-site in small quantities, but there are no implements in this material, only waste. Five bloodstone flakes and chips, as well as one bloodstone core, were recovered. In prehistory, bloodstone was probably mainly obtained from the vicinity of Bloodstone Hill on Rùm, an island south of Skye (Clarke \& Griffiths 1990, 156). In addition, there are a number of artefacts in a variety of unidentifiable siliceous raw materials which are simply listed as 'other' raw material. It is unclear whether the few pieces of struck basalt/ dolerite in the assemblage are deliberate or incidental products. One large dolerite pebble from C36 is characterised by five removals along one edge, and it may be a chopper-like tool. However, its sharp edge appears unused, suggesting that the detached flakes may have been the intended products, and it was subsequently classed as a core. Basalt and dolerite are common rock forms on Skye, where they form part of the island's volcanic complex (Emeleus \& Bell 2005, 98).

\subsubsection{Distribution by context}

The distribution of raw materials through the contexts differs (Table 4), with baked mudstone being rather more common in the upper levels, but the differences are small overall and probably of little archaeological significance. Thus, both baked mudstone and chalcedony appear to have been exploited in whatever phases are represented by contexts C36 through to C41.

\subsubsection{Surface alteration}

A number of baked mudstone artefacts (1879 pieces, or $59 \%$ ) are characterised by clearly altered flaked surfaces (Table 5), with a lighter-coloured surface 


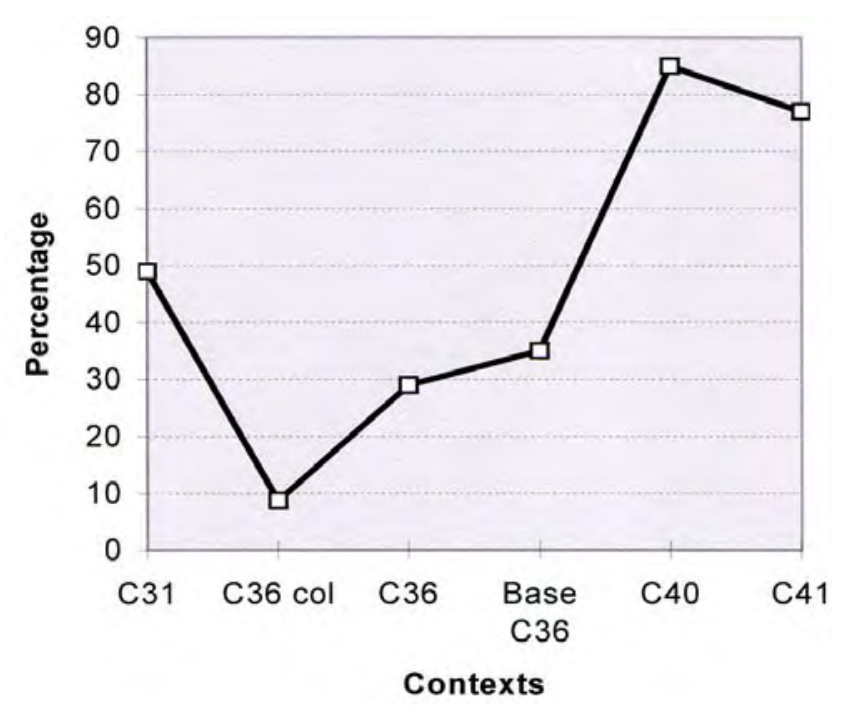

Illus 27 Baked mudstone artefacts with surface alteration, as a percentage of all baked mudstone artefacts in each context

overlying a darker-coloured interior, which may have been exposed by edge damage or fragmentation. The precise causes of this surface alteration are not known, but it is probably related to localised contextual conditions ('weathering'). Artefacts CAT 422 and CAT 423 , with differently coloured refitting parts, suggest that at least some of this alteration is post-depositional and local.

The unaltered baked mudstone (1314 pieces, or $41 \%$ ) occurs in three major colour groups: light olive-grey, darker grey and black. Some of the colours probably represent different degrees of exposure to heat during original formation, with at one extreme a shiny jet black, fine-grained baked mudstone, and at the other a dark-grey, dull, coarser-grained baked mudstone. However, most of the present colours are thought to represent postdepositional effects.

The proportions of artefacts with surface alteration vary between contexts (illus 27). Almost all baked mudstone artefacts from $\mathrm{C} 40$ and $\mathrm{C} 41$ are altered. No soil analyses are available from An Corran but, since these contexts are the ones without shell and bone and probably represent the original soil and subsoil, they probably had a much higher acidity, which probably had a bearing on the alteration of the baked mudstone.

\subsection{Weight}

All lithic artefacts were weighed. The total weight of the assemblage is $20 \mathrm{~kg}$, with an average artefact weight of $3.8 \mathrm{~g}$. Separation by raw material type shows that, on average, the weight of baked mudstone artefacts $(4.5 \mathrm{~g})$ is twice that of chalcedony ones $(2.2 \mathrm{~g})$. This is thought to relate to the different character of the procured material, with baked mudstone having been procured in part as relatively large blocks from the nearby quarry or beach, whereas chalcedony was procured in the form of relatively small pebbles further away from the site.

\subsection{Reduction techniques}

Reduction techniques were assessed using the criteria of Newcomer (1975) and Ohnuma \& Bergman (1982), which include bulb type (pronounced or diffuse), presence or absence of lip, size of platform remnant, and trimming of the platform margin. Almost all the flakes and blades in this assemblage have very small, plain platform remnants and diffuse bulbs, and many have notable lips below the platform. A large number are trimmed, and many platform remnants are punctiform or linear (often less than $1 \mathrm{~mm}$ wide). Occasional large flakes show indicators of hard-hammer percussion, such as pronounced bulbs and conchoidal rings, cones and obvious points-of-impact, but otherwise the evidence overwhelmingly suggests reduction by direct percussion with soft hammers.

\subsection{Refitting}

Some refits of two and three successive flakes were achieved, involving both baked mudstone and chalcedony flakes. All the refits involved artefacts from within the same contexts; no inter-context refits were noted. The chalcedony refits include several instances involving primary and secondary flakes, providing a further indication that complete pebbles of this material were brought to the site for reduction.

\subsection{The assemblage}

In Table 6 the assemblage is subdivided by main artefact categories and main contexts, and in Table 7 by main artefact categories and raw materials.

\subsubsection{Flakes and blades (illus 28)}

A substantial number (approximately 2500 pieces) of the unretouched flakes are small flakes and spalls with a greatest dimension of $10 \mathrm{~mm}$ or less (chips). The presence of these pieces demonstrates that primary reduction occurred routinely at the site. Table 6 shows that blades represent a notable proportion of the assemblage (6\%). According to Bordes \& Gaussen (1970), a blade ratio of 20 per cent is required to classify an industry as a blade one, suggesting that the An Corran assemblage is not the product of a blade industry. In the authors' view, the approach of Bordes and Gaussen is too mechanistic, and the classification of an industry as a flake or blade industry should not be based entirely on 
Table 6 Main lithic artefact categories subdivided by main context

\begin{tabular}{lrrrrrr}
\hline Main category & C31 & C36 & $\begin{array}{c}\text { Base of C36 } \\
\text { Number }\end{array}$ & $\mathbf{C 4 0}$ & C41 & Total \\
\hline Flakes & 1086 & 702 & 541 & 1526 & 632 & 4487 \\
Blades & 34 & 54 & 32 & 164 & 50 & 334 \\
Cores and core frags & 19 & 29 & 2 & 20 & 8 & 78 \\
Tools & 25 & 49 & 6 & 49 & 18 & 147 \\
Chunks & 9 & 4 & 3 & 6 & 5 & 27 \\
TOTAL & $\mathbf{1 1 7 3}$ & $\mathbf{8 3 8}$ & $\mathbf{5 8 4}$ & $\mathbf{1 7 6 5}$ & $\mathbf{7 1 3}$ & $\mathbf{5 0 7 3}$ \\
& & & Per cent & & & 88 \\
Flakes & 92 & 84 & 92 & 87 & 88 & 8 \\
Blades & 3 & 6 & 6 & 9 & 7 & 2 \\
Cores & 2 & 3 & $<1$ & 1 & 3 & 3 \\
Tools & 2 & 6 & 1 & 3 & 3 & 1 \\
Chunks & 1 & 1 & 1 & $<1$ & $\mathbf{1 0 0}$ & $\mathbf{1 0 0}$ \\
TOTAL & $\mathbf{1 0 0}$ & $\mathbf{1 0 0}$ & $\mathbf{1 0 0}$ & $\mathbf{1 0 0}$ & $\mathbf{1 0 0}$
\end{tabular}

Note: as this table does not include finds from insignificant contexts or unstratified finds, its total is lower than that of Table 2

Table 7 Main lithic artefact categories subdivided by raw material

\begin{tabular}{|c|c|c|c|c|c|c|}
\hline \multirow[t]{2}{*}{ Raw material } & Flakes & Blades & Cores & Tools & Chunks & Total \\
\hline & \multicolumn{6}{|c|}{ Number } \\
\hline Baked mudstone & 2895 & 231 & 48 & 69 & 16 & 3259 \\
\hline Chalcedony & 1585 & 104 & 29 & 78 & 4 & 1800 \\
\hline Chert & 63 & 1 & & & 7 & 71 \\
\hline Basalt/dolerite & 6 & & 1 & & & 7 \\
\hline Quartz & 14 & 1 & & & & 15 \\
\hline Bloodstone & 6 & & & & & 6 \\
\hline Other (incl. burnt) & 26 & & & & & 26 \\
\hline \multirow[t]{2}{*}{ TOTAL } & 4595 & 337 & 78 & 147 & 27 & 5184 \\
\hline & \multicolumn{6}{|c|}{ Per cent } \\
\hline Baked mudstone & 89 & 7 & 2 & 2 & $<1$ & 100 \\
\hline Chalcedony & 88 & 6 & 2 & 4 & $<1$ & 100 \\
\hline Chert & 89 & 1 & & & 10 & 100 \\
\hline Basalt/dolerite & 86 & & 14 & & & 100 \\
\hline Quartz & 93 & 7 & & & & 100 \\
\hline Bloodstone & 100 & & & & & 100 \\
\hline Other & 100 & & & & & 100 \\
\hline TOTAL & 89 & 6 & 2 & 3 & $<1$ & 100 \\
\hline
\end{tabular}

a ratio. Instead, it should be based on whether it could be argued that blades are intentional products of that industry or not (that is, a fuller understanding of the operational schema in question), whatever the collection's blade ratio. The regularity of the An Corran blades and blade blanks (i.e. their parallel lateral sides and dorsal arrises) clearly define these as intentional (i.e. non-random) blades, and thereby the assemblage as the product of an industry focusing on specialised blade production.

Too few of the blades are complete enough for detailed metrical comparisons, but it can be said that most baked mudstone blades are quite broad, whereas the chalcedony blades include many elegant narrow specimens. It is perhaps noteworthy that the five largest baked mudstone blades are from the 


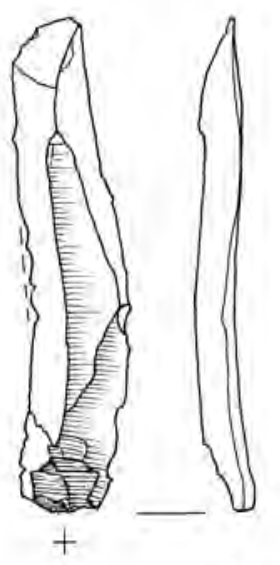

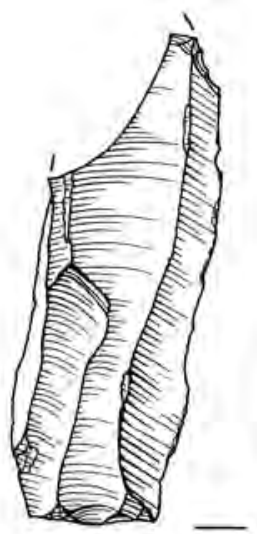

$+$
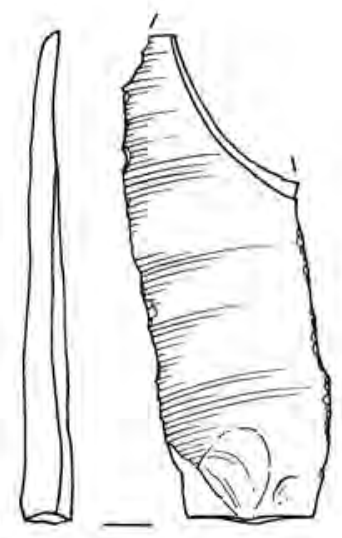

1165

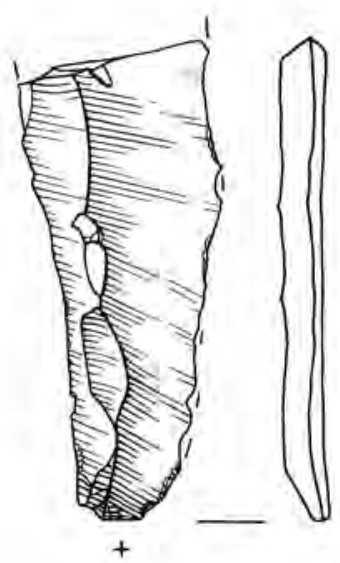

3946

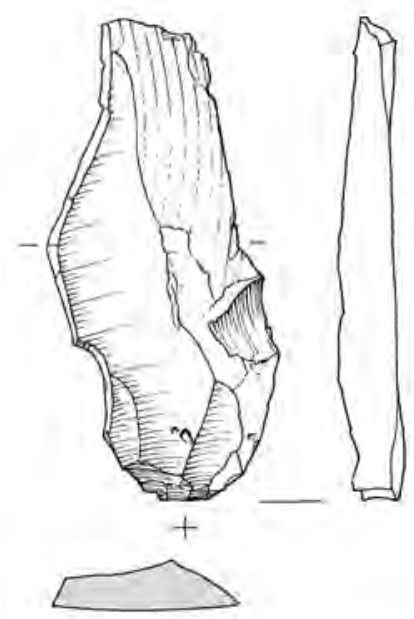

913
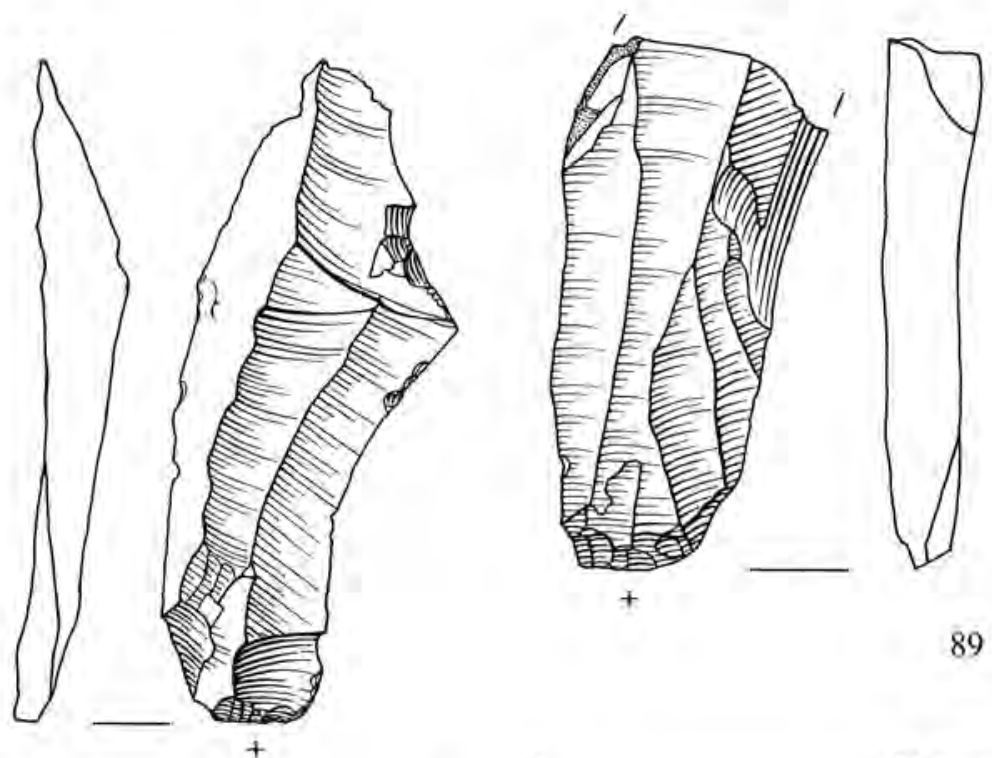

89

$50 \mathrm{~mm}$

Illus 28 Blades: CAT 913 is chalcedonic silica, the others are baked mudstone (drawn by Marion O'Neil)

lowest level, C41. One large chalcedony blade (CAT 913 from C36; illus 28) is exceptional, since the average small pebble-size of this raw material would normally preclude their production. The blades also embrace seven crested pieces, which in Table 6 are included amongst the flakes and blades.

\subsubsection{Cores (illus 29)}

Cores and core fragments amount to 78 pieces. The 56 typologically definable cores were distributed throughout the stratigraphic sequence (Table 8), with a concentration in C31-36. Baked mudstone is the more common raw material (Table 9). Although the baked mudstone allowed the production of larger cores (also see blades, above), the average core size in both raw materials is similar and small, reflecting the exhausted nature of many of the cores. In their present state, only seven of the cores were characterised as blade cores, the others being either blade and flake cores (23 pieces) or flake cores (25 pieces).

The predominant type is the opposed-platform core (32 pieces), supplemented by single-platform cores and irregular (multi-directional) cores (10 pieces each). One small chalcedony opposed-platform core (from C36) is an anvil-struck bipolar core (CAT 84), but otherwise no conclusive evidence for hammerand-anvil technology was noted amongst the waste or implements, and most of the An Corran flakes and blades were produced by platform technique. This is confirmed by the presence of core rejuvenation flakes in both baked mudstone and chalcedony.

\subsubsection{Tools}

In Table 7 the tools are subdivided by raw material and in Table 10 an overview is presented of all imple- 
Table 8 Typologically classifiable cores by context

\begin{tabular}{|c|c|c|c|c|c|c|c|}
\hline Core type & C31 & C36 & Base of C36 & $\mathbf{C 4 0}$ & $\mathbf{C 4 1}$ & Unstratified & Total \\
\hline Single-platform cores & 2 & 5 & & 1 & 1 & 1 & 10 \\
\hline Opposed-platform cores & 7 & 12 & & 8 & 4 & 1 & 32 \\
\hline Cores with two platforms at an angle & & & & & 1 & & 1 \\
\hline Irregular cores & 5 & 5 & & 2 & & & 12 \\
\hline Bipolar anvil cores & & 1 & & & & & 1 \\
\hline TOTAL & 14 & 23 & $\mathbf{0}$ & 11 & 6 & 2 & 56 \\
\hline
\end{tabular}

Table 9 Cores and core fragments by raw material and context

\begin{tabular}{lcccc}
\hline Context & Baked mudstone & Chalcedony & Other & Total \\
\hline C31 & 13 & 4 & 1 & 18 \\
C36 & 20 & 7 & & 27 \\
Base of C36 & 1 & 1 & & 2 \\
C40 & 9 & 10 & & 19 \\
C41 & 3 & 5 & & 8 \\
Unstratified & 2 & 2 & $\mathbf{1}$ & 4 \\
TOTAL & $\mathbf{4 8}$ & $\mathbf{2 9}$ & $\mathbf{7 8}$ \\
\hline
\end{tabular}

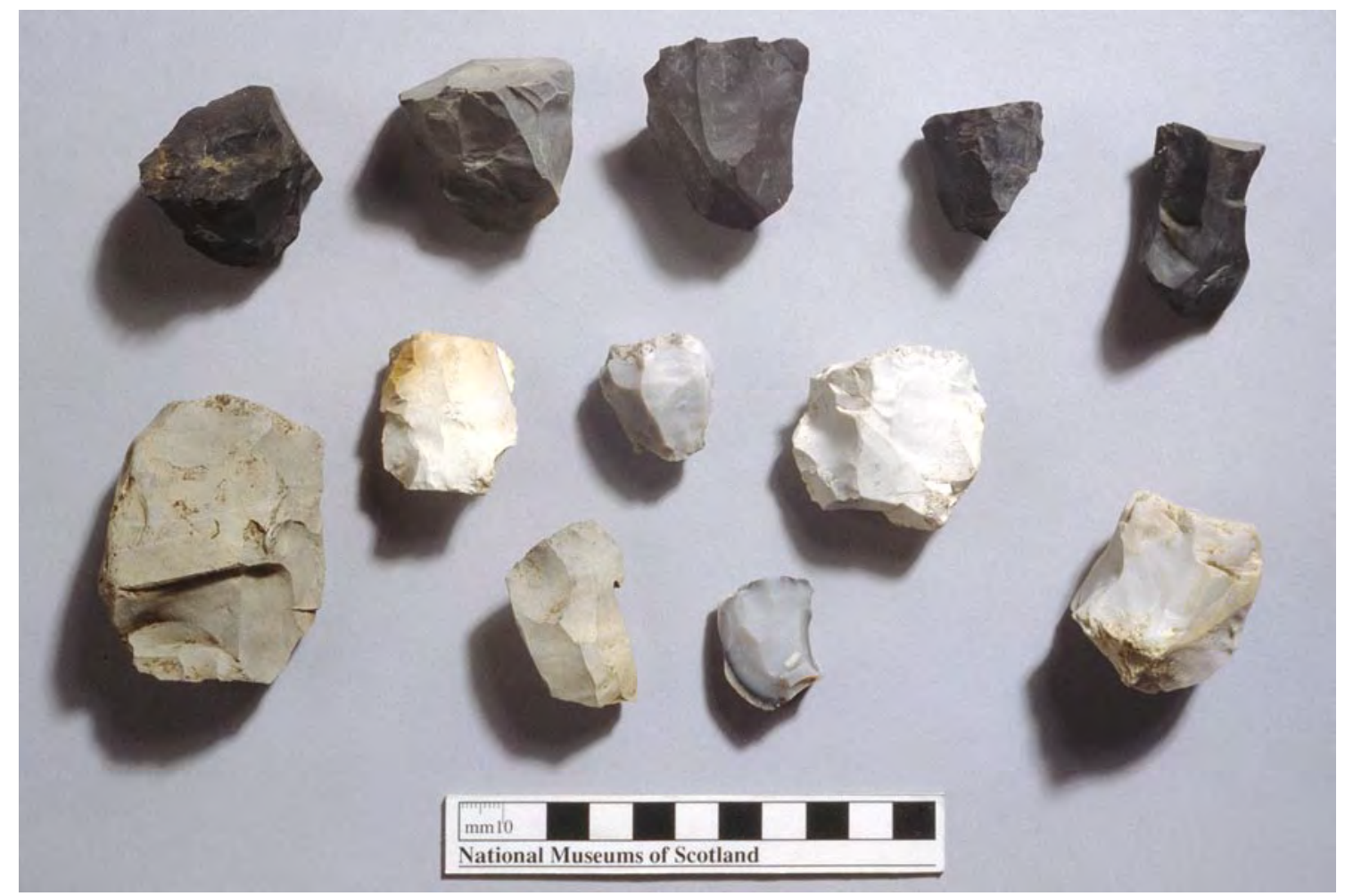

Illus 29 Cores: the middle three and the two at the lower right are chalcedonic silica, the others are baked mudstone (photo: Alan Saville/NMS)

ments by type and context. The most numerous formal tools are the microliths and related pieces, including microburins (53 pieces in total), followed by scrapers (20 pieces), piercers (10 pieces), and edge-trimmed pieces (14 pieces). The remainder includes rare formal tool types (e.g. some notched pieces) and a relatively numerous group of informal or expedient pieces. Approximately three-quarters 
Table 10 Lithic tools by type and context

\begin{tabular}{|c|c|c|c|c|c|c|}
\hline Tool type & C31 & C36 & Base of C36 & $\mathrm{C} 40$ & C41 & Total \\
\hline Microliths etc & 7 & 6 & 5 & 22 & 13 & 53 \\
\hline Scrapers & 7 & 7 & - & 5 & - & 19 \\
\hline Piercers & 2 & 5 & - & 2 & 1 & 10 \\
\hline Edge-trimmed & 2 & 6 & - & 4 & 2 & 14 \\
\hline Miscellaneous & 7 & 25 & 1 & 16 & 2 & 51 \\
\hline TOTAL & 25 & 49 & 6 & 49 & 18 & 147 \\
\hline
\end{tabular}

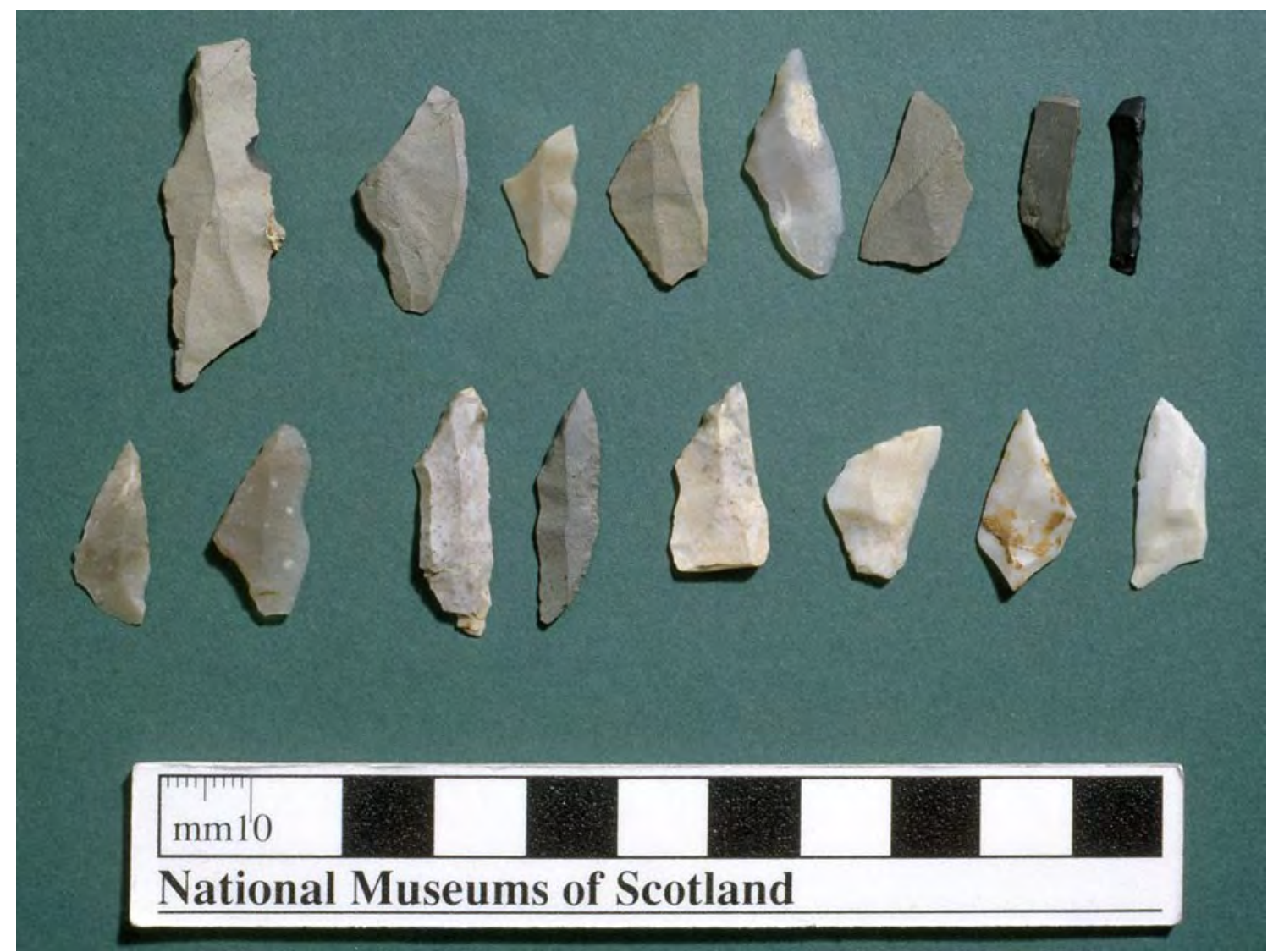

Illus 30 Microliths (photo: NMS)

of the tools are based on flakes, with blades forming a comparatively small proportion of the tool blanks (c 10\%). The remainder of the tool blanks includes small numbers of discarded cores, chunks, pebbles and indeterminate pieces.

Microliths, microburins, and related forms (illus 30-31)

In total 32 microliths, including fragments, and 14 microburins were recovered, along with seven microlith-related pieces. The microlithic pieces are distributed across sub-types as in Table 11, which also indicates context and subdivides the pieces by raw material.

The microliths are clearly dominated by obliquely blunted points (illus 31), most of which are plain
(Table 12) and also fairly small (Tables 13-14). One of the baked mudstone pieces (CAT 35; illus 31 ) is particularly interesting, as this is the only large obliquely blunted point. Although broken, the surviving dimensions of the piece (length $38 \mathrm{~mm}$; weight $1.3 \mathrm{~g}$ ) are still far in excess of the values for the other microliths. Two of the triangular microliths (CAT 4 \& 30; illus 31) approach the isosceles form, and contrast markedly with the site's three small, scalene pieces (CAT 1932, 4824 \& 5122; illus 31 ), one of which (CAT 4824) is atypically made transversely on a flake fragment. Two microliths (CAT 5121 \& 5134; illus 31), blunted on both arc and chord, are crescents, one (5121) more sub-angular than the other, whereas the site's other possible crescent (CAT 51) is fragmented at either end and thus regarded as unclassifiable. The assemblage also includes one edge-blunted type with a fine point 

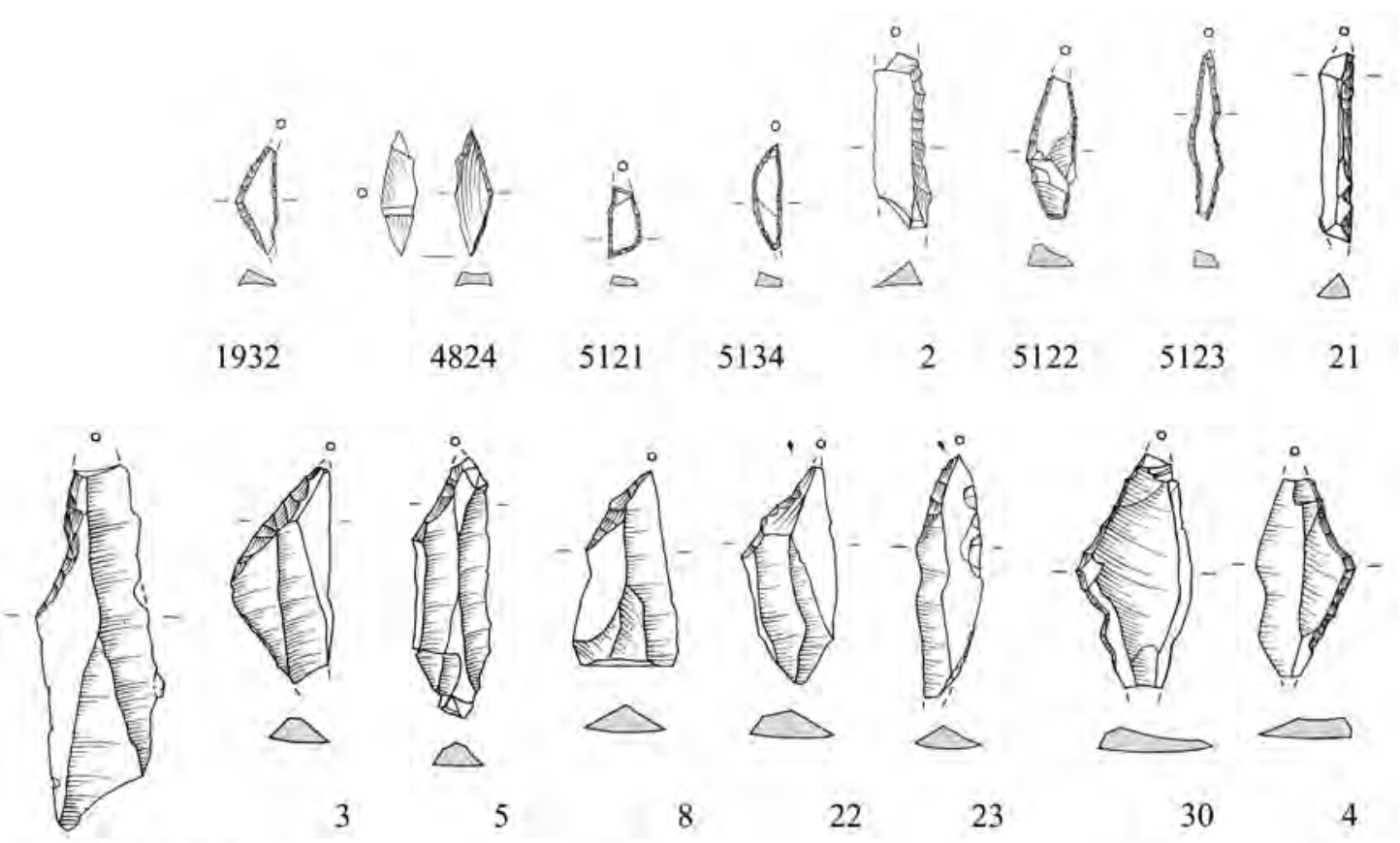

8

22

23

30

4
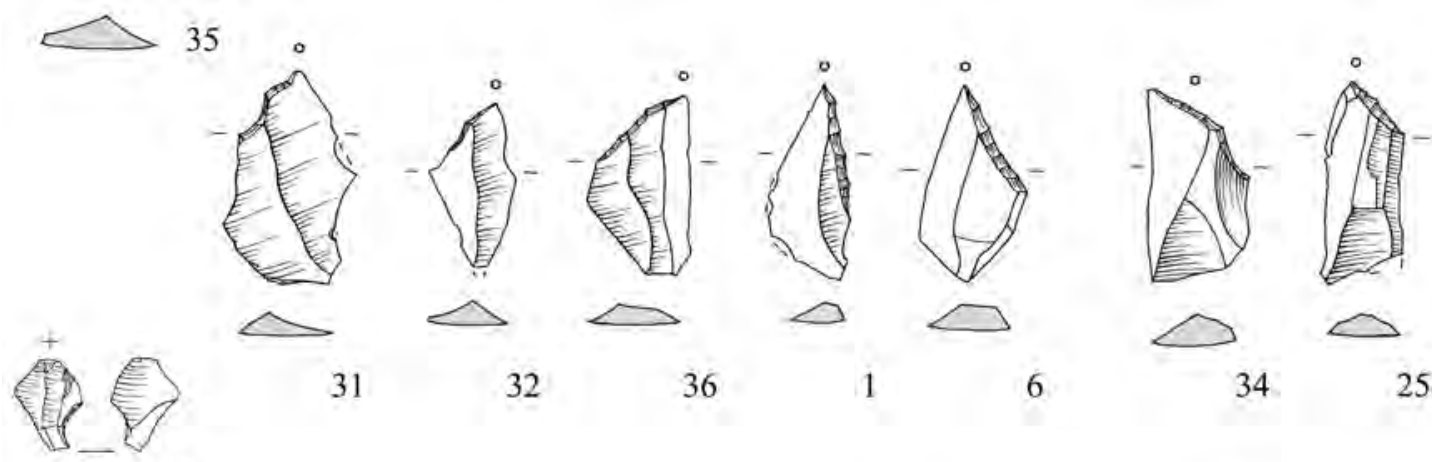

31

32

36

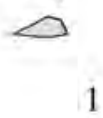

6

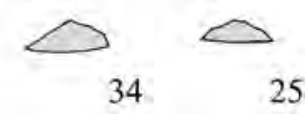

1934
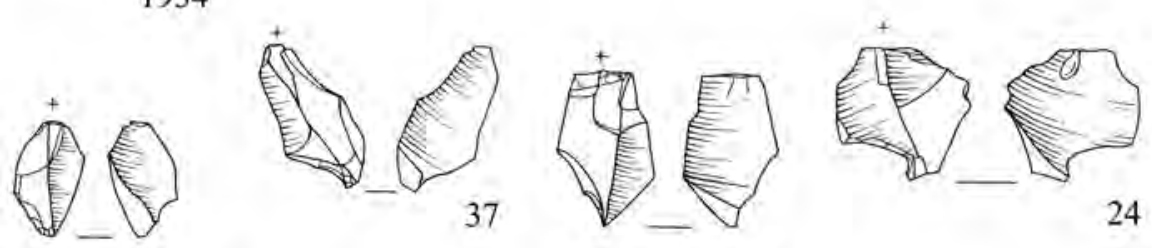

24

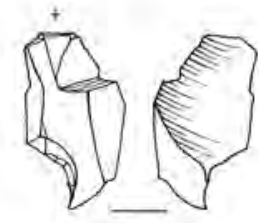

10

39
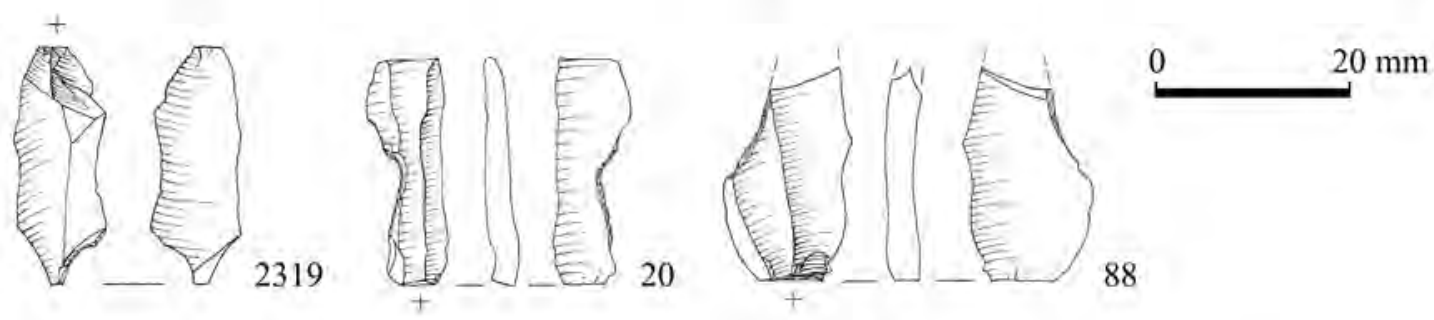

Illus 31 Microliths, microburins and related forms: CAT 2, 21, 35, 3, 23, 30, 34, 37, 10, \& 2319 are baked mudstone, the others are chalcedonic silica (drawn by Marion O'Neil)

(CAT 5123; illus 31) and an atypical edge-blunted form (CAT 21; illus 31).

Eleven microliths were not classifiable within the generally accepted standard microlith typologies (e.g. Clark 1934a, Jacobi 1978; cf Butler 2005 for an overview). However, most of these are broken implements, with four being potential fragments of obliquely blunted pieces (CAT 7, 33, $997 \& 1296$ ), two possible fragments of small triangular microliths (CAT $9 \& 2746$ ), and one seems to be the terminal of a small bilateral point (CAT 5224).

With such a small number of clearly classifiable forms, possibly spanning a broad chronological range, it is difficult to draw firm conclusions. However, it 
Table 11 Microliths, microburins, and microlith-related forms

\begin{tabular}{|c|c|c|c|c|c|c|c|}
\hline Type & C31 & C36 & $\begin{array}{c}\text { C36 } \\
\text { base }\end{array}$ & $\mathbf{C 4 0}$ & C41 & Totals & $\begin{array}{c}\text { Type } \\
\text { Totals }\end{array}$ \\
\hline \multicolumn{8}{|l|}{ MICROLITHS } \\
\hline Obliquely blunted points - chalcedony & - & - & 1 & 4 & 4 & 9 & \\
\hline Obliquely blunted points - mudstone & - & - & 1 & 2 & 1 & 4 & 13 \\
\hline Isosceles triangles - chalcedony & - & - & - & - & 1 & 1 & \\
\hline Isosceles triangles - mudstone & - & - & - & 1 & - & 1 & 2 \\
\hline Scalene triangles - chalcedony & 2 & - & - & 1 & - & 3 & 3 \\
\hline Crescents - chalcedony & 1 & 1 & - & - & - & 2 & 2 \\
\hline Edge-blunted - mudstone & - & - & - & - & 1 & 1 & 1 \\
\hline Bilaterally edge-blunted - chalcedony & 1 & - & - & - & - & 1 & 1 \\
\hline Unclassified fragments - chalcedony & 1 & 1 & - & 2 & 1 & 5 & \\
\hline Unclassified fragments - mudstone & 1 & 1 & 1 & 1 & 1 & 5 & 10 \\
\hline MICROLITH TOTALS & 6 & 3 & 3 & 11 & 9 & 32 & 32 \\
\hline \multicolumn{8}{|l|}{ MICROBURINS } \\
\hline Chalcedony & - & 2 & 1 & 6 & 1 & 10 & \\
\hline Mudstone & 1 & - & - & 2 & 1 & 4 & \\
\hline MICROBURIN TOTALS & 1 & 2 & 1 & 8 & 2 & 14 & 14 \\
\hline \multicolumn{8}{|l|}{ MICROLITH-RELATED } \\
\hline Chalcedony & - & - & 1 & 2 & 1 & 4 & \\
\hline Mudstone & - & 1 & - & 1 & 1 & 3 & \\
\hline MICROLITH-RELATED TOTALS & - & $\mathbf{1}$ & 1 & 3 & 2 & 7 & 7 \\
\hline Totals - chalcedony & 5 & 4 & 3 & 15 & 8 & 35 & \\
\hline Totals - mudstone & 2 & 2 & 2 & 7 & 5 & 18 & \\
\hline GRAND TOTALS & 7 & 6 & 5 & 22 & 13 & 53 & 53 \\
\hline
\end{tabular}

Table 12 Microliths - obliquely blunted point types

\begin{tabular}{lcccccc}
\hline Obliquely blunted type & C31 & C36 & C36 base & C40 & C41 & Totals \\
\hline LHS plain - chalcedony & - & - & - & 3 & 2 & 5 \\
LHS plain - mudstone & - & - & 1 & 1 & 1 & 3 \\
RHS plain - chalcedony & - & - & - & 1 & 2 & 3 \\
RHS plain - mudstone & - & - & - & 1 & - & 1 \\
LHS with opposed retouch - mudstone & - & - & 1 & - & - & $\mathbf{5}$ \\
Totals & - & - & $\mathbf{2}$ & $\mathbf{6}$ & $\mathbf{1 3}$ \\
\hline
\end{tabular}

should be noted that most of the microliths derive from the lower contexts, and that these levels include all the obliquely blunted and isosceles pieces, whilst the small geometric microliths are mainly from elsewhere in the stratigraphy (C40, 36 \& 31). There is a slight preference for chalcedony as the raw material for microliths. Contrasting the typology, raw material and context did not produce any absolute trends, other than for the baked mudstone microliths to be larger than their chalcedony counterparts.

The 14 microburins (illus 31 ) are also mainly in chalcedony, and they are mostly from the lower contexts (Tables $11 \& 13-15)$. Thirteen are proximal 
Table 13 Dimensions of complete, and near complete (+), microliths and microburins of chalcedony

\begin{tabular}{|c|c|c|c|c|c|}
\hline $\begin{array}{l}\text { Catalogue } \\
\text { number }\end{array}$ & Context & Type & $\begin{array}{l}\text { Length } \\
\text { in } \mathbf{~ m m ~}\end{array}$ & $\begin{array}{c}\text { Breadth } \\
\text { in } \mathbf{~ m m}\end{array}$ & $\begin{array}{c}\text { Thickness } \\
\text { in } \mathbf{m m}\end{array}$ \\
\hline 1 & 41 & Obliquely blunted & 19.9 & 8.2 & 2.3 \\
\hline 5 & 41 & Obliquely blunted & $27.1+$ & 8.1 & 2.6 \\
\hline 6 & 41 & Obliquely blunted & 20.0 & 10.7 & 2.6 \\
\hline 8 & 41 & Obliquely blunted & 20.3 & 10.8 & 2.6 \\
\hline 25 & 40 & Obliquely blunted & 21.1 & 8.2 & 2.2 \\
\hline 31 & 40 & Obliquely blunted & 21.9 & 13.5 & 2.1 \\
\hline 32 & 40 & Obliquely blunted & 16.5 & 8.3 & 2.4 \\
\hline 36 & 40 & Obliquely blunted & 17.8 & 10.4 & 1.8 \\
\hline 22 & 36 base & Obliquely blunted & 24.9 & 9.7 & 2.9 \\
\hline 4 & 41 & Isosceles triangle & $20.9+$ & 10.5 & 2.1 \\
\hline 1932 & 40 & Scalene triangle & $11.1+$ & 4.4 & 1.6 \\
\hline 4824 & 31 & Scalene triangle & 13.6 & 3.5 & 1.5 \\
\hline 5122 & 31 & Scalene triangle & $14.8+$ & 4.8 & 2.2 \\
\hline 5134 & 36 & Crescent & 10.8 & 3.1 & 1.5 \\
\hline 5121 & 31 & Crescent & $7.3+$ & 3.4 & 1.2 \\
\hline \multirow[t]{2}{*}{5123} & 31 & Bilaterally edge-blunted & 17.3 & 3.5 & 2.6 \\
\hline & & Mean & 17.8 & 7.6 & 2.1 \\
\hline 3111 & 41 & Microburin proximal & 9.3 & 8.8 & 1.8 \\
\hline 38 & 40 & Microburin proximal & 11.6 & 6.8 & 2.6 \\
\hline 39 & 40 & Microburin proximal & 17.5 & 10.3 & 2.9 \\
\hline 1933 & 40 & Microburin proximal & 5.4 & 6.9 & 3.1 \\
\hline 1934 & 40 & Microburin proximal & 9.0 & 6.9 & 2.0 \\
\hline 2226 & 40 & Microburin proximal & 7.7 & 5.1 & 1.9 \\
\hline 24 & 36 base & Microburin proximal & 13.5 & 13.6 & 3.3 \\
\hline 590 & 36 & Microburin proximal & 8.1 & 9.4 & 2.4 \\
\hline \multirow[t]{2}{*}{591} & 36 & Microburin distal & 9.5 & 3.3 & 1.9 \\
\hline & & Mean & 10.2 & 7.9 & 2.4 \\
\hline
\end{tabular}

Table 14 Dimensions of complete, and near complete (+), microliths and microburins of baked mudstone

\begin{tabular}{|c|c|c|c|c|c|}
\hline $\begin{array}{l}\text { Catalogue } \\
\text { number }\end{array}$ & Context & Type & $\begin{array}{l}\text { Length } \\
\text { in mm }\end{array}$ & $\begin{array}{l}\text { Breadth } \\
\text { in } \mathbf{m m}\end{array}$ & $\begin{array}{l}\text { Thickness } \\
\text { in } \mathrm{mm}\end{array}$ \\
\hline 3 & 41 & Obliquely blunted & $22.4+$ & 10.8 & 2.6 \\
\hline 34 & 40 & Obliquely blunted & 19.5 & 10.3 & 3.1 \\
\hline 35 & 40 & Obliquely blunted & $38.1+$ & 13.0 & 3.5 \\
\hline 23 & 36 base & Obliquely blunted & $25.8+$ & 6.9 & 2.2 \\
\hline \multirow[t]{2}{*}{30} & 40 & Isosceles triangle & $24.9+$ & 12.0 & 2.6 \\
\hline & & Mean & 26.1 & 10.6 & 2.8 \\
\hline 10 & 41 & Microburin proximal & 15.2 & 9.6 & 2.5 \\
\hline 37 & 40 & Microburin proximal & 16.1 & 7.8 & 2.3 \\
\hline \multirow[t]{2}{*}{2319} & 40 & Microburin proximal & 23.9 & 9.2 & 2.6 \\
\hline & & Mean & 18.4 & 8.9 & 2.5 \\
\hline
\end{tabular}


Table 15 Microburin types

\begin{tabular}{lcccccc}
\hline Microburin type & C31 & C36 & C36 base & C40 & C41 & Totals \\
\hline Proximal LHS - chalcedony & & & 1 & 3 & 1 & 5 \\
Proximal LHS - mudstone & 1 & & & 1 & 1 & 3 \\
Proximal RHS - chalcedony & & 1 & & 3 & & 4 \\
Proximal RHS - mudstone & & & & 1 & & 1 \\
Distal RHS - chalcedony & & 1 & & & & 1 \\
Totals & $\mathbf{1}$ & $\mathbf{2}$ & $\mathbf{1}$ & $\mathbf{8}$ & $\mathbf{2}$ & $\mathbf{1 4}$ \\
\hline
\end{tabular}

Table 16 Scrapers by type, context and raw material

\begin{tabular}{|c|c|c|c|c|c|c|c|c|}
\hline Type & C31 & C36 & $\begin{array}{c}\text { Base of } \\
\text { C36 }\end{array}$ & $\mathbf{C 4 0}$ & C41 & $\begin{array}{l}\text { Spoil- } \\
\text { heap }\end{array}$ & Totals & $\begin{array}{c}\text { Type } \\
\text { Totals }\end{array}$ \\
\hline End - chalcedony & 1 & 3 & - & 2 & - & 1 & 7 & \\
\hline End - mudstone & 2 & 1 & - & - & - & - & 3 & 10 \\
\hline Extended-end - chalcedony & - & 2 & - & - & - & - & 2 & \\
\hline Extended-end - mudstone & 1 & - & - & - & - & - & 1 & 3 \\
\hline Double-end - mudstone & - & 1 & - & - & - & - & 1 & 1 \\
\hline Side - mudstone & 2 & - & - & 1 & - & - & 3 & 3 \\
\hline Sub-disc - chalcedony & - & - & - & 1 & - & - & 1 & 1 \\
\hline Atypical - mudstone & 1 & - & - & 1 & - & - & 2 & 2 \\
\hline Totals & 7 & 7 & $\mathbf{0}$ & 5 & $\mathbf{0}$ & 1 & 20 & 20 \\
\hline
\end{tabular}

pieces, with eight having a notch on the left lateral side, and five on the right side (when orientated with the proximal end away from the analyst, and the dorsal face up; cf Martingell \& Saville 1988, fig.1). One microburin is a distal specimen. The striking platforms are all plain. The presence of so many microburins in an assemblage including only 32 microliths (a ratio of $c$ 1:2) is unusual, but does suggest that the production of microliths by microburin technique was the norm and indicates that the manufacture of microliths did indeed take place on-site. Although only a small sample, the baked mudstone microburins are notably larger than those in chalcedony.

The seven microlith-related forms include two obliquely blunted proximal bladelet segments (CAT 88 (illus 31) \& 131), one notched bladelet which is probably an unsnapped microlith/microburin (CAT 20, illus 31), two notched bladelet segments with transverse breaks which are probably microlith/ microburin miss-snaps (CAT 11 \& 2227) and two tiny unclassifiable fragments with microlith-like retouch (CAT $2323 \& 2784$ ).

\section{Scrapers (illus 32)}

The 20 scrapers, which for the sake of completeness include one (CAT 45) recovered from the spoilheap, comprise 10 of baked mudstone and 10 of chalcedony (Table 16). Most (10 examples) are simple short end-scrapers on flakes, with convex retouch at the distal end. Three are extended end-scrapers, where the distal retouch continues on both lateral edges, although mostly without pronounced shoulders between working-edge and lateral sides. One double end-scraper (CAT 401) has convex scraper-edges at both terminals. In addition, the assemblage includes three side-scrapers (CAT 42, $43 \& 47$ ), one of which is an atypical example of elongated shape (CAT 43; illus 32), one sub-discoidal type (CAT 49) and two atypical scrapers (CAT 50 \& 1131). Eighteen of the twenty scrapers (ten baked mudstone, eight chalcedony) are intact enough for measurement, giving mean dimensions of length $30.2 \mathrm{~mm}$, breadth $29.3 \mathrm{~mm}$ and thickness $9.9 \mathrm{~mm}$. The length and breadth means for the baked mudstone scrapers are greater than those for the chalcedony examples (length $33.1 \mathrm{~mm}$ and $26.6 \mathrm{~mm}$; breadth $33.0 \mathrm{~mm}$ and $24.8 \mathrm{~mm}$ respectively) but the mean thicknesses are the same. Four of the chalcedony and two of the baked mudstone scrapers are on flakes with faceted platforms, and two of the baked mudstone scrapers are on core rejuvenation flakes. In terms of distribution there is a clear concentration of the scrapers in the upper levels. 

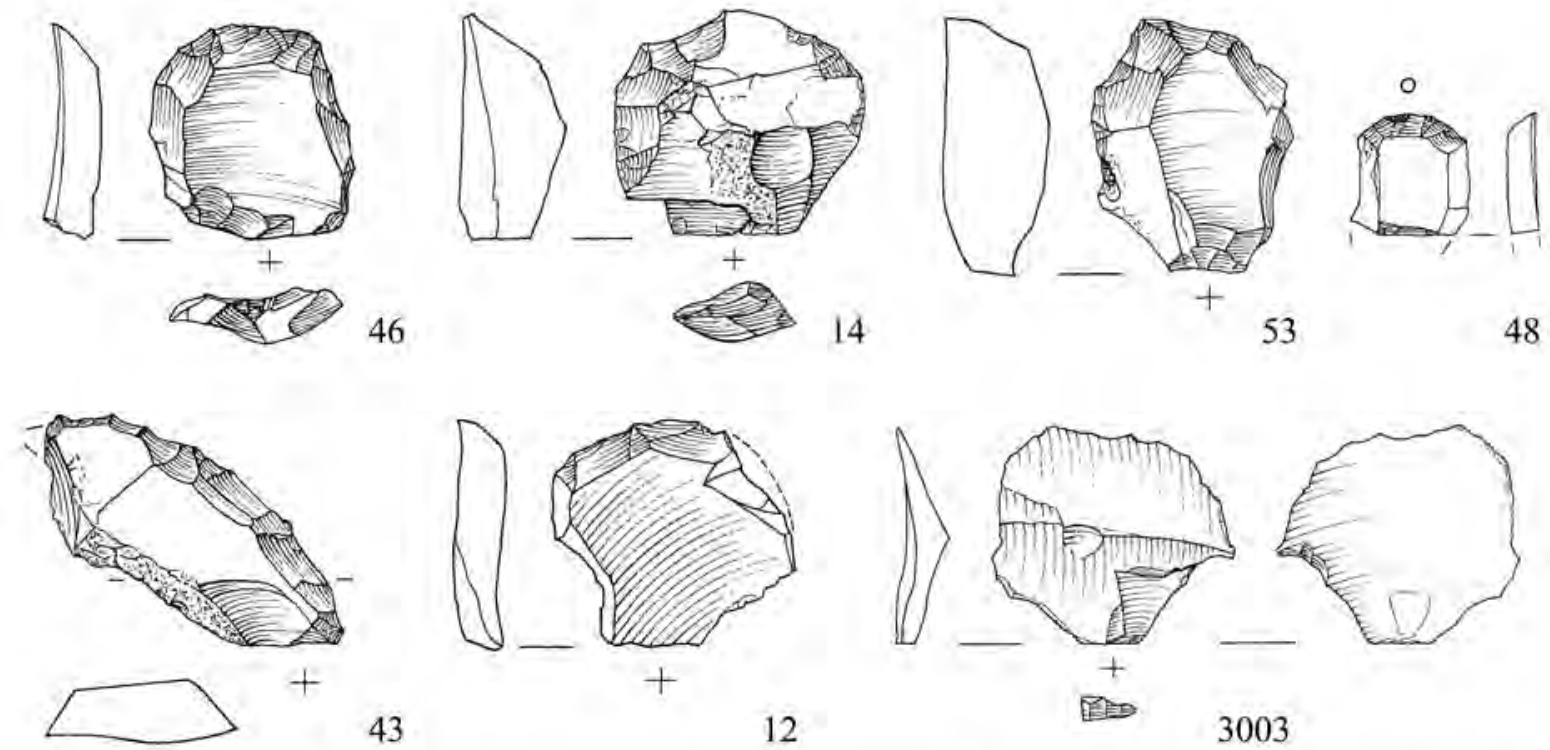

43

12

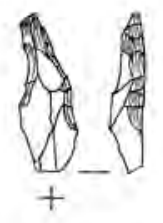

5124
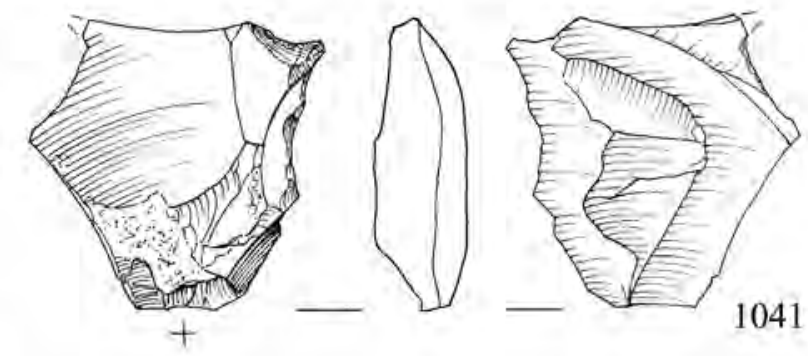

18

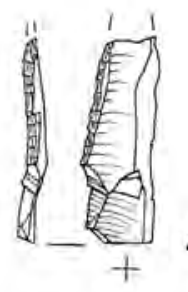

$50 \mathrm{~mm}$

0

$20 \mathrm{~mm}$

Illus 32 Scrapers, piercers, edge-trimmed bladelet and miscellaneous retouched piece: CAT 46, 43, 12, \& 44 are baked mudstone, the others are chalcedonic silica (drawn by Marion O'Neil)

\section{Piercers (illus 32)}

The assemblage includes 10 piercers (Table 17). These are predominantly on chalcedony and it may be that chalcedony was specifically preferred as a better raw material for this tool type. However, the greater propensity for the somewhat softer baked mudstone to become damaged may mean that breakage of projections has hampered the identification of piercers in this material. Only one of the piercers (CAT 3003; illus 32) has a projection formed by true 'propeller' retouch (i.e. retouch of one edge by dorsal retouch and one by ventral retouch), whereas most of the piercers have a point - of varying degrees of robustness - formed by retouch from the ventral face only. The most elaborate example (CAT 86; illus 32) has an elongated tip formed by blunting retouch on one edge, with minimal trimming at the tip of the opposed edge, which has otherwise been blunted by previous retouch from the crest. This piercer, and even more so a small bladelet with dorsal bilateral blunting retouch (CAT 5124; illus 32), have similarities with mèche de foret drill bits (Jacobi 1980, 154). The other, less elaborate, piercers are mostly serendipitous exploitation of natural projections, with lesser or greater enhancement.

\section{Edge-trimmed flakes and blades}

This category includes artefacts with visible modification on part or all of one or both lateral edges, but which do not fit any other formal tool categories. In a few cases, the modification may be edge-damage 
Table 17 Piercers: context and raw material type

\begin{tabular}{lcccccc}
\hline Material & C31 & C36 & Base of C36 & C40 & C41 & Totals \\
\hline Chalcedony & 2 & 3 & - & 2 & 1 & 8 \\
Mudstone & - & 2 & - & - & - & 2 \\
Totals & 2 & 5 & 0 & 2 & 1 & 10 \\
\hline
\end{tabular}

caused by use or 'trampling', but most are probably true tools. In the majority of cases these pieces have one sharp unmodified edge, and they may have functioned as knives. However, separating true edge-trimmed pieces from edge-damaged pieces with any degree of certainty would require microscopic use-wear analysis.

The 14 pieces included in this category have varying morphologies, but include, inter alia, two fragmentary, but substantial, baked mudstone blades from C41 (CAT 1165 \& 3946; illus 28), and one baked mudstone bladelet from C31 (CAT 44; illus 32 ), the semi-abrupt edge-retouch of which exposes the black interior through the altered grey-coloured surface. This indicates that the modification considerably post-dates the production of the blank.

\section{Miscellaneous}

In total, 51 artefacts with some apparently deliberate modification lay outwith the formal tool categories. In many cases this was due to fragmentation. In several instances, such as the notched pieces, it is difficult to ascertain that the modification is deliberate rather than accidental. However, one of these pieces is a well-executed tool with extensive and careful bilateral retouch on a stout chalcedony flake (CAT 18 from C36; illus 32). It does not appear to have functioned as a piercer and it is too thick to be regarded as a knife, but it is clearly an intentionally designed tool.

\subsection{Discussion of the lithic artefacts}

The typological composition of this lithic assemblage suggests a general date entirely within the Mesolithic period, with later diagnostic pieces being absent. However, in view of the wide spread of radiocarbon dates from the contexts which produced this assemblage, and in particular the post-Mesolithic dates for some of the bevel-ended bone tools, it cannot be ruled out that the basically Mesolithic lithic collection includes a small amount of later intrusive material.

The range of the Mesolithic radiocarbon dates, the disparate nature of the stratigraphic components, and the dumped character of the main deposits, suggest that the assemblage may represent accumulation over an extended period during the Mesolithic. The earliest of the radiocarbon dates is 7590 BP (OxA-4994), which is well within the Later Mesolithic as currently defined. The Early Mesolithic as known from England and Wales (e.g. Reynier 2005) has never been satisfactorily radiocarbon dated in Scotland, where even the earliest dates are associated with assemblages of Later Mesolithic narrow-blade type (Saville 2008). However, Early Mesolithic broad-blade assemblages clearly exist, albeit frequently with some admixture of later material. These assemblages include Morton Site A in Fife, and Glenbatrick Waterhole Site G1 and Lussa Bay, both on Jura (Coles 1971; Mercer 1970; 1974a; also see Saville 2004a).

In the An Corran collection, special attention should be drawn to the broad blades, which correspond to the blades recovered at Morton, Glenbatrick, and Lussa Bay, as well as, outside Scotland, at sites such as Star Carr in Yorkshire (Clark 1954, figs. 38 and 45; Reynier 2005). The microliths are equally noteworthy, with the category being dominated by broad obliquely blunted points and isosceles triangles, which also dominate the microliths of Morton, Glenbatrick, and Lussa Bay (Saville 2004a), as well as Flixton and Star Carr (Clark 1954, fig.35; Moore 1950, fig.4; Reynier 2005). So the broad blades and broad microliths do suggest a possible Early Mesolithic aspect to the An Corran assemblage. On the other hand, the complete absence of burins (and any associated groove-and-splinter antler/bone working) at An Corran is particularly noteworthy as, in Britain, this tool type is generally associated with the Later Upper Palaeolithic and Early Mesolithic periods. The only Scottish locations where burins have been recovered in significant numbers are the Lateglacial sites at Kilmelfort Cave, Argyll (Saville \& Ballin 2009) and Howburn, South Lanarkshire (Ballin et al 2010).

In the general Inner Hebrides area, most Mesolithic assemblages are dominated by Later Mesolithic artefact forms. This includes the finds from Kinloch, Rùm (Wickham-Jones 1990), various sites on Islay and Colonsay (McCullagh 1989; Mithen 2000), Camas Daraich on Skye (Wickham-Jones \& Hardy 2004), and Sand on the mainland east of Skye (Hardy \& Wickham-Jones 2007). All these assemblages are characterised by microblade technology and narrow microliths.

Unsurprisingly, the several lithic artefact concentrations identified around Staffin Bay during the Scotland's First Settlers Project revealed a spread of Mesolithic activity away from the rockshelter, though the almost equal use of baked mudstone 
and chalcedonic silica provides a contrast (Hardy \& Wickham-Jones 2007: section 2.2.7). In addition to Camas Daraich, only one excavated Mesolithic assemblage from Skye has been published, namely that of Tote, near Skeabost, at the southern end of Loch Snizort Beag (Lacaille 1954, 299-300). Lacaille described the raw material as buckite or vitrified shale, but examination of the artefacts in the University Museum of Archaeology and Ethnology at Cambridge (by Alan Saville) has shown the material to be identical to the baked mudstone from An Corran. These artefacts, which include a single edge-blunted microlith and two substantial blades (Lacaille 1954, fig.135: 2-3 \& 8), were recovered during the excavation of a cairn (Lethbridge 1920). The excavator described them as deriving from the primary cist, but it seems most probable that these artefacts were either excavated from a buried soil below the cist, or they may have been redeposited during the construction of the cist and cairn. Of the 'upwards of 150 flint and other flakes and two rude scrapers' mentioned in the original report (Lethbridge 1920, 135), only those pieces illustrated by Lacaille, and four others, are present in the Cambridge collection. The four unillustrated items include two of a translucent siliceous material, although this does not resemble the An Corran chalcedony.

Further consideration of the chronological position of the An Corran lithic assemblage is given in the final discussion, but one of the more significant results of the present analysis is the identification of baked mudstone and chalcedonic silica as additions to the already extensive repertoire of raw material exploited in early prehistoric Scotland (Saville 1994; Wickham-Jones 1986; cf Hardy \& Wickham-Jones 2007). The properties of baked mudstone in particular are conducive to the production of large blades, more so than any other raw material available in Scotland, because of its availability in large angular blocks. However, since the excavation and preliminary publication of An Corran (Saville \& Miket 1994a; 1994b), the association of baked mudstone with a potentially Early Mesolithic site has led some to the misconception that the use of this raw material may be diagnostic of the Early Mesolithic period - which it is not. Thus, at Home Farm, near Portree on Skye, a small baked mudstone assemblage of well-executed Early Bronze Age implements was recovered from a pit associated with a hengiform enclosure (Ballin forthcoming), and baked mudstone seems to have been one of the raw materials present in the small, probably mixed assemblage of lithic artefacts, including pieces with Mesolithic traits, recovered from the Rudh' an Dunain Cave on the west coast of Skye (Clark 1934b, 222, note 1; Scott 1934a) 


\section{BONE AND ANTLER ARTEFACTS (see Appendix Two), by Alan Saville, with contributions by Ywonne Hallén and László Bartosiewicz}

\subsection{Introduction}

Two pieces of antler and 114 pieces of bone were identified as modified for, or by, use. In the main these artefacts belong to the category of bevel-ended tools; the remainder are bone points or miscellaneous pieces. The typology and provenance are summarised in Table 18 (a detailed catalogue including all worked pieces is given in Appendix Two). Most worked artefacts derive from C36, the main shellbearing deposit at the rear of the ledge, where conditions for the preservation of bone were most favourable. All remaining bone tools were recovered from C31 (or the C38 and C39 subdivisions of it), which, like C36, was characterised by several shell layers. Radiocarbon dating of the bone artefacts is discussed in Section 11 below.

\subsection{Bevel-ended tools (illus 33-38)}

This category includes implements with a characteristic bevel at one or both ends. The assemblage comprises seventy-nine tools with a single bevel-end, nine tools with a bevel at both ends, and two tools where a bevel at one end is combined with a functional point at the other. The opposed ends of five double-bevelled tools may have been used sequen-

Table 18 Typology and context of bone and antler artefacts

\begin{tabular}{lrrrrr}
\hline Type & C31 & C36 & C38 & C39 & Total \\
\hline Single bevel-ended tools & 26 & 51 & 2 & 0 & 79 \\
Double bevel-ended tools & 2 & 7 & 0 & 0 & 9 \\
Combined bevel-ended tools and points & 0 & 2 & 0 & 0 & 2 \\
Points & 2 & 11 & 0 & 0 & 13 \\
Miscellaneous & 2 & 10 & 0 & 1 & 13 \\
TOTAL & $\mathbf{3 2}$ & $\mathbf{8 1}$ & $\mathbf{2}$ & $\mathbf{1}$ & $\mathbf{1 1 6}$ \\
\hline
\end{tabular}

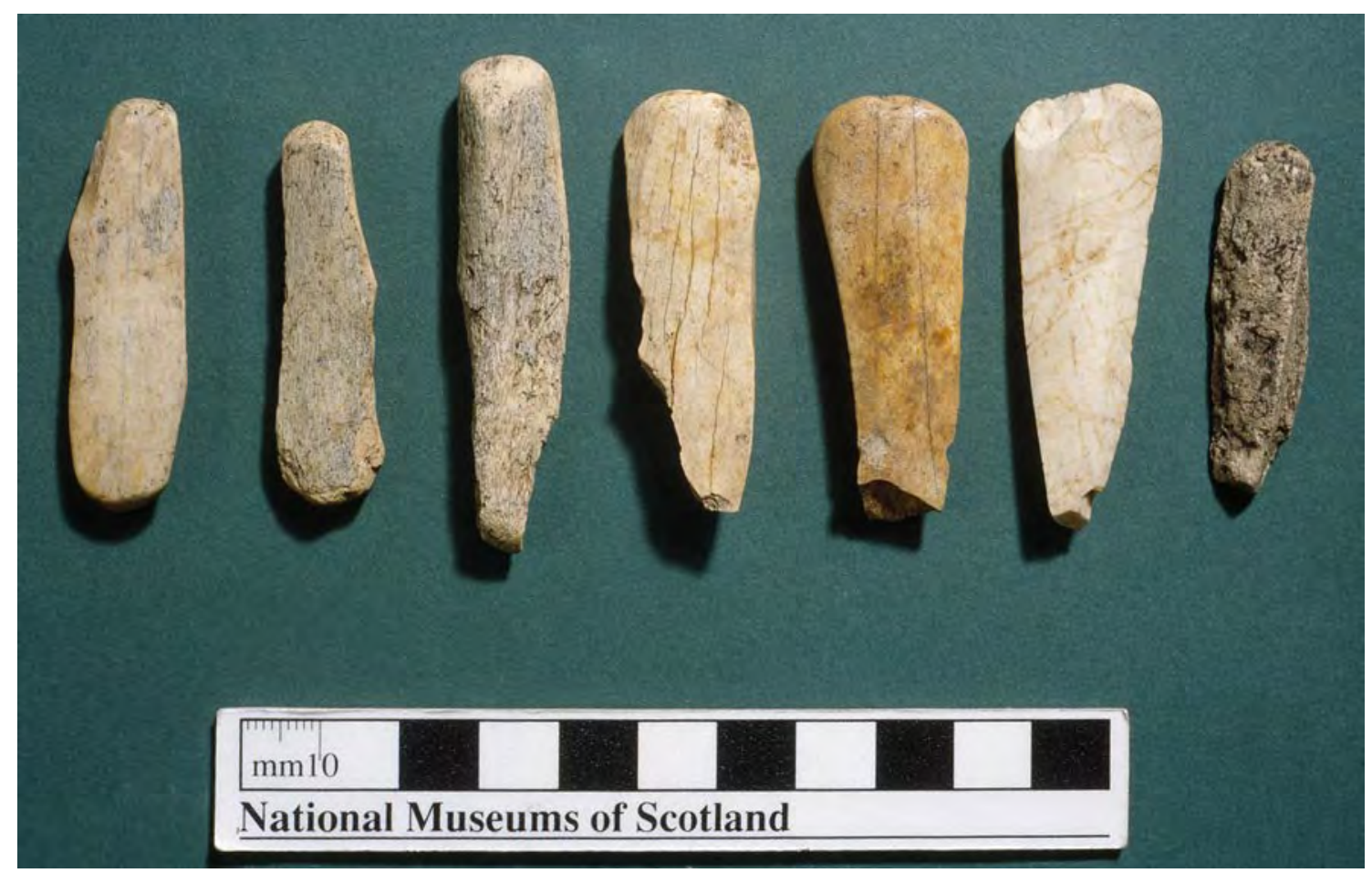

Illus 33 Bevel-ended tools. Left to right: CAT 81; 83; 80; 1; 8; 37; 31 (see Appendix Two for details) (photo: $N M S)$ 


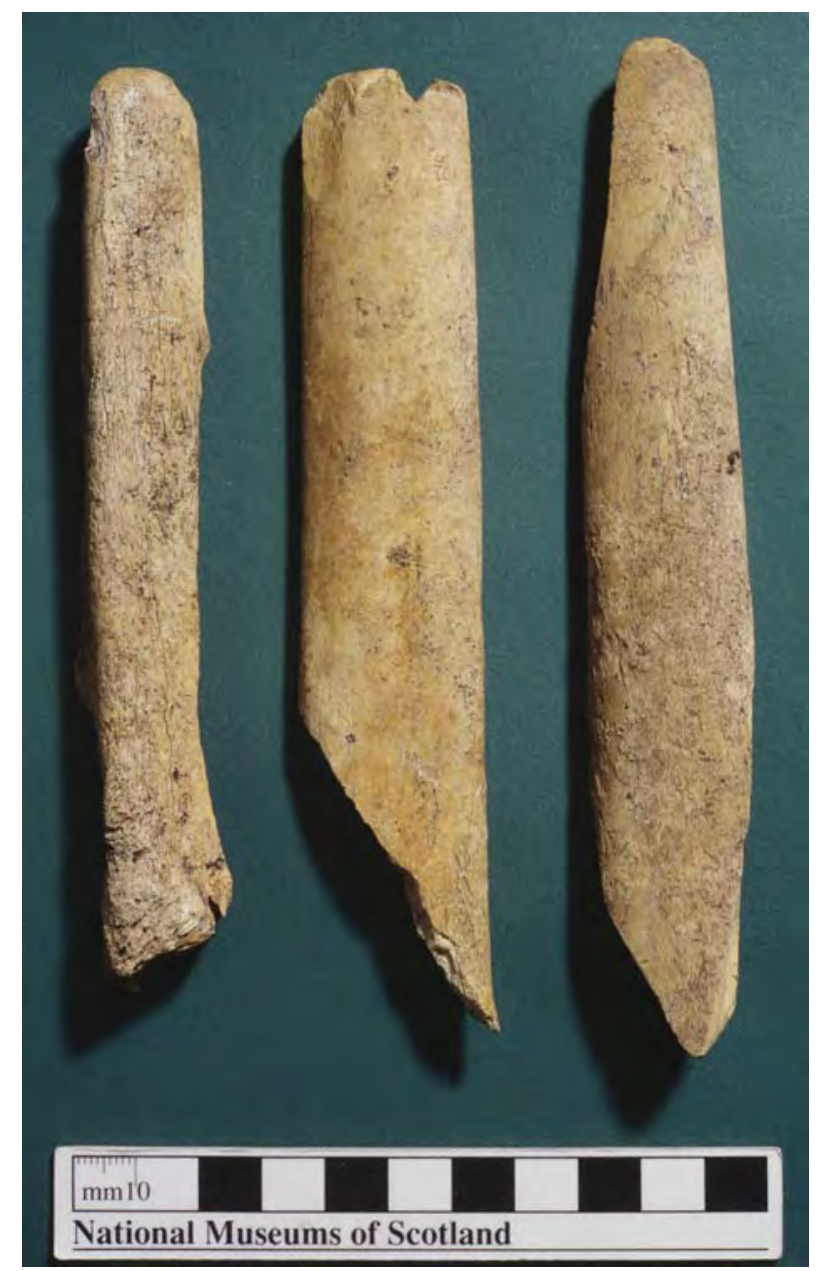

Illus 34 Large bevel-ended tools. Left to right: CAT 45; 44; 32 (see Appendix Two for details) (photo: NMS)

tially rather than concurrently. This is indicated by notable damage - usually a longitudinal split - to one bevelled end, and it is thought that the opposite bevel may have been formed when it replaced the former as the tool's functional part. Six of the eight double-ended pieces, where both ends are sufficiently intact for recording, have the most heavily worn part of the bevel on the same face at both ends of the tool.

As the double bevel-ended pieces are characterised by two surviving opposed working-ends, they are clearly intact in terms of their lengths (illus 35-36). It is much more difficult to assess the intactness of the single-bevelled examples, and only the completeness of the following types of specimen is certain:

1) pieces where the end opposite the bevel is formed by an original articular end of the bone, e.g. illus 36: 69; illus 37: 45;

2) pieces where the lateral edges at the bevel continue uninterrupted to the base of the support, e.g. illus 33: 8, $37 \& 31$; illus $35: 76 \&$ $65 ;$ and
3) pieces where there is obvious polish and/or rounding of the basal edges, e.g. illus 33: 1 .

In most other cases it is a matter of conjecture as to whether the tool is broken at the base or not.

However, as the length ranges in Table 19 show, most tools appear to be between $40 \mathrm{~mm}$ and $70 \mathrm{~mm}$ long. Since the ranges of the definitely and probably broken tools are almost identical to the range of the intact tools, most of the damaged pieces are probably only slightly shorter than they were immediately after manufacture. A small number of bevel-ended tools which are significantly longer than average pieces, in the range of $110-170 \mathrm{~mm}$, may belong to a functionally different tool type (illus 34, 36 \& 37). Alternatively, it is possible that the smaller tools were hafted for use, whereas the longer examples were hand-held. The tapered form of the nonbevelled ends on some pieces, and the occasional evidence for shaping of the lateral sides or lateral chipping, may indicate hafting. However, the fact that the polished bases of some tools never have an abrupt edge to a polished zone, as might be anticipated if part of the tool was inside and part outside a haft, speaks against this interpretation, as does the rarity of transverse snapping.

Only one of the bevel-ended tools is made on antler (CAT 7), identified as from a red deer, but another (CAT 65; illus 35) is on a raw material, which, although not definitely identified to species, is most likely to be cetacean bone. All the others appear to be made from longbones of mammals of the sub-order ruminantia, of the size of roe deer or larger. Where a positive identification can be made to species (44 of 89 cases), all instances are red deer, except for one possible roe deer. The identifiable skeletal parts (47 of the 89 cases) comprise 18 metatarsi, 13 metacarpi, 11 unspecified medapodia, 4 tibiae and 1 femur. The metapodial bones of red deer are thus the preferred raw material for these tools (cf Foxon 1991, 108).

The bevel-ended tools in bone appear to be made by longitudinal fracturing of the raw material, probably by pounding it with a stone hammer to produce suitably shaped and sized blanks. In some cases, the lateral edges appear to have been shaped by subsequent flaking or chipping. The segments of bone used in manufacture seem to condition the shape of the bevel; where the bevel is positioned on the ridged surfaces found anteriorly and posteriorly on red deer metatarsals, it is irregular in depth, while other segments of bone with a convexconcave profile (marrow cavity) show a more uniform bevel.

The bevelled surfaces normally exhibit spalling and/or pocking, and sometimes they have easily visible striations, which tend to be aligned perpendicular to the breadth of the bevel. There is also relatively frequent longitudinal splitting of the bevel. All these features are interpreted as relating to the use, rather than the manufacture, of the tools. Although it is unclear exactly how a working 
Table 19 Bevel-ended bone tools: length values

\begin{tabular}{lcccc}
\hline Length (mm) & D/E \& point & Complete & Fragmentary & Total \\
\hline $20-29$ & 0 & 0 & 1 & 1 \\
$30-39$ & 0 & 3 & 6 & 9 \\
$40-49$ & 4 & 10 & 10 & 24 \\
$50-59$ & 2 & 18 & 6 & 14 \\
$60-69$ & 3 & 8 & 2 & 7 \\
$70-79$ & 1 & 4 & 0 & 2 \\
$80-89$ & 0 & 2 & 0 & 0 \\
$90-99$ & 0 & 0 & 1 & 1 \\
$100-109$ & 0 & 0 & 1 & 2 \\
$110-119$ & 0 & 1 & 0 & 0 \\
$120-129$ & 0 & 0 & 0 & 0 \\
$130-139$ & 0 & 0 & 0 & 2 \\
$140-149$ & 1 & 1 & 1 & 1 \\
$150-159$ & 0 & 0 & 0 & $\mathbf{9 0}$ \\
$160-169$ & 0 & 1 & $\mathbf{3 1}$ & \\
TOTAL & $\mathbf{1 1}$ & $\mathbf{4 8}$ & \\
\hline
\end{tabular}

Notes: 1) D/E \& point = double-ended bevelled tools and bevelled tools and points combined; 2) Complete = all single bevel-ended tools characterized as complete, virtually complete, probably complete, and possibly complete; 3) Fragmentary = all (apparently) single-ended bevelled tools characterized as definitely, or probably, or possibly broken; 4) The mean length value for the 59 tools in the first two columns is $61.9 \mathrm{~mm}$; the mean length value for the 31 fragmentary tools is $54.7 \mathrm{~mm}$; the overall mean is $59.4 \mathrm{~mm}$.

edge was formed at the end of the chosen blank, it is suggested that the bevelled surface as present when the tool was abandoned was largely the result of use. The implication is that the bevelled end was used in such a way that pressure of the tool against an abrasive surface created or enhanced the smooth, rounded bevel. This use probably involved forceful pressure, which led to the more dramatic features of spalling and breakage.

A selection of the bevel-ended tools (including those which were radiocarbon dated) is illustrated to demonstrate their general attributes. All the double-ended bevelled tools are illustrated, as are the two combined points and bevel-ended tools (illus 35-38).

Implements like these, in stone, antler and bone, have been found in abundance on Scottish coastal Mesolithic sites, and they are one of the most distinctive tool-types of the so-called 'Obanian' (Lacaille 1954; Mellars 1987). The nature and function of these implements have been discussed since they were first discovered and termed either 'limpethammers' (Grieve 1885, 57), 'skin-dressing tools' (Anderson 1895, 222), 'limpet scoops' (Bishop 1914, 95) or 'flaking tools'(Breuil 1922, 267). Recent studies of these implements (Birch 2003 \& 2007; Connock et al 1992; Foxon 1991; Griffitts \& Bonsall 2001; Hardy 2007; Reynolds 1983) have shed some light on their character and manufacture, and metrical analysis has confirmed the essential homogeneity in size of the bevelled bone tools. The mean length of the An Corran tools (Table 19) appears somewhat greater than that cited for most other 'Obanian' assemblages (Connock et al 1992, table 3; Griffitts \& Bonsall 2001, table 1; Reynolds 1983, table 4), even allowing for the bias introduced by the seven exceptional pieces longer than $100 \mathrm{~mm}$, but this does not affect the general pattern. The earliest of the An Corran radiocarbon dates is on one of the longer, larger examples of a bevel-ended bone tool (CAT 44; illus 37), confirming that this type, previously known from the MacArthur Cave and Druimvargie rockshelter assemblages (Anderson 1895; 1898; Lacaille 1954, figs 81-82), but not independently dated, is definitely a Mesolithic form.

Both Foxon (1991, 109) and Reynolds (1983) disagree with the view of Clark (1956, 92) - and thereby with that of the present study - that the bevel is created primarily by use, preferring to see the bevel as the result of initial preparation prior to use. No absolutely clear picture of the specific function or functions of bevel-ended tools has yet emerged. In the most recent studies, however, based on both experimental and microscopic analyses, there seems to be strongest support for the use of the bone and antler examples in hide processing (Birch 2003 \& 2007; Hardy 2007). No association of bevelled tools with pigments was observed, unlike at Sand (Hardy 2007), but was not specifically searched for when the An Corran pieces were studied.

The absence of any bevel-ended stone tools at An Corran is noteworthy. This may simply reflect the 


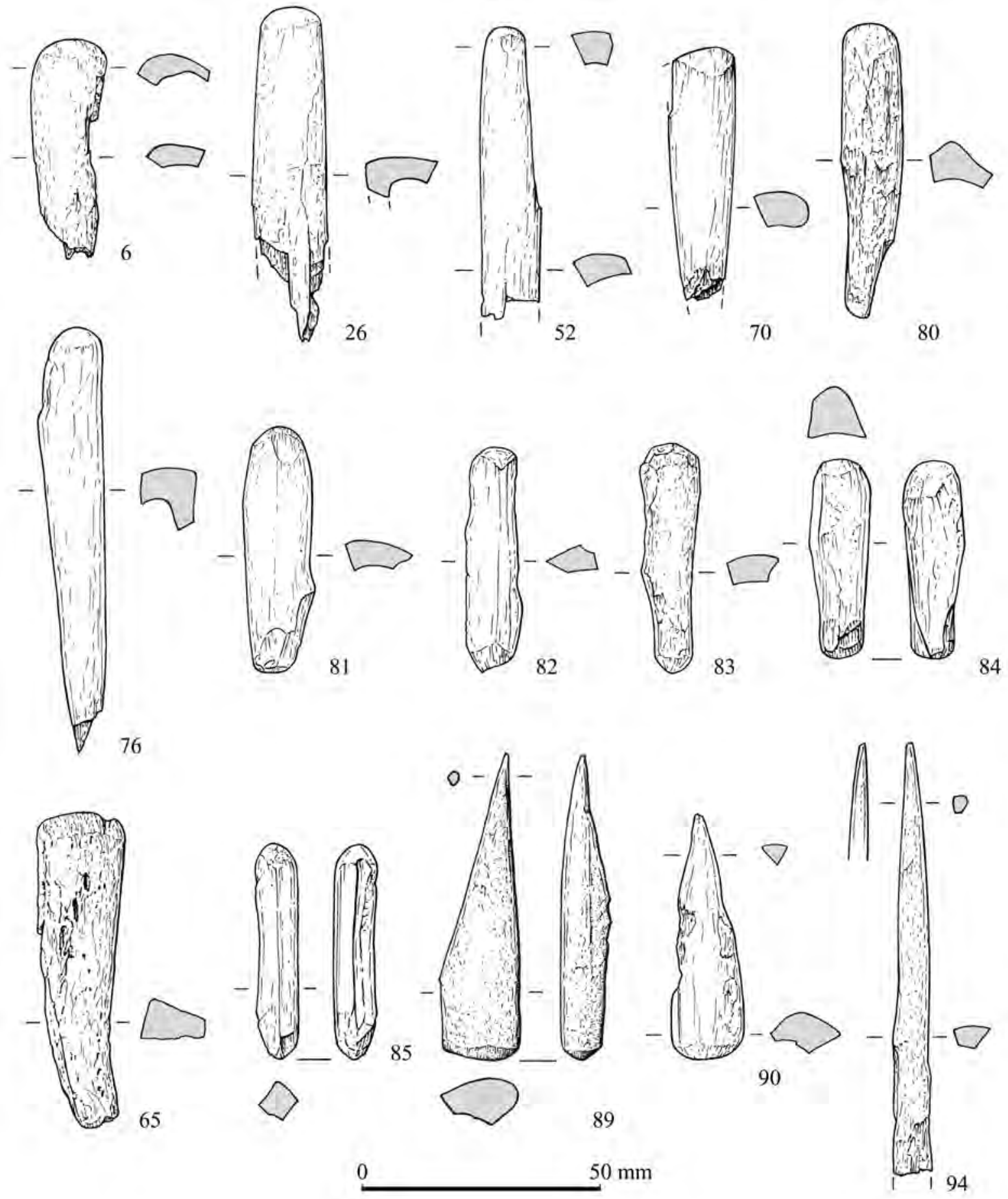

Illus 35 Bevel-ended tools and points: CAT 6, 26, 52, $70 \& 76$ are radiocarbon dated; CAT 80, 81, 82, 83, 84 $\& 85$ are double-ended bevelled tools; CAT $89 \& 90$ are combined points and bevelled tools (see Appendix Two for further details) (drawn by Marion O’Neil)

absence of suitably shaped schistose or siltstone pebbles in the immediate environs of the site.

\subsection{Points (illus $35-36 \& 39)$}

The thirteen points include one (CAT 100; illus 36 $\& 39)$ which is pointed at both terminals. Five are sufficiently complete to allow the conclusion that they never had more than one single pointed end; the remainder are incomplete and their original character uncertain. The two pieces with a point at one end, and a bevel at the other, have already been mentioned. One of the complete bone points has a ground facet at the non-pointed end (CAT 91; illus 36 \& 39); this probably relates to some unknown 

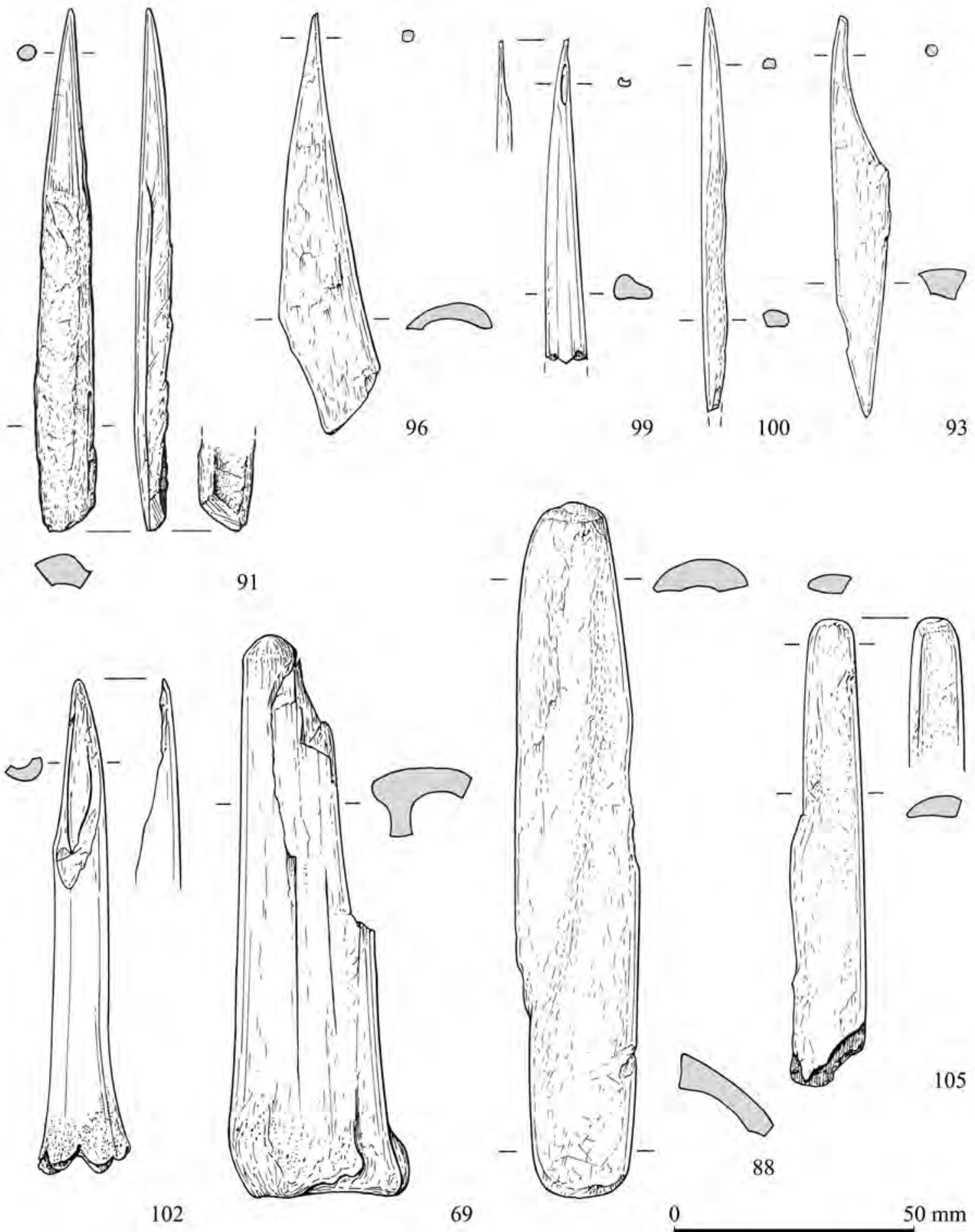

Illus 36 Bevel-ended tools and points: CAT 88 is a double-ended bevelled tool; CAT 100 is a double-ended point; CAT 102 is a gouge / awl; CAT 105 is a spatula-like tool (see Appendix Two for further details) (drawn by Marion O'Neil)

function prior to its being converted into a point (probably after breakage of the original form).

These are generally simple tools, with round or oval cross-sections, and tapering points of various lengths and thicknesses. The degree of polish and edge-rounding on some indicates extensive and/or prolonged use.

The only more elaborate tool is a point based on a roe deer tibia (CAT 102; illus 36). It was made by an oblique diagonal cut or split of the shaft in a longitudinal direction, which exposed the medullary canal. The non-pointed end is formed by the intact epiphyseal terminal, which is not perforated or otherwise modified. The entire surface has a smooth, 'waxy' feel, the tip of the point shows no sign of circular movement or wear, and the tool is well-preserved. 


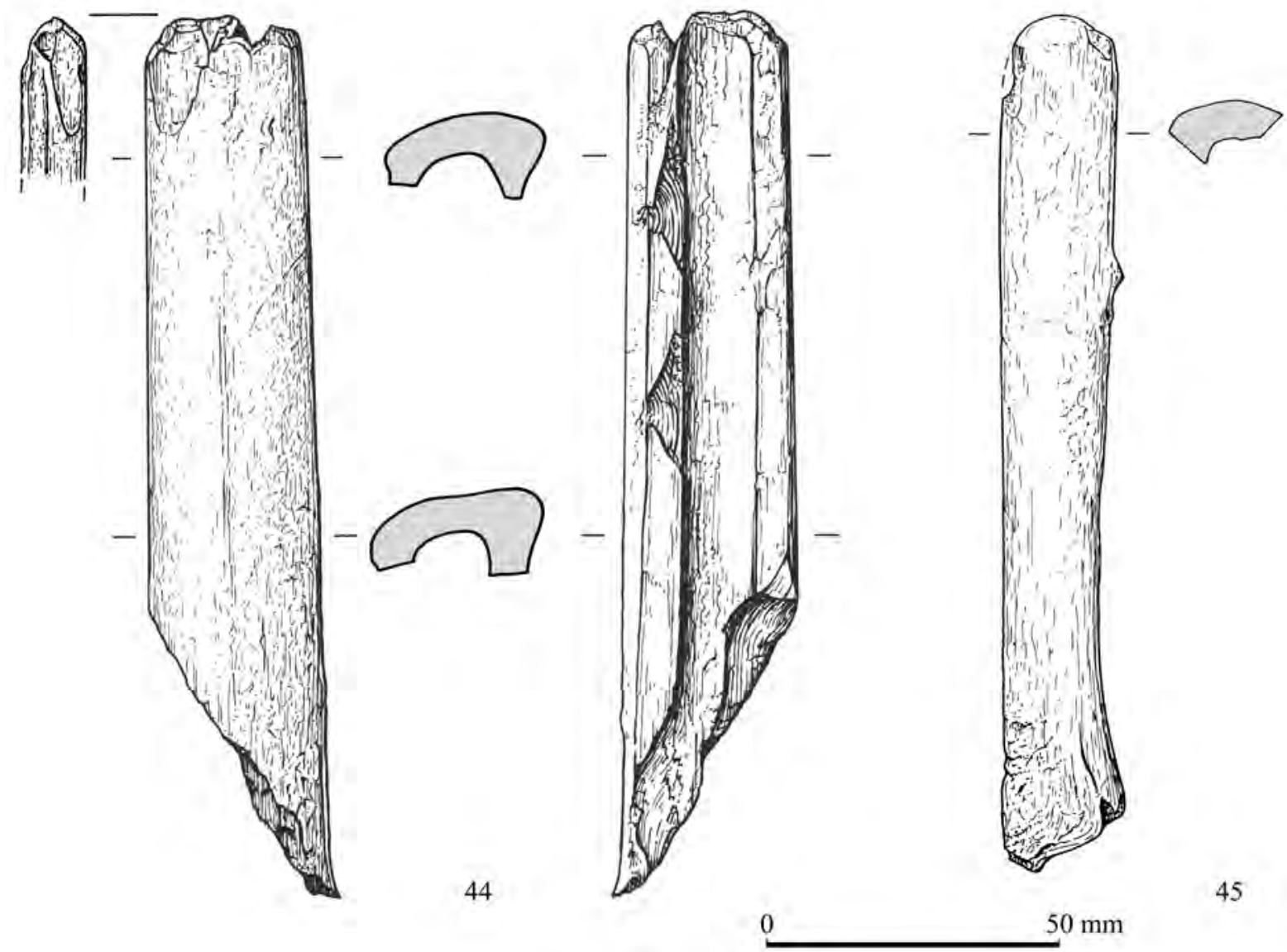

Illus 37 Large bevel-ended tools: CAT 44 is radiocarbon dated (see Appendix Two for further details) (drawn by Marion O'Neil)

It was possible to identify one bone point as from a red deer and four others as from roe deer; the remainder could only be identified as ruminant bones. One point is probably red deer antler. Skeletal parts utilised were identified as metatarsi (two), metacarpi (two), rib (one), tibiae (two) and unspecified longbones (five).

Apart from the obvious use as piercing tools - and several pieces show indications of wear of their tips - it has not been possible to ascribe a specific function to these implements. Points have frequently been described as awls, and in most cases (as at An Corran) they are made on splinters and slivers of bone. They are a characteristic feature of 'Obanian' assemblages (Bishop 1914, fig. 40; Clark 1956, 93; Hardy 2007, illus 89). Similar pieces were found in excavations at shell middens on Oronsay, including exact parallels for the combined point/bevelled tool type (Mellars 1987, 119, fig. 8.4). However, not all 'Obanian' assemblages include points (e.g. Carding Mill Bay: Connock et al 1992), whereas the collection from Risga embraces 16 pieces (Foxon 1991, 101). Foxon divided the Risga examples into points and points/pins, the latter being more highly finished and likely to have been used for fastening rather than piercing; Hardy (2007) distinguishes between triangular and fine points, suggesting a link between the latter and winkle consumption.

There are no Mesolithic parallels in Britain for the more elaborate specimen from An Corran context 36 (CAT 102; illus 36). On the other hand, this type of point, sometimes referred to as an awl or gouge, is a well-known implement type of later prehistory, especially the Iron Age (Cunnington 1923, 82-91; Sellwood 1984, 382-387). Iron Age examples were usually made on sheep metapodia or tibiae, and some analysts have suggested that they may have been used as threaders or shuttles (also known as 'dagger beaters') in connection with weaving on a vertical loom (see Hallén 1994, 205-207; Laws \& Armour-Chelu 1991; MacGregor 1974, 78). Scottish examples are recorded from several sites including the crannog at Lochlee, Ayrshire (Munro 1882, 111, fig. 70), the wheelhouses at Clickhimin, Shetland (Hamilton 1968, fig.60, 2) and Cnip, Lewis (Armit 2006, illus 3.20b), and the broch at Howe, Orkney (Ballin Smith 1994, illus 96). The radiocarbon dating of this implement (see below) has confirmed its later prehistoric age, and its position in C36 further complicates assessment of the homogeneity of the An Corran bone tool assemblage. 


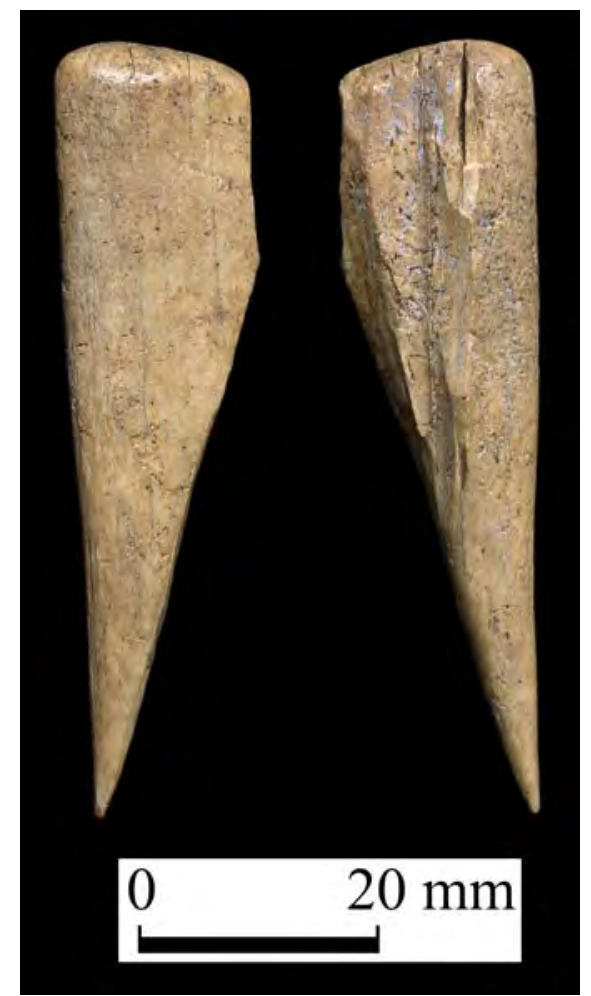

Illus 38 Combined bevel-ended tool and point: CAT 89, context C36, dorsal (left) and ventral (right) views (photo: Alan Saville)

\subsection{Miscellaneous/unclassified worked pieces}

This heterogeneous category includes 13 intact or fragmented pieces with definite or probable signs of modification, but which cannot be formally classified. Three pieces may be damaged bevel-ended tools. One

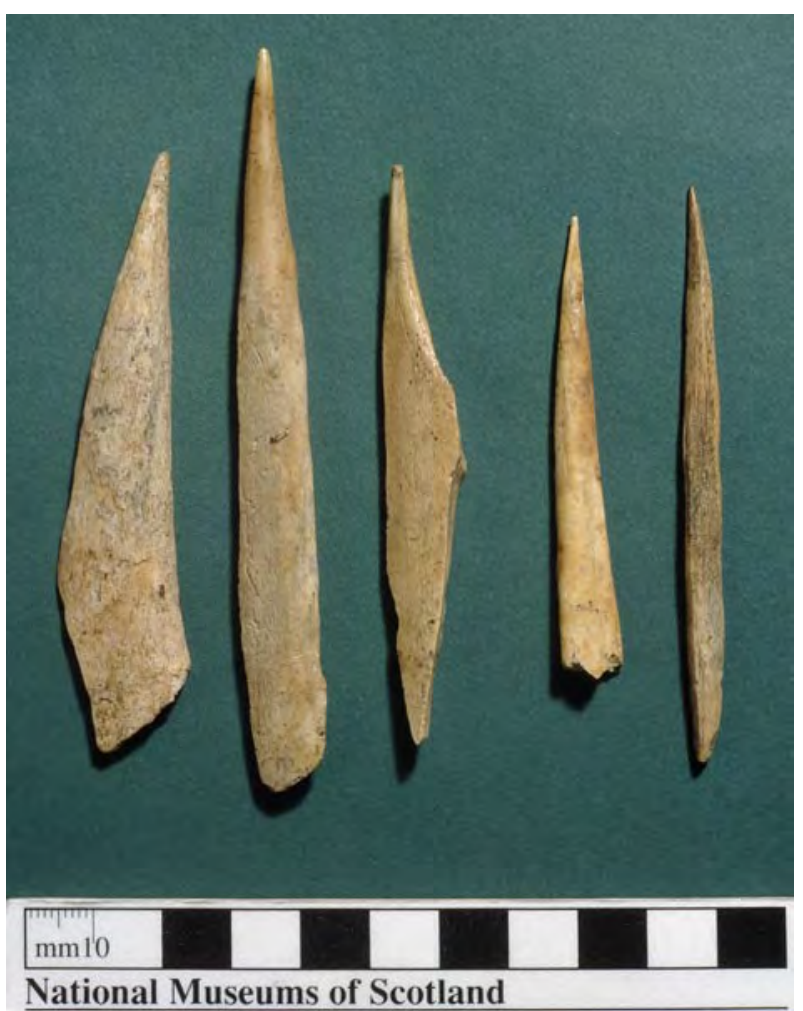

Illus 39 Bone points. Left to right: CAT 96; 91; 93; 99; 100 (see Appendix Two for details) (photo: NMS)

longbone fragment has a notch or part of a broken perforation. A worn suid fibula, with one intact semibevelled terminal, is probably a broken point (CAT 104). One substantial fragment represents a more elaborate tool, perhaps a spatula-like implement; it has extensive polish from use (CAT 105; illus 36). 


\section{THE COPPER-ALLOY PIN, by Trevor Cowie}

\subsection{Description}

The site produced an example of a simple copperalloy pin with curved neck from context C17 (illus 21). Although this precise form lacks immediate Scottish parallels, it can be compared to a small number of pins from elsewhere in Britain and Ireland belonging to the wider family of so-called swan's-neck and ring-headed pins of mainly Early Iron Age date.

The pin is cast, with curved upper portion terminating in a plain head, while the lower part tapers slightly towards the now missing tip (illus 40 \& 41). The cross-section varies from near circular at the shank to markedly oval towards the head. Some longitudinal distortion of the shank has occurred, probably as a result of wear, but its present overall condition is very good; the pin retains a glossy dark green patina which is relatively intact apart from an area with some light pocking of the surface, and minor corrosion at the head and tip. Some fine longitudinal splits probably result from the original working of the metal, while finishing of the pin has left a series of fine lengthwise striations on the shaft and some fine transverse striations in the upper portion. Two small blisters of corrosion on the shaft where the surface has swollen may reflect some inherent flaw in the metal or, just possibly, the former presence of organic material. Length 127 $\mathrm{mm}$; average thickness $3 \mathrm{~mm}$.

The pin was analysed by Dr Susy Kirk, Department of Conservation and Analytical Research, NMS, using X-ray fluorescence (XRF) to determine the alloy type present. The results showed that the alloy was most probably a leaded bronze; however, exact quantification was not possible due to the presence of a significant corrosion layer (Kirk 2011).

\subsection{Discussion}

While the pin appears to have undergone some distortion as a result of wear and tear, there seems to be no reason to doubt that the overall form is original. Despite its simplicity, therefore, the form of the An Corran pin immediately invites comparison with the simplest forms of the types of pin conventionally known as swan's-neck pins, characterised by the distinctive S-curved form of the neck and head and occurring in both bronze and iron. The British series of swan's neck and related ring-headed pins was first described by Dunning (1934), but apart from a brief review of the material in the light of the continental evidence by O'Connor (1980, 256-257), such pins

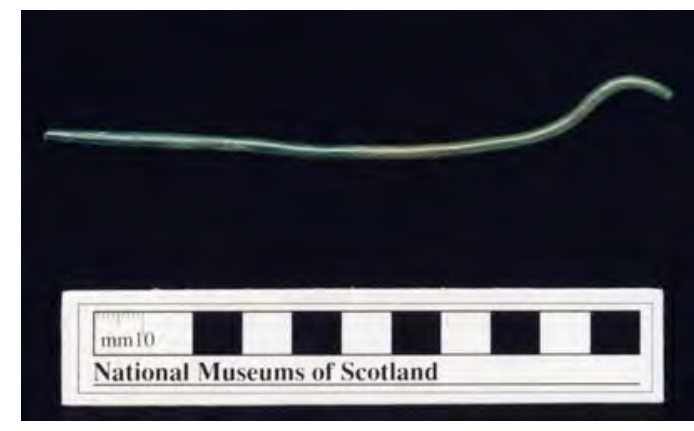

Illus 40 Copper-alloy pin (photo: NMS)

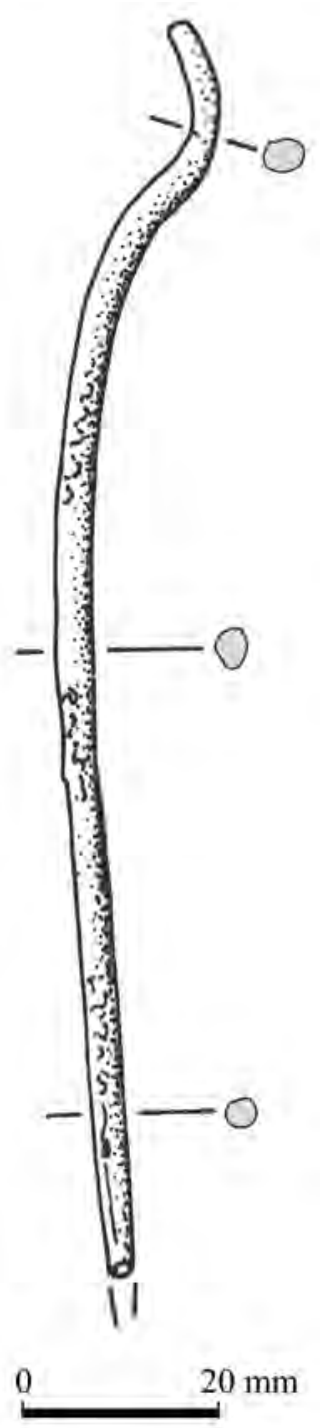

Illus 41 Copper-alloy pin (drawn by Alan Braby) 
have received little detailed attention until recent research by Katharina Becker (2000; 2008).

While a relationship to the wider family of insular swan's-neck pins seems evident, finding direct comparisons for the An Corran pin is made difficult because it is not always clear from the published data whether we are dealing with intact pins of equally simple form or more complex pins that have lost their heads (eg as in the superficially similar copper alloy pins from Meols: Griffiths et al 2007, 37 , nos 83-85). In some instances, however, the presence of distinct crimping at the end suggests that the pin heads are complete, rather than simply broken at the neck.

The insular forms of swan's neck and ring-headed pins had all emerged by the Early Iron Age (Becker 2008), considerably earlier than originally proposed by Dunning. However, detailed chronology continues to be a problem as so few pins have been recovered from securely dated contexts. In publishing a swan's neck pin from Coolure Demesne, Co Westmeath, Kelly (2005, 30) raised the possibility that some such pins of a fairly simple hooked form, all from Irish crannog sites, might even be Early Medieval in date. However in the case of An Corran, the conventional prehistoric dating is supported by the identification of the metal composition as probably leaded bronze. Moreover, one or two examples of complete pins of comparably simple overall form occur among the swan's neck and ring-headed pins from the excavated settlement and midden site at Llanmaes in Glamorgan, suggesting a likely core date range of $c$ 800-400 BC for such pins, spanning the period from the Late Bronze Age/Earliest Iron Age transition through the Early Iron Age (Gwilt 2007, 302-303 and pers comm).

In summary, therefore, despite the apparent simplicity of its form, the pin from An Corran invites comparison with a range of pins broadly datable to the period from the end of the Late Bronze Age through the Early Iron Age. While this form is unparalleled in Scotland, examples of related ring- or crook-headed pins in bronze and iron are known from a number of sites of this period in Scotland (eg Dunagoil, Bute: Harding 2004, 12, fig 2; Oakbank, Perthshire: Dixon 2004 , 158). The relatively poor survival of ironwork and the problems of identification of the original forms of the contemporary iron pins, and the relatively low numbers of excavated settlement sites probably go some way to accounting for the current limited and possibly unrepresentative inventory of Early Iron Age pins from Scotland. The particular circumstances which led to the loss or deposition of the pin at An Corran must remain unknown. 


\section{HUMAN BONE, by Margaret Bruce (Bone) and $N W \operatorname{Kerr}($ Teeth)}

\subsection{Introduction}

A total of thirty-nine bones and seven teeth were identified as human at An Corran. The samples came from two contexts: C31 contained twelve bones and three teeth, and C36 contained twenty-seven bones and four teeth.

At least five individuals are represented - two children, a late teenager, an adult not more than $c 35$ years old and an adult over 40 years of age. The only significant pathology was discovered in the oldest individual, who had suffered from osteoarthritis of the cervical spine. Virtually all parts of the skeleton are represented.

\subsection{Skull}

There are seven teeth, one attached to a mandibular fragment. These are from two individuals, one aged about nine months to one year, and the other about five years old. No adult or immature neurocranial fragments were found.

One lower right deciduous incisor tooth (CAT 909 ) with two-thirds of the roots formed had not yet erupted as there is no evidence of occlusal contact. This tooth is from a child aged about nine months to one year. The crown dimensions are: mesio-distal $4.7 \mathrm{~mm}$ and labio-lingual $4.3 \mathrm{~mm}$, which puts the tooth at the larger end of the scale in terms of size. The size of the tooth suggests that the sex of the deceased may have been male.

CAT 641 is a fragment of a mandible from a child, with a crypt of the lower right mandibular permanent canine. The mental foramen is just visible at the distal part of the specimen. It is likely that CAT 639 may be the tooth from this crypt. If this is correct, then it is likely to have been from a child aged five years \pm nine months. Sockets of deciduous canine, the mesial root of the first deciduous molar tooth, and the crypts of the permanent lateral incisor and first premolar teeth are present.

CAT 639 is the developing crown of a permanent lower right canine, just over three-quarters formed. This specimen most likely formed part of the same tooth as CAT 641, as it is from a child aged five years \pm nine months, and it fits the other developmental features of the mandible fragment. Its crown dimensions (mesio-distal $6.5 \mathrm{~mm}$; labio-lingual $5.8 \mathrm{~mm}$ ) put the tooth at the small end of permanent canines in terms of mesio-distal width. In view of the fact that it is not fully formed at the cervical part of the crown, no proper assessment can be made of the labio-lingual width.

CAT 910 is a lower-right deciduous central incisor tooth. This tooth has been in occlusal contact for some time and has marked attrition at the incisal edge. The crown enamel is well formed with a highly polished appearance. The first signs of resorption are occurring at the apex. The crown dimensions (mesio-lingual $4.2 \mathrm{~mm}$; labio-lingual $3.6 \mathrm{~mm}$; root length $9.0 \mathrm{~mm}$ ) indicate that this tooth is from a child aged five years \pm nine months.

CAT 683 is a fragment of a mandible from the premolar region, with the lower-left first deciduous molar tooth present. The crypt, with early formation of the first permanent premolar tooth, is also present. There are no obvious attrition facets of the cusps of the tooth, although the cusps are rounded and indicate that the deciduous tooth has been in occlusion for some time. The age of development of the permanent tooth suggests an age of five years \pm nine months.

CAT 604 is a fragment of a mandible with the lower-right deciduous molar sockets present. Radiographs reveal the outline of the crypt of a developing second permanent premolar tooth. This fragment fits CAT 641, and is the distal continuity of the canine fragment; it completes the structure of the mental foramen. A radiograph of the specimen shows the outline of the sockets of the deciduous molars and the crypts of the permanent first and second premolar teeth. This fragment is very similar to that of CAT 683 , and it is probably the opposite side of the mandible of the same individual.

CAT 908 is a developing permanent premolar tooth, most likely an upper premolar. The age of development suggests an age of five years \pm nine months.

All the specimens, apart from CAT 909, appear to be from the same individual. From the recorded tooth measurements, it is likely to have been a young female aged five years \pm nine months; given the rather young age for CAT 639, the age at death may have been at the younger end of this range.

The single lower right deciduous incisor is from a different individual, probably a young male infant aged nine months to one year.

\subsection{Vertebral column}

Two vertebrae were found. One (CAT 458) is from the cervical or upper end, while the other (CAT 632) is a lumbar vertebra from the lower end of the back. Due to the great difference in the degenerative changes seen in them, these vertebrae may not belong to the same individual.

The cervical vertebra (CAT 458), possibly the fourth, shows extensive degenerative change on the superior articular facets on both right and left 
sides, with eburnation on both facets. Degenerative pitting on the inferior facets is more marked on the right side, where there is also eburnation, although less marked than on the upper facets. Osteophytes on the posterior aspect of the vertebral body (right, inferior), and on the inferior aspect of the right pedicle, encroach on the intervertebral foramen. This may have caused some nerve compression. There is some degenerative pitting on the upper surface of the vertebral body but not on the under-surface. The vertebral foramen is single, not bifid. This bone is from a mature to old individual. The wear on the bone is commensurate with heavy loads being carried equally on both sides of the body.

The lumbar vertebra (CAT 632), probably the fifth, since inferior facets are wider apart than upper facets, is almost intact. It is relatively small, with no degenerative change to the facets or the upper and lower surfaces of the vertebral body, except for minor roughening on the left side of the upper body margin. There is no asymmetry of facet joint size or wear, and no Schmorl's nodes. It may have been subjected to a hyperextension of the lower back since there are deep fossae below and mediae to the superior articular facets. This bone came from an adult, who was unlikely to have been older than the mid-thirties.

\subsection{Ribs}

Eight rib bones were also recovered [n.b. this includes the bone (CAT 143) subsequently reclassified as pig, not human - see below]. One of these may be from an adult individual, one from a sub-adult and the remainder, some of which are very small, probably from a child.

\subsection{Upper limb}

Five fragments from upper limb bones are present in the assemblage. Two of these appear to have come from a small adult. These are CAT 283, a fragment of scapula, and CAT 615, a distal fragment of a right humerus shaft. The left ulna (CAT 270), showing marked muscle attachments, is likely to be that of a mature adult, and a metacarpal I (CAT 17), showing the last stages of epiphysis fusion, suggests an individual in the late teens. Finally, there is a phalange (CAT 705) from an immature individual.

\subsection{Lower limb}

There are several bones and bone fragments from the lower limbs. Six foot bones, both tarsals and metatarsals from the right and left feet, and a phalange from one adult big toe, may all have come from one individual, as none of these elements is replicated.
There is one child's tibial epiphysis, one long bone shaft fragment, one fragment of a femoral head and one small fragment of the acetabulum.

\subsection{Pathology}

The only significant pathological change observed in the human remains was the extensive osteoarthritis on the facet joints of the cervical vertebra (CAT 458). This was identified by the extensively pitted and broken down articular surface with eburnation. The wear appeared to be more or less symmetrical, with both right and left upper facets equally affected, although on the lower surface there was rather more degenerative change on the right side. The encroaching of the space for the passage of the nerve on the right side may have led to some nerve compression.

Some minor degenerative change was observed on the phalange of the big toe (CAT 912), and there was some enthesopathy at the attachments of the muscles on the proximal ulna (CAT 270), which may be age or activity related.

Periostitis (inflammation of the sheath surrounding the bone) was probably the cause of the greyish deposits seen on CAT 190, which cannot however be positively identified as human.

\subsection{Number of individuals represented}

Obviously, each fragment of bone could be from a different individual. However, it is possible to estimate a minimum number of individuals from the number of replicated elements of the skeleton, taking into account age and size indicators. It appears that there are at least two children represented by dental and jaw fragments, and possibly by some rib fragments. There is evidence of another immature skeleton, nearing skeletal maturity at the time of death, as seen in the rib CAT 143 and metacarpal CAT 117. This individual is likely to have been in his or her late teens. The two adult vertebrae are so dissimilar in the degree to which each was in the 'degenerative' phase of maturity that they are unlikely to have come from the same individual. The other skeletal elements are less useful in determining how many more individuals were represented, and it is possible that the remaining bone fragments could have come from the same two individuals as the vertebrae.

Thus, a minimum number of five individuals is represented, including two children, a late teenager and two adults (one no more than about thirty-five years old, and one over forty years of age).

The size of the teeth suggests that the youngest child may have been male and the older, female. Unfortunately, the sex of the older individuals could not be determined, since many of the bones were incomplete, and the skull and pelvis were scarcely represented in the bone assemblage. 


\subsection{Addendum}

The reclassification of the rib CAT 143 as pig rather than human arose from the detailed scientific study of selected skeletal parts from An Corran undertaken at the University of York by Nicky Milner and Oliver Craig (Milner \& Craig 2009; and see section 12 of this report). The identification as pig was further confirmed in consultation with László Bartosiewicz.
Since then further studies of the An Corran human bones have been made by Emily Hellewell as part of the research for her University of York PhD project. Her preliminary comments, which clarify and expand on certain aspects of the above report, but which do not materially affect its conclusions, are available as part of the site archive (Hellewell 2011). 


\section{VERTEBRATE REMAINS, by László Bartosiewicz}

\subsection{Introduction}

Animal remains were found in seven stratigraphically related major contexts of the midden (C31, C34, C36, C37, C38, C40 \& C41). Charred and calcined bones from various contexts and some features termed 'hearths' above the midden horizon seem to represent subsequent accumulations that will not be discussed in detail.

Given the stratigraphic complexity of the site, the aim of this study is to characterise animal remains from the aforementioned major contexts. The number of identifiable specimens (NISP) was counted, and fragment weights were measured. Sub-assemblage sizes as well as the numbers of identifiable bones varied considerably between contexts (C31: NISP = 1864, 775.4g; C34: NISP = 173, 544.30g; C36: NISP $=982,1673.2 \mathrm{~g} ;$ C $37:$ NISP $=11,2.73 \mathrm{~g} ;$ C $38:$ NISP $=$ 28, 50.28g; C40: NISP = 65, 6.14g; and C41: NISP = $1,1.04 \mathrm{~g})$. It is possible that the greater number of species in some contexts is, to a great extent, the consequence of larger sample size (illus 42; Grayson $1984,137)$. The results are detailed by context in Tables 20-27.

The zoological nomenclature used depended on the degree to which bones were identifiable. Linnaean binomial names were generally used in the identification of species. Sometimes, however, it was only possible to recognise broader categories, such as 'large ungulate' (aurochs, cattle, red deer, wild pig or horse), 'large artiodactyl' (aurochs, cattle, red deer or wild pig), 'large ruminant' (aurochs, cattle or red deer) or 'large bovine' (aurochs or cattle). The same hierarchical scheme was applied for small ungulates/ ruminants. Measurements taken, following the standard published by von den Driesch (1976), are presented in the catalogue in the site archive.

The analysis of vertebrate remains from An Corran was carried out in 1996-97. This text has been updated only in terms of the most directly relevant publications post-dating its first submission.

\subsection{Preservation and recovery}

The taxonomic composition, as well as the heterogeneous state of preservation of this assemblage, suggest varying forms of deposition. Gautier (1987) distinguished at least four major sources of animal remains at archaeological sites. In the order of increasing complexity, faunal materials may originate from:

- intrusive animals (at An Corran, possibly bones of most rodents, shrews, puffins and occasional amphibians);

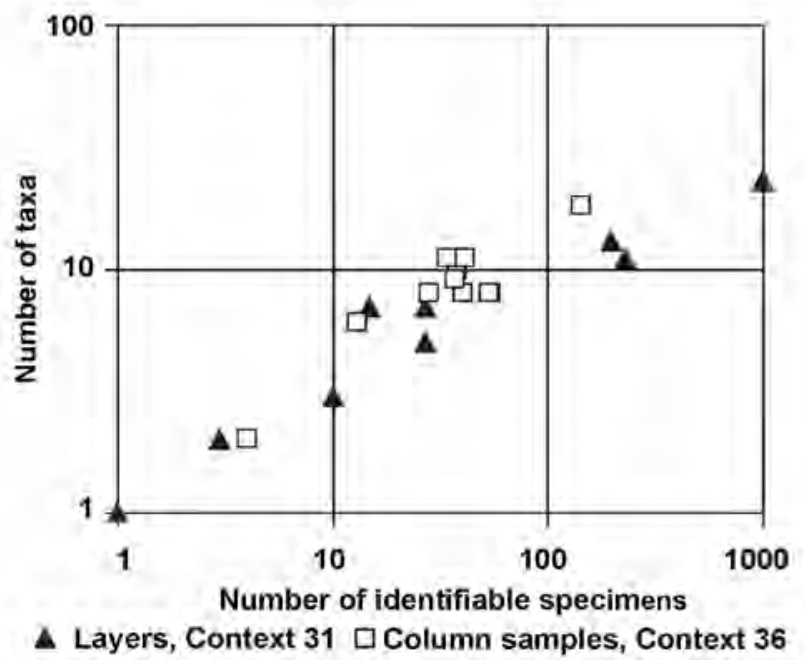

Illus 42 The relative abundance of taxa in major wet-sieved samples. The graph shows clearly that greater numbers of animal taxa are represented in samples of statistically viable sizes.

- carcasses originating from in situ death, water transport or importation by predatory animals (some bird bones, otter holts, owl pellets, as well as the gut-contents of larger fish preyed upon by otter or humans, may fall into this category);

- food refuse (for example bones showing marks of defleshing or marrow-extraction);

- waste material from craft activities (raw material from in situ bone and antler manufacturing, and bones with skinning marks).

Although many sites in central-west Scotland older than $c 6500$ BP may have been submerged and/or destroyed by the sea during the Main Postglacial Transgression (Bonsall \& Sutherland 1992), the evidence at An Corran suggests that it is unlikely to have been affected even by storm waves. However, some bones of terrestrial microfauna (amphibians, insectivores and rodents) may have been washed into the midden by rainwater from higher areas of the cliff, a phenomenon frequently observed in rockshelters and caves (Bartosiewicz et al 2010). This type of accumulation is a characteristic source of microvertebrate remains.

In addition to differences in the origins of the archaeozoological material, it is also possible that bones found in pockets of the shell midden underwent different post-depositional taphonomic modifications. The lack of even incomplete articulated skeletal sections, a high degree of fragmentation, as well as the often heterogeneous state of preservation within 
Table 20 Animal taxa identified

\begin{tabular}{|c|c|c|c|c|c|}
\hline \multirow[t]{2}{*}{ Vernacular name } & \multirow[t]{2}{*}{ Latin name } & \multicolumn{2}{|c|}{ Mesolithic } & \multicolumn{2}{|c|}{ Post-Mesolithic } \\
\hline & & NISP & Weight, $\mathbf{g}$ & NISP & Weight, $\mathrm{g}$ \\
\hline common eel & Anguilla anguilla L. 1758 & 53 & 0.9 & & \\
\hline salmon/trout & Salmonidae & 138 & 3.9 & 8 & 0.3 \\
\hline gadids & Gadidae & 1589 & 46.2 & 4 & 3.0 \\
\hline $\operatorname{cod}$ & Gadus morrhua L. 1758 & 48 & 21.9 & & \\
\hline whiting & Merlangius merlangus L. 1758 & 5 & 0.1 & & \\
\hline saithe & Pollachius virens L. 1758 & 44 & 3.3 & & \\
\hline cuckoo wrasse & Labrus cf. mixtus L. 1758 & 39 & 1.8 & & \\
\hline cottids & Cottidae & 20 & 0.3 & & \\
\hline plaice & Pleuronectes platessa L. 1758 & 40 & 0.6 & & \\
\hline dab & Limanda limanda L. 1758 & 9 & 0.2 & & \\
\hline frog/toad indet. & Anura sp. & 11 & 0.6 & & \\
\hline great auk & Alca impennis L. 1758 & 17 & 50.8 & & \\
\hline gannet & Sula bassana L. 1758 & 1 & 6.1 & 1 & 1.4 \\
\hline cormorant & Phalacrocorax carbo L. 1758 & 7 & 16.9 & & \\
\hline white-tailed eagle & Haliaetus albicilla L. 1758 & 2 & 5.5 & & \\
\hline pomarine skua & Stercorarius pomarinus L. 1758 & 2 & 1.6 & & \\
\hline gull & Larus argentatus seu marinus & 2 & 1.0 & & \\
\hline guillemot & Uria aalge L. 1758 & 1 & 1.1 & & \\
\hline puffin & Fratercula arctica L. 1758 & 81 & 44.7 & & \\
\hline willow tit & Parus atricapillus L. 1758 & 3 & 0.1 & & \\
\hline thrush & Turdus cf. merula L. 1758 & 1 & 0.1 & & \\
\hline perching bird indet. & Passeriformes & 7 & 0.0 & & \\
\hline common shrew & Sorex araneus L. 1758 & 16 & 0.2 & & \\
\hline pigmy shrew & Sorex minutus L. 1758 & 6 & 0.1 & 2 & $<0.1$ \\
\hline bank vole & Clethyrminomys glareolus L. 1758 & 21 & 0.1 & & \\
\hline field vole & Microtus agrestis L. 1758 & 6 & 0.1 & & \\
\hline rodent indet. & Rodentia & 48 & 1.0 & 1 & $<0.1$ \\
\hline common hare & Lepus timidus L. 1758 & 9 & 7.1 & & \\
\hline wild cat & Felis silvestris Schreb. 1777 & 3 & 2.8 & & \\
\hline otter & Lutra lutra L. 1758 & 1 & 7.5 & & \\
\hline brown bear & Ursus arctos L. 1758 & 1 & 1.7 & & \\
\hline large canid & Canidae & 1 & 1.4 & & \\
\hline wild pig & Sus scrofa L. 1758 & 10 & 62.7 & & \\
\hline pig indet. & Suidae & 57 & 246.8 & 1 & 2.1 \\
\hline roe deer & Capreolus capreolus L. 1758 & 114 & 371.7 & 12 & 14.2 \\
\hline red deer & Cervus elaphus L. 1758 & 173 & 1628.9 & 14 & 76.7 \\
\hline cattle indet. & Bovinae & 17 & 194.8 & 6 & 175.3 \\
\hline NISP TOTAL & & 2603 & 2734.6 & 49 & 273.0 \\
\hline fish indet. & Pisces & 2228 & 56.5 & 62 & 1.7 \\
\hline frog/toad indet. & Anura sp. & 11 & 55.9 & & \\
\hline bird indet. & Aves & 114 & 49.3 & 3 & 0.3 \\
\hline small ruminant indet. & Ruminantia & 42 & 63.8 & & \\
\hline large ruminant indet & Ruminantia & 371 & 858.1 & 896 & 298.8 \\
\hline small artiodactyl & Artiodactyla & 1286 & 225.8 & 221 & 64.1 \\
\hline non-identifiable & & 731 & 35.5 & 205 & 21.1 \\
\hline Non-identifiable TOT & & 4783 & 1344.9 & 1387 & 386.0 \\
\hline
\end{tabular}


Table 21 The distribution of major types of animal remains by archaeological context

\begin{tabular}{|c|c|c|c|c|c|c|c|c|}
\hline & \multicolumn{2}{|c|}{ Total } & \multicolumn{2}{|c|}{ Small artiodactyl } & \multicolumn{2}{|c|}{ Large artiodactyl } & \multicolumn{2}{|c|}{ Other taxa } \\
\hline & $\mathbf{n}$ & $\mathbf{W}, \mathbf{g}$ & $\mathbf{n}$ & $\mathbf{W}, \mathbf{g}$ & $\mathbf{n}$ & $\mathbf{W}, \mathbf{g}$ & $\mathbf{n}$ & $\mathbf{W}, \mathbf{g}$ \\
\hline Hearths & 1437 & 644.2 & 234 & 86.4 & 916 & 533.7 & 287 & 24.0 \\
\hline C 31 & 99 & 518.0 & 24 & 100.9 & 63 & 400.9 & 32 & 31.2 \\
\hline 1 & 916 & 99.9 & 269 & 48.7 & 16 & 39.7 & 621 & 11.5 \\
\hline $1 / 2$ & 308 & 46.3 & 49 & 4.3 & 33 & 36.2 & 226 & 5.8 \\
\hline 2 & 11 & 0.3 & 3 & 0.2 & 0 & 0.0 & 8 & 0.1 \\
\hline $2 / 3$ & 758 & 85.5 & 49 & 14.9 & 41 & 35.3 & 668 & 35.3 \\
\hline 3 & 150 & 16.8 & 59 & 3.2 & 16 & 8.5 & 75 & 5.2 \\
\hline 4 & 2369 & 407.0 & 475 & 110.4 & 81 & 252.1 & 1810 & 51.4 \\
\hline $4 / 5$ & 1 & 1.1 & 0 & 0.0 & 1 & 1.1 & 0 & 0.0 \\
\hline 5 & 50 & 19.7 & 0 & 0.0 & 0 & 0.0 & 50 & 19.7 \\
\hline 6 & 52 & 10.5 & 11 & 1.7 & 13 & 8.1 & 28 & 0.7 \\
\hline $7 / 8$ & 122 & 5.4 & 11 & 3.1 & 0 & 0.0 & 111 & 2.3 \\
\hline C 34 & 216 & 515.4 & 28 & 95.1 & 33 & 390.6 & 155 & 29.7 \\
\hline C 36 & 493 & 2001.5 & 140 & 340.2 & 209 & 1532.2 & 144 & 103.1 \\
\hline Sample A & 144 & 34.2 & 45 & 6.7 & 3 & 0.7 & 96 & 27.8 \\
\hline Sample B & 60 & 23.9 & 19 & 3.4 & 3 & 0.5 & 38 & 21.0 \\
\hline Sample C & 138 & 32.9 & 20 & 4.2 & 8 & 20.3 & 110 & 8.4 \\
\hline Sample D & 458 & 51.5 & 64 & 9.6 & 8 & 10.1 & 384 & 31.4 \\
\hline Sample E & 90 & 30.1 & 9 & 1.1 & 0 & 0.0 & 81 & 29.0 \\
\hline Sample F & 84 & 7.7 & 8 & 0.4 & 0 & 0.0 & 76 & 7.3 \\
\hline Sample G & 79 & 45.5 & 10 & 1.8 & 1 & 0.1 & 68 & 42.6 \\
\hline Sample H & 79 & 6.3 & 2 & 1.2 & 0 & 0.0 & 77 & 5.2 \\
\hline Sample I & 93 & 26.3 & 4 & 0.4 & 10 & 6.4 & 79 & 22.5 \\
\hline Sample J & 81 & 12.2 & 15 & 1.4 & 5 & 3.4 & 61 & 7.4 \\
\hline Sample R & 5 & 5.5 & 0 & 0.0 & 1 & 0.4 & 4 & 5.1 \\
\hline C 38 & 191 & 64.8 & 24 & 8.5 & 19 & 59.0 & 144 & 0.4 \\
\hline C 37 & 144 & 7.5 & 4 & 1.0 & 2 & 1.7 & 138 & 4.8 \\
\hline C 40 & 189 & 9.9 & 86 & 0.0 & 16 & 5.0 & 86 & 2.2 \\
\hline C 41 & 5 & 4.4 & 1 & 1.0 & 4 & 3.4 & 0 & 0.0 \\
\hline TOTAL & 8822 & & 1663 & & 1502 & & 5657 & \\
\hline TOTAL W, g & & 4734.3 & & 849.8 & & 3349.4 & & 535.1 \\
\hline
\end{tabular}

the same context, suggest repeated prehistoric redeposition at the site.

At An Corran, vertebrate remains owe their survival, indirectly, to human activity, regardless of their origins (e.g. primary taphocoenoses, or remains of prey items accumulated by predatory animals or humans), as the calcareous organic matrix of massive shell deposits creates an alkaline environment. Masses of predominantly limpet shells (Bonsall et al 1994; Russell 1992, 34) buffer soil acidity, thereby promoting the preservation of bone within the midden.

Although the surface preservation of most bones from An Corran is good (relatively few eroded and weathered bones were observed during the examination), the overall state of the material is extremely fragmented. In addition to the probably intentional breakage of large mammalian long bones, trampling and multiple redeposition probably played a role in this process.

Shades of very pale brown (HUE 10YR 8/3-8/4 \& 7/3-7/4: MUNSELL 1990) dominate in the handcollected midden material not affected by heat (burning may cause various forms of discoloration that obliterates the natural patina of excavated bone finds). Sieving of other midden material through mesh sizes of $1-4 \mathrm{~mm}$ guaranteed that most bones and bone fragments were recovered, especially from 

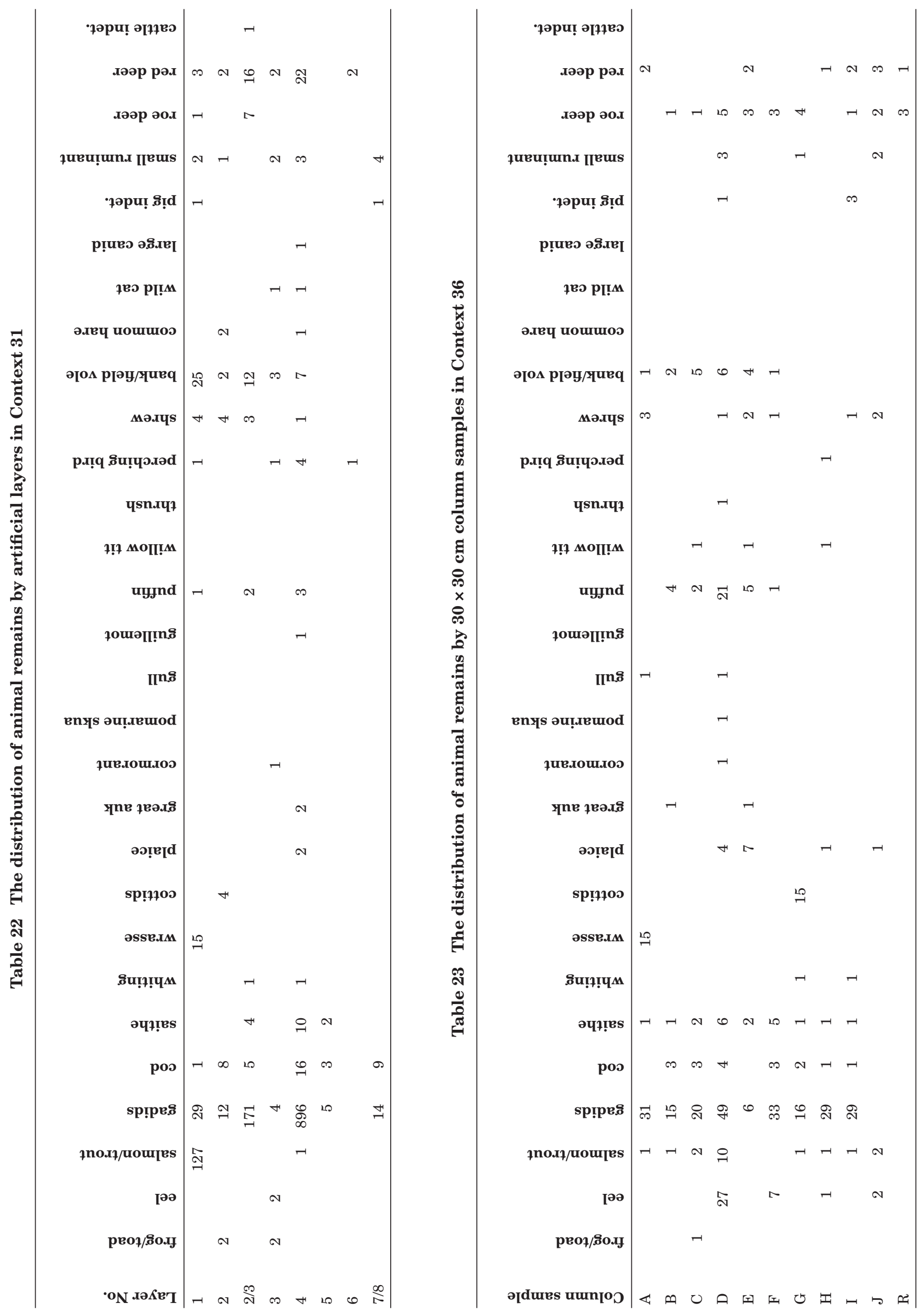


\begin{tabular}{|c|c|c|c|c|c|c|c|c|c|c|}
\hline & $\Phi$ & 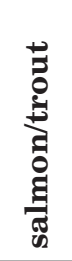 & : & 总 & 象 & 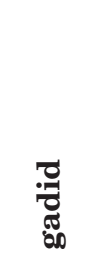 & $\begin{array}{l}0 \\
0 \\
0 \\
0 \\
0 \\
0 \\
0 \\
0 \\
0 \\
0 \\
0 \\
0 \\
0\end{array}$ & 苞 & $\frac{0}{\frac{\pi}{0}}$ & 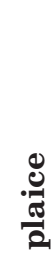 \\
\hline vomer & & & 3 & 4 & & 1 & & & & \\
\hline parasphenoideum & & & 2 & 4 & & 3 & & & & \\
\hline basioccipitale & & & & & & 7 & & & & \\
\hline prooticum & & 1 & & & & & & & & \\
\hline exoccipitale & & & & & & 1 & & & & \\
\hline otolith* & & & 1 & 2 & & 2 & & & & \\
\hline angulare & & & 4 & 2 & & 6 & & & & 2 \\
\hline dentale & 2 & & 4 & 9 & 3 & 5 & & & & \\
\hline pharingeal tooth & & & & & & & 2 & & & \\
\hline premaxillare & & & 16 & 13 & 2 & 47 & 8 & & & \\
\hline maxillare & & 1 & 7 & 9 & & 44 & & & & \\
\hline suboperculare & & & & & & & & 1 & & \\
\hline branchyostegale & & & & & & 3 & & & & \\
\hline palatinum & & 2 & & & & 4 & & & & \\
\hline quadratum & & & 2 & 1 & & 6 & 1 & & 1 & \\
\hline hyomandibulare & & & 1 & & & 1 & & 1 & & 1 \\
\hline epihyale & & & & & & 3 & & & & \\
\hline ceratohyale & & 3 & 1 & & & & & & & \\
\hline hypohyale & & & & & & 1 & & & & 2 \\
\hline urohyale & & 1 & & & & 1 & & & & \\
\hline scapula & & & 1 & & & & & & & \\
\hline coracoideum & & 1 & 1 & & & & & & & \\
\hline posttemporale & & & & & & 6 & & & & \\
\hline cleithrum & & & 1 & & & 5 & & & & 1 \\
\hline basipterygium & & & & & & 1 & & & & \\
\hline atlas & & & 1 & & & 7 & & & & \\
\hline vertebra praecaudalis & 29 & 74 & 3 & & & 919 & 15 & 3 & & 21 \\
\hline vertebra caudalis & 22 & 53 & & & & 514 & 13 & 15 & 8 & 6 \\
\hline radii & & 2 & & & & & & & & 4 \\
\hline pterygiophori & & & & & & 2 & & & & 3 \\
\hline TOTAL & 53 & 138 & 48 & 44 & 5 & 1589 & 39 & 20 & 9 & 40 \\
\hline
\end{tabular}

*Otoliths were also recovered from the flotation samples: see addendum to section 10 .

fish and micromammals. Flotation samples prepared for the purposes of macrobotanical analyses also yielded small fragments of vertebrate bones.

\subsection{Results}

Below, the major groups of animals listed in Tables 20-27 are briefly described in the order of their taxonomic affiliations. The biological features of the taxa deemed most relevant to prehistoric exploitation are summarised in order to elucidate the role they may have played at the time of midden formation.

\subsubsection{Poikilothermic vertebrates}

Common eel (Anguilla anguilla L. 1758) may attain a maximum length of $1.4 \mathrm{~m}$ (Campbell 1989, 274). 


\begin{tabular}{|c|c|c|c|c|c|c|c|c|c|c|c|c|}
\hline & 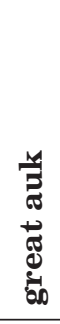 & 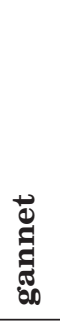 & 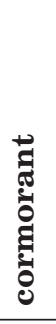 & 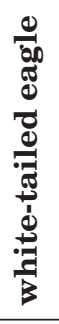 & 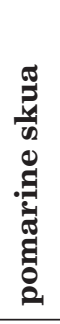 & 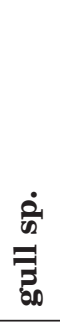 & 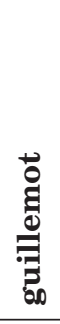 & 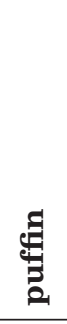 & 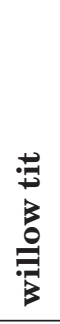 & 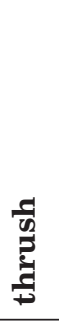 & 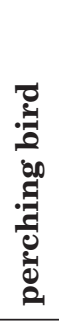 & 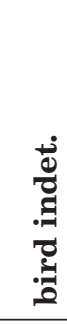 \\
\hline neurocranium fragment & & & & & & & & & & & & 2 \\
\hline frontale & & & & & & & & 1 & & & & \\
\hline mandibula & 3 & & & & & 1 & & 1 & & & & 1 \\
\hline \multicolumn{13}{|l|}{ atlas } \\
\hline epistropheus & 1 & & & & & & & & & & & \\
\hline cervical vertebra & 1 & & & & & & & 4 & & & & 5 \\
\hline thoracic vertebra & 1 & & & & & & & 2 & & & & \\
\hline synsacrum & & & 1 & & & & & & & & & 3 \\
\hline rib & & & & & & & & & & & & 21 \\
\hline sternum & & & & & & 1 & & & & & & 3 \\
\hline clavicula & & & & & & & & 1 & & & & 1 \\
\hline coracoideum & 2 & & & & & & & 9 & & & & 3 \\
\hline scapula & 1 & & & & & & & 4 & & & & \\
\hline humerus & 2 & 1 & 3 & & & & & 16 & & & & 7 \\
\hline radius & & & & 1 & & & & 7 & & & & 3 \\
\hline ulna & 2 & & 1 & & & & & 14 & & & 4 & 7 \\
\hline carpometacarpus & & & 2 & & & & 1 & 6 & & & 1 & \\
\hline femur & 1 & & & 1 & & & & 1 & 1 & & & 2 \\
\hline \multicolumn{13}{|l|}{ patella } \\
\hline tibiotarsus & 2 & & & & 1 & & & 4 & & 1 & 2 & 9 \\
\hline tarsometatarsus & 1 & & & & & & & 2 & 2 & & & 2 \\
\hline phalanx proximalis & & & & & 1 & & & 8 & & & & 4 \\
\hline phalanx media & & & & & & & & 1 & & & & 2 \\
\hline phalanx distalis & & & & & & & & & & & & 2 \\
\hline long bone & & & & & & & & & & & & 33 \\
\hline flat bone & & & & & & & & & & & & 3 \\
\hline TOTAL & 17 & 1 & 7 & 2 & 2 & 2 & $\mathbf{1}$ & 81 & 3 & 1 & 7 & 113 \\
\hline
\end{tabular}

Bones of this species occurred sporadically at the site. The colourless elvers of eel move into brackish water and then up the rivers to live in fresh water for several years. Some of them, however, remain in the brackish waters of the estuaries in the lower reaches of the rivers. The rest move downstream on their spawning migration towards the end of the summer (Angel 1977, fig. 40). In September-October, the silver eels move into the sea. With the exception of a large but non-measurable dentale fragment, the An Corran bones seem to represent small individuals. Present-day otter spraints from Mull (Argyll) contained up to $7.4 \%$ eel remains (Watt 1991, 24, table 7).
Remains from salmon and trout (Salmonidae) were found exclusively in wet-sieved samples (illus 43). This may be due to the poor preservation of their structurally weak, fatty bones. Nevertheless, most of the remains originate from fairly large, adult individuals. This may be indicative of the site's location several hundred metres from the mouth of the nearest stream. Approximately $170 \mathrm{~mm}$ long smolts of salmon (Salmo salar L. 1758; Angel 1977, fig. 36) move down rivers and into the sea in May and June. They spend some time in estuaries, where they acclimatise to salinity; most migrate to the sea when they are approximately $100-190 \mathrm{~mm}$ long (Muus \& Dahlstrøm 1977, 76). The maximum 


\begin{tabular}{|c|c|c|c|c|c|c|c|c|c|c|c|c|c|}
\hline & 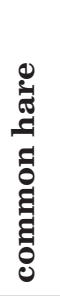 & 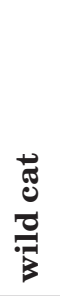 & 巳ँّ & 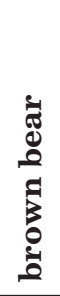 & 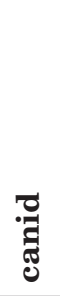 & $\frac{0.0}{2}$ & 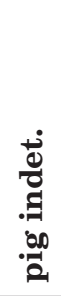 & 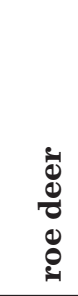 & 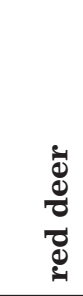 & $\stackrel{0}{8}$ & 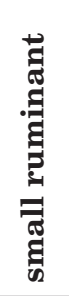 & 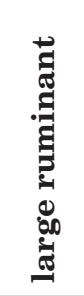 & 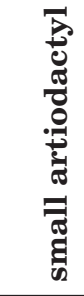 \\
\hline neurocranium fragment & & & & & & & 2 & 2 & 3 & & & 3 & \\
\hline \multicolumn{14}{|l|}{ frontale } \\
\hline \multicolumn{14}{|l|}{ nasale } \\
\hline os incisivum & & & & & & & & & & & & 1 & \\
\hline zygomaticum & & & & & & & 1 & 1 & 1 & & & & \\
\hline maxilla & & & & & & & & & 1 & 1 & & & \\
\hline mandibula & & & & & & 1 & 2 & 5 & 5 & & & 5 & \\
\hline upper tooth & & & & & & 1 & 1 & 11 & 5 & 3 & & & \\
\hline lower tooth & & & & & & 2 & & 13 & 6 & & & & 1 \\
\hline atlas & & & & & & & & 1 & 1 & & & & \\
\hline epistropheus & & & & & & & 2 & 1 & 2 & 1 & & & \\
\hline cervical vertebra & & & & & & & 3 & 3 & 3 & 1 & 3 & 4 & 6 \\
\hline thoracic vertebra & & & & & & & 4 & 4 & 6 & & 1 & 4 & 5 \\
\hline lumbal vertebra & & & & & & & 2 & 6 & 4 & 1 & 1 & 7 & 1 \\
\hline sacral vertebra & & & & & & & & 1 & & & & & \\
\hline rib & & & & & & & 5 & & 4 & 5 & 7 & 40 & 228 \\
\hline sternum & & & & & & & & & & & 5 & & 6 \\
\hline scapula & & & & & & & & & & & 1 & 5 & \\
\hline humerus & 1 & & & & & & 1 & 1 & 1 & & 1 & 2 & 1 \\
\hline radius & & & & & & & & & 3 & 2 & 2 & 6 & 2 \\
\hline ulna & & 1 & 1 & & & & 1 & 2 & 5 & & 1 & 2 & 3 \\
\hline carpalia & & & & & & & 1 & 6 & 5 & 2 & & & \\
\hline metacarpus & 1 & & & & & 3 & 7 & 15 & 39 & & & 4 & \\
\hline ilium & & & & & & & & 1 & 1 & & & & \\
\hline acetabulum pelvis & & & & & & & & 1 & 1 & & & & 1 \\
\hline femur & 1 & & & & & & 1 & 5 & 5 & 1 & 3 & 9 & 6 \\
\hline patella & & & & & & & & 1 & 1 & & & & \\
\hline tibia & 4 & & & & & 1 & & 11 & 6 & & & 8 & 3 \\
\hline fibula & & & & & & & 1 & & & & & & \\
\hline calcaneus & & & & & & & 1 & & 1 & & & & \\
\hline astragalus & & & & & & & & & 4 & & & & \\
\hline centrotarsale & & & & & & & 3 & 1 & 1 & & & & \\
\hline metatarsus & & & & & & 2 & 4 & 16 & 36 & & & 4 & 1 \\
\hline phalanx proximalis & 1 & 1 & & 1 & 1 & & 6 & 3 & 7 & & & & \\
\hline phalanx media & 1 & 1 & & & & & 6 & 2 & 6 & & 1 & & 1 \\
\hline phalanx distalis & & & & & & & 3 & 1 & 4 & & & & \\
\hline long bone & & & & & & & & & 6 & & 16 & 124 & 413 \\
\hline flat bone & & & & & & & & & & & & 143 & 608 \\
\hline TOTAL & 9 & 3 & 1 & 1 & 1 & 10 & 57 & 114 & 173 & 17 & 42 & 371 & 1286 \\
\hline antler (206.8 g) & & & & & & & & & 41 & & & & \\
\hline
\end{tabular}


Table 27 Bone measurements (mm)

\begin{tabular}{|c|c|c|c|c|c|c|c|c|}
\hline Species/bone & Context & GL & Bp & Bd & SD & $\begin{array}{c}\text { Smallest } \\
\text { depth }\end{array}$ & Bd & Dd \\
\hline \multicolumn{9}{|l|}{ Great auk } \\
\hline coracoideum & C 31 & 55.2 & & & & & & \\
\hline coracoideum & C 36 & 55.2 & & & & & & \\
\hline humerus & Sample E(a) & & 24.5 & 12.1 & & & & \\
\hline humerus & Sample B(a) & 55.9 & 24.9 & 9.5 & 9.9 & 4.9 & 10.6 & 12.1 \\
\hline ulna & C 36 & 55.6 & & & & & & \\
\hline ulna & C 36 & 55.7 & & & & & & \\
\hline femur & C 36 & & 15.1 & 11.0 & & & & \\
\hline tibiotarsus & C 31 & & 13.6 & 14.1 & & & & \\
\hline tibiotarsus & C 36 & & & & & & 12.5 & 12.9 \\
\hline tarsometatarsus & C 36 & 52.9 & 13.6 & 10.8 & 6.9 & 4.2 & 13.9 & 10.2 \\
\hline \multicolumn{9}{|l|}{ Cormorant } \\
\hline humerus & C 36 & & & & & & 14.0 & 10.2 \\
\hline humerus & C 36 & & & & 7.8 & 6.1 & 15.2 & 11.1 \\
\hline carpometacarpus & C 36 & 57.2 & & & & & & \\
\hline carpometacarpus & C 36 & 60.1 & & & & & & \\
\hline \multicolumn{9}{|c|}{ White-tailed eagle } \\
\hline radius & C 36 & & 11.0 & 8.9 & & & & \\
\hline femur & C 34 & & 26.1 & 16.2 & & & & \\
\hline \multicolumn{9}{|l|}{ Guillemot } \\
\hline carpometacarpus & C 31 & 43.1 & & & & & & \\
\hline \multicolumn{9}{|l|}{ Pomarine skua } \\
\hline tibiotarsus & C 36 & 81.1 & & & & & 7.9 & 6.1 \\
\hline \multicolumn{9}{|l|}{ Puffin } \\
\hline coracoideum & Sample D & 38.1 & & & & & & \\
\hline coracoideum & Sample E(a) & 36.4 & & & & & & \\
\hline coracoideum & C 36 & 31.2 & & & & & & \\
\hline coracoideum & C 36 & 34.1 & & & & & & \\
\hline coracoideum & C 31 & 37.9 & & & & & & \\
\hline humerus & C 36 & 59.6 & 13.9 & 5.2 & 5.2 & 3.1 & & \\
\hline humerus & Sample D & 57.8 & & & & & & \\
\hline humerus & C 31 & 60.2 & & & & & & \\
\hline humerus & C 31 & 60.6 & 14.1 & 6.8 & 3.2 & 5.0 & 8.7 & 6.5 \\
\hline humerus & C 36 & & 13.8 & 6.3 & & & & \\
\hline humerus & C 31 & 59.8 & 13.6 & 6.5 & 3.0 & 4.8 & 8.9 & 5.7 \\
\hline humerus & C 36 & 59.8 & 13.2 & 6.9 & 3.2 & 4.7 & 6.5 & 7.0 \\
\hline humerus & C 36 & & 14.1 & 7.2 & 5.1 & 3.3 & & \\
\hline humerus & C 36 & 59.1 & 13.5 & 6.6 & 4.9 & 3.2 & 6.7 & 8.0 \\
\hline humerus & C 36 & 62.8 & 13.2 & 6.8 & 5.1 & 3.2 & 6.7 & 7.9 \\
\hline humerus & C 36 & 61.9 & 13.8 & 7.0 & 3.2 & 5.0 & 6.8 & 7.2 \\
\hline humerus & C 36 & 61.9 & 14.1 & 7.0 & 5.1 & 3.2 & 6.8 & 7.1 \\
\hline radius & C 36 & 44.9 & & & & & & \\
\hline radius & C 36 & 45.1 & & & & & & \\
\hline radius & C 36 & 46.1 & & & & & & \\
\hline ulna & Sample E & 58.2 & & & & & & \\
\hline ulna & Sample E & 49.3 & & & & & & \\
\hline ulna & Sample D & 47.1 & & & & & & \\
\hline
\end{tabular}


Table 27 (cont.) Bone measurements (mm)

\begin{tabular}{|c|c|c|c|c|c|c|c|c|}
\hline Species/bone & Context & GL & Bp & Bd & SD & $\begin{array}{c}\text { Smallest } \\
\text { depth }\end{array}$ & Bd & Dd \\
\hline ulna & C 36 & 45.2 & & & & & & \\
\hline ulna & C 36 & 47.2 & & & & & & \\
\hline ulna & C 36 & 45.2 & & & & & & \\
\hline ulna & C 36 & 47.3 & & & & & & \\
\hline ulna & C 36 & 58.5 & & & & & & \\
\hline ulna & C 36 & 48.0 & & & & & & \\
\hline ulna & C 36 & 49.5 & & & & & & \\
\hline ulna & C 36 & 49.7 & & & & & & \\
\hline ulna & C 36 & 46.9 & & & & & & \\
\hline ulna & C 36 & 58.5 & & & & & & \\
\hline carpometacarpus & C 36 bottom & 37.2 & & & & & & \\
\hline carpometacarpus & C 36 & 42.1 & & & & & & \\
\hline carpometacarpus & C 36 & 38.7 & & & & & & \\
\hline carpometacarpus & C 36 & 32.7 & & & & & & \\
\hline femur & C 31 & 46.2 & 8.7 & 6.0 & 3.9 & 4.8 & 8.1 & 8.2 \\
\hline tibiotarsus & C 36 & & & & & & 5.7 & 5.9 \\
\hline tarsometatarsus & Sample F(a) & 35.9 & 8.2 & 6.1 & 3.8 & 3.1 & 7.2 & 6.1 \\
\hline \multicolumn{9}{|l|}{ Common hare } \\
\hline humerus & C 36 & & & & 5.3 & 5.1 & 11.1 & 9.0 \\
\hline \multicolumn{9}{|l|}{ Otter } \\
\hline ulna & C 36 & 91.2 & & & & & & \\
\hline Pig indet. & & & $\begin{array}{l}\text { Cranial } \\
\text { art. surf. }\end{array}$ & & & & & \\
\hline epistropheus, subadult & C 36 & & 56.9 & & & & & \\
\hline epistropheus & C 36 & & 38.1 & & & & & \\
\hline \multicolumn{9}{|l|}{ Roe deer } \\
\hline humerus & C 31 & & 36.1 & 45.5 & & & & \\
\hline radius & C 31 & & 26.2 & 16.9 & & & & \\
\hline radius & C 36 & & 29.0 & 17.5 & & & & \\
\hline tibiotarsus & Sample G(a) & & 45.9 & & & & & \\
\hline astragalus & C 34 & 32.2 & 30.4 & & & & 20.3 & 18.0 \\
\hline metatarsus & C 34 & & & & & & 22.2 & 15.3 \\
\hline metatarsus & C 34 & & & & & & 22.9 & 15.9 \\
\hline metatarsus & C 34 & & 19.8 & & & & & \\
\hline \multicolumn{9}{|l|}{ Red deer } \\
\hline antler, lower beam & C 36 & & & & 33.0 & 26.9 & & \\
\hline antler, upper beam & C 36 & & & & 31.1 & 21.9 & & \\
\hline humerus & C 34 & & & & & & 64.3 & 58.2 \\
\hline radius, subadult & Sample A(a) & & & & & & 47.1 & 36.9 \\
\hline metacarpus, subadult & C 36 & & & & & & 41.5 & 28.9 \\
\hline metacarpus & C 34 & & & & & & 41.2 & 27.1 \\
\hline metacarpus & C 36 & & & 32.2 & & & & \\
\hline metacarpus & C 36 & & GLm & 32.5 & & & & \\
\hline astragalus & C 31 & 53.4 & & & & & 31.9 & 27.2 \\
\hline astragalus & C 31 & 53.2 & 50.1 & & & & 33.8 & 29.9 \\
\hline astragalus, subadult & C 31 & 42.0 & 39.9 & & & & 27.0 & 23.2 \\
\hline metatarsus & C 31 & & 31.2 & & & & & \\
\hline
\end{tabular}




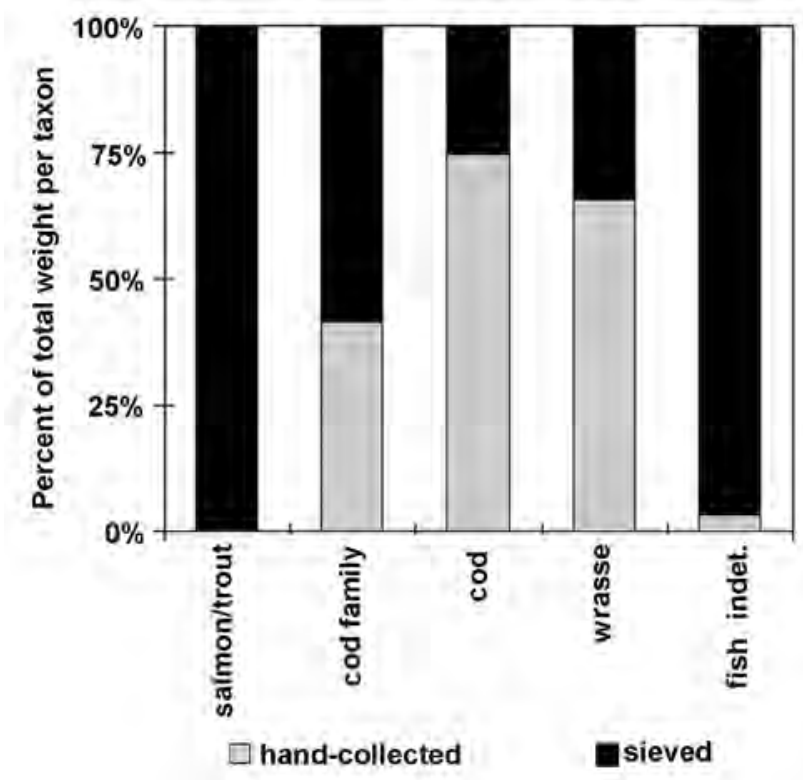

Illus 43 Percentage proportions of fish bone weights recovered by different methods

adult length of these fish is $1.5 \mathrm{~m}$, although none of the bones recovered at An Corran belonged to such large individuals. However, mediolateral diameters measured on the caudal articular surface of a modern reference specimen (total length $423 \mathrm{~mm}$; weight $986 \mathrm{~g}$ ), are smaller than the $7.6 \mathrm{~mm}$ and $8.9 \mathrm{~mm}$ observed on prehistoric individuals identified in the $1-4 \mathrm{~mm}$ fraction of the wet-sieved samples. Trout (Salmo trutta L. 1758, maximum adult length $1 \mathrm{~m})$, a species of very similar life history, is distinguished from salmon by its plumper body. Young trout migrate to the sea when $150-250 \mathrm{~mm}$ long, but they stay in the vicinity of the coast for $0.5-5$ years (Muus \& Dahlstrøm 1977, 78). Consequently, fragments not identifiable at a species level may equally originate from salmon or trout.

With the exception of cod itself, species in the cod family (Gadidae) prefer waters of high salinity. Their remains dominate the An Corran fish bone assemblage, both in terms of NISP and bone weight. The young especially, represented by masses of small bones in the wet-sieved material, may be caught along the shore. Species identification was limited to the few most diagnostic skeletal elements. Cod also formed the major part of identified fish remains at the east-coast site of Morton (McCormick \& Buckland 1997, 90). More recently, fishing in Scottish waters has increasingly concentrated on species in the cod family (Barrett et al 1997, 1).

At An Corran, cod (Gadus morhua L. 1758) and saithe (Pollachius virens L. 1758) contributed most identifiable Gadidae bones. Both small and some larger individuals are present. A dentale inner length of $47.5 \mathrm{~mm}$ was measured on one specimen. The majority of cod remains, however, originate from small individuals, possibly in their first year of life. Saithe, also common at An Corran, reach a maximum length of $1.3 \mathrm{~m}$, while they are $600-700 \mathrm{~mm}$ long in their fifth year. The young fish spend their first 3-4 years in shallow water (Muus \& Dahlstrøm 1977, 110). Numerous small maxillaria and premaxillaria (8-12mm long) from An Corran correspond to the first-year age group in the bimodal size distributions obtained for this species by Mellars \& Wilkinson (1980, 21). Whiting (Merlangius merlangus L. 1758) can attain maximum lengths of $400-500 \mathrm{~mm}$. These fish occur in the coastal eel-grass zone down to depths of 200m (Muus \& Dahlstrøm 1977, 106). They are about $200 \mathrm{~mm}$ long at the age of two years, which is in line with the small size of bones observed at An Corran.

Wrasse (Labrus cf mixtus L. 1758) vary in length between 300 and $350 \mathrm{~mm}$. Some unusually large premaxillare fragments recovered in the hand-collected assemblage from An Corran must represent adult individuals. They live in the algal zone on rocky coasts (Muus \& Dahlstrøm 1977, 128), usually below 10m (Campbell 1989, 288). Among the non-gadid species, the contribution of Labrids to prehistoric faunal assemblages seems to decrease through time (Barrett et al 1997, fig. 4).

Bullheads, or sea scorpions (Cottidae), are predatory, bottom-living fish with no swimbladder. They do not move far from the area in which they grew up (Muus \& Dahlstrøm 1977, 12). Although these usually small fish are of no known commercial value today, their remains made up 11.3-12.4 per cent of the fish bone recovered from otter spraints in Mull (Argyll; Watt 1991, 24, table 7). The remains of similarly small individuals were recovered at An Corran.

The family of right-eyed flatfish (Pleuronectidae) is represented by dab (Limanda limanda L. 1758), commonly occurring in coastal waters. The length of this flatfish species rarely exceeds $400 \mathrm{~mm}$ (Muus \& Dahlstrøm 1977, 182). The other flatfish, plaice (Pleuronectes cf platessa L. 1758), is a bottomliving species on mixed mud and sandy grounds from the shore to depths of $200 \mathrm{~m}$. Although most adult plaice occur at depths of $10-15 \mathrm{~m}$, the young usually frequent shallower coastal waters (Muus \& Dahlstrøm 1977, 184) and may even be caught by hand. At An Corran, all plaice bones suggest young individuals.

A sporadic presence of long bones of frogs/toads (Anura) was recognised, although some less typical bones of these animals may have been included among the non-identifiable fish bones. Remains from these small terrestrial animals typically represent the 'taphonomic gain' caused by active intrusion or water transport (precipitation) of their bones.

\subsubsection{Birds}

The exploitation of birds was of great importance in coastal adaptations throughout the Mesolithic and later periods in north-west Europe (e.g. Grigson 1989 , 60). In the An Corran collection, numerous species 
are represented by relatively few bones, although it is unclear how many originate from natural deaths, rather than human foraging. Avian skeletons only contain approximately half the number of bones of mammals, a natural phenomenon that also contributes to their greater variety in samples, regardless of the origins of the find material (Bartosiewicz \& Gál 2007, 42).

Seventeen bones of great auk (Alca impennis L. 1758), extinct in Britain since 1844 (Barnes 1975, $\mathrm{XV}$ ), were identified. Remains of this bird have also been recorded from Mesolithic assemblages on Oronsay (Mellars 1978, 319). Most dimensions of these bones correspond to those of the single reference skeleton from Funk Island(Newfoundland) kept in National Museums Scotland (registration no. Z.1951.74).

Although today the British Isles are among the most important breeding grounds for gannet (Sula bassana L. 1758), this large pelicaniform bird is represented by only two heavily weathered bones, one of these in the post-Mesolithic material. Bones from the other species in this order, cormorant (Phalacrocorax carbo L. 1758), are more common and occur in two size groups. The two gracile carpometacarpalia bones found in C36 may be shag (Phalacrocorax cf aristotelis L. 1758), a species characterised by a strong preference for marine habitats (Barnes 1975, 23).

A femur and a radius fragment from white-tailed eagle (Haliaeetus albicilla L. 1758) were also identified. This once-common species is more typical of coastal habitats than the golden eagle, and its eyries are usually on sea cliffs and pinnacles (Barnes $1975,83)$. The bones from this bird are also rather weathered, although less so than the gannet bones (see above).

Remains of pomarine skua (Stercorarius pomarinus L. 1758), common or herring gull (Larus marinus seu argentatus L. 1758) and guillemot (Uria aalge L. 1758) form a group of finds that originate from birds most commonly encountered in marine environments. Although their bones occur sporadically in the material and represent meat-poor regions of the animals' body, it is possible that these animals occasionally served as a complementary resource of animal protein.

Puffin (Fratercula arctica L. 1758) bones dominate among the bird remains. Of known Scottish Mesolithic assemblages, these birds were recorded only at Morton, although they occur sporadically in archaeozoological assemblages throughout later periods (McCormick \& Buckland 1997, table 2). It seems possible that many of the extremity bones recovered are actually paired elements from the same individual. Although the presence of this bird at a site located along the rocky seashore should not be surprising, its massive presence in the archaeozoological assemblage is remarkable.

Willow tit (Parus atricapillus L. 1758) and a nonidentifiable species of thrush (Turdus cf merula L. 1758), as well as sporadic remains of small perching birds, may be considered natural deposits at this site As opposed to the aforementioned species, all characteristic of marine habitats, these small birds remind us that the midden was located in the woodland/ littoral ecotone, although they are unlikely to be connected to the human occupation of the site.

\subsubsection{Mammals}

Bones of common shrew and pigmy shrew (Sorex araneus et minutus L. 1758) are also present. Although these insectivores are known from Carding Mill Bay I and II (Bartosiewicz et al 2010; Hamilton-Dyer \& McCormick 1992) they were not recorded at Morton or Oronsay. It is possible that these animals found their way into the cracks and cavities of the An Corran midden in recent times. Equally, the possibility of water transport should not be discounted.

Of the numerous rodent bones deposited at this site, only bank vole (Clethyrminomys glareolus L. 1758) and field vole (Microtus agrestis L. 1758) could be identified to species on the basis of tooth enamel patterns. This is interesting from an environmental perspective, as bank voles inhabit mixed woodland, and it is the only vole species that climbs bushes (Mitchell \& Delap 1974, 56). Field vole was also considered one of the faunal indicators of a forested environment at the site of Carding Mill Bay I (Hamilton-Dyer \& McCormick 1992). Nine fragmented bones of common hare (Lepus cf timidus L. 1758) in the Mesolithic deposits most probably represent prey brought to the site by humans.

Possible remains of a wild cat (Felis silvestris Schreb 1777) were tentatively identified on the basis of the unusual robusticity of otherwise non-measurable bone fragments. No marks of skinning are evident, either on the proximal end of the ulna or on the phalanges recovered from the midden deposit. This adaptable terrestrial animal has not yet been reported from Mesolithic sites in Scotland, although Barbara Noddle (McCormick \& Buckland 1997, 87) identified its remains in the Neolithic assemblage at Skara Brae, Orkney, where it was interpreted as a possible import from the Scottish mainland. If, as is possible, the An Corran bones originate from a former inhabitant of the rockshelter, it may be hypothesised that prehistoric wild cat contributed to the accumulation of bones from smaller animals at this site.

Otter (Lutra lutra L. 1758) is an important carnivore representing a class of its own at shell midden sites along the west coast of Scotland, both taphonomically and culturally. Although only two bones were recovered at An Corran, the number of otter bones was second only to those of seal at the 'Obanian' site of Cnoc Coig, Oronsay, where these animals had evidently been hunted (Grigson \& Mellars 1987, 274). Although otter thrives in fresh water, populations adapted to marine environments have regularly been observed (Mitchell 


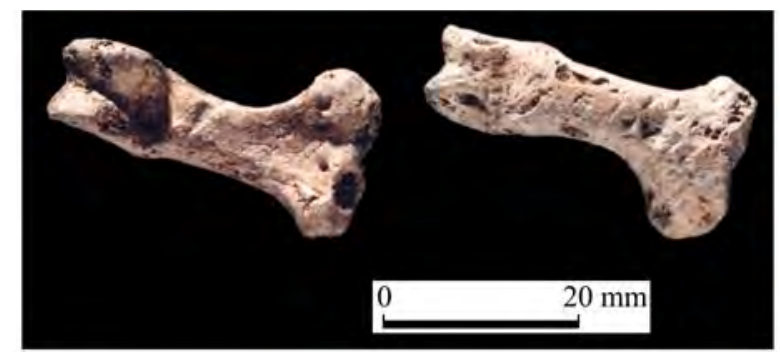

Illus 44 Brown bear phalanx CAT 98 from C34 (photo: NMS)

\& Delap 1974, 64). The ulna and phalanx found at An Corran show no signs of skinning, and surface preservation suggests moderate weathering. Whilst the diet of otters is varied, high concentrations of small fish bone, especially when flattened, distorted and showing signs of digestion, would alternatively be characteristic of offal and faeces from otter holts (Cerón-Carrasco 1992，3), the daily hideouts of these animals. This, however, is not the case at An Corran.

The second posterior phalanx from a relatively small and gracile brown bear (Ursus arctos L. 1758) is one of the more remarkable zoological finds from this site (CAT 98; illus 44). Its surface is eroded and of a pinkish grey colour (HUE 7.5YR 7/2: MUNSELL 1990), which is somewhat different from the typical pale brown shades observed on the bones of this site. Exposure to weathering may either be indicative of a natural deposit, or differential treatment by humans. Terminal phalanges of the distal extremity segment are often left in skins, and are therefore easily interpreted as a sign of exploitation for pelt (Bartosiewicz 1989, 612). Unfortunately, in the absence of skinning marks on this piece of bone, it is possible that this find is more indicative of the forested surroundings than the human occupation of the site. Recent radiocarbon measurement of a bear skull from Shaws (Dumfriesshire) resulted in a date of $7590 \pm 95$ вP (AA-18503; Kitchener \& Bonsall 1997), corresponding to the oldest determination available for the An Corran shell midden. Brown bear became extinct in Scotland some time after $\mathrm{AD}$ 500 , but before the 10th century (Kitchener et al 2004, 75).

The fifth anterior proximal phalanx of a canid was also found in the prehistoric material. On the basis of its dimensions, this bone may either originate from a medium-sized dog (Canis familiaris L. 1758) or a small wolf (Canis lupus L. 1758). Although wolf was almost certainly the first animal to be domesticated by prehistoric people, its remains have not yet been encountered in Mesolithic shell middens in Scotland. The skeletal element recovered here is not sufficiently characteristic to resolve the problem of Mesolithic dog domestication in Scotland. Similar to other carnivore remains from An Corran, no marks of skinning were recognised on this bone.

Wild boar (Sus scrofa L. 1758) is another mammal the domestic form of which is often difficult to recognise. Only ten of the sixty-seven suid bones are large enough to be determined definitively as wild pig, also present at Morton and on Oronsay (McCormick \& Buckland 1997, table 6.1). The remainder are either from young individuals or medium-sized animals of unknown age. Although pig domestication is unlikely to have taken place before the Neolithic period, several biological traits of this species could have facilitated the development of a 'special relationship' between wild pigs and humans that preceded domestication in a classical sense (Bolomey 1973, 48). As with dogs, these multipara, social animals were more likely to have scavenged on human refuse than the ancestors of other herbivorous domesticates. The presence of these indeterminate pig bones may also be related to contamination from later prehistoric layers, where pig had become incorporated into the domestic fauna.

In terms of NISP, roe deer (Capreolus capreolus L. 1758 ) is the second best represented mammal in the faunal assemblage from An Corran. In addition to identifiable remains, the majority of small ruminant bone splinters also undoubtedly represent roe deer bones. Although some of these bones are indistinguishable from those of sheep (hence the term 'small ruminant'), this latter species is present only in the form of post-Mesolithic contamination of the midden. Roe deer remains occurred both on Oronsay and at Morton (McCormick \& Buckland 1997, table 6.1). Together with wild pig, roe deer is considered to be an animal of deciduous woodland or parkland habitats, although recently increasing adaptation to open grassland has been recorded in Hungary (Bencze 1979, 56). Although roe deer bones, especially metapodia, were a highly prized raw material in prehistoric central Europe (e.g. Bartosiewicz \& Choyke 1994; Schibler 1981), relatively few modified pieces were found at An Corran. None of the antler fragments were identified as belonging to roe deer. Although age-able bones were documented for large game animals, the percentage distribution by age groups is primarily influenced by assemblage size (illus 45).

Red deer (Cervus elaphus L. 1758) was probably the most important game animal exploited at An Corran. However, both the high number of identifiable bones and more than $1.5 \mathrm{~kg}$ of deer remains are distorted by the disproportional representation of dense metapodial fragments that make up over one-third of the material.

Although only a few measurable red deer bones are present in the An Corran collection, earlier research has shown that Mesolithic red deer remains from elsewhere in Scotland (Risga \& the Oban caves) fall within the size range of Mesolithic samples from England, whilst comparable measurements of bones from some island sites are considerably smaller (illus 46; Grigson \& Mellars 1987, 258). As is shown by the size indices calculated according to Uerpmann (1982), all measurements taken on the bones from 


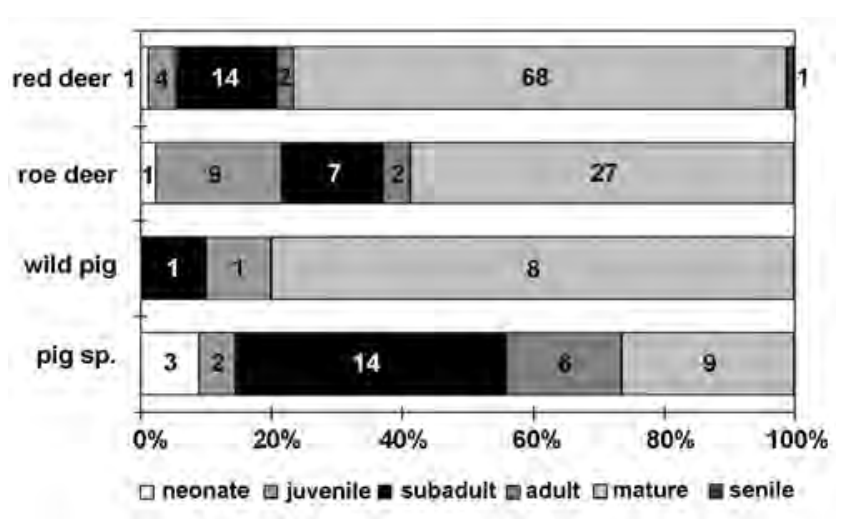

Illus 45 The age distribution of bones from large game. The greater age variability in red deer may in part be a product of sample size, while the high proportion of immature pig remains shows how difficult it is to assign these bones to either the wild or domestic category.

An Corran fall below the average of mainland red deer measurements.

Animal remains underwent several post-mortem processes prior to being deposited in the midden. The full sequence of these events is best represented by the example of red deer. These animals were evidently killed elsewhere; there is no evidence of primary butchery. Many of the bones must have been brought in with portions of meat. Others may have been carried to the midden for manufacturing purposes. Following possible marrow-fracturing and/or pot-sizing (as much as the ethnocentric term 'pot' can be used in such early contexts), some long bone splinters were used as simple tools, which apparently further influenced the loci and modes of their final deposition.

Only a few small red deer antler fragments (a total of $207 \mathrm{~g}$ ) were recovered from the midden. Two of them show marks of rudimentary carving, and many are carbonised and crushed. It is not possible to determine whether the fragments originate from shed antler or from hunted stags. Due to different procurement strategies and fragmentation properties, antler fragments are not normally included in the quantitative evaluation of skeletal materials.

On the basis of their size and morphology, the 17 bovine remains identified in the Mesolithic assemblage were originally thought to represent domestic cattle (Bos taurus L. 1758). However, little is known of the Mesolithic status and size of aurochs (Bos primigenius Boj. 1827) in coastal Scotland, and the stratigraphic uncertainty of many of these bones (some of them definitely from C36) makes interpretation difficult. This difficulty was confirmed when three of the Bos bones were radiocarbon dated and shown categorically to be of Mesolithic age (see below), thus suggesting they are from aurochsen rather than domestic cattle. Bovine remains at this site are much less common than those of red deer.

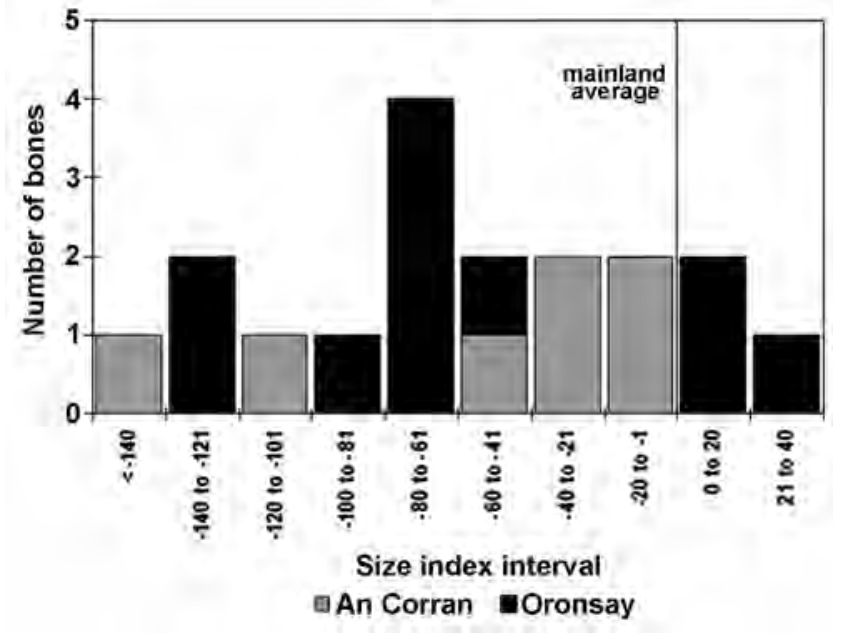

Illus 46 The distribution of size indices calculated from the parameters of red deer measurements from mainland sites. The few measurable specimens from An Corran all fall below the mainland average (index value 0).

\subsection{Discussion}

It is thought that, at An Corran, bones from terrestrial large game animals may largely have been introduced by humans with meat. It is more difficult to interpret the remains of smaller animals (including those of fish and birds) of limited dietary capacity as human food remains, unless such hypotheses are directly corroborated by evidence for butchery or burning (Hamilton-Dyer \& McCormick 1992, 34). The taxonomic review of animal remains identified at An Corran suggests that, although a number of natural taphonomic factors clearly contributed, the majority of animal remains could indeed be linked to human activity. Therefore, in spite of the undeniable chronological and stratigraphic uncertainties, some environmental and functional interpretations may be attempted.

Of the fish species identified at An Corran, gadid fish (especially cod and saithe), salmon/trout and flatfish were of major importance throughout human history. The occasional larger individual bones from these fish may be regarded as clear evidence of human fish consumption, although none shows evidence of butchery. However, numerous charred and carbonised small fish remains were also recovered. Although the possibility of secondary burning cannot be ruled out, it is noteworthy that a comparable combination of small fish bone (interpreted alternatively as otter spraints) and burnt whiting vertebrae were reported from the 'Obanian' shell midden of Carding Mill Bay I (Hamilton-Dyer n.d.) near Oban.

Seasonality may have been an important element in the occupation and use of the An Corran site, as was demonstrated by the analysis of fish otoliths from the island of Oronsay (Mellars \& Wilkinson 1980). Fully grown Salmonids, the bones of which 


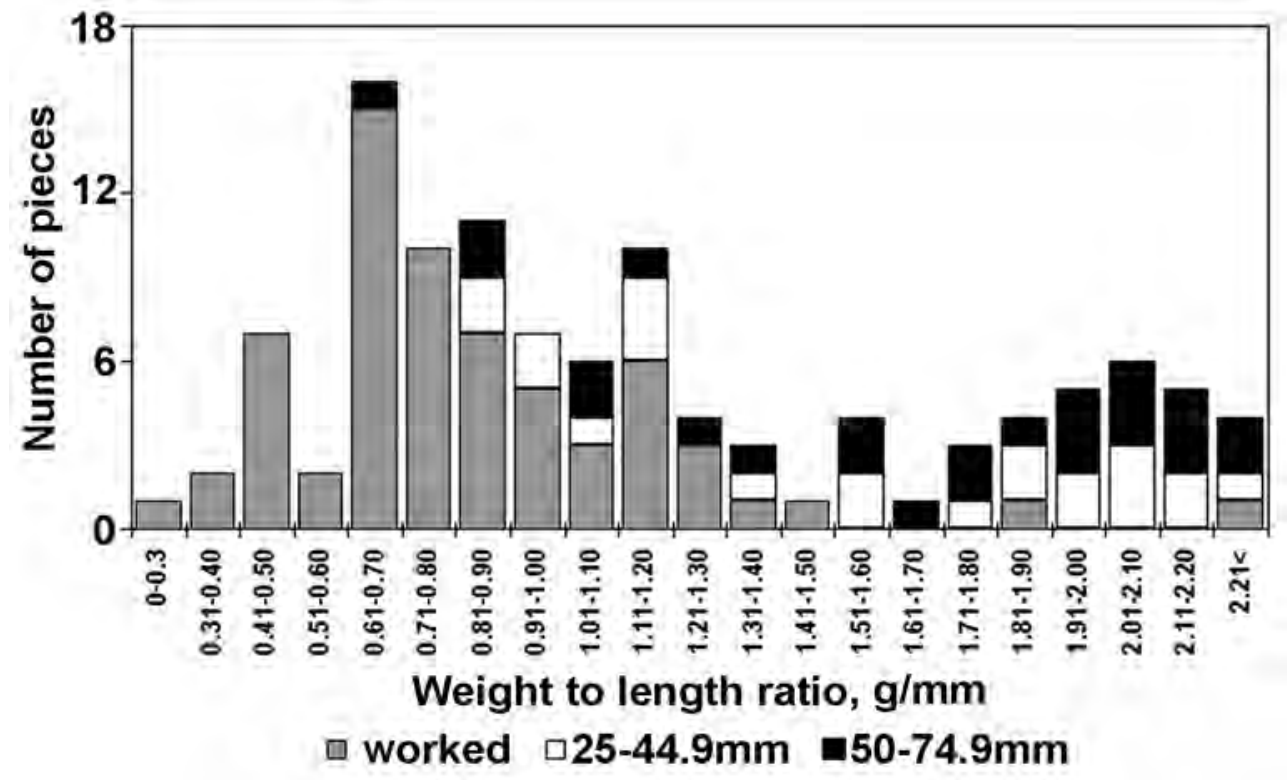

Illus 47 The weight to length distribution of bevel-ended tools ('limpet scoops') and potential raw materials (refuse bone splinters).

were recovered at An Corran, must have been available most easily during the second half of the year in the proximity of estuarine environments (Bonsall 1981, 466). Several other species (especially the young of non-cod Gadidae and flatfish) are indicative of a rather saline environment along this section of the coast (today, the estuary area of the closest major stream is to be found inside Staffin Bay; see illus 1). The massive presence of cod is indicative of moderate salinity, which cod is able to tolerate better than many other gadid species. In the open sea, the salinity of water averages $35 \mathrm{~g} / \mathrm{l}$. In the uppermost approximately $40 \mathrm{~m}$ thick water layer of lesser specific gravity, lower salinity and insulation favour the growth of algae (Muus \& Dahlstrøm 1977, 19) and creatures feeding on them, which are, in turn, preyed upon by carnivorous fish, such as cod. Moreover, this is also the layer of coastal waters where marine resources of animal protein could be best exploited.

The overwhelming majority of measurable fish remains at this site represent $150-300 \mathrm{~mm}$-long individuals. Along with shellfish gathering, opportunistic fishing (i.e. trapping or harvesting fish by hand in tidal pools) may also have been practised. This tactic has been followed seasonally for millennia in the floodplains of the Danube and Tisza rivers in Hungary (Bartosiewicz 2007; Bartosiewicz et al 1994). According to Mellars \& Wilkinson (1980, 29) angling tends to be less efficient; catching oneyear-old, c 130mm-long specimens, with a variety of hooks at differing depths, failed to provide a sufficiently large sample of fish for the purposes of statistical analysis.

Mesolithic faunal assemblages from the west coast of Scotland show that, similarly to the whole of the country (including the islands of the Southern Hebrides; Mercer 1974b, 33), this area was originally forested and occupied by a pertinent terrestrial fauna. The universal early Holocene tree cover, as suggested by palynological (Edwards \& Whittington $1997,82)$ as well as anthracotomical evidence (Bartosiewicz et al 2010), is most unlikely to have started radically decreasing at the time this shell midden was deposited. The known habitat preferences of red deer neatly fit this type of forested environment at An Corran. Osteological evidence of blackbird and other passeriform birds all point in the same direction. Regardless of their actual taphonomic history, remains of micromammalia, that is, rodents and shrews, further support this general picture also emerging from contemporaneous botanical evidence from Carding Mill Bay, where oak, alder, elm and willow/aspen remained important charcoal samples throughout the Neolithic (Bartosiewicz et al 2010). Otter, a species represented only by the direct evidence of a single bone, may be regarded as a link between the waters of the forested inland and the marine environment. Remains of some mammals, especially those of predators, seem to indicate that the small rockshelter offered refuge, not only for humans but sometimes also for animals. Although carnivores may mainly have been exploited for their pelt, the lack of skinning marks (for example on the bear phalanx) makes it difficult to interpret these bones as the result of direct human activity.

Deer bones, on the other hand, may have been brought to the site from just about anywhere in the evidently forested environment, including occasional kill-sites in the vicinity of the shell midden. Similarly to other 'Obanian' sites, deer bones may be directly linked to human activity at the shell midden (meat consumption and tool use). Artefacts tentatively labelled 'limpet scoops' (Bishop 1914, 95), or as in this report, bevel-ended tools, have consistently attracted attention. Such tools may 


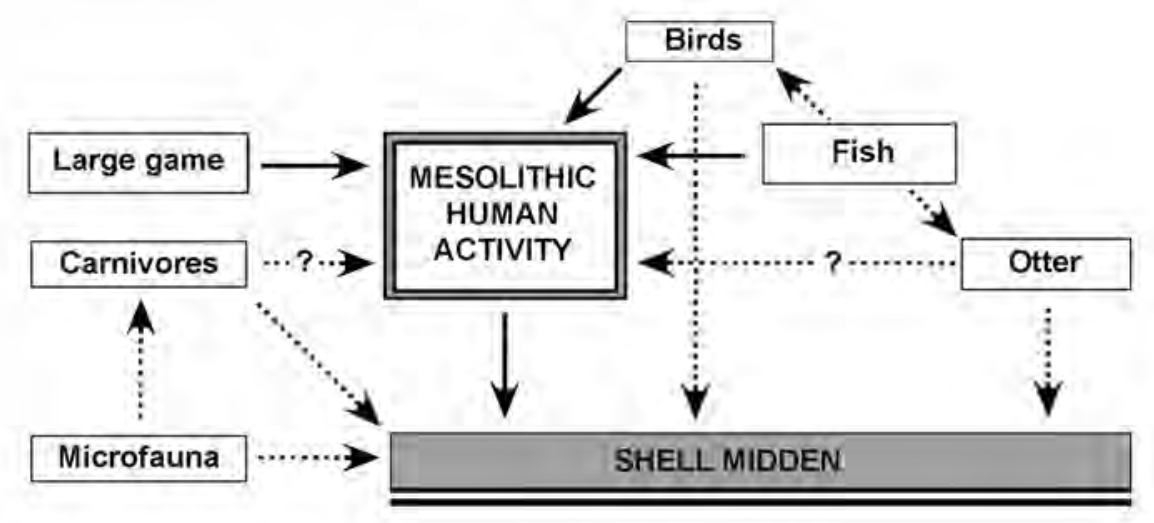

Illus 48 The possible origins of vertebrate remains in the An Corran midden deposits. Continuous arrows indicate human mediation through predation (hunting, fowling and fishing); dashed lines indicate nonanthropogenic processes contributing to the formation of archaeozoological assemblages.

be made of stone or, alternatively, either from long bone diaphysis splinters or antler (e.g. Anderson 1895; Clark 1956). The aforementioned high concentration of deer metapodia among the refuse bone recovered from the An Corran midden may relate to the manufacturing of bevel-ended tools, which almost exclusively originate from these bones. A great number of slender metapodial bones seem to have been used this way, whilst robust fragments were less frequently selected (illus 47). Signs of other, more sophisticated, multi-stage bone manufacturing are also visible in the worked bone assemblage (for example bone points).

In consonance with the results of previous botanical and faunal studies carried out in the broader region, mammalian and bird bones identified at this site are all indicative of a wooded environment. The coastal strip studied here must have represented an ecotone between land and water, well worth human exploitation during Mesolithic/Neolithic times. It is unlikely, however, that prehistoric occupation would have been limited to the coastal area. The relatively small number of vertebrate remains which were unambiguously attributable to human activity (as opposed to the gathering of molluscs, the shells of which make up much of the deposits) suggest that fishing, fowling and hunting may have been practised by the occupants of this site, but sporadically so. Some remains may have been deposited in alternative, natural ways at the site (illus 48). This observation supports the temporary, if not strongly specialised, character of the site. 


\section{THE MARINE MOLLUSCS, by Catriona Pickard and Clive Bonsall}

\subsection{Introduction}

The presence of marine shells in varying states of preservation was noted in many of the contexts excavated at the An Corran site, but samples for analysis were available only from contexts $\mathrm{C} 1-4,31$, 34 and 36-40. With the exception of C31 and C36, only single samples were available for analysis. C31 was represented by 13 samples, although precise information on the locations of those samples was not available. The samples from C36 include a vertical series taken from a $300 \times 300 \mathrm{~mm}$ column through the site (see illus 18). Samples B-J of this column come from C36 and were taken from lenses or layers observed within this, the largest deposit of shell material excavated. The uppermost sample from the column (sample A) comes from the deposit overlying C36 (presumed to be C31).

From the stratigraphic and radiocarbon evidence available, the shell-rich deposits at An Corran may be assigned to three broad phases in the use of the site:

- Phase I is represented by contexts $\mathrm{C} 34,36,37$ and 40. The shells in C36 are assumed to relate mainly or wholly to the Mesolithic between $c$ 6600-3800 cal BC, although significantly younger radiocarbon dates on a human bone and on a bone artefact suggest that some of the shells could have been introduced from higher levels at a later date. C34 and C37 occupy equivalent stratigraphic positions with respect to C31, and are assigned to the same phase as C36. Only two identifiable shells were recovered from the sample from $\mathrm{C} 40$ and possibly derived from C36.

- Phase 2 is represented by $\mathrm{C} 31$, which contains $\mathrm{C} 38$ and $\mathrm{C} 39$. The radiocarbon dates for C31 and C38 form a consistent series, and suggest that much of the shell material in those contexts could have been deposited between $c$ 3630-1880 cal BC (Late Neolithic-Early Bronze Age).

- Phase 3 is represented by $\mathrm{C} 1-\mathrm{C} 4$. No radiocarbon dates are available for these deposits, but their stratigraphic positions indicate that they postdate C31. They may therefore be assumed to have been deposited later (probably substantially later) than $1880 \mathrm{cal}$ BC.

\subsection{Procedures}

Sampling of the An Corran deposits for marine molluscan analysis was undertaken by the excavators. The bulk samples were subsequently dried, then passed through a nest of sieves with meshes at $4 \mathrm{~mm}$ and $1 \mathrm{~mm}$ - this initial stage of the postexcavation processing was not carried out by the authors of this report, and at the time of writing no information was available on the sizes (by weight or volume) of the original samples. All identifiable fragments of marine molluscs were picked out of the $>4 \mathrm{~mm}$ fractions, and apices of gastropods and fragments of bivalve shells which included the 'umbo' were collected from the $>1 \mathrm{~mm}$ fractions. These were identified and recorded for each sample.

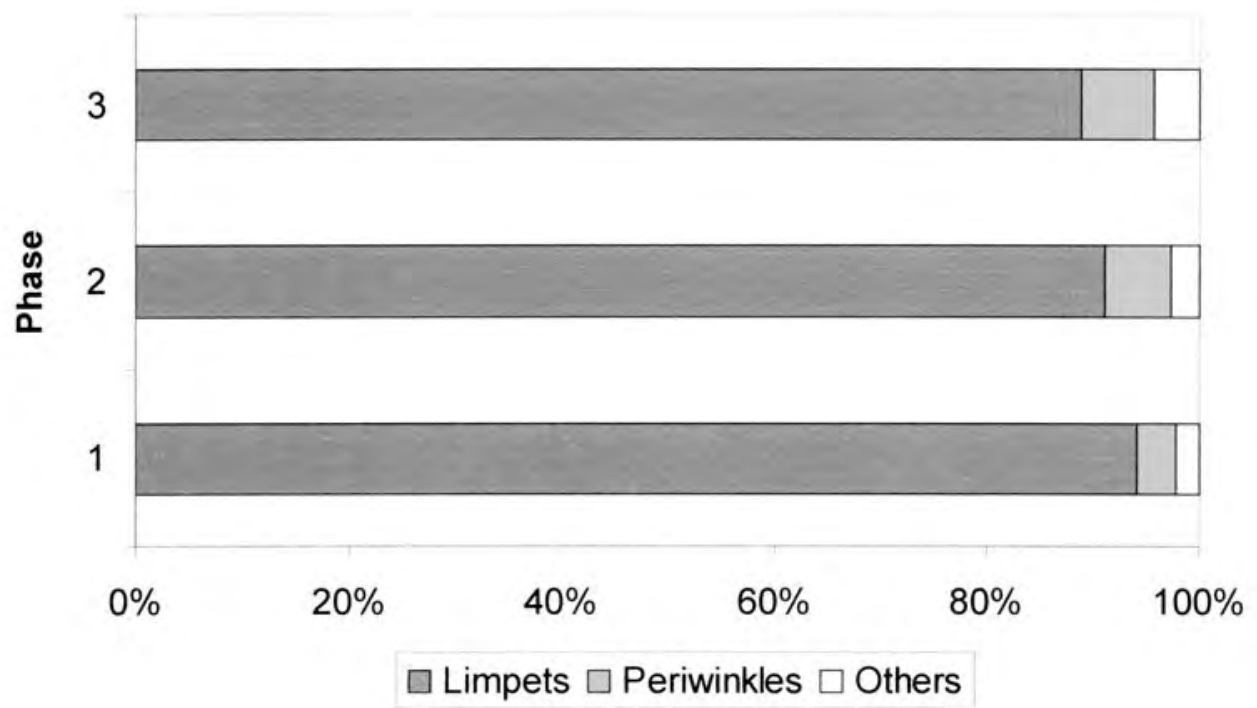

Illus 49 Temporal changes in the frequencies of limpets, periwinkles and other shellfish. 

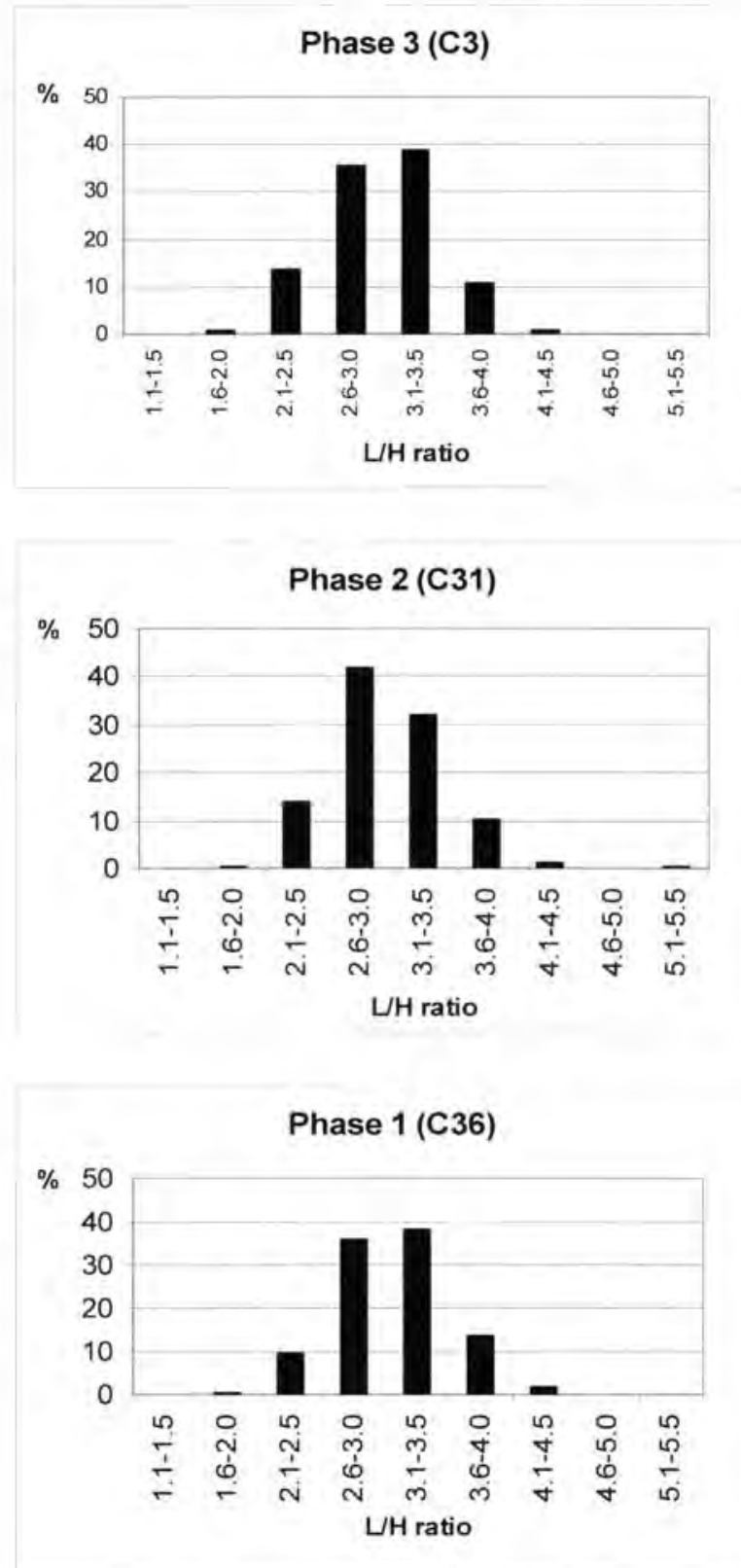

Illus 50 Frequency histograms of length/height ratios $(L / H)$ of limpet shells from successive phases.

The results are presented in Table 28. For the gastropods, MNI (minimum number of individuals) was derived by counting the apices; for the bivalves, MNI was obtained by counting the 'umbo' fragments and dividing the total by two.

In addition, measurements were taken on the complete shells of limpets, edible periwinkles and dog-whelks following the procedures adopted by Russell et al (1995). These data are presented in Tables 29-31 and illus 49-50.

\subsection{Results-discussion and interpretation}

Since some of the samples analysed are extremely small ( $<500$ identifiable specimens), sampling bias is a potential problem. This is reflected in the fact that a significant degree of correlation was noted between sample size and number of species represented. Because of the small size of many of the samples and the lack of information on the stratigraphic positions of the samples, the results are discussed by context rather than individual samples. Interpretation of the data is further constrained by poor chronological resolution and by a lack of information on modern shellfish populations in the vicinity of the An Corran site and local shore ecology in general.

\subsubsection{Species representation}

TheAn Corran deposits contain shells from at least 14 species of marine molluscs. Some shells, for example limpets, could not be identified at the species level, and so the actual number of species present may be greater. Of the fourteen species identified, eleven are present in Phase 1 (C34, C36, C37 \& C40), eleven in Phase 2 (C31, C38 \& C39), but only eight occur in Phase 3 (Cl-C4). Notable absentees from the youngest deposits (C1-C4) are Arctica islandica, Pecten maximus and Trivia monacha, which in the earlier phases appear to have been collected occasionally as empty shells for use as raw material (see below).

The shells deposited in the An Corran site all come from species which normally inhabit rocky shorelines, and all can be found today around the coasts of central-west Scotland. There is no reason to suppose, therefore, that any of the shellfish was not collected in the vicinity of the site.

\subsubsection{Exploitation patterns}

Limpets (Patella spp.) predominate among the species represented in all of the contexts sampled. This is a consistent feature of prehistoric shell middens on or near rocky shores in western Scotland, including so-called 'Obanian' sites (cf Russell et al 1995). Comparing only the richest contexts from each phase (those with $>1000$ identifiable shells), there is evidence of a slight decline in the importance of limpets over time - the proportion of limpets is highest in Phase 1 (C36 - 94\%) and lowest in Phase $3(\mathrm{C} 3-89 \%)$. There is a corresponding increase in the proportion of the edible periwinkle (Littorina littorea), rising from $3.7 \%$ in C36 (Phase 1) to 6.9\% in C3 (Phase 3) (illus 49).

Shells of dog-whelk (Nucella lapillus) and common mussel (Mytilus edulis) occur in relatively small numbers in all phases (never exceeding $4 \%$ and $1 \%$ of the total, respectively). In some contexts, shells of mussels are outnumbered by those of rarer species of Littorina (L. mariae, L. saxatilis, L. obtusata), the larger specimens of which may have been collected incidentally in the search for L. littorea.

For reasons discussed elsewhere (Jones 1985; 
Table 28 Occurrence of marine molluscs in the archaeological contexts sampled

\begin{tabular}{|c|c|c|c|c|c|c|c|c|}
\hline \multirow[t]{2}{*}{ PHASE 3} & \multicolumn{2}{|c|}{ Context 1} & \multicolumn{2}{|c|}{ Context 2} & \multicolumn{2}{|c|}{ Context 3} & \multicolumn{2}{|c|}{ Context 4} \\
\hline & MNI & $\%$ & MNI & $\%$ & MNI & $\%$ & MNI & $\%$ \\
\hline Patella spp. & 78 & 97.50 & 588 & 76.09 & 2541 & 88.88 & 212 & 91.77 \\
\hline Littorina littorea & 2 & 2.50 & 174 & 22.48 & 197 & 6.89 & 17 & 7.35 \\
\hline Nucella lapillus & & & 5 & 0.65 & 94 & 3.29 & 1 & 0.44 \\
\hline Mytilus edulis & & & 1 & 0.13 & 16 & 0.56 & & \\
\hline Littorina mariae & & & & & 7 & 0.24 & 1 & 0.44 \\
\hline Littorina saxatilis & & & 3 & 0.39 & 1 & 0.03 & & \\
\hline Littorina obtusata & & & 1 & 0.13 & 1 & 0.03 & & \\
\hline Gibbula umbilicalis & & & 2 & 0.26 & 2 & 0.07 & & \\
\hline Trivia monacha & & & & & & & & \\
\hline Pecten maximus & & & & & & & & \\
\hline Modiolis modiolis & & & & & & & & \\
\hline Littorina neritoides & & & & & & & & \\
\hline Gibbula sp. & & & & & & & & \\
\hline Arctica Islandica & & & & & & & & \\
\hline Unidentified apex & & & & & & & & \\
\hline Burnt shell & & & & & & & & \\
\hline Acorn barnacle & & & & & & & & \\
\hline TOTAL & 80 & & 774 & & 2859 & & 231 & \\
\hline
\end{tabular}

\begin{tabular}{|c|c|c|c|c|c|c|}
\hline \multirow[t]{2}{*}{ PHASE 2} & \multicolumn{2}{|c|}{ Context 31} & \multicolumn{2}{|c|}{ Context 38} & \multicolumn{2}{|c|}{ Context 39} \\
\hline & MNI & $\%$ & MNI & $\%$ & MNI & $\%$ \\
\hline Patella spp. & 11110 & 91.04 & 127 & 84.11 & 318 & 94.93 \\
\hline Littorina littorea & 757 & 6.20 & 18 & 11.92 & 9 & 2.69 \\
\hline Nucella lapillus & 275 & 2.25 & 5 & 3.31 & 5 & 1.49 \\
\hline Mytilus edulis & 7 & 0.06 & 1 & 0.66 & 2 & 0.60 \\
\hline Littorina mariae & 17 & 0.14 & & & 1 & 0.29 \\
\hline Littorina saxatilis & 19 & 0.16 & & & & \\
\hline Littorina obtusata & 13 & 0.11 & & & & \\
\hline Gibbula umbilicalis & 1 & 0.01 & & & & \\
\hline Trivia monacha & 2 & 0.02 & & & & \\
\hline \multicolumn{7}{|l|}{ Pecten maximus } \\
\hline Modiolis modiolis & 2 & 0.02 & & & & \\
\hline \multicolumn{7}{|l|}{ Littorina neritoides } \\
\hline \multicolumn{7}{|l|}{ Gibbula sp. } \\
\hline Arctica Islandica & 1 & 0.01 & & & & \\
\hline \multicolumn{7}{|l|}{ Unidentified apex } \\
\hline \multicolumn{7}{|l|}{ Burnt shell } \\
\hline \multicolumn{7}{|l|}{ Acorn barnacle } \\
\hline TOTAL & 12204 & & 151 & & 335 & \\
\hline
\end{tabular}

\begin{tabular}{|c|c|c|c|c|c|c|c|c|}
\hline \multirow[t]{2}{*}{ PHASE 1} & \multicolumn{2}{|c|}{ Context 34} & \multicolumn{2}{|c|}{ Context 36} & \multicolumn{2}{|c|}{ Context 37} & \multicolumn{2}{|c|}{ Context 40} \\
\hline & MNI & $\%$ & MNI & $\%$ & MNI & $\%$ & MNI & $\%$ \\
\hline Patella spp. & 724 & 87.97 & 10843 & 94.16 & 252 & 82.62 & 2 & 100.00 \\
\hline Littorina littorea & 64 & 7.78 & 425 & 3.69 & 36 & 11.80 & & \\
\hline Nucella lapillus & 22 & 2.67 & 199 & 1.73 & 12 & 3.93 & & \\
\hline Mytilus edulis & 10 & 1.22 & 17 & 0.15 & 2 & 0.66 & & \\
\hline Littorina mariae & & & 18 & 0.16 & 1 & 0.83 & & \\
\hline Littorina saxatilis & 2 & 0.24 & 1 & 0.01 & & & & \\
\hline Littorina obtusata & & & 4 & 0.03 & 1 & 0.33 & & \\
\hline Gibbula umbilicalis & & & 5 & 0.04 & & & & \\
\hline \multicolumn{9}{|l|}{ Trivia monacha } \\
\hline Pecten maximus & 1 & 0.12 & 1 & 0.01 & & & & \\
\hline \multicolumn{9}{|l|}{ Modiolis modiolis } \\
\hline Littorina neritoides & & & 1 & 0.01 & & & & \\
\hline Gibbula sp. & & & & & 1 & 0.33 & & \\
\hline \multicolumn{9}{|l|}{ Arctica Islandica } \\
\hline Unidentified apex & & & 1 & 0.01 & & & & \\
\hline \multicolumn{9}{|l|}{ Burnt shell } \\
\hline \multicolumn{9}{|l|}{ Acorn barnacle } \\
\hline TOTAL & 823 & & 11515 & & 305 & & 2 & \\
\hline
\end{tabular}


Table 29 Length measurements of limpet (Patella spp.) shells

\begin{tabular}{|c|c|c|c|c|c|c|}
\hline Context & Sample & Number & Mean length & Standard deviation & Smallest & Largest \\
\hline 1 & & 45 & 3.9 & 0.39 & 3.2 & 4.6 \\
\hline 2 & & 231 & 3.5 & 0.50 & 2.4 & 5.4 \\
\hline 3 & & 442 & 3.0 & 0.55 & 1.9 & 5.1 \\
\hline 4 & & 87 & 4.2 & 0.57 & 2.5 & 5.5 \\
\hline 31 & & 3 & 2.8 & 0.39 & 2.4 & 3.3 \\
\hline 31 & BB 1 & 2 & 3.6 & 0.10 & 3.5 & 3.6 \\
\hline 31 & BB $1 / 2$ & 7 & 3.2 & 0.69 & 2.4 & 4.4 \\
\hline 31 & BB $2 / 3$ & 237 & 3.0 & 0.53 & 1.9 & 4.3 \\
\hline 31 & BB 4 & 8 & 2.7 & 0.55 & 2.2 & 3.7 \\
\hline 31 & BB $4 / 5$ & 137 & 2.9 & 0.51 & 2.0 & 4.4 \\
\hline 31 & BB 6 & 382 & 2.9 & 0.49 & 1.7 & 4.5 \\
\hline 31 & BB $7 / 8$ & 8 & 2.6 & 0.45 & 2.1 & 3.4 \\
\hline 31 & Col A & 71 & 2.9 & 0.49 & 2.0 & 4.4 \\
\hline 31 & $\mathrm{CoIA}(\mathrm{a})$ & 108 & 3.0 & 0.56 & 1.9 & 4.7 \\
\hline 34 & & 123 & 3.0 & 0.49 & 2.0 & 4.8 \\
\hline 36 & $\mathrm{C} 36$ & 16 & 2.9 & 0.38 & 2.3 & 3.7 \\
\hline 36 & Col B & 175 & 2.8 & 0.48 & 1.9 & 4.3 \\
\hline 36 & $\mathrm{Col} \mathrm{B}(\mathrm{a})$ & 172 & 2.9 & 0.50 & 2.0 & 4.6 \\
\hline 36 & Col C(a) & 170 & 2.9 & 0.51 & 1.9 & 4.5 \\
\hline 36 & Col D & 915 & 2.8 & 0.49 & 1.7 & 5.4 \\
\hline 36 & $\mathrm{Col} \mathrm{D(a)}$ & 238 & 2.8 & 0.43 & 1.9 & 4.8 \\
\hline 36 & $\mathrm{Col} \mathrm{E}$ & 460 & 3.0 & 0.53 & 1.6 & 5.3 \\
\hline 36 & Col E(a) & 136 & 3.0 & 0.55 & 2.0 & 4.6 \\
\hline 36 & $\mathrm{Col} \mathrm{F}$ & 15 & 2.8 & 0.54 & 2.1 & 3.8 \\
\hline 36 & $\mathrm{Col} \mathrm{F}(\mathrm{a})$ & 119 & 2.8 & 0.50 & 1.9 & 4.4 \\
\hline 36 & $\mathrm{Col} \mathrm{G}$ & 241 & 2.9 & 0.49 & 1.9 & 4.7 \\
\hline 36 & $\mathrm{Col} \mathrm{G(a)}$ & 189 & 2.8 & 0.51 & 1.9 & 4.8 \\
\hline 36 & $\mathrm{Col} \mathrm{H}$ & 322 & 2.8 & 0.42 & 1.9 & 4.1 \\
\hline 36 & Col I & 166 & 2.8 & 0.59 & 2.0 & 4.1 \\
\hline 36 & $\mathrm{Col} \mathrm{I}(\mathrm{a})$ & 153 & 2.8 & 0.45 & 2.0 & 4.4 \\
\hline 36 & Col J & 59 & 2.7 & 0.51 & 2.0 & 4.8 \\
\hline 36 & Col J(a) & 48 & 2.8 & 0.49 & 2.0 & 4.6 \\
\hline 37 & & 6 & 3.4 & 0.40 & 3.0 & 4.0 \\
\hline 38 & & 2 & 3.5 & 0.16 & 3.3 & 3.6 \\
\hline 39 & & 18 & 3.2 & 0.44 & 2.5 & 4.2 \\
\hline
\end{tabular}

Russell et al 1995), the shape of a limpet's shell (reflected in the length/height ratio) is a useful indicator of the shore zone from which the animal was collected. At An Corran, the vast majority of limpet shells from most of the contexts sampled have $\mathrm{L} / \mathrm{H}$ ratios in the range 2.6-3.5 (illus 50). Time did not permit the acquisition of modern comparative samples from the shore below the site, but comparison of these results with archaeological and modern data from Ulva (Russell et al 1995) and Oronsay
(Jones 1985) suggests that the limpets, the shells of which occur in the various midden deposits at An Corran, were obtained mainly from the middle and lower zones of the shore.

The collecting strategy implied by these data may be a reflection of the relative ease with which limpets may be harvested at lower shore positions, where rock-pools are more frequent and of longer duration and conditions generally damper. Jones (1984) has presented evidence to suggest that the meat from 
Table 30 Length measurements of periwinkle (Littorina littorea) shells

\begin{tabular}{|c|c|c|c|c|c|c|}
\hline Context & Sample & Number & Mean length & Standard deviation & Smallest & Largest \\
\hline 1 & & 2 & 2.7 & 0.35 & & \\
\hline 2 & & 162 & 2.5 & 0.40 & 1.8 & 3.5 \\
\hline 3 & & 95 & 2.4 & 0.36 & 1.6 & 3.1 \\
\hline 4 & & 13 & 2.8 & 0.30 & 2.3 & 3.2 \\
\hline 31 & $\mathrm{BB} 1 / 2$ & 3 & 2.7 & 0.06 & & \\
\hline 31 & BB $2 / 3$ & 135 & 2.6 & 0.39 & 0.9 & 3.4 \\
\hline 31 & BB 3 & 1 & 2.3 & & & \\
\hline 31 & BB 4 & 21 & 2.5 & 0.24 & 1.7 & 2.9 \\
\hline 31 & $\mathrm{BB} 4 / 5$ & 13 & 2.7 & 0.20 & 2.4 & 3.0 \\
\hline 31 & BB 6 & 256 & 2.4 & 0.36 & 1.4 & 3.4 \\
\hline 31 & Col A & 4 & 2.6 & 0.26 & 2.2 & 2.8 \\
\hline 36 & C36 & 14 & 2.4 & 0.27 & 1.9 & 2.8 \\
\hline 36 & Col B & 5 & 2.7 & 0.30 & 2.5 & 3.3 \\
\hline 36 & Col B(a) & 14 & 2.6 & 0.23 & 2.3 & 3.2 \\
\hline 36 & Col D & 75 & 2.6 & 0.34 & 1.8 & 3.2 \\
\hline 36 & Col D(a) & 6 & 2.7 & 0.31 & 2.3 & 3.1 \\
\hline 36 & Col E & 32 & 2.6 & 0.23 & 2.0 & 2.9 \\
\hline 36 & Col F & 15 & 2.4 & 0.28 & 2.1 & 3.0 \\
\hline 36 & Col F(a) & 7 & 2.5 & 0.16 & 2.7 & 2.3 \\
\hline 36 & Col G & 10 & 2.6 & 1.47 & 1.4 & 3.4 \\
\hline 36 & $\mathrm{Col} \mathrm{H}$ & 21 & 2.6 & 0.26 & 2.1 & 3.1 \\
\hline 36 & Col I & 70 & 2.5 & 0.30 & 1.5 & 2.9 \\
\hline 36 & Col J & 9 & 2.4 & 0.18 & 2.2 & 2.6 \\
\hline 36 & Col J(a) & 17 & 2.5 & 0.18 & 2.2 & 2.8 \\
\hline 37 & & 24 & 2.5 & 0.20 & 1.8 & 3.1 \\
\hline 38 & & 13 & 2.4 & 0.20 & 2.0 & 2.8 \\
\hline 39 & & 7 & 2.6 & 0.22 & 2.3 & 3.0 \\
\hline
\end{tabular}

limpets collected on the upper shore may be less palatable to humans than that from limpets inhabiting the lower reaches of the shore - this argument, however, presupposes that the shellfish were gathered primarily for human consumption rather than for use as bait (see below). That some collecting did take place on the upper shore is suggested by the occurrence of a few limpets with unusually 'tall' shells in many contexts and the occasional presence of shells of the rough periwinkle (L. saxatilis).

It is interesting that the $\mathrm{L} / \mathrm{H}$ ratio of limpets from C4 has a different distribution from those from other contexts, with over 35 per cent of the shells having $\mathrm{L} / \mathrm{H}$ ratios in the range 1.6 to 2.0. Possible explanations for this pattern are that many of the shells were gathered from the upper shore, or that collection coincided with a prolonged period of unusually severe weather conditions - under stormy conditions, even limpets that live continually below the water line have to attach strongly to the rock to prevent dislodging by wave action, hence their shells become more conical in shape (Yonge 1972). This latter explanation, however, is at variance with the results of analyses of the shell-length-to-aperturelength ratio of dog-whelk shells (see below).

Clear evidence of temporal variation in shellfish exploitation patterns is difficult to identify among the An Corran data. As noted above, there are some minor changes over time in the proportions of the main species exploited (illus 49). Tables 29-31 present the average sizes of shells of limpet, periwinkle and dog-whelk for each sample examined. The average length of the periwinkle and dogwhelk shells remains consistent throughout the deposits. But some variation is evident in the size of limpets. Average length is relatively high $(>3.2 \mathrm{~cm})$ in $\mathrm{C} 1, \mathrm{C} 2$ and $\mathrm{C} 4$, which are among the more recent deposits excavated. Several samples from the earlier deposits (C37 and C38, and one sample from C31) show similarly high values, but these samples are extremely small and therefore more prone to sampling bias. One explanation for the pattern seen in the later contexts is that they represent collecting episodes which followed prolonged periods when 
Table 31 Length measurements of dog-whelk (Nucella lapillus) shells

\begin{tabular}{|c|c|c|c|c|c|c|}
\hline Context & Sample & Number & Mean length & Standard deviation & Smallest & Largest \\
\hline 2 & & 5 & 2.5 & 0.24 & 2.2 & 2.8 \\
\hline 3 & & 36 & 2.5 & 0.26 & 2.1 & 3.4 \\
\hline 4 & & 1 & 2.8 & & & \\
\hline 31 & BB 2/3 & 29 & 2.7 & 0.32 & 1.8 & 3.7 \\
\hline 31 & BB 3 & 2 & 2.6 & & & \\
\hline 31 & BB 4 & 1 & 2.8 & & & \\
\hline 31 & $\mathrm{BB} 4 / 5$ & 1 & 3.0 & & & \\
\hline 31 & BB 6 & 47 & 2.7 & 0.30 & 1.9 & 3.3 \\
\hline 31 & BB 7/8 & 2 & 2.9 & & & \\
\hline 31 & $\mathrm{CoI} A(a)$ & 1 & 2.9 & & & \\
\hline 34 & & 6 & 2.7 & 0.24 & 2.2 & 2.9 \\
\hline 36 & C36 & 5 & 2.6 & 0.21 & 2.4 & 3.0 \\
\hline 36 & Col B & 3 & 2.6 & 0.24 & 2.3 & 2.9 \\
\hline 36 & Col B(a) & 1 & 2.6 & & & \\
\hline 36 & Col C(a) & 1 & 2.9 & & & \\
\hline 36 & Col D & 16 & 2.8 & 0.32 & 2.2 & 3.3 \\
\hline 36 & Col E & 5 & 2.7 & 0.31 & 2.1 & 3.0 \\
\hline 36 & Col F & 3 & 2.7 & 0.16 & 2.5 & 2.9 \\
\hline 36 & $\mathrm{Col} F(\mathrm{a})$ & 3 & 2.9 & 0.26 & 2.7 & 3.3 \\
\hline 36 & Col G(a) & 1 & 2.9 & & & \\
\hline 36 & Col H & 2 & 2.7 & & & \\
\hline 36 & Col I & 10 & 2.5 & 0.16 & 2.5 & 2.9 \\
\hline 36 & Col J & 6 & 2.6 & 0.32 & 2.2 & 3.1 \\
\hline 36 & Col J(a) & 7 & 2.5 & 0.14 & 2.3 & 2.6 \\
\hline 37 & & 5 & 2.6 & 0.29 & 2.4 & 2.9 \\
\hline 38 & & 1 & 2.7 & & & \\
\hline 39 & & 2 & 2.7 & & & \\
\hline
\end{tabular}

the shellfish were essentially free from human predation. Conversely, the character of the (probably much older) Mesolithic and Neolithic/EBA (Phases 1-2) deposits suggests that they relate to periods in the history of the site when shellfish-gathering was a more frequent activity.

\subsubsection{Shore exposure}

The shell-length-to-aperture-length ratio of dogwhelk shells provides an indicator of local shore conditions. Studies elsewhere have shown a close relationship between shore exposure conditions and the overall shapes of dog-whelk shells (Crothers 1985; Kitching 1985). Dog-whelks inhabiting sheltered parts of the shoreline tend to have elongated shells with narrow apertures, this form providing a better defence against predation by crabs, which are more abundant on such shores. By contrast, dog-whelks living in more exposed locations, where crabs are less common, have wider apertures and more squat forms.

Differences were noted between the shell length/ aperture length ratio of modern dog-whelks and those from 'Obanian' shell middens on Oronsay (Andrews et al 1987) and Ulva (Russell et al 1995), indicating that local shore exposure conditions during the Mesolithic differed from those at the present day. In the case of Oronsay, this was linked to variations in storm frequency during the Holocene, whereas in the case of Ulva, it was attributed to changes in the configuration of the shoreline, resulting from sealevel movements.

A similar analysis was undertaken of the complete dog-whelk shells from the various contexts at An Corran. No significant differences were found between the contexts. From this, it may be concluded that no major changes in local shore exposure conditions occurred over the time-range represented by the samples analysed. However, the lack of comparative data for modern dog-whelks from the 
shore below the site, and the absence of radiocarbon determinations for many contexts, hinder further discussion of this topic.

\subsubsection{Processing methods}

The main species represented at An Corran - limpet, edible periwinkle, dog-whelk and common mussel - are all known to have been exploited in the past as human food, although recent ethnohistorical evidence from Scotland also points to the widespread use of limpets as fish bait (Fenton 1984).

Among ethnographically-known coastal communities in many parts of the world, processing of shellfish for human consumption often involved cooking. Most forms of cooking (e.g. boiling, baking) may leave no traces on the shells (Waselkov 1987). However, the reported presence of ash and charcoal in the deposits at An Corran, and the sporadic occurrence of burnt shell fragments in the samples examined, are consistent with this activity.

The easiest and most efficient way of extracting meat from bivalves is by roasting, and mussels were often processed in this way. Periwinkles are easier to remove from their shells if the animal is first killed by immersion in boiling water, and the large number of intact periwinkles recovered from the An Corran deposits suggests some form of cooking to aid meat extraction. The same applies to limpets, although experiments have shown that they are not difficult to remove from their shells without boiling (Griffitts \& Bonsall 2001).

Gastropods may be broken to aid extraction of the meat, and it is interesting that the dog-whelk shells from An Corran are more fragmentary than those of periwinkles. Since dog-whelks have thicker, more robust shells than periwinkles, this evidence suggests deliberate breakage of the dog-whelk shells rather than post-depositional damage. Breakage of dog-whelk shells suggestive of processing was also observed in the midden in Ulva Cave (Russell et al 1995).

Deith (1989) has suggested that a high incidence of broken shells in archaeological deposits is indicative of collection of the shellfish for use primarily as bait. She argued that breakage often results in small fragments of shell adhering to the meat, rendering it less palatable to humans. Ethnographic studies, however, suggest that shellfish can be eaten even with shell fragments in the meat, and often are (Waselkov 1987). Dog-whelks, moreover, have a very distinctive taste that is often preferred to that of limpets and periwinkles, and in western Scotland they may have been collected primarily to add variety to the diet (Jones 1984).

\subsubsection{Taphonomic considerations}

In their analysis of the Ulva Cave midden, Russell et al (1995) found many very small shells of marine molluscs, including L. littorea, $N$. lapillus and Helcion pellucidum (blue-rayed limpet), which they argued were too small to have been collected as food or bait, and had probably reached the site attached to seaweed on which the animals often live. It was suggested that the seaweed had been collected for use in food processing, either as fuel or for 'wrapping' around fish or shellfish prior to baking in open fires. This interpretation was supported by the presence of pieces of vitreous slag in the midden, thought to have resulted from the burning of seaweed.

Some of the very small shells found in the An Corran deposits may have reached the site by a similar mechanism. For example, flat periwinkle (L. obtusata) is present in small numbers in many contexts. This species inhabits the zone of fucoid seaweeds on which it feeds, and small specimens (which are evident in the samples) often attach themselves to seaweed for safety. Acorn barnacles, the calcareous plates of which are well-represented in the larger samples examined, are also likely to have been transported to the site unintentionally, attached to objects such as stones, pieces of seaweed, driftwood or shells of marine molluscs.

\subsubsection{Shell artefacts}

Many coast-dwelling communities, known from both the archaeological and ethnographic records, made use of shells for the manufacture of artefacts of various kinds (Stewart 1973; Waselkov 1987). A limited range of artefacts made from marine shells occurs in 'Obanian' sites on Oronsay and elsewhere in western Scotland. These include shells of scallops (Pecten maximus) with manufactured perforations and/or modified edges, and shells of the European cowrie (Trivia monacha) which had been perforated, possibly for use as ornaments (Mellars 1987, 124).

At An Corran, two cowrie shells were recovered from C31 and fragments of scallop shells from C31, C34 and C36. None of these specimens shows clear signs of having been humanly modified, but it is possible that they were collected for use as raw material - Pecten maximus usually lives in fairly deep water, but the empty shells often wash up on the shore and are readily available for collection. The single valve of Arctica islandica found in C31 may also have been an empty shell picked up on the shore. It is interesting that all these specimens occurred in deposits assigned to the first two (Mesolithic and Neolithic/EBA) phases, and that no examples of these species were identified from the latest phase.

\subsection{Conclusions}

The shellfish represented at An Corran were probably all collected from the shore within a short distance of the site. Limpets predominate in each 
of the contexts sampled, and they were clearly the main species exploited during all phases in the use of the site. However, there is some evidence of a slight decline in the importance of limpets over time, and a corresponding increase in the importance of periwinkles. Analysis of the shape of the limpet shells suggests that they were normally collected from the middle and lower shore.

Most of the shellfish represented in the deposits were probably collected for human consumption, but some (especially limpets) may also have been used as bait for fishing. A minority of the shells (especially those from very small animals) probably reached the site unintentionally attached to materials such as seaweed or stones brought from the shore.

Evidence for the processing methods used is limited. The presence of charcoal and other traces of burning in the deposits is consistent with processing activities involving cooking, and there is some (circumstantial) evidence for intentional breakage of the shells of dog-whelks, probably to extract the meat.

No evidence was found for the deliberate modification of shells for use as tools or ornaments, but cowrie shells, as well as fragments of scallop shells, and a single valve of Arctica islandica, from early (Mesolithic and Neolithic/EBA) contexts, may have been collected as raw material for artefacts.

The archaeological deposits at An Corran evidently represent a considerable period of time, but there were few indications from the marine molluscan analyses of temporal variations in shellfish-collecting patterns, or major changes in shore exposure conditions during that period. 


\section{FLOTATION SAMPLES, by Timothy G Holden, with contributions by Stephen Carter and Jennifer Miller}

\subsection{Introduction}

Thirty-five flotation samples were received for the purpose of assessing the potential of the charred and other remains for palaeoenvironmental and palaeoeconomic analysis (Table 32). The samples were rapidly scanned under the binocular microscope and the composition of each recorded. The $>4 \mathrm{~mm}$ fraction, containing the larger fragments of charcoal, was then separated for charcoal analysis. Twenty randomly chosen charcoal fragments from each of thirty different contexts were used to provide a record of the species composition. An additional scan of each sample was also undertaken in order to determine whether there were any obvious fragments of other species that may only have been present in small quantities. During scanning, apical fragments of terrestrial snail shells were removed and identifications of these made by Stephen Carter.

\subsection{Uncharred remains}

Low levels of uncharred plant and insect remains were noted in a high proportion of samples (Table 32). These included beetles, insect pupae, leaves, stem fragments from mosses and higher plants, bud scales and occasional roots. In most samples, they are present in only small quantities, indicating a low level of contamination, which would be compatible with the activities of invertebrates. However, C36 had one uncarbonised animal dropping, possibly rabbit or ovicaprine, and C4 contained large quantities of leaf fragments. These two samples would therefore appear to have been contaminated, possibly through small mammal burrows.

The low level of contamination observed in most samples is not expected to affect significantly the interpretation of the remains. It should, however, be taken into account wherever particularly low numbers of small artefacts or ecofacts were recovered from contaminated contexts.

\subsection{Charred plant remains}

With the exception of wood charcoal (see below), the plant remains are dominated by two categories of material, hazel-nut shell (Corylus avellana) and cleavers (Galium aparine) (Table 32). The first of these is likely to represent a wild food resource, deliberately collected and brought to the site for processing and consumption. Discarding of the nut shells into the fire is an obvious means of disposal and must account for the high proportion of these encountered amongst the wood charcoal, although charred hazel-nut shells have also been associated with the deliberate roasting of nuts (e.g. Duvensee 6, Bokelmann 1983, Abb. 41-42). The second taxoncleavers - is a common plant of modern hedgerows, scree and maritime shingle (Clapham et al 1962). It is of no use as a food plant and is more likely to have arrived at the site incidentally. The hooked fruits, stems and leaves of cleavers readily adhere to hair and clothing and they are likely to have grown close to the site.

The remaining plant material consists of a low concentration of small fruits and seeds. Restricted numbers of these were removed for assessment and

Table 32 Material recovered from the flotation samples

\begin{tabular}{|c|c|c|c|c|c|c|c|}
\hline Context & Seeds & $\begin{array}{c}\text { Cleavers } \\
\text { fruits }\end{array}$ & $\begin{array}{c}\text { Hazel } \\
\text { shell }\end{array}$ & $\begin{array}{l}\text { Charcoal } \\
\text { quantity }\end{array}$ & $\begin{array}{c}\text { Charcoal } \\
\text { AMS }\end{array}$ & $\begin{array}{c}\text { Modern } \\
\text { plant }\end{array}$ & Vesicular material \\
\hline 3 & & & & ++ & $*$ & + & \\
\hline 4 & & +++ & & ++++ & $*$ & & + \\
\hline 31 & + & +++ & +++ & ++++ & $*$ & + & + \\
\hline 34 & + & & & ++++ & $*$ & & \\
\hline 36 & + & + & + & ++++ & $*$ & + & + \\
\hline 37 & & & + & + & $*$ & & \\
\hline 38 & & & & ++ & $*$ & & \\
\hline 39 & & & & ++ & $*$ & & \\
\hline 40 & + & + & + & ++++ & $*$ & & \\
\hline
\end{tabular}

Legend: + = rare $++=$ occasional $;+++=$ common; $++++=$ abundant; $*$ = sufficient for an AMS date 
identified as somewhat eroded labiates (dead-nettle family) and other common weedy genera.

\subsection{Terrestrial snail shell}

As can be seen from Table 33, snail shell was recovered from 17 samples, including all of those from Column 1. This pattern may, however, be partially due to the different ways in which samples were processed. Eleven different taxa were recovered. The taxa recorded in Table 33 represent a group of terrestrial molluscs that would be typical of moist rubble habitats on generally acid soils. An assemblage such as this is very similar to that which might be expected from the modern fauna at An Corran. This represents a potentially welldated early assemblage of snails. Such assemblages are very rare in Scotland and therefore provide important information regarding the evolution of the modern fauna.

\subsection{Vesicular fragments}

Seventeen samples contained carbonised material that was vesicular in character (Table 32). These could represent either the burnt remains of a mixed organic material, such as faeces or well-processed food remains, or a material that does not readily survive charring, either because it has a delicate structure, it was wet when charred, or it is oil-rich this might include materials such as seaweed, plant roots and tubers or animal products.

\subsection{Charcoal}

The results of the charcoal analysis are presented in Table 34. Although a high proportion of the charcoal fragments are much smaller than those ideally used for identification purposes, it proved possible to identify the majority from a single longitudinal section. Considering the small sample size, the assemblage is relatively diverse, with
Table 33 Terrestrial snail species*

\section{Aegopinella pura \\ Carychium tridentatum \\ Clausilia bidentata \\ Cochlicopa lubrica \\ Discus rotundatus \\ Lauria cylindracea \\ Nesovitrea hammonis \\ Oxychilus sp. \\ Spermodea lamellata \\ Vitrea contracta \\ Zonitoides excavatus}

*Terrestrial snails were present in contexts C2, C3, C4, C31, C34, C36, C39 and C40.

four genera positively identified. Willow (Salix sp.), hazel (Corylus avellana) and birch (Betula sp.) are well represented in the majority of samples. Lesser quantities were also identified from the Pomoideae, a sub-family which includes rowan, hawthorn, apple and pear, and Prunus, a genus which includes the cherry and blackthorn. The small size of many fragments precluded a more specific identification, apart from two fragments that could be blackthorn (Prunus cf spinosa).

The taxa represented do not indicate the selection of any particular species and, in view of this, they are likely to provide a reasonably representative picture of the local environment. Pollen analyses on the Trotternish peninsula, primarily on cores from Loch Cleat, have already enabled Birks \& Williams (1983) to postulate the presence of a birch and hazel scrub vegetation with willow, rowan and cherry between the 9th and 7th millennia BP (cf Green \& Edwards 2007; Lowe \& Walker 1991). This scrub cover is entirely consistent with the charcoal results from An Corran. If the Loch Cleat data can be extrapolated further to the area around An Corran, then localised areas of more open grassland and tall herbs may also have been present.

Table 34 List of charcoal identifications (J. Millar)

\begin{tabular}{|c|c|c|c|c|c|c|c|c|c|c|}
\hline Context & Betula & Corylus & $\begin{array}{l}\text { Corylus } \\
\text { nutshell }\end{array}$ & Pomoideae & Prunus & $P$ cf spinosa & Salix & cf Prunus & cf Pomoideae & Indet. \\
\hline 3 & 1 & 9 & & & 2 & & 8 & & & \\
\hline 4 & 15 & 2 & & & & & 3 & & & \\
\hline 31 & 49 & 65 & 5 & 36 & 16 & 2 & 42 & 2 & & 4 \\
\hline 34 & & 12 & & 8 & & & & & & \\
\hline 36 & 29 & 67 & 1 & 33 & 12 & & 84 & & & \\
\hline 37 & 3 & 10 & 3 & & & & & & & 4 \\
\hline 38 & 4 & 2 & & 1 & & & & & & 13 \\
\hline 39 & & & & & & & & & 1 & 19 \\
\hline 40 & 6 & 1 & & 10 & & & & & & \\
\hline
\end{tabular}




\subsection{Conclusions}

The flotation samples from An Corran provided a number of valuable pieces of information. The charcoal data place the site within, or close to, areas of birch, hazel and willow scrub. Areas of rocky disturbed ground close to the cliff are also indicated by the snail fauna and the limited seed identifications undertaken to date. Birks (Birks \& Williams 1983) has commented that the postglacial forest history of Skye corresponds to present-day distribution of woodland fragments on the island. The evidence presented here tends to support this, indicating that the environment around An Corran in the 8th millennium BP and later was not very different from that found in the wooded valleys and sheltered areas of the coast below $200 \mathrm{~m}$ today.

Addendum. Small numbers of fish otoliths were also recovered from the flotation samples as follows:

C31 gadid 1; cod 2; pogge (bullhead) 1; pollack 1; saithe 8

C34 cod 1; pollack 1, saithe 1

C36 pollack 1; saithe 10

C37 pollack 1; saithe 2

C39 saithe 1 


\section{RADIOCARBON DATES, by Alan Saville and Karen Hardy}

In total, 18 radiocarbon dates have been obtained from An Corran. One initial date (OxA-4994) was carried out at the Oxford University Radiocarbon Accelerator Unit in 1994 (Saville \& Miket 1994a; 1994b), ten dates were carried out by the Scottish Universities Research and Reactor Centre between 1997 and 1998 at the AMS facility of the University of Arizona (Saville 1998), and a further seven dates were obtained more recently from Oxford by Nicky Milner (Bronk Ramsey et al 2009, 330; Milner \& Craig 2009, table 15.1).

Six dates were taken from bevel-ended tools, one from a bone point, five from human bones, two from pig, three from aurochs and one from

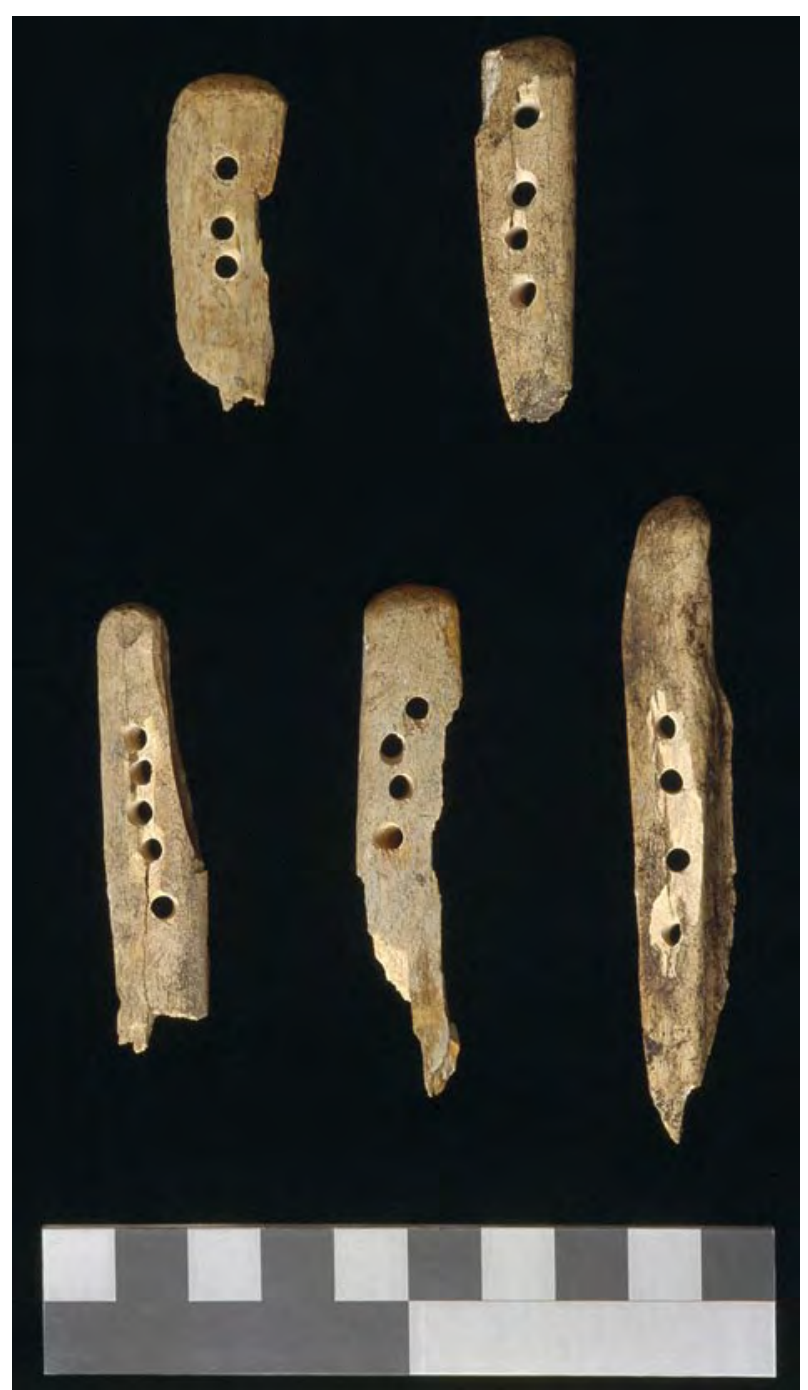

Illus 51 Radiocarbon-dated bevel-ended tools (after sampling). Upper row: left CAT 6, right CAT 70. Lower row: left CAT 52, centre CAT 26, right CAT 76. Scale $=100 \mathrm{~mm}$ (photo: Alan Saville) an unspecified ruminant (illus 51-52). Table 35 presents all the determinations from An Corran in descending 'stratigraphic' order of the contexts from which the samples derived. All the dates in this table are given as uncalibrated radiocarbon years BP (i.e. before AD 1950). In Table 36 these determinations are presented in descending chronological sequence on the basis of their age in calibrated years BC.

Two of the determinations are on burnt animal bones (AA-27745 \& 27746) and both of these are from $\mathrm{C} 41$. This was the basal context from which no unburnt bone survived, so the burnt samples were, reluctantly, used for dating. It has to be concluded that the results from these burnt samples are probably unreliable and neither result accurately dates the bones themselves nor the context, and they should probably be ignored.

Nevertheless, the other dates show a significant lack of cohesion, even within individual contexts. Assuming all the determinations, apart from those from $\mathrm{C} 41$, are themselves accurate, there are at least four possible reasons for the diversity of dates within individual contexts. First of all, the nature and speed of the excavation, and the difficult conditions under which it was carried out, may have led to inadvertent misidentification of contexts. Secondly, due to these same difficult conditions, some samples may have become incorrectly labelled. Thirdly, the lowest layers of An Corran (C31-38) may have become mixed at some time in antiquity - either by accident or design. And fourthly, bioturbation and disturbance of various kinds could account for the movement of bones and artefacts between contexts. We have no specific reasons for suggesting the first two reasons apply, and therefore incline towards a combination of the other two as the explanation.

The human remains clearly demonstrate the difficulties of using the An Corran radiocarbon dates to understand the Mesolithic activity. Four of these pieces (three from C31 and one from C36) have 4th millennium BC Neolithic ages which overlap at the 95.4 per cent confidence level. The fifth piece, again from C36, has a mid-3rd millennium $\mathrm{BC}$ age which separates it entirely from the other four, and allows for interpretation as either Late Neolithic or Early Bronze Age. One possibility which might explain the presence of the human remains in these contexts is that they had been deliberately intruded into them.

This potential complexity indicated by the position of the human remains is further compounded by the dates for the bevel-ended tools from C31, C36 and C38, which range from the 
Table 35 Uncalibrated radiocarbon determinations BP in descending 'stratigraphic' order

\begin{tabular}{|c|c|c|c|c|c|}
\hline Lab. No. & $\begin{array}{l}\text { Catalogue } \\
\text { No. }\end{array}$ & $\delta \mathrm{C} 13$ & Material & Context & BP (uncal) \\
\hline AA-27744 & AC/HB0628 & $-20.2 \%$ & $\begin{array}{l}\text { human bone } \\
\text { (metatarsal III) }\end{array}$ & C31 & $4405 \pm 65$ \\
\hline AA-29311 & AC/BT0076 & $-23.3 \%$ & bevelled tool (red deer) & C31 & $4175 \pm 60$ \\
\hline AA-29314 & AC/BT0052 & $-20.6 \%$ & bevelled tool (ruminant) & C31 & $3975 \pm 50$ \\
\hline OxA-13549 & AC/HB0627 & $-19.4 \%$ o & $\begin{array}{l}\text { human bone } \\
\text { (navicular tarsal) }\end{array}$ & C31 & $4650 \pm 55$ \\
\hline OxA-13550 & AC/HB0632 & $-20.5 \%$ & $\begin{array}{l}\text { human bone } \\
\text { (vertebra) }\end{array}$ & C31 & $4360 \pm 55$ \\
\hline OxA-14753 & $\mathrm{AC} / \mathrm{AB} 0713$ & $-21.6 \%$ & animal bone, rib (bovine) & C34 & $7525 \pm 45$ \\
\hline AA-27743 & $\mathrm{AC} / \mathrm{HB} 0270$ & $-24.0 \%$ & human bone (ulna) & C36 & $3885 \pm 65$ \\
\hline AA-29312 & AC/BT0102 & $-22.0 \%$ & bone point (roe deer) & $\begin{array}{l}\text { C36 } \\
\text { Col.1:SH }\end{array}$ & $2045 \pm 60$ \\
\hline AA-29315 & АC/BT0026 & $-21.3 \%$ & bevelled tool (red deer) & $\mathrm{C} 36$ & $5190 \pm 55$ \\
\hline AA-29316 & AC/BT0006 & $-20.6 \%$ & bevelled tool (ruminant) & C36 & $6215 \pm 60$ \\
\hline OxA-4994 & AC/BT0044 & $-21.6 \%$ & bevelled tool (red deer) & C36 (base) & $7590 \pm 90$ \\
\hline OxA-13551 & AC/HB0143 & $-21.5 \%$ & animal bone, rib (pig)* & C36 & $7485 \pm 55$ \\
\hline OxA-13552 & AC/HB0458 & $-19.9 \%$ & human bone (vertebra) & C36 & $4535 \pm 50$ \\
\hline OxA-14751 & $\mathrm{AC} / \mathrm{AB} 0132$ & $-22.3 \%$ & $\begin{array}{l}\text { animal bone, lumbar } \\
\text { vertebra (bovine) }\end{array}$ & C36 & $7555 \pm 45$ \\
\hline OxA-14752 & $\mathrm{AC} / \mathrm{AB} 0178$ & $-22.0 \%$ & $\begin{array}{l}\text { animal bone, radius } \\
\text { (bovine) }\end{array}$ & C36 & $7595 \pm 50$ \\
\hline AA-29313 & AC/BT0070 & $-23.9 \%$ & bevelled tool (red deer) & C38 & $3660 \pm 65$ \\
\hline AA-27745 & $\mathrm{AC} / \mathrm{AB} 0675$ & $-26.0 \%$ & $\begin{array}{l}\text { animal bone, proximal phalanx (pig; } \\
\text { burnt) }\end{array}$ & $\mathrm{C} 41$ & $3120 \pm 60$ \\
\hline AA-27746 & $\mathrm{AC} / \mathrm{AB} 0678$ & $-22.8 \%$ & $\begin{array}{l}\text { animal bone, unident. long } \\
\text { bone (ruminant; burnt) }\end{array}$ & $\mathrm{C} 41$ & $6420 \pm 75$ \\
\hline
\end{tabular}

* Originally identified as a human rib fragment, subsequently reclassified as pig (see Bronk Ramsey et al 2009: 330)

7 th millennium $\mathrm{BC}$ to the 3 rd or 2 nd millennia $\mathrm{BC}$. These dates not only pre- and post-date the human bone dates from the same contexts, but they also, at the recent end, fall entirely outside the chronological framework for the Mesolithic in Scotland. Although bevel-ended bone tools have generally been perceived as a Mesolithic tool type, these dates clearly indicate that bevel-ended bone tools were also in use during the Neolithic and into the Bronze Age period (cf Saville 2004a, 204).

The three dated bovine bones from C34-36 form a close grouping within the 7 th millennium $\mathrm{BC}$ and are presumably therefore from aurochsen, whilst the pig rib bone from C36 also dates to the 7th millennium $\mathrm{BC}$ and is presumably from a wild boar.

The most elaborate of the bone points (CAT 102), which was identified typologically as of probable Iron Age date, has reassuringly been confirmed as such by the radiocarbon age of $336-78$ cal вс. The fact that this implement comes from C36, well below the potentially earlier Late Bronze Age/ Early Iron Age copper-alloy pin from C17, further confirms the stratigraphic difficulties.

Irrespective of the more recent items, the determinations which fall within the Mesolithic period are themselves diverse. They range from the 7 th to the 5th millennia for C36, and this makes it impossible to allocate individual non-dated bone tools within this range, let alone chronologically discriminate amongst the flaked stone tools. The latter can in effect be regarded as undated by the radiocarbon dates. This is doubly unfortu- 
Table 36 Calibrated radiocarbon dates $\mathrm{BC}$ in descending chronological sequence

\begin{tabular}{|c|c|c|c|c|c|c|}
\hline Lab. No. & $\begin{array}{l}\text { Catalogue } \\
\text { No. }\end{array}$ & $\delta \mathrm{C} 13$ & Material & Context & $\begin{array}{l}\text { BP } \\
\text { (uncal) }\end{array}$ & cal $\mathrm{BC}$ \\
\hline OxA-4994 & $\begin{array}{l}\text { AC/ } \\
\text { BT0044 }\end{array}$ & $-21.6 \%$ & $\begin{array}{l}\text { bevelled tool } \\
\text { (red deer) }\end{array}$ & $\begin{array}{l}\text { C36 } \\
\text { (base) }\end{array}$ & $7590 \pm 90$ & $6607-6247$ \\
\hline OxA-14752 & $\begin{array}{l}\mathrm{AC} / \\
\mathrm{AB} 0178\end{array}$ & $-22.0 \%$ & $\begin{array}{l}\text { animal bone, } \\
\text { radius (bovine) }\end{array}$ & C36 & $7595 \pm 50$ & $6588-6378$ \\
\hline OxA-14751 & $\begin{array}{l}\mathrm{AC} / \\
\mathrm{AB} 0132\end{array}$ & $-22.3 \%$ & $\begin{array}{l}\text { animal bone, } \\
\text { lumbar vertebra } \\
\text { (bovine) }\end{array}$ & C36 & $7555 \pm 45$ & 6480-6264 \\
\hline OxA-14753 & $\begin{array}{l}\text { AC/ } \\
\text { AB0713 }\end{array}$ & $-21.6 \%$ & $\begin{array}{l}\text { animal bone, rib } \\
\text { (bovine) }\end{array}$ & C34 & $7525 \pm 45$ & $6462-6256$ \\
\hline OxA-13551 & $\begin{array}{l}\text { AC/ } \\
\text { HB0143 }\end{array}$ & $-21.5 \%$ & $\begin{array}{l}\text { animal bone, rib } \\
\text { (pig)* }\end{array}$ & C36 & $7485 \pm 55$ & $6440-6240$ \\
\hline AA-27746 & $\begin{array}{l}\mathrm{AC} / \\
\mathrm{AB} 0678\end{array}$ & $-22.8 \%$ & $\begin{array}{l}\text { animal bone, } \\
\text { unident. long bone } \\
\text { (ruminant; burnt) }\end{array}$ & $\mathrm{C} 41$ & $6420 \pm 75$ & $5517-5225$ \\
\hline AA-29316 & $\begin{array}{l}\text { AC/ } \\
\text { BT0006 }\end{array}$ & $-20.6 \%$ & $\begin{array}{l}\text { bevelled tool } \\
\text { (ruminant) }\end{array}$ & C36 & $6215 \pm 60$ & $5312-5018$ \\
\hline AA-29315 & $\begin{array}{l}\text { AC/ } \\
\text { BT0026 }\end{array}$ & $-21.3 \%$ & $\begin{array}{l}\text { bevelled tool } \\
\text { (red deer) }\end{array}$ & C36 & $5190 \pm 55$ & 4229-3807 \\
\hline OxA-13549 & $\begin{array}{l}\text { AC/ } \\
\text { HB0627 }\end{array}$ & $-19.4 \%$ & $\begin{array}{l}\text { human bone } \\
\text { (navicular tarsal) }\end{array}$ & C31 & $4650 \pm 55$ & $3632-3196$ \\
\hline OxA-13552 & $\begin{array}{l}\text { AC/ } \\
\text { HB0458 }\end{array}$ & $-19.9 \%$ & $\begin{array}{l}\text { human bone } \\
\text { (vertebra) }\end{array}$ & C36 & $4535 \pm 50$ & 3488-3035 \\
\hline AA-27744 & $\begin{array}{l}\text { AC/ } \\
\text { HB0628 }\end{array}$ & $-20.2 \%$ & $\begin{array}{l}\text { human bone } \\
\text { (metatarsal III) }\end{array}$ & C31 & $4405 \pm 65$ & 3335-2903 \\
\hline OxA-13550 & $\begin{array}{l}\text { AC/ } \\
\text { HB0632 }\end{array}$ & $-20.5 \%$ & $\begin{array}{l}\text { human bone } \\
\text { (vertebra) }\end{array}$ & C31 & $4360 \pm 55$ & $3316-2884$ \\
\hline AA-29311 & $\begin{array}{l}\text { AC/ } \\
\text { BT0076 }\end{array}$ & $-23.3 \%$ & $\begin{array}{l}\text { bevelled tool } \\
\text { (red deer) }\end{array}$ & C31 & $4175 \pm 60$ & 2896-2581 \\
\hline AA-29314 & $\begin{array}{l}\text { AC/ } \\
\text { BT0052 }\end{array}$ & $-20.6 \%$ & $\begin{array}{l}\text { bevelled tool } \\
\text { (ruminant) }\end{array}$ & C31 & $3975 \pm 50$ & 2621-2301 \\
\hline AA-27743 & $\begin{array}{l}\text { AC/ } \\
\text { HB0270 }\end{array}$ & $-24.0 \%$ & $\begin{array}{l}\text { human bone } \\
\text { (ulna) }\end{array}$ & C36 & $3885 \pm 65$ & 2566-2146 \\
\hline AA-29313 & $\begin{array}{l}\text { AC/ } \\
\text { BT0070 }\end{array}$ & $-23.9 \%$ & $\begin{array}{l}\text { bevelled tool } \\
\text { (red deer) }\end{array}$ & C38 & $3660 \pm 65$ & 2274-1881 \\
\hline AA-27745 & $\begin{array}{l}\text { AC/ } \\
\text { AB0675 }\end{array}$ & $-26.0 \%$ & $\begin{array}{l}\text { animal bone, } \\
\text { proximal phalanx } \\
\text { (pig; burnt) }\end{array}$ & $\mathrm{C} 41$ & $3120 \pm 60$ & 1517-1219 \\
\hline AA-29312 & $\begin{array}{l}\text { AC/ } \\
\text { BT0102 }\end{array}$ & $-22.0 \%$ & $\begin{array}{l}\text { bone point } \\
\text { (roe deer) }\end{array}$ & $\begin{array}{l}\text { C36 } \\
\text { Col.1:SH }\end{array}$ & $2045 \pm 60$ & $336-78$ \\
\hline
\end{tabular}

*Originally identified as a human rib fragment, subsequently reclassified as pig (see Bronk Ramsey et al 2009: 330)

Calibrations use OxCal 4.1 (Bronk Ramsey 2009) and IntCal 09 (Reimer et al 2009) and are expressed at 95.4\% confidence level. 


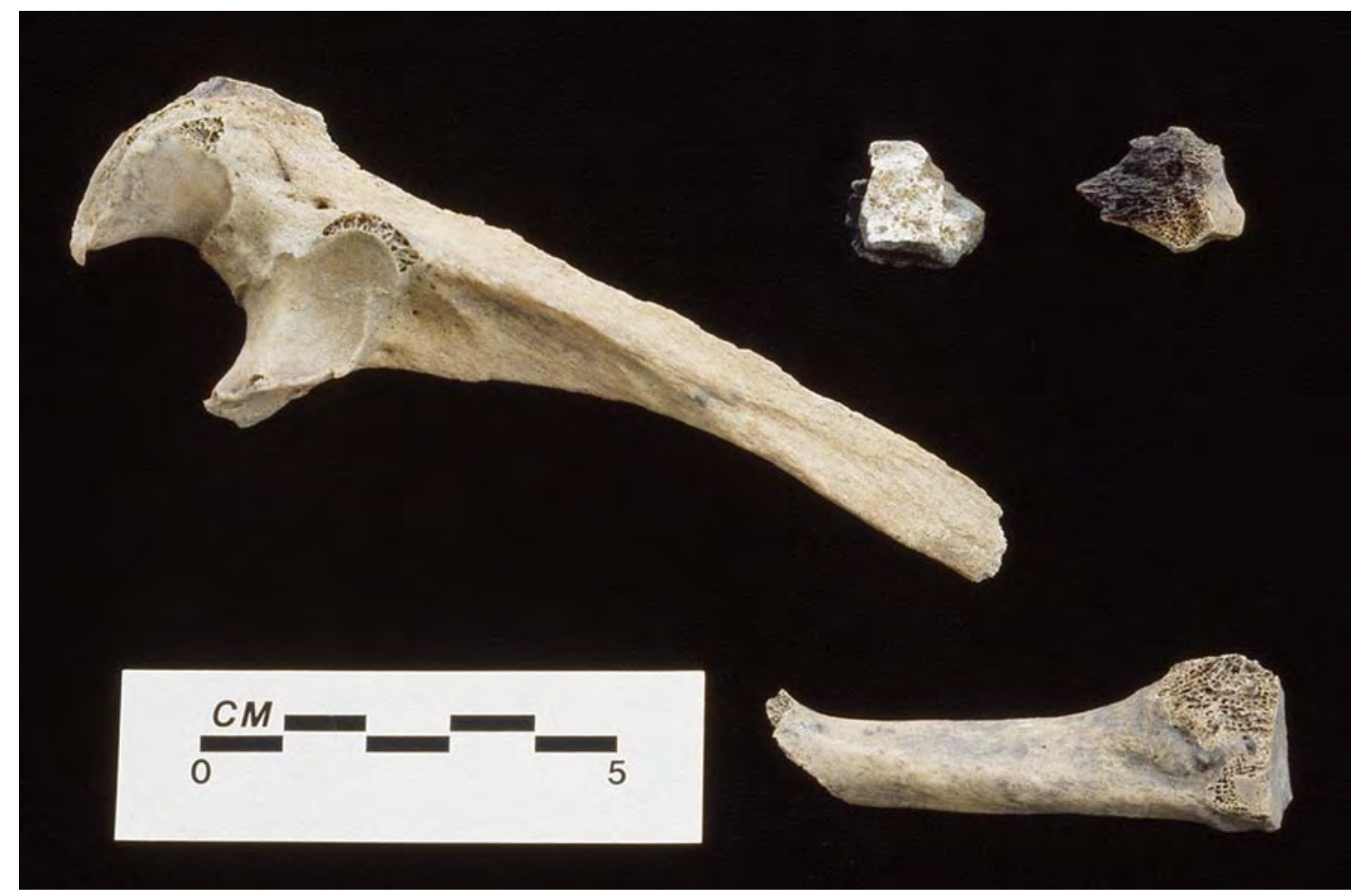

Illus 52 Radiocarbon-dated bones (before sampling). Larger bone: human ulna CAT 270, context 36 . Smaller bone: human metatarsal III CAT 628, context 31 (BB4). Burnt bone fragments: CAT $675 \& 678$, context 41 (photo: Alan Saville)

nate because of the typological indications, from the microliths in particular, for Early Mesolithic presence. The initial radiocarbon determination of $7590 \pm 90$ вр (OxA-4994), from the base of C36, was greeted with some surprise as it appeared to suggest that the typologically 'Early Mesolithic' microliths were 'Later Mesolithic' in date. It would now seem that it is more probable that none of the dated bones is necessarily indicative of the actual age of any of the lithic artefacts. 


\section{ISOTOPE ANALYSES, by Nicky Milner and Oliver Craig}

\subsection{Introduction}

The measurement of carbon $\left(\delta^{13} \mathrm{C}\right)$ and nitrogen $\left(\delta^{15} \mathrm{~N}\right)$ stable isotope ratios in bone collagen has become an important technique in palaeodietary studies. It has been widely applied to reconstruct past human diets from a range of geographical locations and periods. Unlike other forms of palaeodietary evidence, it provides a long-term record of an individual's diet. Studies also suggest that bone collagen isotopes predominantly reflect the protein portion of diet, although this may be modulated by overall nutritional status. Applied to the Mesolithic and Neolithic samples from north-west Europe, stable isotope analysis has been used to distinguish between marine and terrestrial consumers. Carbon derived from marine sources is enriched in $\delta^{13} \mathrm{C}$. Marine foods also tend to be at higher trophic levels than terrestrial foods and therefore are also enriched in $\delta^{15} \mathrm{~N}$. It should be stressed, however, that the absolute values can vary both temporally and geographically and therefore measurements of contemporary marine and terrestrial fauna are important to provide an accurate interpretation of human diets. The $\delta^{13} \mathrm{C}$ and $\delta^{15} \mathrm{~N}$ values of plant foods in the archaeological record are not well characterised (due to lack of preservation), although they may vary substantially, therefore herbivores are often used as proxies.

Stable sulphur isotope ratios $\left(\delta^{34} \mathrm{~S}\right)$ are also beginning to be applied to archaeological materials (Craig et al 2006; Richards et al 2001). Sulphur isotope analysis has proved useful in studies of complex food webs in modern marine and estuarine ecosystems. There is only a small offset between food and consumer, and large variations in the sulphur isotope ratios derived from different ecosystems and geographical locations. Marine producers have extremely uniform $\delta^{34} \mathrm{~S}$ values $(c+20 \%)$, consistent with values of oceanic sulphates, whereas $\delta^{34} \mathrm{~S}$ values of terrestrial and freshwater producers are much more variable $(c-20 \%$ to $+20 \%$ o), depending on local sources of sulphates. Richards et al (2001) have demonstrated that sulphur isotopes can be extracted from human bone collagen to discriminate marine and terrestrial diets and that sea spray and coastal precipitation, both high in marine sulphate, can also introduce marine sulphates into the terrestrial food chain (McArdle et al 1998).

\subsection{Sampling and methods}

The human skeletal remains were sampled initially

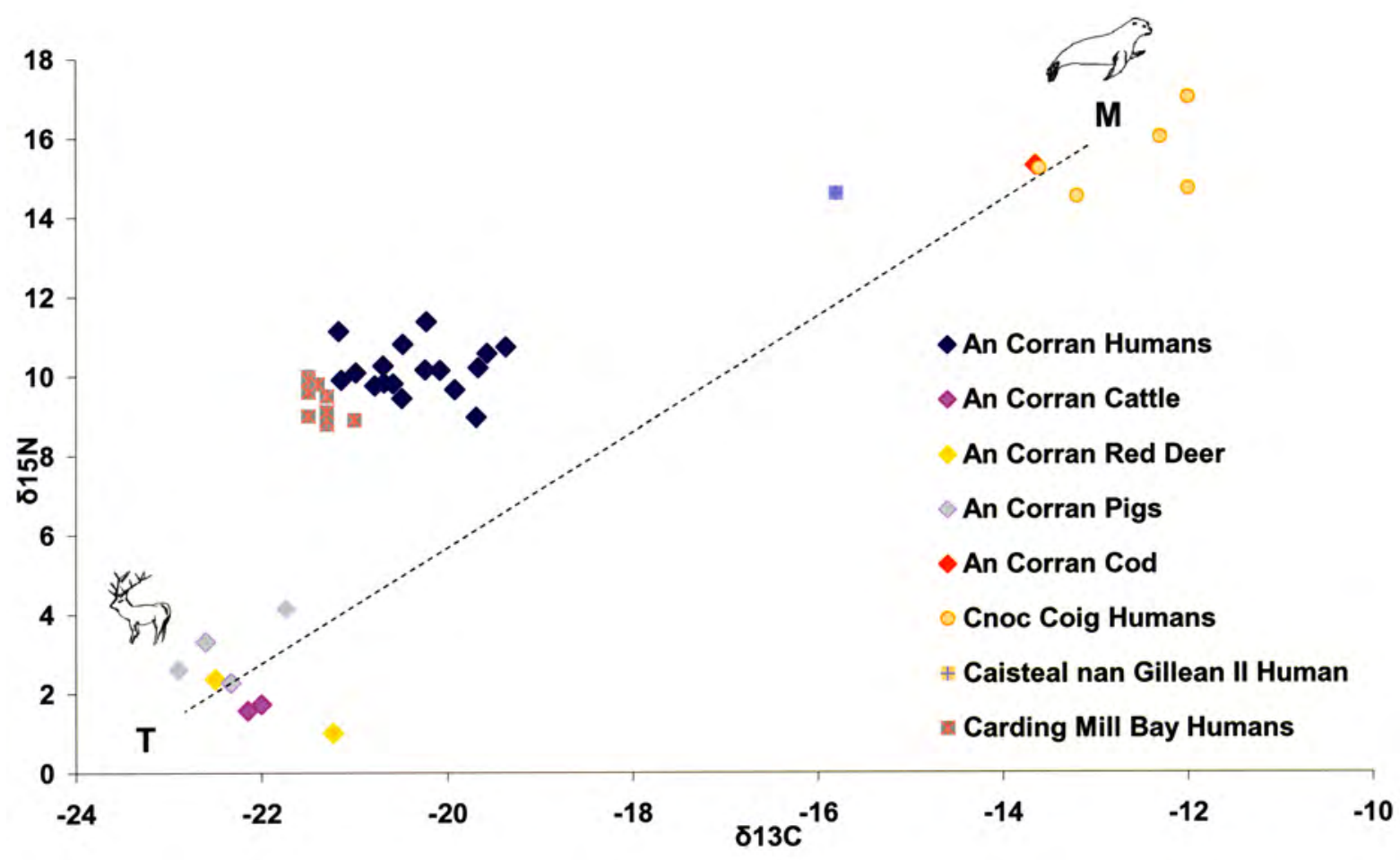

Illus 53 Divergent dietary signals from An Corran and other west coast of Scotland $\delta^{15} \mathrm{~N}$ and $\delta^{13} \mathrm{C}$ data. $T=$ terrestrial; $m$ = marine. 
Table 37 Stable isotope data

\begin{tabular}{|c|c|c|c|c|c|}
\hline Catalogue No. & Species & & Mean $\delta^{13} \mathbf{C}$ & Mean $\delta^{15} \mathbf{N}$ & Mean $\delta^{34} \mathbf{S}$ \\
\hline 0196 & Human & & -22.9 & 2.6 & \\
\hline 0143 & [Human] & juvenile, later identified as pig & -21.7 & 4.1 & 19.7 \\
\hline 0911 & Human & & -21.2 & 11.1 & \\
\hline 0278 & Human & & -21.1 & 9.9 & \\
\hline 0217 & Human & & -21.0 & 10.1 & \\
\hline 0631 & Human & & -20.7 & 10.3 & \\
\hline 0118 & Human & & -20.8 & 9.8 & \\
\hline 0283 & Human & small adult & -20.7 & 9.8 & \\
\hline 0632 & Human & mature adult $(<35)$ & -20.6 & 9.8 & 18.4 \\
\hline 0615 & Human & small adult & -20.5 & 9.4 & \\
\hline 0912 & Human & & -20.5 & 10.8 & \\
\hline 0458 & Human & mature adult (>40) & -20.2 & 10.2 & 18.1 \\
\hline 0572 & Human & & -20.2 & 11.4 & \\
\hline 0279 & Human & & -20.1 & 10.1 & \\
\hline 0627 & Human & & -19.9 & 9.7 & 18.4 \\
\hline 0125 & Human & & -19.7 & 9.0 & \\
\hline 0629 & Human & & -19.7 & 10.2 & \\
\hline 0628 & Human & & -19.6 & 10.6 & \\
\hline 0270 & Human & mature adult & -19.4 & 10.7 & \\
\hline 0113 & Pig & & -22.3 & 2.3 & \\
\hline 0156 & Pig & & -22.6 & 3.3 & \\
\hline 0096 & Red deer & & -21.2 & 1.0 & \\
\hline 0147-r & Red deer & & -22.5 & 2.4 & \\
\hline 0132-r & Cattle & & -22.2 & 1.6 & \\
\hline 0178-r & Cattle & & -22.0 & 1.7 & \\
\hline 0055-r & Cod & & -13.6 & 15.3 & \\
\hline
\end{tabular}

with the assumption/hope on our part that these were of Mesolithic date, given that much of the midden material dated to this period. In fact these samples turned out to date to the Neolithic (see dating section); however, they still provide useful information which can be used in wider palaeodietary debates (see Milner \& Craig 2009 for a discussion of the results in the wider context of the Mesolithic/Neolithic transition in this area).

The human skeletal assemblage at An Corran was highly fragmented, making assessment of the number of individuals represented by the assemblage difficult. Only a minimum of two adult individuals could be established through osteological analysis based on age criteria, out of thirty-nine bones recovered (see the human bone section above). Collagen was extracted from seventeen skeletal elements securely identified as adult human for stable isotope analysis. In addition, seven animal bones recovered from the An Corran midden horizons were included in the stable isotope analysis in order to establish the isotopic values associated with pure terrestrial and marine diets at this specific location, thus providing a framework for interpreting the human stable isotope data. These included terrestrial herbivores (two red deer, two cattle), terrestrial omnivores (two pig) and a marine fish (a single cod vertebra).

Carbon $\left(\delta^{13} \mathrm{C}\right)$ and nitrogen $\left(\delta^{15} \mathrm{~N}\right)$ stable isotope ratios were measured in all the extracted collagen samples using standard methods and procedures. In addition, sulphur isotope ratios $\left(\delta^{34} \mathrm{~S}\right)$ were measured in four of the samples (three humans and a pig).

\subsection{Results}

The results are presented in Table 37 and the carbon and nitrogen isotope data are plotted in illus 53 with other data from the west coast of Scotland. The results for CAT 143, which had been identified as human, appeared to indicate an individual with anomalous diet which plotted with the terrestrial animals. This bone was re-examined by Terry O'Connor and Don Brothwell and was confirmed 
(also in agreement with László Bartosiewicz) to be pig rather than human (see Table 37).

The stable isotope values of the other individuals indicate a predominantly terrestrial diet, supplemented with various amounts of marine products as indicated by slightly enriched $\delta^{13} \mathrm{C}$ values. These individuals consumed more marine foods than Neolithic humans from either Crarae (Schulting \& Richards 2002) or Carding Mill Bay (Connock et al 1992), but did not have 'extreme' marine diets that characterise the humans buried on Oronsay, particularly Cnoc Coig (Milner \& Craig 2009).

Another notable feature of the stable isotope data is that the human nitrogen isotope values are much higher than the terrestrial animal values at An Corran (Table 37; mean difference $=7.9 \%$, minimum difference $=4.8 \%$, maximum difference $=10.4 \%$ ). Although the exact values for $\delta^{15} \mathrm{~N}$ enrichment between humans and the foods they consume are unknown, values of between 3-5\% are usually assumed (see Hedges \& Reynard 2007 for a review of this issue). The nitrogen isotope data are therefore at odds with the interpretation of diet predominantly composed of terrestrial animals.

There may be several explanations for this discrepancy. First, the relatively high $\delta^{15} \mathrm{~N}$ values may imply a much greater level of high trophic marine food consumption at An Corran than suggested by the carbon isotope values. It should be noted that the possibility that carbon and nitrogen atoms in bone collagen are derived from different dietary sources, as this implies, has been given serious consideration, specifically in relation to dietary change at the Mesolithic/Neolithic transition (Hedges 2004; 2006; Milner et al 2004), but so far there is no consensus regarding the extent to which this may occur physiologically. Second, freshwater fish with generally high $\delta^{15} \mathrm{~N}$ values but much lower $\delta^{13} \mathrm{C}$ may have been a strong dietary component. This is perhaps less likely given the sites' coastal setting and the fact that salmon which may have been available in nearby rivers have strongly marine isotope signatures. As most of the animal bones dated were found to be several millennia older than the human remains (see Table 36) a final consideration is that the animal bones analysed from An Corran were not isotopically representative of the animals available to the humans at this time. To check this, stable isotope analysis was carried out on two bevel-ended bone tools both securely dated to after 4000 cal BC. The analysis revealed that the $\delta^{15} \mathrm{~N}$ values were similar to the other animals with earlier dates and therefore this does not seem a likely explanation for the high $\delta^{15} \mathrm{~N}$ values.

Marine sulphur values are found in all the collagen samples analysed. However, these also include a pig sample with terrestrial $\mathrm{C}$ and $\mathrm{N}$ values, indicating that sulphur was derived from sea-spray rather than through diet. The results indicate that the humans analysed lived on or near the coast, at least during the last ten years of their lives.

\subsection{Discussion}

There has been keen debate as to the rate and extent of the transition from wild foods to domestic plants and animals at the Mesolithic/Neolithic transition in this region. The data have been used to argue for a (more or less) complete shift from marine to terrestrial foods over a short space of time, reinvoking the possibility of colonisation by Neolithic populations with economies dedicated to agriculture and pastoralism. This theory has been criticised (Milner et al 2004) because the interpretation of the isotope data comes from a limited number of available samples, particularly for the Mesolithic period, which is only represented by two very late Mesolithic sites on Oronsay (Milner \& Craig 2009). However, the fact that human bones from the west coast of Scotland with dates later than 4000 cal $\mathrm{BC}$ have predominantly terrestrial stable carbon isotope signatures cannot be ignored. Furthermore, similar stable isotope data have been recorded from Neolithic coastal sites in England and Wales (Richards \& Hedges 1999; Schulting 2009).

Although the extent of consumption of marine versus other foods is difficult to assess, the stable isotope data from An Corran suggest that some marine foods were consumed by the humans buried there well into the 4th millennium. However, the only way to further elucidate palaeodiet and economic changes at this time is to conduct more studies on midden material, particularly in order to determine to what extent the middens were being formed in the 4 th millennium and also the timing of the introduction of domesticates. 


\section{GENERAL DISCUSSION, by Alan Saville and Karen Hardy}

Other than a few fragments of pottery dated to around 100-150 years ago, there is no clear indication of the date of the uppermost layers, which also contained a number of hearths. However, as with many caves and rockshelters in Scotland, it is to be expected that An Corran saw use as an expedient temporary shelter, workshop or dwelling by people throughout history (Hardy \& Wickham-Jones 2007; Leitch \& Smith 1997; Saville 2004b; Tolan-Smith 2001). The virtual absence of Iron Age to modern finds indicates that such use was never intensive and that, for example, it was never used for metalworking, as was the case at Rudh' an Dunain Cave, Skye (Scott 1934b), and caves in Argyll (Tolan-Smith 2001, 169) and on the Applecross peninsula (Hardy \& Wickham-Jones 2007). In this regard, however, it must be remembered that only a relatively small part of the rockshelter was sampled by excavation, and thus the picture obtained of activities at any stage of its use could be misleading.

The next temporal indicator occurs in context C17. A copper-alloy pin was found on the surface of this context. The pin has provisionally been dated typologically to the Late Bronze Age/Early Iron Age (c 800-400 BC) and is the first of its kind from Scotland. No other artefacts were found between C17 and C30, nor were there any other indications to suggest the use of the site at this time. However, the bone point from $\mathrm{C} 36$ which has been radiocarbon dated to 336-78 cal $\mathrm{BC}$ is a clear sign that other activity was taking place at An Corran during the Iron Age.

If the date of 1517-1219 cal $\mathrm{BC}$ obtained on the burnt pig bone from C41 is discounted as probably spurious (see the section on radiocarbon dates above), then the only indications of earlier Bronze Age usage of the site are one of the bevel-ended tools and a human bone, with dates of 2274-1881 and 2566-2146 cal BC respectively, and possibly another bevel-ended tool with an age of 2621-2301 cal BC, which is on the Late Neolithic/Early Bronze Age cusp (Table 36).

On the basis of the human bones which have been radiocarbon dated, it is assumed that almost all of the human remains at An Corran relate to the Neolithic period. It is further assumed that they signify inhumations which have been deliberately intruded into the pre-existing deposits within the rockshelter, or that the remains have become incorporated by natural processes following more superficial disposal of cadavers on the ledge (cf Hellewell 2011). As such they fit very neatly into the emerging pattern of evidence for Neolithic cave and rockshelter burial practice, particularly during the 4th millennium cal BC, throughout Britain (Cham- berlain 1996; Saville 2005, 358), but also locally on the west coast of Scotland (see especially the dates for human remains from Carding Mill Bay and Raschoille; Milner \& Craig 2009, 175). There are other instances of later re-use of middens for burial, both in Scotland (Connock et al 1992; Milner \& Craig 2009; Pollard 1990; Saville \& Hallén 1994) and further afield (e.g. Bjørnsholm, Denmark: Andersen 1991, 78). Since this mode of Neolithic burial is very widespread - indeed quite normal there is no reason to think that the association here with a Mesolithic midden site has any bearing on questions of the continuity of human groups across the millennia (cf Armit \& Finlayson 1992, 668-669). Whether Neolithic people used this rockshelter for purposes other than funerary must remain obscure without any other specific cultural indicators from this period, such as pottery or flintwork. In this respect it is of interest that none of the bevelled tools has been shown to date to the same mid-4th millennium cal $\mathrm{BC}$ period to which most of the human remains belong, but that they reappear, typologically unchanged, in the 3rd millennium cal BC (Table 36). This technological resurgence, which could be argued to reflect particular types of locally conditioned subsistence practices started in Mesolithic times, comes - at An Corran at least - after too wide a chronological gap for any conclusions to be drawn from it about continuity or transition.

The most recently dated of the An Corran human bones, at c 2566-2146 cal BC, relates to the Early Bronze Age period, and suggests there may have been at least two separate phases of burial. Cave and rockshelter burials of this period are less prolific than in the Neolithic, but they do occur, as at Carding Mill Bay, Oban (Connock et al 1992).

The semi- or sub-circular setting of stones found abutting the cliff-face at the top of C30 has no ready functional interpretation since there was nothing to differentiate the fill from the deposits surrounding it (illus 15 and 22). Whilst an interpretation as a hearth would seem the most feasible, there was no actual evidence in the form of charcoal, ash or burning of the stones to support this. The shape and diameter of this feature compare almost exactly with those of the stone settings from Lussa Wood, Jura (Mercer 1980; Wickham-Jones 2004; see also Hardy et al 2010), but in the An Corran case there is no evidence to indicate an association with Mesolithic activity.

Immediately below this setting lay the upper midden layers. These layers were all initially thought to be Mesolithic, based upon the artefacts present, but as previously explained the radiocarbon dates have shown the situation to be more com- 
plicated. Within the 'Mesolithic' horizon (C31-41) there are two different types of deposit. The upper layers (C31-39) are midden deposits, in that they are spatially restricted, variegated areas of shelly matrix with contained lithic artefacts, human and animal bones, bone tools, charcoal and some organic plant remains.

Contexts C40-41 and the basal part of context C36 do not fall into this pattern. Based upon the area excavated, they seem to be extensive horizontal layers which might spread across the whole ledge. The contents, particularly of C40-41, are quite different from the upper midden layers. They contain very few shells, have no bone tools and contain only a small amount of animal bone, much of it burnt. Between them they contain some 50 per cent of the lithic assemblage and most of the microliths and microburins.

The upper layers (C31-39) thus appear to represent a shell processing and lithic working site with an abundance of bone tools, while the lower layers (C40-41) predate the shell processing phase(s) but clearly relate to activity involving the manufacture and use of lithic artefacts. Taking the most diagnostic lithic artefacts, there are 32 microliths and 14 microburins in the An Corran assemblage (Table 11). Nine microliths and three microburins come from the midden contexts C31 and C36. Three microliths and one microburin come from the horizon at the base of C36, which lies directly below the midden. The remaining 20 microliths and 10 microburins come from the basal layers C40-41. Of the microliths from C31 there are two scalene triangles, one crescent, one bilaterally edgeblunted fine point and one unclassifiable fragment, and the microliths from C36 are a crescent and two unclassifiable fragments. The basal horizon of C36 contains two obliquely blunted points and one unclassifiable fragment, whilst the microliths from C40-41 are almost all broad blade, with the majority being obliquely blunted points, and including only one scalene triangle, from $\mathrm{C} 40$. Although it is not possible to make any rigid stratigraphic, typological or technological separation within the lithic assemblage, which is likely to be a palimpsest of material produced at times separated by centuries if not millennia, there is a distinct possibility that the basal layers contain 'Early' Mesolithic artefacts predominantly (in the case of $\mathrm{C} 41$ this could be expressed as a distinct probability), and the midden layers contain 'Later' Mesolithic predominantly.

Recent work has shown that in east-central
Scotland Mesolithic assemblages of Later Mesolithic, narrow blade type, are present by $c 8400 \mathrm{cal}$ BC (Saville 2008). In the west, the earliest date for the Later Mesolithic so far is rather later, around the middle of the 8th millennium cal BC at Kinloch, Rùm (Wickham-Jones 1990), and the earliest date in association with a shell midden is much later, at $c$ $7050-6500$ cal BC ( $7620 \pm 75$ BP; Ashmore \& WickhamJones 2007), at Sand, Lochalsh (NB the initially announced early date (OxA-10152) for a bevelled tool from Sand of $8470 \pm 90$ BP (7750-7200 cal BC; see Ashmore 2004, 102; Hardy 2001, 125; Saville 2004a, table 10.2) has now been withdrawn, see Ashmore \& Wickham-Jones 2007). A bevelled tool from Druimvargie rockshelter, Oban, another midden site, is dated to $c 7580-7180 \mathrm{cal} \mathrm{BC}(7890 \pm 80 \mathrm{BP}$; Bonsall et al 1995), but it is not associated with any microliths. The earliest dates from An Corran are another millennium later, in the mid-7th millennium cal $\mathrm{BC}$, and can be seen as in acceptable potential correlation with parts of the lithic assemblage, whilst accepting that the dated bone items could represent completely different phases of activity from those which produced the lithic artefacts.

Typologically, however, it can be argued that at least part of the lithic assemblage, most notably the obliquely blunted microliths, are out of character for such a late date, since comparable material has not been dated so late anywhere in the UK. All things being equal, it can be suggested on typo-chronological grounds that this Early Mesolithic, broad blade element of the An Corran assemblage is most likely to predate the mid-8th millennium cal BC, and possibly to predate the later 9th millennium cal BC date of the Cramond assemblage. Whilst some parallels can be seen in the Early Mesolithic microlithic assemblages from excavation and surface collection at Morton Farm, Fife (Candow 1989; Coles 1971), these contain a significant element of large isosceles triangle microliths, of which An Corran has only two. In some ways it is perhaps more similar to the microlithic inventory of Early Mesolithic North Yorkshire sites such as Flixton (Moore 1950, fig.4), which would align it with the so-called Star Carr assemblage type (Reynier 2005), dated to the middle of the 9th millennium cal BC or earlier.

In the absence of any dating evidence from layer C41 it is difficult to substantiate any further speculation on this point, but there does seem to be a strong chance that part of the An Corran assemblage represents the earliest Early Mesolithic type of lithic finds from Scotland. 


\section{CONCLUSION, by Alan Saville and Karen Hardy}

The location of An Corran would have been an excellent place for people who were dependent upon natural resources. The rockshelter was somewhat protected from wind and rain, even in mid-winter, and it lay adjacent to a headland yet slightly to the east of it, and was therefore protected from the extremes of westerly weather by the cliff above. Directly below was a small sandy beach with extensive areas of rocky foreshore to both sides. Opposite, less than $100 \mathrm{~m}$ out to sea, lay Staffin Island, the presence of which served to provide protection from the open sea and is associated with a small channel which would have been ideal for collecting crustaceans and in-shore fishing. Staffin Island, which also has traces of Mesolithic activity (K Hardy, pers comm), is home to seal colonies, and otters are frequently seen swimming in the channel between the island and the mainland. The rocky foreshore houses millions of shells and contains thousands of rock pools which could have been exploited as fish traps. Above, on the cliffs, birds still nest and the abundance of bird bones in the assemblage suggests their exploitation for food.

Less than $100 \mathrm{~m}$ from the site lay a large outcrop of baked mudstone, and the beach further to the west has chalcedony pebbles eroding out from the Trotternish escarpment and being brought down to the beach by the nearby Stenscholl River. These two sources provided most of the required lithic raw material, though some bloodstone was also imported. A small way up the river, large areas of marshland would have provided many useful resources such as reeds, while fish traps can still now be seen at the mouth of the river which lies only half a mile from An Corran. Above the cliff is a wide area of relatively flat, open land and about two miles to the west the Trotternish escarpment towers over everything. These inland areas would have been home to red deer and other terrestrial animals, all in easy reach of An Corran. Small pockets of trees still survive and the bone and charcoal assemblages suggest that the area nearby contained more trees than it does today.

The deposits at An Corran show evidence of having been repeatedly disturbed, most likely throughout antiquity (cf Scott 1934b). As a result there is much temporal mixing, which makes any interpretation of specific activity at the site difficult. The lithic artefacts suggest occupation during various times in the Mesolithic and without benefit of radiocarbon dating it might have been concluded that most of the other evidence for human presence at An Corran from prior to the horizon with the copperalloy pin (i.e. the bone tools, the human bones and the midden material) was also of Mesolithic date. However, the radiocarbon analyses make it clear that intermittent activity took place on the rockshelter throughout prehistory, from the Mesolithic to the Iron Age. Radiocarbon dating at An Corran has also been instrumental in decoupling the previously assumed association between bevel-ended bone and antler tools and the Mesolithic - this is a very long-lived tool type on the Scottish west coast (cf Saville 2004a). Reasons for use of the rockshelter obviously varied through time, as reflected most particularly by the human remains interpreted as the residue from burials.

In the final analysis, the significance of the snapshot provided by the chance opportunity to investigate the An Corran rockshelter is to point up once again the enormous potential that such sites have for studying Mesolithic economy and technology, and particularly in this case for examining the little understood Early Mesolithic phase of Scottish prehistory. Fortunately at An Corran, as a result of the exploratory work reported here, a substantial part of the ledge deposits survive, are protected, and could in the future be investigated further. At the several cave and rockshelter sites in the vicinity of Oban (Anderson 1895 \& 1898; Coles 1983; Connock 1985; Connock et al 1992), the archaeological response has, for various historical reasons, been largely too little too late (Pollard 1990). An Corran now provides a classic example of this kind of heritage asset, and the publication of this report should serve as a reminder to those responsible for curating and monitoring the archaeological resource that any cave or rockshelter with intact deposits warrants high priority, and that it is imperative that - if and when another site of this type becomes threatened by development or other factors - the appropriate level of archaeological response is applied. 


\section{ACKNOWLEDGEMENTS}

The field work at An Corran was organised and supervised by Roger Miket. Those who assisted in the excavation include June and Gareth Gerard, Louise Kerr, George Kozikowski, Keith Macleod, Elizabeth McNally, Thomas Rees and Martin Wildgoose. Thomas Rees and Martin Wildgoose undertook the site drawings, and Thomas Rees led in preparing the 1994 interim report. George and Alex Kozikowski are thanked for their help in sorting and washing the hand-collected artefacts. Sheila Boardman is acknowledged for undertaking sub-sampling and bulk sieving in Edinburgh. David Stephenson (BGS) and Brian Jackson (NMS) are thanked for their help in resolving some of the geological questions.

Thanks are due to the Scottish Office Agriculture and Fisheries Department for permission to excavate on their property and to the then Highland Region Department of Roads and Transport for access in advance of the removal of the cliff face. The Department of Roads and Transport provided a small grant towards the immediate costs of excavation and $\mathrm{Mr}$ S J MacNaughton, Assistant Director of the Department, was extremely helpful throughout. The late Bob Gourlay, formerly Highland Region Archaeologist, is thanked for liaising with the Department of Roads and Transport, Highland Regional Council, and with Dualchas, which arranged for the rescue excavation work to be undertaken.

Direct funding for post-excavation was provided by grants from Historic Scotland, Highland Regional Council, Highland Council and the Society of Antiquaries of Scotland, whilst National Museums Scotland, which acted as the coordinating institution and home base for the post-excavation project, provided a major contribution in kind. John Wood and Roger Miket at Highland Council, and Dr Richard Hingley at Historic Scotland, were extremely helpful over the acquisition of grant-aid. The final exercise to bring An Corran to publication was supported financially by Historic Scotland and National Museums Scotland, and at Historic Scotland thanks are due particularly to Patrick Ashmore, Dr Noel Fojut and Roderick McCullagh.

Numerous individuals have provided advice and other help during the post-excavation project, including Professor Clive Bonsall, Dr Ruby CerónCarrasco, Trevor Cowie, Dr Bill Finlayson, Ywonne Hallén, Dr Andrew Kitchener, George Kozikowski, Dr Nicola Murray, Dr Alison Sheridan, Martin Wildgoose and John Wood.

Initial radiocarbon dates were obtained from or via the SUERC laboratory with the help of Professor Gordon Cook, with funding provided by Historic Scotland with the help of Patrick Ashmore; and from the Oxford laboratory with the help of Dr Rupert Housley, funded by National Museums Scotland. Subsequent radiocarbon dates and stable isotope analyses were organised by Dr Nicky Milner of York University. The work undertaken by Dr Nicky Milner and Dr Oliver Craig was carried out as part of an AHRB funded study of shell middens and coastal palaeodiets (Grant \#: B/RG/AN1717/APN14658).

Trevor Cowie is very grateful to Katharina Becker (University of Bradford), Nick Dixon (the Scottish Crannog Centre), Adam Gwilt (National Museum of Wales), Susy Kirk (NMS) and Brendan O'Connor for help and information during the preparation of his report on the copper-alloy pin.

All the final site and location drawings in the report are by Alan Braby, as is that of the copper-alloy pin; all other artefact illustrations are by Marion O'Neil, and Craig Angus performed the necessary digital manipulation.

Finally, thanks are due to the anonymous peer reviewers for their comments on the previous version of this report. 


\section{REFERENCES}

Andersen, S H 1991 'Bjørnsholm: a stratified køkkenmødding on the central Limfjord, north Jutland', Journal of Danish Archaeology 10, 59-96.

Anderson, F W \& Dunham, K C 1966 The Geology of Northern Skye. Edinburgh: HMSO (Memoirs of the Geological Survey Scotland).

Anderson, J 1895 'Notice of a cave recently discovered at Oban, containing human remains, and a refuse-heap of shells and bone of animals, and stone and bone implements', Proceedings of the Society of Antiquaries of Scotland 29 (1894-95), 211-230.

Anderson, J 1898 'Notes on the contents of a small cave or rock-shelter at Druimvargie, Oban; and of three shell-mounds in Oronsay', Proceedings of the Society of Antiquaries of Scotland 32 (1897-98), 298-313.

Andrews, M V; Gilbertson, D D \& Kent, M 1987 'Storm frequencies along the Mesolithic coastline', in $\mathrm{P}$ Mellars, Excavations on Oronsay: Prehistoric Human Ecology on a Small Island, 108-114. Edinburgh: Edinburgh University Press.

Angel, H 1977 Life in Our Estuaries. Norwich: Jarrold Colour Publications (Jarrold Aquatic Life Series 2).

Armit, I 2006 Anatomy of an Iron Age Roundhouse: The Cnip Wheelhouse Excavations, Lewis. Edinburgh: Society of Antiquaries of Scotland.

Armit, I \& Finlayson, B 1992 'Hunter-gatherers transformed: the transition to agriculture in northern and western Europe', Antiquity 66, 664-676.

Ashmore, P 2004 'A date list (to October 2002) for early foragers in Scotland', in A Saville (ed.), Mesolithic Scotland and its Neighbours. The Early Holocene Prehistory of Scotland, its British and Irish Context and some Northern European Perspectives, 95-157. Edinburgh: Society of Antiquaries of Scotland.

Ashmore, P \& Wickham-Jones, C 2007 'Radiocarbon determinations in context', in K Hardy \& C Wickham-Jones (eds), Mesolithic and Later Sites around the Inner Sound, Scotland: the Work of the Scotland's First Settlers Project 1998-2004, section 4. Scottish Archaeological Internet Reports (SAIR) 31 [http://www.sair.org. uk/sair31].

Ballin, T B forthcoming 'The lithic assemblage', in I Suddaby Home Farm, Portree, Skye \& Lochalsh.

Ballin, T B; Saville, A; Tipping, R \& Ward, T 2010 'An Upper Palaeolithic flint and chert assemblage from Howburn Farm, South Lanarkshire, Scotland: first results'. Oxford Journal of Archaeology 29(4), 323-360.

Ballin Smith, B (ed) 1994 Howe: Four Millennia of Orkney Prehistory, Excavations 19781982. Edinburgh: Society of Antiquaries of Scotland.

Barnes, J A G (ed.) 1975 Birds of the British Isles and their Eggs. London/New York: Frederick Warne \& Co. Ltd.

Barrett, J; Nicholson, R \& Cerón-Carrasco, R 1997 'Archaeo-ichthyological evidence for long-term socioeconomic trends in northern Scotland: 3500 $\mathrm{BC}$ to $\mathrm{AD} 1500$ ', Journal of Archaeological Science $26,353-388$.

Bartosiewicz, L 1989 'Animal remains from the fort', in D Gabler (ed.), The Roman Fort of ÁcsVaspuszta (Hungary) on the Danubian Limes. Part II, 600-623. Oxford: BAR British Series, 531.

Bartosiewicz, L 2007 'Fish remains', in A Whittle (ed.), The Early Neolithic on the Great Hungarian Plain: Investigations of the Körös Culture Site of Ecsegfalva 23, County Békés I, 377-394. Budapest: Archaeological Institute of the Hungarian Academy of Sciences (Varia Archaeologica Hungarica 21).

Bartosiewicz, L \& Choyke, A M 1994 'Taxonomie und Typologie der Knochenartefakte von St Blaise', in M Kokabi \& J Wahl (eds.), Beiträge zur Archäozoologie und Prähistorischen Anthropologie, 263-268. Stuttgart: Konrad Theiss Verlag (Forschungen und Berichte zur Vor- und Frühgeschichte in Baden-Württemberg 53).

Bartosiewicz, L \& Gál, E 2007 'Sample size and taxonomic richness in mammalian and avian bone assemblages from archaeological sites', Archeometriai Mühely 2007(1), 37-44.

Bartosiewicz, L; Hertelendi, E \& Figler, A 1994 'Seasonal dating of hand-collected fish remains from a prehistoric settlement in Hungary', in W Van Neer (ed.), Fish Exploitation in the Past, 107-114. Tervuren: Koninklijk Museum voor Midden-Afrika (Annalen Zoologische Wetenschappen 274).

Bartosiewicz, L; Zapata, L \& Bonsall, C 2010, 'A tale of two shell middens: the natural versus the cultural in "Obanian" deposits at Carding Mill Bay, Oban, western Scotland', in T Peres \& A Van Derwarker (eds), Integrating Zooarchaeology and Paleoethnobotany, 205-225. New York: Springer.

Becker, K 2000 'Eisenzeitliche Ringkopfnadeln in Grossbritannien und Irland'. Unpublished MA thesis, University of Cologne/Köln.

Becker, K 2008 'Iron Age ring-headed pins in Ireland and Britain and on the Continent', Archäologisches Korrespondenzblatt, 38, 513-519.

Bell, B R \& Harris, J W 1986 An Excursion Guide to 
the Geology of the Isle of Skye. Glasgow: Geological Society of Glasgow.

Bencze, L 1979 A Vadállomány Fenntartásának Lehetöségei. Budapest: Akadémiai Kiadó.

Benn, D I 1991 'Raised shorelines on Skye', in C K Ballantyne; D I Benn; J J Lowe \& M J C Walker (eds), The Quaternary of the Isle of Skye: Field Guide, 90-97. Cambridge: Quaternary Research Association.

Birch, S 2003 'Preliminary Research to Determine the Function of Bone and Antler "Bevel-ended Tools" from the Mesolithic Shell Middens of Scotland'. Unpublished MS submitted for the Archaeology Dissertation Course at the University of Aberdeen.

Birch, S 2007 'The production and use of bone bevel ended tools', in K Hardy \& C Wickham-Jones (eds), Mesolithic and Later Sites around the Inner Sound, Scotland: the Work of the Scotland's First Settlers Project 1998-2004, section 3.4.4. Scottish Archaeological Internet Reports (SAIR) 31 [http://www.sair.org.uk/sair31].

Birks, H J P \& Williams, W 1983 'Late Quaternary Vegetational History of the Inner Hebrides', Proceedings of the Royal Society of Edinburgh 83, 269-292.

Bishop, A H 1914 'An Oransay shell-mound - a Scottish pre-Neolithic site', Proceedings of the Society of Antiquaries of Scotland 48 (1913-14), $52-108$.

Bokelmann, K 1983 'Mesolithische Wohnplätze im Duvenseer Moor', in Führer zu archäologischen Denkmälern in Deutschland, 2: Kreis Herzogtum Lauenburg II, 93-103. Stuttgart: Nordwestdeutscher und West- und Süddeutscher Verband für Altertumsforschung.

Bolomey, A 1973 'An outline of the late epipalaeolithic economy at the "Iron Gates", the evidence on bones', Dacia XVII, 41-52.

Bonsall, C 1981 'The coastal factor in the Mesolithic settlement of north-west England', in B Gramsch (ed.), Mesolithikum in Europa. 2 Internationales Symposium, Potsdam, 3 bis 8 April 1978, Bericht, 451-472. Berlin: VEB Deutscher Verlag der Wissenschaften (Veröffentlichungen des Museums für Ur- und Frühgeschichte Potsdam 14/15).

Bonsall, C 1996 'The "Obanian problem": coastal adaptation in the Mesolithic of western Scotland', in T Pollard \& A Morrison (eds), The Early Prehistory of Scotland, 183-197. Edinburgh: Edinburgh University Press.

Bonsall, C 1997 'Coastal adaptation in the Mesolithic of Argyll: rethinking the "Obanian problem", in Ritchie, G (ed.), The Archaeology of Argyll, 2537. Edinburgh: Edinburgh University Press.

Bonsall, C \& Sutherland, D G 1992 'The Oban Caves', in M J C Walker; J M Gray \& J J Lowe (eds), The South-West Scottish Highlands: Field Guide, 115-121. Cambridge: Quaternary Research Association.

Bonsall, C; Sutherland, D \& Payton, R 1994 'The
Eskmeals coastal foreland: archaeology and shoreline development' in J Boardman \& J Walden (eds), Cumbria Field Guide, 90-103. Oxford: Quaternary Research Association.

Bonsall, C; Tolan-Smith, C \& Saville, A 1995 'Direct dating of Mesolithic antler and bone artifacts from Great Britain: new results for bevelled tools and red deer antler mattocks', Mesolithic Miscellany 16(1), 2-10.

Bordes, F \& Gaussen, J 1970 'Un Fonde de tente Magdalénien près de Mussidan (Dordogne)', Frühe Menschheit und Umwelt 1, 313-329.

Breuil, H 1922 'Observations on the pre-Neolithic industries of Scotland', Proceedings of the Society of Antiquaries of Scotland 56 (1921-22), 261-281.

Bronk Ramsey, C 2009 'Bayesian analysis of radiocarbon dates', Radiocarbon 51(1), 337-360.

Bronk Ramsey, C; Higham, T F G; Brock, F; Baker, D \& Ditchfield, P 2009 'Radiocarbon dates from the Oxford AMS system: Archaeometry datelist 33' Archaeometry 51 (2), 323-349.

Butler, C 2005 Prehistoric Flintwork. Stroud: Tempus.

Campbell, A C 1989 The Hamlyn Guide to Seashores and Shallow Seas of Britain and Europe. London: Hamlyn Publishing Group Ltd.

Candow, R 1989 Prehistoric Morton. Dundee: privately printed.

Cerón-Carrasco, R 1992 'Assessment of the fish bone remains from Scar, Sanday'. Edinburgh: AOC (Scotland) Ltd. Unpublished report.

Chamberlain, A T 1996 'More dating evidence for human remains in British caves', Antiquity 70, 950-953.

Clapham, A; Tutin, T \& Warburg, E 1962 Flora of the British Isles. Cambridge: Cambridge University Press.

Clark, J G D 1934a 'The classification of a microlithic culture: the Tardenoisian of Horsham', The Archaeological Journal 90, 52-77.

Clark, J G D 1934b 'Report on the worked-stone industry', in W L Scott 'Excavation of Rudh' an Dunain Cave, Skye', Proceedings of the Society of Antiquaries of Scotland 68 (1933-34), 222-223.

Clark, J G D 1954 Excavations at Star Carr. An Early Mesolithic Site at Seamer, near Scarborough, Yorkshire. Cambridge: Cambridge University Press.

Clark, J G D 1956 'Notes on the Obanian with special reference to antler- and bone-work', Proceedings of the Society of Antiquaries of Scotland 89 (1955-56), 91-106.

Clarke, A \& Griffiths, D 1990 'The use of bloodstone as a raw material for flaked stone tools in the west of Scotland', in C R Wickham-Jones Rhum: Mesolithic and Later Sites at Kinloch, Excavations 1984-86, 149-156. Edinburgh: Society of Antiquaries of Scotland.

Coles, J M 1971 'The early settlement of Scotland: excavations at Morton, Fife', Proceedings of the Prehistoric Society 37(2), 284-366. 
Coles, J M 1983 'Excavations at Kilmelfort Cave, Argyll', Proceedings of the Society of Antiquaries of Scotland 113, 11-21.

Connock, KD 1985 Rescue Excavation of the Ossuary Remains at Raschoille Cave, Oban: an Interim Report. Oban: Lorn Archaeological and Historical Society.

Connock, K D; Finlayson, B \& Mills, C M 1992 'Excavation of a shell midden site at Carding Mill Bay near Oban, Scotland', Glasgow Archaeological Journal 17 (1991-92), 25-38.

Craig, O E; Ross, R; Milner, N \& Bailey, G N 2006 'FOCUS: sulphur isotope variation in archaeological marine fauna from Northern Europe', Journal of Archaeological Science 33 (11), 1642-1646.

Crothers, J H 1985 'Dog-whelks: an introduction to the biology of Nucella lapillus (L.)', Field Studies 6, 291-360.

Cunnington, M E 1923 The Early Iron Age Inhabited Site at All Cannings Cross Farm, Wiltshire. Devizes: George Simpson \& Co.

Dawson, A 2007 'Late-glacial and Holocene relative sea-level change in Applecross, Raasay and eastern Skye', in K Hardy \& C Wickham-Jones (eds) Mesolithic and Later Sites around the Inner Sound, Scotland: the Work of the Scotland's First Settlers Project 1998-2004, section 7.1. Scottish Archaeological Internet Reports (SAIR) 31 [http://www.sair.org.uk/sair31].

Deith, M R 1989 'Clams and salmonberries: interpreting seasonality data from shells', in $\mathrm{C}$ Bonsall (ed.), The Mesolithic in Europe. Papers Presented at the Third International Symposium, Edinburgh 1985, 73-79. Edinburgh: John Donald Publishers Ltd.

Dixon, N 2004 The Crannogs of Scotland: An Underwater Archaeology. Stroud: Tempus.

Dunning, G C 1934 'The swan's-neck and ringheaded pins of the early Iron Age in Britain', Archaeological Journal 91, 269-295.

Edwards, K J \& Whittington, G 1997, 'Vegetation change', in K J Edwards \& I B M Ralston (eds), Scotland: Environment and Archaeology, 8000 $B C-A D$ 1000, 63-82. Chichester: John Wiley \& Sons.

Emeleus, C H \& Bell, B R 2005 The Palaeogene Volcanic Districts of Scotland. Nottingham: British Geological Survey (British Regional Geology).

Fenton, A 1984 'Notes on shellfish as food and bait in Scotland', in B Gunda (ed.), The Fishing Culture of the World, 121-142. Budapest: Akadémiai Kiadó.

Foxon, A D 1991 'Bone, Antler, Tooth and Horn Technology and Utilisation in Prehistoric Scotland'. Glasgow: University of Glasgow. Unpublished $\mathrm{PhD}$ thesis.

Gautier, A 1987 'Taphonomic groups: how and why?', Archaeozoologia 1(2), 47-52.

Grayson, D K 1984 Quantitative Zooarchaeology. New York: Academic Press.
Green, F \& Edwards, K 2007, 'Palynological studies in northeast Skye and Raasay', in K Hardy \& C Wickham-Jones (eds) Mesolithic and Later Sites around the Inner Sound, Scotland: the Work of the Scotland's First Settlers Project 1998-2004, section 8.1. Scottish Archaeological Internet Reports (SAIR) 31 [http://www.sair.org. $\mathrm{uk} / \mathrm{sair} 31]$.

Grieve, S 1885 The Great Auk, or Garefowl: its History, Archaeology and Remains. London: Thomas C. Jack.

Griffiths D; Philpott R A \& Egan G 2007 Meols, The Archaeology of the North Wirral Coast. Discoveries and observations in the 19th and 20th centuries with a catalogue of collections. Oxford: Oxford University School of Archaeology Monograph Series 68.

Griffitts, J \& Bonsall, C 2001 'Experimental determination of the function of antler and bone "bevel-ended tools" from prehistoric shell middens in western Scotland', in A Choyke \& L Bartosiewicz (eds), Crafting Bone: Skeletal Technologies Through Time and Space: Proceedings of the 2nd Meeting of the (ICAZ) Worked Bone Research Group, Budapest, 31 August - 5 September 1999, 207-220. Oxford: BAR International Series 937.

Grigson, C 1989 'Bird-foraging patterns in the Mesolithic', in J C Bonsall (ed.), The Mesolithic in Europe. Papers Presented at the Third International Symposium, Edinburgh 1985, 60-72. Edinburgh: John Donald Publishers Ltd.

Grigson, C \& Mellars, P 1987 'The mammalian remains from the middens', in $\mathrm{P}$ Mellars (ed.), Excavations on Oronsay. Prehistoric Human Ecology on a Small Island, 243-289. Edinburgh: Edinburgh University Press.

Gwilt, A 2007 'Silent Silures?: Locating people and places in the Iron Age of south Wales', in C Haselgrove \& $\mathrm{T}$ Moore, The Later Iron Age in Britain and Beyond, 297-328. Oxford: Oxbow Books.

Hallén, Y 1994 'The use of bone and antler at Foshigarry and Bac Mhic Connain, two Iron Age sites on North Uist, Western Isles', Proceedings of the Society of Antiquaries of Scotland 124, 189-231.

Hamilton, J R C 1968 Excavations at Clickhimin, Shetland. Edinburgh: HMSO.

Hamilton-Dyer, S \& McCormick, F 1992 'The animal bones', in K D Connock; B Finlayson \& C M Mills, 'Excavation of a shell midden site at Carding Mill Bay near Oban, Scotland', Glasgow Archaeological Journal 17 (1991-92), 34 (main report in fiche M90-97, summary only in text).

Hamilton-Dyer, S n.d. 'Carding Mill Bay: Summary Note on the Bird and Fish Bones and the Crustacean Remains'. Edinburgh: Historic Scotland. Unpublished report.

Harding, D 2004 'Dunagoil, Bute, reinstated', Transactions of the Buteshire Natural History Society $26,1-19$.

Hardy, K 2001 'Sand, Highland', Discovery and Excavation in Scotland (n.s.) 2, 125. 
Hardy, K 2007 'Worked bone from Sand', in K Hardy \& C Wickham-Jones (eds) Mesolithic and Later Sites around the Inner Sound, Scotland: the Work of the Scotland's First Settlers Project 1998-2004, section 3.4. Scottish Archaeological Internet Reports (SAIR) 31 [http://www.sair.org. uk/sair31].

Hardy, K \& Wickham-Jones, C (eds) 2007 Mesolithic and Later Sites around the Inner Sound, Scotland: the Work of the Scotland's First Settlers Project 1998-2004. Scottish Archaeological Internet Reports (SAIR) 31 [http://www.sair.org. uk/sair31].

Hardy, K; Estevez, J \& Vila, A 2010 'Point of Sleat, Skye: excavation', Discovery \& Excavation in Scotland 11, 102.

Hedges, R E M 2004 'Isotopes and red herrings; comments on Milner et al and Lidén et al' Antiquity 78, 34-37.

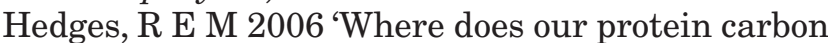
come from?', British Journal of Nutrition 95, 1031-1032.

Hedges, R E M \& Reynard L 2007 'Nitrogen isotopes and the trophic level of humans in archaeology', Journal of Archaeological Science 34, 1240-1251.

Hellewell, E 2011 'An Corran (Human) Bone Analysis Report'. Unpublished archive report (copies in NMS and site archive).

Jacobi, R M 1978 'The Mesolithic of Sussex', in P L Drewett (ed.), Archaeology in Sussex to AD 1500, 15-22. London: Council for British Archaeology (Research Report 29).

Jacobi, R M 1980 'The early Holocene settlement of Wales', in J A Taylor (ed.), Culture and Environment in Prehistoric Wales, 131-206. Oxford: BAR British Series 76.

Jones, D A 1984 'An Ecological Interpretation of Mesolithic Shellfish Remains on the Island of Oronsay, Inner Hebrides. Sheffield: Department of Archaeology and Prehistory', University of Sheffield. Unpublished PhD thesis.

Jones, D A 1985 'Ecological investigations of marine molluscs: an examination of changes in body weight and shape as aids to the interpretation of the Mesolithic shell middens of the island of Oronsay, Inner Hebrides', in N J R Fieller; D D Gilbertson \& N G Ralph (eds), Palaeoenvironmental Investigations: Research Design, Methods and Data Analysis, 209-221. Oxford: BAR International Series 258.

Kelly, E 2005 'The finds from Coolure demesne crannog', in A O'Sullivan; E Kelly \& R Sands, Archaeological Investigations of a Crannog at Coolure Demesne, Co. Westmeath. Report for Licence 04E1076. Dublin (unpublished report).

Kirk, S 2011 'Analytical Research Section Report No. AR 2011/20. XRF analysis of swan-necked copper alloy pin from An Chorran, Skye'. Department of Conservation \& Analytical Research, National Museums Scotland (unpublished report).

Kitchener, A C \& Bonsall, J C 1997 ‘AMS radiocarbon dates for some extinct Scottish mammals', Quaternary Newsletter 83, 1-11.

Kitchener, A C; Bonsall, C \& Bartosiewicz, L 2004 'Missing mammals from Mesolithic middens: a comparison of the fossil and archaeological records from Scotland', in A Saville (ed.), Mesolithic Scotland and its Neighbours: the Early Holocene Prehistory of Scotland, its British and Irish Context, and some Northern European Perspectives, 73-82. Edinburgh: Society of Antiquaries of Scotland.

Kitching, J A 1985 'The ecological significance and control of variability in dog-whelks from temperate rocky shores', in P G Moore \& $\mathrm{R}$ Seed (eds), The Ecology of Rocky Coasts: Essays Presented to J. R. Lewis, 234-248. London: Hodder \& Stoughton.

Lacaille, A D 1954 The Stone Age in Scotland. London: Oxford University Press.

Laws, K \& Armour-Chelu, M 1991 'The worked bone and antler', in N M Sharples Maiden Castle: Excavations and Field Survey 1985-6, 234-238. London: English Heritage.

Leitch, R \& Smith, C 1997 'Archaeology and the ethnohistory of cave dwelling in Scotland', in C Bonsall \& C Tolan-Smith, The Human Use of Caves, 122-126. Oxford: BAR International Series 667.

Lethbridge, T C 1920 "A burial of the "Viking Age" in Skye', Archaeological Journal 77, 135-136.

Lowe, J J \& Walker, M J C 1991 'Vegetational history of the Isle of Skye, II: the Flandrian', in C K Ballantyne; D I Benn; J J Lowe \& M J C Walker (eds), The Quaternary of the Isle of Skye: Field Guide, 119-142. Cambridge: Quaternary Research Association.

McArdle, M; Liss, N P \& Dennis, P 1998 'An isotopic study of atmospheric sulphur at three sites in Wales and at Mace Head, Eire', Journal of Geophysical Research - Atmospheres 103, 31, 079-31, 094.

McCullagh, R J 1989 'Excavation at Newton, Islay', Glasgow Archaeological Journal 15, 23-51.

MacGregor, A 1974 'The Broch of Burrian, North Ronaldsay, Orkney', Proceedings of the Society of Antiquaries of Scotland 105 (1972-74), 63-118.

Martingell, H \& Saville, A 1988 The Illustration of Lithic Artefacts: A Guide to Drawing Stone Tools for Specialist Reports. Northampton: Association of Archaeological Illustrators \& Surveyors / Lithic Studies Society.

McCormick, F \& Buckland, P C 1997 'Faunal change', in K J Edwards \& I B M Ralston (eds), Scotland: Environment and Archaeology, 8000 BC-AD 1000, 83-104. Chichester: John Wiley \& Sons.

Mellars, P 1978 'Excavation and economic analysis of Mesolithic shell middens on the island of Oronsay (Inner Hebrides)', in P Mellars (ed.), The Early Postglacial Settlement of Northern Europe: An Ecological Perspective, 371-396. London: Duckworth.

Mellars, P 1987 Excavations on Oronsay: Prehistoric 
Human Ecology on a Small Island. Edinburgh: Edinburgh University Press.

Mellars, P A \& Wilkinson, M R 1980 'Fish otoliths as indicators of seasonality in prehistoric shell middens: the evidence from Oronsay (Inner Hebrides)', Proceedings of the Prehistoric Society $46,19-44$

Mercer, J 1970 'Flint tools from the present tidal zone, Lussa Bay, Isle of Jura, Argyll', Proceedings of the Society of Antiquaries of Scotland 102 (1969-70), 1-30.

Mercer, J 1974a 'Glenbatrick Waterhole, a microlithic site on the Isle of Jura', Proceedings of the Society of Antiquaries of Scotland 105 (1972-74), 9-32.

Mercer, J 1974b Hebridean Islands: Colonsay, Gigha, Jura. Glasgow \& London: Blackie.

Mercer, J 1980 'Lussa Wood 1: the Late Glacial and early Post-Glacial occupation of Jura', Proceedings of the Society of Antiquaries of Scotland 110 (1978-80), 1-32.

Milner, N; Craig, O E; Bailey, G N; Pedersen, K \& Andersen, S H 2004 'Something fishy in the Neolithic? A re-evaluation of stable isotope analysis of Mesolithic and Neolithic coastal populations', Antiquity 78, 9-22.

Milner, N \& Craig, O E 2009 'Mysteries of the middens: change and continuity across the Mesolithic-Neolithic transition', in M J Allen; N Sharples \& T O'Connor (eds), Land and People: Papers in Memory of John G Evans, 169-180. Oxford: Oxbow Books (Prehistoric Society Research Paper No 2).

Mitchell, W R \& Delap, P 1974, Lakeland Mammals. Clapham: Dalesman Publishing Company Ltd.

Mithen, S (ed.) 2000 Hunter-Gatherer Landscape Archaeology: the Southern Hebrides Mesolithic Project 1988-98. Cambridge: McDonald Institute Monograph.

Moore, J W 1950 'Mesolithic sites in the neighbourhood of Flixton, north-east Yorkshire', Proceedings of the Prehistoric Society 16, 101-108.

Munro, R 1882 Ancient Scottish Lake-Dwellings or Crannogs. Edinburgh: David Douglas Publishers Ltd.

MUNSELL 1990 Munsell Soil Color Charts. Baltimore, Ma: Munsell Color.

Muus, B J \& Dahlstrøm, P 1977 Collins Guide to the Sea Fishes of Britain and North-Western Europe. London: Collins.

Newcomer, M 1975 "Punch" technique and Upper Palaeolithic blades', in L Swanson (ed.), Lithic Technology: Making and Using Stone Tools, 97102. The Hague: Mouton.

O'Connor, B 1980 Cross-Channel Relations in the Later Bronze Age. Oxford: BAR International Series 91.

Ohnuma, K \& Bergman, C A 1982 'Experimental studies in the determination of flaking mode', Bulletin of the Institute of Archaeology, University of London 19, 161-170.
Pollard, A 1990 'Down through the ages: a review of the Oban cave deposits', Scottish Archaeological Review 7, 58-74.

Rees, T; Kozikowski, G \& Miket, R 1994 'Investigation of a Shell-Midden at An Chorran, Staffin, Isle of Skye. Portree: Dualchas'. Unpublished report.

Reimer, P J; Baillie, M G L; Bard, E; Bayliss, A; Beck, J W; Blackwell, P G; Bronk Ramsey, C; Buck, C E; Burr, G; Edwards, R L; Friedrich, M; Grootes, P M; Guilderson, T P; Hajdas, I; Heaton, T J; Hogg, A G; Hughen, K A; Kaiser, K F; Kromer, B; McCormac, F G; Manning, S W; Reimer, R W; Richards, D A; Southon, J R; Talamo, S; Turney, C S M; van der Plicht, J \& Weyhenmeyer, C E 2009 'IntCal09 and Marine09 radiocarbon age calibration curves, $0-50,000$ years cal BP', Radiocarbon 51(4), 1111-1150.

Reynier, M 2005 Early Mesolithic Britain: Origins, Development and Directions. Oxford: BAR British Series 393.

Reynolds, T E G 1983 'Form, Function and Technology: A Test Case of Limpet Scoops'. Cambridge: University of Cambridge. Unpublished BA dissertation.

Richards, A 1969 'Some aspects of the evolution of the coastline of north-east Skye', Scottish Geographical Magazine 85, 122-131.

Richards, M P \& Hedges, R E M 1999 'A Neolithic revolution? New evidence of diet in the British Neolithic', Antiquity 73, 891-897.

Richards, M P; Fuller, B T \& Hedges, R E M 2001 'Sulphur isotopic variation in ancient bone collagen from Europe: implications for human palaeodiet, residence mobility, and modern pollutant studies', Earth and Planetary Science Letters 191, 185-190.

Ritchie, A (ed.) 2005 Kilellan Farm, Ardnave, Islay: Excavations of a Prehistoric to Early Medieval Site by Colin Burgess and Others 1954-76. Edinburgh: Society of Antiquaries of Scotland.

Russell, N J 1992 'The marine molluscs', in K D Connock; B Finlayson \& C M Mills, 'Excavation of a shell midden site at Carding Mill Bay, near Oban, Scotland', Glasgow Archaeological Journal 17 (1991-92), 25-38 (main report in fiche M74-89, summary only in text).

Russell, N J; Bonsall, C \& Sutherland, D G 1995 'The exploitation of marine molluscs in the Mesolithic of western Scotland: evidence from Ulva Cave, Inner Hebrides', in A Fischer (ed.), Man and Sea in the Mesolithic: Coastal Settlement Above and Below Present Sea Level, 273-288. Oxford: Oxbow Books.

Saville, A 1994 'Exploitation of lithic resources for stone tools in earlier prehistoric Scotland', in N Ashton \& A David (eds), Stories in Stone, 5770. London: Lithic Studies Society (Occasional Paper 4).

Saville, A 1998 'An Corran, Staffin, Skye [radiocarbon dates]', Discovery and Excavation in Scotland 1998, 126-127. 
Saville, A 2003 'Indications of regionalisation in Mesolithic Scotland', in L Larsson; H Kindgren; K Knutsson; D Loeffler \& A Åkerlund (eds), Mesolithic on the Move: Papers Presented at the Sixth International Conference on the Mesolithic in Europe, Stockholm 2000, 340-350. Oxford: Oxbow Books.

Saville, A 2004a 'The Material Culture of Mesolithic Scotland', in A Saville (ed.), Mesolithic Scotland and its Neighbours: the Early Holocene Prehistory of Scotland, its British and Irish Context, and some Northern European Perspectives, 185-220. Edinburgh: Society of Antiquaries of Scotland.

Saville, A 2004b 'Introducing Mesolithic Scotland: The Background to a Developing Field of Study', in A Saville, A (ed.), Mesolithic Scotland and its Neighbours: the Early Holocene Prehistory of Scotland, its British and Irish Context, and some Northern European Perspectives, 3-24. Edinburgh: Society of Antiquaries of Scotland.

Saville, A 2005 'Archaeology and the Creag nan Uamh bone caves, Assynt, Highland', Proceedings of the Society of Antiquaries of Scotland $135,343-369$.

Saville, A 2008 'The Beginning of the Later Mesolithic in Scotland', in Z Sulgostowska \& A J Tomaszewski (eds), Man - Millennia - Environment. Studies in Honour of Romuald Schild, 207-213. Warsaw: Institute of Archaeology and Ethnology, Polish Academy of Sciences.

Saville, A \& Ballin, T B 2009 'Upper Palaeolithic evidence from Kilmelfort Cave, Argyll: a re-evaluation of the lithic assemblage', Proceedings of the Society of Antiquaries of Scotland $139,1-36$.

Saville, A \& Hallén, Y 1994 “The "Obanian Iron Age”: human remains from the Oban cave sites, Argyll, Scotland', Antiquity 68, 715-723.

Saville, A \& Miket, R 1994a 'An Corran, Staffin, Skye (Kilmuir parish): rock-shelter', Discovery and Excavation in Scotland 1994, 40-41.

Saville, A \& Miket, R 1994b 'An Corran rock-shelter, Skye: a major new Mesolithic site', PAST 18, 9-10.

Schibler, J 1981 Typologische Untersuchungen der cortaillodzeitlichen Knochenartefakte. Die neolithischen Untersuchungen von Twann, Band 8. Bern: Staatlicher Lehrmittelverlag.

Schulting, R 2009 'Worm's Head and Caldey Island (south Wales, UK) and the question of Mesolithic territories', in S McCartan; R Schulting; G Warren \& PWoodman (eds), Mesolithic Horizons, 354-361 Oxford: Oxbow Books.

Schulting, R J \& Richards, M P 2002 'The wet, the wild and the domesticated: the Mesolithic-Neolithic transition on the west coast of Scotland', European Journal of Archaeology $5(2), 147-189$.

Scott, W L 1934a 'Stone-knapping industry', in W
L Scott 'Excavation of Rudh' an Dunain Cave, Skye', Proceedings of the Society of Antiquaries of Scotland 68 (1933-34), 204-206.

Scott, W L 1934b 'Excavation of Rudh' an Dunain Cave, Skye', Proceedings of the Society of Antiquaries of Scotland 68 (1933-34), 200-223.

Selby, K A; Smith, D E; Dawson, A G \& Mighall, T M 2000 'Late Devensian and Holocene relative sea level and environmental changes from an isolation basin in southern Skye', Scottish Journal of Geology 36(1), 73-86.

Sellwood, L 1984 'Objects of bone and antler' in B Cunliffe, Danebury, an Iron Age Hillfort in Hampshire. Vol.2. The Excavations 1969-1978: The Finds, 371-395. London: Council for British Archaeology (Research Report 52).

Stewart, H 1973 Artifacts of the Northwest Coast Indians. Saanichton (British Columbia): Hancock House Publishers.

Tolan-Smith, C 2001 The Caves of Mid Argyll: An Archaeology of Human Use. Edinburgh: Society of Antiquaries of Scotland.

Uerpmann, H-P 1982, 'Faunal remains from Shams ed-din Tannira, a Halafian site in northern Syria', Berytus 30, 3-52.

Von den Driesch, A 1976 A Guide to the Measurement of Animal Bones from Archaeological Sites. Cambridge, Ma: Harvard University Press (Peabody Museum Bulletin 1).

Waselkov, G A 1987 'Shellfish gathering and shell midden archaeology', in M B Schiffer (ed.), Advances in Archaeological Method and Theory 10, 93-210. London: Academic Press.

Watt, J 1991 'The Diet of Otters'. Aberdeen: University of Aberdeen. Unpublished $\mathrm{PhD}$ dissertation.

Wickham-Jones, C R 1986 'The procurement and use of stone for flaked tools in prehistoric Scotland', Proceedings of the Society of Antiquaries of Scotland 116 (1985-86), 1-10.

Wickham-Jones, C R 1990 Rhum: Mesolithic and Later Sites at Kinloch, Excavations 1984-86. Edinburgh: Society of Antiquaries of Scotland.

Wickham-Jones, C R 2004 'Structural evidence in the Scottish Mesolithic', in A Saville (ed.), Mesolithic Scotland and its Neighbours: the Early Holocene Prehistory of Scotland, its British and Irish Context, and some Northern European Perspectives, 229-242. Edinburgh: Society of Antiquaries of Scotland.

Wickham-Jones, C R \& Hardy, K 2004 'Camas Daraich: A Mesolithic site at the Point of Sleat, Skye'. Edinburgh: Society of Antiquaries of Scotland. Scottish Archaeological Internet Reports (SAIR) 12 [http://www.sair.org.uk/ sair12/index.html].

Wildgoose, M 1988 'An Choran (Kilmuir parish), shell midden, flints', Discovery \& Excavation in Scotland 1988, 17.

Yonge, C M 1972 The Seashore. London: Collins. 


\section{APPENDIX ONE: DESCRIPTION OF THE CONTEXTS, by Roger Miket, Karen Hardy and Alan Saville}

\section{Context 1 (illus 16 and 17)}

The uppermost layer encountered was a grey/silver sand which overlay the entire platform area. It showed regular disturbance from sheep, which used the ledge as a path around the cliff face. Within the area of excavation, it reached a maximum thickness of $0.65 \mathrm{~m}$ and contained loosely distributed limpet shells (Patella vulgata) and a lesser quantity of common periwinkle (Littorina littorea), as well as incorporating some massive angular blocks, presumably derived from the rock face above. Running throughout, and contained within $\mathrm{C} 1$, were sporadic lenses of darkened brown sand (C1a), potentially representing palaeosols. The content and structure of these palaeosols suggested that the entire deposit might have originated from wind-blown erosion, with periods of sufficient stability to allow limited soil formation to occur.

\section{Context 2 (illus 16)}

Underlying $\mathrm{C} 1$, at a depth of $0.25 \mathrm{~m}$ and extending along the rock face, lay a lens of reddish/orange ash with a maximum thickness of $0.21 \mathrm{~m}$. It contained charcoal, crushed shell, and some stones, both angular and rounded. It did not extend beyond $0.45 \mathrm{~m}$ from the rock face, at which point it appeared to have been truncated by $\mathrm{C} 1$. Much of $\mathrm{C} 2$ appeared to have derived from the clearance of two hearths (C3 and C4), each set within clefts in the rock face. It was not possible to distinguish between material from the individual hearths, and it is possible that the two hearths were in use at the same time, or the time between the abandonment of one hearth and the construction of the next may have been too short to allow the two features to be separated chronologically. A few fragments of modern glazed pottery from C2 indicated deposition or disturbance sometime within the last 100 to 150 years.

\section{Context 3}

C3 was a hearth within $\mathrm{C} 2$, and it was set within the southern cleft in the rock face and consisted of angular flag-like stones. The location of the hearth may have capitalised on using this cleft as a natural chimney within the rock face, as this natural flue still retained sooting from fires.

\section{Context 4}

$\mathrm{C} 4$ was also a hearth within $\mathrm{C} 2$. It was set within the northern cleft in the rock face and was formed on a base of rounded beach cobbles. As in the case of $\mathrm{C} 3$, the location of the hearth may have been dictated by the use of this cleft as a natural chimney, as it also retained traces of sooting.

\section{Context 5 (illus 16 and 17)}

Below the hearths lay a reddish-brown sand deposit, which, though relatively sterile, nevertheless contained a small number of complete shells, predominantly limpet.

\section{Context 6}

In the northern part of the trench, within $\mathrm{C} 5$, a thin lens of charcoal and ash disappeared into the section, perhaps representing the southern limits of a more extensive context lying beyond.

\section{Context 7 (illus 16)}

Below C5, there was a brown ash deposit, containing extensive lenses of charcoal and some crushed shell. It extended out from the rock face to a distance of $0.9 \mathrm{~m}$.

\section{Context 8}

Within $\mathrm{C} 7$, and hard up against the rock face approximately $1.0 \mathrm{~m}$ to the north of the southern cleft, was a hearth. It was defined by an orange/red ash deposit, which incorporated some rounded stones, and it had a truncated domed cross-section.

\section{Context 9}

Within $\mathrm{C} 7$, and near C8, was a second hearth (C9), $1.5 \mathrm{~m}$ east of the rock face and approximately $1 \mathrm{~m}$ from the northern section. It was characterised by a lens of dark soil and charcoal, roughly $0.9 \mathrm{~m}$ in diameter, centred upon a well-laid bed of beach cobbles, $0.6 \mathrm{~m}$ in diameter.

Context 10 (illus 16, 17 and 18)

C10 formed another reddish-brown sand layer, comparable in nature to $\mathrm{C} 5$ but thicker and much more extensive. It was sandwiched between C5, $\mathrm{C} 7, \mathrm{C} 8$, and $\mathrm{C} 9$ above and $\mathrm{C} 31$ below, and it was probably accumulated over a long period of time as 
it contained a number of deposits of some complexity and varied extent. C10 may have been formed by natural processes, interspersed with some phases of cultural activity. Where such cultural deposits existed, they rose away from the rock face. The rise continued eastwards to a distance from the rock face of at most $1.3 \mathrm{~m}$. Approximately $2 \mathrm{~m}$ beyond this point was the western limit of a north-south trending line of angular boulders (C16). They corresponded to the crest of the talus and, as far as C26 in the southern part of the sondage and C30 and C31 in the northern part, all cultural activity appeared to have been contained between these boulders and the rock face.

\section{Context 11 (illus 16)}

C11 was a loose shell deposit composed almost wholly of limpet shells (Patella vulgata) and fine charcoal lenses within a sandy matrix. It occurred in a hollow in the surface of C10 and abutted the cliff face at its northern limit within the sondage.

\section{Context 12 (illus 16 and 17)}

C12 was a brown ash layer containing lenses of charcoal and crushed shell, identified as probably limpet (Patella vulgata). As it extended upslope towards the east, C12 was gradually lost within $\mathrm{C} 10$ at a distance of approximately $1.5 \mathrm{~m}$. Within the northern part of the sondage it met the rock face. Further south this did not occur, with an earlier accumulation (C10) filling an undercutting of the rock face. The deposit split as it rose upslope to the east. This bifurcation suggests two stages of deposition. This context was notably richer in compacted shell within the north-west corner of the sondage, where it extended to around $0.5 \mathrm{~m}$ from the rock face.

\section{Context 13}

C13 was a hearth with a beach cobble base. Its diameter was at most $0.4 \mathrm{~m}$. It formed part of $\mathrm{C} 12$, and it was located adjacent to the rock face, tucked beneath the northern cleft.

\section{Context 14}

C14 was another beach-cobble based hearth. It lay in $\mathrm{C} 12$ and had similar dimensions to $\mathrm{C} 13 . \mathrm{C} 14$ was partially covered by $\mathrm{C}$, although its centre lay slightly further to the south.

\section{Context 15}

The construction of $\mathrm{C} 15$ contrasted markedly with C13 and C14. It was made by carefully fitting several flagstones, creating a well-crafted oval hearth. It measured $0.9 \mathrm{~m}$ by $0.4 \mathrm{~m}$, with its long axis parallel to the wall-face. It formed part of $\mathrm{C} 12$ adjacent to the rock face, slightly north of the southern cleft.

\section{Context 16 (illus 16 and 17)}

$\mathrm{C} 16$, within $\mathrm{C} 10$, is thought to represent debris from a rockfall of angular boulders forming an irregular north-south alignment at between 1.5 and $3 \mathrm{~m}$ from the rock face.

\section{Context 17}

Stratigraphically earlier than $\mathrm{C} 12-15$, and situated to the west of the C16 area of angular boulders, lay a surface of beach cobbles. Although forming a relatively coherent surface where present, the cobbles did not extend throughout the excavated area. There was a line of discontinuity at a point approximately $1.4 \mathrm{~m}$ from the rock face and parallel with it. Equally, the extent of the cobble surface was patchy, more so in the southern portion of the sondage; it is unclear whether this reflects the original intention, or whether it was the result of post-depositional activities. Lying on the surface of the cobbles adjacent to the northern section, and at a distance of $2.1 \mathrm{~m}$ from the rock face, lay an incomplete copper-alloy pin, of later prehistoric type.

\section{Context 18}

C18 was a lens of charcoal and burning, probably related to C17. It lay close to the rock face and it was too small to reflect any significant activity.

\section{Context 19}

Another small lens of charcoal and burning, possibly related to $\mathrm{C} 17$, which also, as with $\mathrm{C} 18$, lay close to the rock face.

\section{Context 20}

C20 was a lens of shells, possibly related to C17. It was too small to reflect any significant activity.

\section{Context 21}

Another lens of shells similar to C20.

\section{Context 22 (illus 17)}

Beginning $0.2 \mathrm{~m}$ from the rock face, and extending eastwards for $2.3 \mathrm{~m}$, was a dark brown layer, densely 
packed with shell and with evidence of burning. No obvious focus of origin was identified, but it was larger in the southern section than in the northern.

\section{Context 23 (illus 17)}

C23 lay within the southern section of C22 in a niche undercutting the rock face. It was an unconsolidated deposit of shells, predominantly limpet. C23 overlay C10.

\section{Context 24 (illus 16)}

$\mathrm{C} 24$ was a reddish-brown sand layer within $\mathrm{C} 10$. The layer was notably darker towards its base. Within the southern portion of the sondage, C24 lay below C22, and in the northern portion it lay at the base of $\mathrm{C} 10$ and overlay C31. It is possible that C24 is simply a different manifestation of $\mathrm{C} 10$ but here affected by leaching from the overlying deposit (C22).

\section{Context 25}

C25 was a small lens (0.2m long) of dark-brown burning, containing some shells. It formed the earliest cultural horizon within the $\mathrm{C} 10$ layer.

\section{Context 26 (illus 17)}

Below C10, in the southern section, lay a black layer with charcoal lenses as well as crushed and whole shells. It extended $2.8 \mathrm{~m}$ to the east, rising gradually before dipping downslope. The final $0.25 \mathrm{~m}$ of the layer overlay C29.

\section{Context 27 (illus 17)}

Below C10, in the southern section, lay another black layer with charcoal lenses and crushed and whole shells. Within $0.2 \mathrm{~m}$ of the rock face, C26 and C27 merged, coincident with a deposit of beach cobbles.

\section{Context 28 (illus 17)}

C26 and C27 were separated by a fine light sand deposit, incorporating some shells (this layer was only identified as such at the west end of the section; it is unclear whether it represents the same layer as the unnumbered sandy deposit underlying C29 in the centre of the section).

\section{Context 29 (illus 17)}

C29 was a rich brown to orange layer incorporating many large angular blocks. Although these blocks had some similarities to the lower levels of C16 they were distinguished from this upper context by being held within a different matrix.

\section{Context 30 (illus 16)}

To the north a brown layer, up to $0.2 \mathrm{~m}$ in thickness and incorporating many large angular blocks, straddled the talus. To the west, and some $0.8 \mathrm{~m}$ from the rock face, it merged with the underlying black layer (C31). This possibly represented a variant of C29, as both layers underlay C10. Within the southern part of C30, an apparent semi-circular stone-setting abutted the cliff face (illus 22). The 'walls' of this setting, made of two layers of angular stone, were approximately $0.4 \mathrm{~m}$ in depth. The significance of this stone-setting, which measured $1.2 \mathrm{~m}$ by $1 \mathrm{~m}$, is not apparent as it is too small to represent a living space and too large to be a normal hearth.

\section{Context 31 (illus 15, 16, 18 and 20)}

From this point downwards, the character of the site differed radically from that encountered at higher levels. From the top of C31 to the top of C40 (a depth of at most $55 \mathrm{~cm}$ ), a black 'claggy' and 'greasy' humic layer predominated. Like C10, this deposit incorporated a series of subsidiary deposits. However, where C10 appeared to reflect a largely natural accumulation, C31 clearly did not, and is thought to be the product of anthropogenic deposition. C31 included several shell horizons. This distinctive deposit extended east from the rock face for at least $3.1 \mathrm{~m}$, where it was truncated by the erosion of the slope deposit at the base of $\mathrm{C} 1$. It appeared higher in the northern section, where it capped a series of natural deposits (C32 and C33). To the south, it dipped below C29 and, although it was not visible in the relevant section, it seemed to run underneath C26, C27 and C28. C31 was excavated in $100 \mathrm{~mm}$ units from its surface, resulting in a total of 10 spits. These spits were identified by the antefix BB; BB1 represented the uppermost $100 \mathrm{~mm}$, BB2 the level $100-200 \mathrm{~mm}$, and so forth. BB4/5 represented shell deposit C34, and BB5 deposit C38, both of which were contained within C31. Below these, two other spits, BB6 and $\mathrm{BB} 7 / 8$, continued, with $\mathrm{BB} 7 / 8$ reaching the base of C31.

\section{Context 32 (illus 16)}

C32 was a deposit of probably natural reddishorange sand underlying C31.

\section{Context 33 (illus 16)}

C33 was a deposit of probably natural brown sand with shells underlying C31. 
Only one shelly deposit within C31 was visible in the northern section. This layer included unconsolidated shells, some of which had been crushed. Like many other deposits within C31, it contained large quantities of animal bones and lithic artefacts. Only a small part of C34 was visible in the north-eastern corner of the trench, probably representing the southern limit of another midden, the main area of which lay outside, and north of, the trench.

\section{Context 35 (illus 15, 18 and 20)}

C35 was an intrusive feature with an archaeologically sterile fill of black silt, $c 0.75 \mathrm{~m}$ deep and $c$ $250 \mathrm{~mm}$ in diameter. It appeared to be related to the semi-circular stone-setting, as it underlay one of the angular stones forming part of its 'wall'.

\section{Context 36 (illus 15 and 20)}

C36 was a tripartite deposit of loose and crushed shells over a small, thin deposit of black silt. Although, during the excavation, these deposits were all lumped together as C36, it is more likely that they represented different contexts deposited at different times. The main part of C36 consisted of a large, unconsolidated shell midden which rested against the rock face on the west. In the east, it appeared to have been truncated by C35. The main C36 shell midden contained numerous lithic and bone artefacts, pieces of human and animal bone and fragments of charcoal. At the base of the main midden, and directly overlying the basal black silt of C36, was a layer of crushed shell. This layer began at the rock face with a thickness of $50 \mathrm{~mm}$. From this point it gradually curved upwards and expanded as it extended eastwards. It was truncated almost to its base by the intrusive feature C35. Beyond this context it continued curving upwards, incorporating several layers of ash and charcoal, and it reached almost $0.6 \mathrm{~m}$ in thickness. After this point it was apparently cut by C31, finally disappearing $2.45 \mathrm{~m}$ from the rock face. The C36-like deposit of crushed shell reappeared at the eastern end of the trench, at the same point as C40, which it overlay directly, and it continued for $1.1 \mathrm{~m}$ to the end of the trench. This represented an earlier deposit than the unconsolidated shell midden above it (another part of C36). Below this, and extending for almost $2 \mathrm{~m}$ outwards from the rock face, was a thin deposit of black silty organic material (also a part of C36). This layer, which attained a maximum depth of $100 \mathrm{~mm}$, possibly represented a deposit which was earlier and separate from the rest of C36.
Within C36, a $0.3 \mathrm{~m}^{2}$ column was sampled, with 10 samples being taken at $100 \mathrm{~mm}$ intervals. It was decided to examine a column under the overhang to lessen the chance of seeping contamination between deposits. The sample squares were numbered SA to SJ, and each sample had a volume of $c 15$ litres. SA represented C31, and the remainder came from C36. $\mathrm{SB}$ to $\mathrm{SH}$ were taken from the main midden, while SI was taken from the lower crushed shell layer. SJ came from the basal black silt layer of C36.

\section{Context 37 (illus 15 and 18)}

C37 was a midden area of unconsolidated shells which lay beyond the drip ring from the overhang, beginning $2.6 \mathrm{~m}$ from the rock face and extending for $1.29 \mathrm{~m}$ towards the east. There were a number of tip lines within the midden, which contained lithic artefacts, animal and fish bones, as well as a small amount of charcoal fragments. The chronological status of C37 in relation to other contexts is unclear, such as C37 in relation to C31 which overlay it, C40 which underlay it, and in particular C36 with which it had no stratigraphic connection. C37 is thought to be largely contemporary with C36.

\section{Context 38}

C38 was a small lens of shells within C31.

\section{Context 39 (illus 15)}

Another small lens of shells within C31, the position of which is recorded in plan, from which it appears to be only $0.25 \mathrm{~m}$ across.

\section{Context 40 (illus 15 and 18)}

C40 was an extensive, often fairly thick layer of darkbrown silty soil, containing some angular stones. It extended for $3.85 \mathrm{~m}$ towards the eastern limit of the trench, but began $1.1 \mathrm{~m}$ from the rock face. Its limit had been identified as a point where large rocks had fallen and lay against the angular bedrock surface, which is visible further inside the rockshelter. It overlay C41 from its start inside the rockshelter up to the eastern end of $\mathrm{C} 41$, after which point it was in direct contact with bedrock. The depth of the C40 deposit varied quite substantially, ranging from a maximum of $0.25 \mathrm{~m}$ inside the rock-shelter to a point where it petered out altogether as the bedrock rose outside the rock-shelter. Beyond this point, it reappeared and continued to the end of the trench at a depth of between 80 and $190 \mathrm{~mm}$. The surface of C40 was fairly level, and the deposit contained numerous lithic artefacts, a small amount of fragmented shell, 
abundant animal bones and a substantial amount of charcoal.

\section{Context 41}

C41 was the basal layer of the stratigraphic sequence. The dolerite bedrock was uneven and consisted of angular pieces of rock. The deposit which made up
C41 was present in hollows and cracks within the bedrock surface. It was a red clay-like deposit, quite different from the other deposits recognised within the site. C41 extended along the length of the trench for $3.2 \mathrm{~m}$ from the rock face, until it petered out $0.8 \mathrm{~m}$ beyond the drip line representing the rockshelter overhang. The C41 deposit contained numerous lithic artefacts and a few pieces of burnt animal bone. 


\section{APPENDIX TWO: WORKED BONE AND ANTLER ARTEFACTS CATALOGUE, by Alan Saville}

Information for each entry is listed in the following sequence: catalogue (CAT) number; previous list number for bone/antler finds; context and any associated information (including the date of recovery if recorded); species identification; skeletal part identification; overall length (L); overall breadth (B); overall thickness (Th) (all measurements in millimetres); weight (Wt) in grams; comments on condition, completeness, presence of polish, etc. Identifications of species and skeletal part are by László Bartosiewicz and Ywonne Hallén. In the case of those pieces which have been individually radiocarbon dated the catalogue number has an asterisk and the laboratory code and age uncal BP are given. Items illustrated in this report have a cross-reference to the illustration number.

Bevel-ended tools, single bevel only (all of bone unless otherwise stated)

\begin{tabular}{|c|c|c|c|}
\hline CAT no. & List no. & Context & Description \\
\hline 1 & 001 & $\begin{array}{l}\text { C36, main midden } \\
(6 / 7-12-1993)\end{array}$ & $\begin{array}{l}\text { ruminant, longbone; L.52.5; B.17.5; Th.8.5; Wt.6.3; probably complete; } \\
\text { polish/rounding; spalled bevel; lateral edge chipped. Illus } 33 .\end{array}$ \\
\hline 2 & 003 & $\begin{array}{l}\text { C36, main midden } \\
(6 / 7-12-1993)\end{array}$ & $\begin{array}{l}\text { ruminant, longbone; L. } 48.0 ; \text { B.15.5; Th. } 6.5 ; \text { Wt.3.0; probably broken on one } \\
\text { lateral edge and at the base; polish/rounding }\end{array}$ \\
\hline 3 & 004 & $\begin{array}{l}\text { C36, main midden } \\
(6 / 7-12-1993)\end{array}$ & $\begin{array}{l}\text { ruminant, longbone; L.50.0; B.10.0; Th.8.5; Wt.3.7; probably complete } \\
\text { except for longitudinal spall on bevel edge; bevel pocked; rounding }\end{array}$ \\
\hline 4 & 005 & $\begin{array}{l}\text { C36, main midden } \\
(6 / 7-12-1993)\end{array}$ & red deer, metapodium; L.42.0; B.14.0; Th.7.5; Wt.3.3; complete; polish \\
\hline 5 & 006 & $\begin{array}{l}\text { C36, main midden } \\
(6 / 7-12-1993)\end{array}$ & $\begin{array}{l}\text { ruminant, longbone; L.30.5; B.13.5; Th.5.0; Wt.1.5; fragment only; snapped } \\
\text { obliquely through stem; spalled bevel }\end{array}$ \\
\hline $6^{*}$ & 007 & $\begin{array}{l}\text { C36, main midden } \\
(6 / 7-12-1993)\end{array}$ & $\begin{array}{l}\text { ruminant, longbone; L.46.0; B.16.5; Th.7.0; Wt.4.5; stem broken at base; } \\
\text { damage to one lateral edge; polish; AA-29316: } 6215 \pm 60 \text { uncal BP. Illus } 35 \\
\text { and 51, upper left. }\end{array}$ \\
\hline 7 & 009 & $\begin{array}{l}\text { C36, main midden } \\
(6 / 7-12-1993)\end{array}$ & $\begin{array}{l}\text { red deer, ANTLER; L.33.0; B.21.0; Th.5.0; Wt.2.4; broken, stem snapped at } \\
\text { base; polish; comprises two joining fragments (009 and former 008) from } \\
\text { modern break }\end{array}$ \\
\hline 8 & 010 & $\begin{array}{l}\text { C36, main midden } \\
(6 / 7-12-1993)\end{array}$ & $\begin{array}{l}\text { red deer, metacarpus; L.53.5; B.19.5; Th.9.0; Wt.6.2; probably complete; } \\
\text { polish/rounding; slightly spalled bevel. Illus } 33 .\end{array}$ \\
\hline 9 & 011 & $\begin{array}{l}\text { C36, main midden } \\
(6 / 7-12-1993)\end{array}$ & ruminant, longbone; L.56.5; B.13.0; Th.6.0; Wt.2.9; probably complete \\
\hline 10 & 012 & $\begin{array}{l}\text { C36, main midden } \\
(6 / 7-12-1993)\end{array}$ & $\begin{array}{l}\text { red deer, metapodium; L.48.5; B.14.5; Th.6.5; Wt.3.3; bevel heavily spalled; } \\
\text { bevel broken by longitudinal split; otherwise complete?; polish/rounding; } \\
\text { one lateral edge is sharp }\end{array}$ \\
\hline 11 & 013 & $\begin{array}{l}\text { C36, main midden } \\
(6 / 7-12-1993)\end{array}$ & $\begin{array}{l}\text { ruminant, longbone; L.32.5; B.11.0; Th.6.5; Wt.1.5; fragment only, split } \\
\text { longitudinally through bevel }\end{array}$ \\
\hline 12 & 015 & $\begin{array}{l}\text { C36, main midden } \\
(6 / 7-12-1993)\end{array}$ & $\begin{array}{l}\text { red deer, metatarsus; L.69.0; B.13.5; Th.7.0; Wt.3.3; probably complete; } \\
\text { lateral chipping; weathered }\end{array}$ \\
\hline 13 & 016 & $\begin{array}{l}\text { C36, main midden } \\
(6 / 7-12-1993)\end{array}$ & $\begin{array}{l}\text { ruminant, longbone; L.50.5; B.13.0; Th.7.0; Wt.3.5; stem broken at base, } \\
\text { snapped; spalled bevel; edges chipped; polish }\end{array}$ \\
\hline 14 & 017 & $\begin{array}{l}\text { C36, main midden } \\
(6 / 7-12-1993)\end{array}$ & $\begin{array}{l}\text { red deer, metapodium; L.54.0; B.13.0; Th.5.5; Wt.3.6; probably complete; } \\
\text { bevel spalled; polish }\end{array}$ \\
\hline 15 & 018 & $\begin{array}{l}\text { C36, main midden } \\
(6 / 7-12-1993)\end{array}$ & $\begin{array}{l}\text { ruminant, metapodium; L.41.0; B.12.5; Th.6.5; Wt.2.4; stem probably } \\
\text { broken; bevel spalled; polish; lateral edge chipping? }\end{array}$ \\
\hline 16 & 019 & $\begin{array}{l}\text { C36, main midden } \\
(6 / 7-12-1993)\end{array}$ & $\begin{array}{l}\text { red deer, metacarpus; L. } 47.0 \text {; B.11.5; Th.6.0; Wt.2.1; slight break at the } \\
\text { base; possibly intentionally pointed at the base; bevel heavily spalled; } \\
\text { polish; BURNT }\end{array}$ \\
\hline 17 & 020 & $\begin{array}{l}\text { C36, main midden } \\
6 / 7-12-1993)\end{array}$ & $\begin{array}{l}\text { red deer, metatarsus; L.48.0; B.11.5; Th.7.0; Wt. 2.5; probably complete; } \\
\text { bevel spalled; polish/rounding }\end{array}$ \\
\hline
\end{tabular}




\begin{tabular}{|c|c|c|c|}
\hline CAT no. & List no. & Context & Description \\
\hline 18 & 021 & $\begin{array}{l}\text { C36, main midden } \\
(6 / 7-12-1993)\end{array}$ & $\begin{array}{l}\text { red deer, metapodium; L.54.0; B.14.0; Th.9.0; Wt.4.5; probably complete; } \\
\text { bevel spalled; polish/rounding }\end{array}$ \\
\hline 19 & 022 & $\begin{array}{l}\text { C36, main midden } \\
(6 / 7-12-1993)\end{array}$ & $\begin{array}{l}\text { red deer, metatarsus; L.51.5; B.13.5; Th.10.0; Wt.3.1; possibly complete; } \\
\text { lateral edge chipped? }\end{array}$ \\
\hline 20 & 023 & $\begin{array}{l}\text { C36, main midden } \\
(6 / 7-12-1993)\end{array}$ & red deer, metatarsus; L.47.0; B.14.0; Th.12.0; complete; polish/rounding \\
\hline 21 & 024 & $\begin{array}{l}\text { C36, main midden } \\
(6 / 7-12-1993)\end{array}$ & $\begin{array}{l}\text { ruminant, longbone; L.47.5; B.13.0; Th.8.5; Wt.4.3; probably complete; bevel } \\
\text { spalled and pocked; polish; ?lateral edge chipping; stain; ?BURNT }\end{array}$ \\
\hline 22 & 025 & $\begin{array}{l}\text { C36, main midden } \\
(6 / 7-12-1993)\end{array}$ & $\begin{array}{l}\text { red deer, metacarpus; L.45.0; B.11.0; Th.9.0; Wt.3.1; probably broken longi- } \\
\text { tudinally down whole tool; dark stain; ?BURNT; polish; bevel striated }\end{array}$ \\
\hline 23 & 026 & $\begin{array}{l}\text { C36, main midden } \\
(6 / 7-12-1993)\end{array}$ & $\begin{array}{l}\text { ruminant, longbone; L.58.5; B.11.5; Th.6.0; Wt.3.8; length complete but } \\
\text { spilt longitudinally through bevel; polish; rounded edges at base }\end{array}$ \\
\hline 24 & 027 & $\begin{array}{l}\text { C36, main midden } \\
(6 / 7-12-1993)\end{array}$ & $\begin{array}{l}\text { red deer, metacarpus; L.57.5; B.17.0; Th.10.0; Wt.8.4; slight break at base; } \\
\text { polish/rounding }\end{array}$ \\
\hline 25 & 029 & $\begin{array}{l}\text { C36, main midden } \\
(6 / 7-12-1993)\end{array}$ & $\begin{array}{l}\text { red deer, metatarsus; L.44.0; B.20.0; Th.10.0; Wt.8.1; probably broken at } \\
\text { the base; bevel spalled; polish/rounding }\end{array}$ \\
\hline $26^{*}$ & 030 & $\begin{array}{l}\text { C36, main midden } \\
(6 / 7-12-1993)\end{array}$ & $\begin{array}{l}\text { red deer, metatarsus; L.70.5; B.15.5; Th.8.5; Wt.6.1; old longitudinal } \\
\text { fracture through the bevel on the inner surface of the base; modern break } \\
\text { at the base; polish/rounding; AA-29315: uncal } 5190 \pm 55 \text { BP (tool split during } \\
\text { sampling). Illus } 35 \text { and } 51 \text {. }\end{array}$ \\
\hline 27 & 031 & $\begin{array}{l}\text { C36, main midden } \\
(6 / 7-12-1993)\end{array}$ & $\begin{array}{l}\text { red deer, metatarsus; L.70.0; B.20.5; Th.7.0; Wt.6.2; probably broken at the } \\
\text { base; probably split longitudinally through the bevel; bevel spalled }\end{array}$ \\
\hline 28 & 034 & $\begin{array}{l}\text { C36, main midden } \\
(6 / 7-12-1993)\end{array}$ & $\begin{array}{l}\text { red deer, metapodium; L.64.0; B.14.5; Th.9.0; Wt.7.7; probably complete; } \\
\text { one lateral edge chipped at the base, the opposite edge chipped in the } \\
\text { middle; polish/rounding }\end{array}$ \\
\hline 29 & 035 & $\begin{array}{l}\text { C36, main midden } \\
(6 / 7-12-1993)\end{array}$ & $\begin{array}{l}\text { ruminant, longbone; L.29.5; B.14.0; Th.8.0; Wt.1.7; fragment only; snapped } \\
\text { at base of stem; bevel split longitudinally but probably reused after; polish/ } \\
\text { rounding; weathered }\end{array}$ \\
\hline 30 & 038 & $\begin{array}{l}\text { C36, main midden } \\
(7-12-1993)\end{array}$ & $\begin{array}{l}\text { ruminant, longbone; L.30.5; B.7.0; Th.4.5; Wt.0.6; fragment only; split off } \\
\text { longitudinally through the bevel }\end{array}$ \\
\hline 31 & 039 & $\begin{array}{l}\text { C36, shell midden } \\
(6 / 7-12-1993)\end{array}$ & $\begin{array}{l}\text { red deer, metapodium; L.45.0; B.12.5; Th.8.0; Wt.2.5; possibly complete or } \\
\text { almost so; heavily weathered. Illus } 33 \text {. }\end{array}$ \\
\hline 32 & 040 & $\begin{array}{l}\text { C36, bottom of main } \\
\text { midden }(7-12-1993)\end{array}$ & $\begin{array}{l}\text { red deer, metatarsus; L.161.0; B.27.0; Th.15.0; Wt.43.1; complete, except } \\
\text { for major spall damage to the bevel and modern damage at the base on one } \\
\text { edge; polish/rounding; one lateral edge chipped. Illus } 34 \text {. }\end{array}$ \\
\hline 33 & 041 & C31 & $\begin{array}{l}\text { red deer, metacarpus; L.109.5; B.15.5; Th.12.5; Wt.9.6; modern break at the } \\
\text { base; bevel broken by longitudinal fracture; weathered }\end{array}$ \\
\hline 34 & 042 & C36, shell midden & $\begin{array}{l}\text { ruminant, longbone; L.58.0; B.12.0; Th.11.0; Wt.3.5; probably complete; } \\
\text { polish; weathered }\end{array}$ \\
\hline 35 & 043 & $\begin{array}{l}\text { C36, main midden } \\
(7-12-1993)\end{array}$ & $\begin{array}{l}\text { ruminant, longbone; L.38.0; B.7.5; Th.8.0; Wt.1.8; ?near complete; possibly } \\
\text { split longitudinally and then reused; polish }\end{array}$ \\
\hline 36 & 044 & C36 & $\begin{array}{l}\text { red deer, tibia; L.65.0; B.14.0; Th.11.0; Wt.8.7; probably complete; polish/ } \\
\text { rounding; tapered base }\end{array}$ \\
\hline 37 & 046 & C36 & $\begin{array}{l}\text { red deer, femur; L.56.0; B.19.0; Th.6.5; Wt.6.6; probably complete; bevel } \\
\text { heavily spalled; polish. Illus } 33 \text {. }\end{array}$ \\
\hline 38 & 047 & C36 & $\begin{array}{l}\text { red deer, metacarpus; L.65.5; B.15.0; Th.9.0; Wt.7.2; probably complete; } \\
\text { bevel spalled, reused after spalling; polish; base tapered }\end{array}$ \\
\hline 39 & 048 & C36 & $\begin{array}{l}\text { ruminant, longbone; L.54.0; B.13.5; Th.6.0; Wt.2.4; probably broken at base; } \\
\text { bevel spalled; polish/rounding }\end{array}$ \\
\hline 40 & 049 & C36 & $\begin{array}{l}\text { ruminant, longbone; L. } 67.0 \text {; B.17.5; Th.8.5; Wt.6.0; probably complete; bevel } \\
\text { spalled; base tapered; polish; has a cutmark }\end{array}$ \\
\hline 41 & 050 & C36 & $\begin{array}{l}\text { red deer, metatarsus; L.70.5; B.19.0; Th.7.0; Wt.6.0; probably complete; } \\
\text { bevel spalled; polish }\end{array}$ \\
\hline 42 & 051 & C36 & $\begin{array}{l}\text { red deer, metatarsus; L.64.0; B.14.0; Th.7.0; Wt.3.9; possibly complete, } \\
\text { but has one fragile, sharp lateral edge; other lateral edge has chipping; } \\
\text { polish/rounding }\end{array}$ \\
\hline
\end{tabular}




\begin{tabular}{|c|c|c|c|}
\hline CAT no. & List no. & Context & Description \\
\hline 43 & 052 & C36 & $\begin{array}{l}\text { ruminant, longbone; L.59.0; B.20.5; Th.7.5; Wt.5.1; probably complete; bevel } \\
\text { spalled; polish/rounding; base tapered }\end{array}$ \\
\hline $44^{*}$ & 054 & $\begin{array}{l}\text { C36, bottom of main } \\
\text { midden }(7-12-1993)\end{array}$ & $\begin{array}{l}\text { red deer, metatarsus; L.152.0; B.30.5; Th.15.5; Wt. } 37.6 \text {; modern break at } \\
\text { base; bevel heavily spalled; sampled for radiocarbon dating (after removal } \\
\text { of sample Wt. }=35.4 \mathrm{~g} \text { ); flaking on one lateral edge; polish/rounding; OxA- } \\
\text { 4994: uncal } 7590 \pm 90 \text { BP. Illus } 34 \text { and } 37 \text {. }\end{array}$ \\
\hline 45 & 055 & C36 & $\begin{array}{l}\text { red deer, metatarsus; L.146.0; B.21.0; Th.15.5; Wt.27.4; complete; bevel } \\
\text { spalled; slight modern damage just below the bevel on one lateral edge; } \\
\text { polish/rounding; base formed by an articular terminal. Illus } 34 \text { and } 37 .\end{array}$ \\
\hline 46 & 057 & C36, shell midden & $\begin{array}{l}\text { ruminant, longbone; L.47.0; B.14.5; Th.7.5; Wt.4.5; possibly complete; } \\
\text { BURNT; has a cutmark; bevel striated }\end{array}$ \\
\hline 47 & 058 & $\begin{array}{l}\text { C36, main midden } \\
(7-12-1993)\end{array}$ & $\begin{array}{l}\text { ruminant, longbone; L.61.5; B.12.5; Th.6.5; Wt.3.6; ?slight break at the } \\
\text { base; bevel spalled }\end{array}$ \\
\hline 48 & 059 & C31 & $\begin{array}{l}\text { ruminant, longbone; L. } 34.0 \text {; B.13.5; Th.7.0; Wt.1.9; probably complete; the } \\
\text { base is heavily spalled and could possibly have formerly been bevelled; } \\
\text { one lateral edge chipped; possibly not a conventional bevel-ended tool } \\
\text { - perhaps the base of a spatula-type implement? }\end{array}$ \\
\hline 49 & 060 & C31 & $\begin{array}{l}\text { ruminant, longbone; L.59.0; B.12.0; Th.6.5; Wt.3.9; probably complete; bevel } \\
\text { spalled and striated; polish/rounding; base tapered }\end{array}$ \\
\hline 50 & 061 & C31, 4 & $\begin{array}{l}\text { red deer, metacarpus; L.52.0; B.12.0; Th.11.5; Wt.2.8; probably complete in } \\
\text { length; bevel split longitudinally, modern; lateral edge chipping? }\end{array}$ \\
\hline 51 & 062 & C31 & $\begin{array}{l}\text { ruminant, longbone; L.54.0; B.14.0; Th.9.0; Wt.3.6; virtually complete; bevel } \\
\text { pocked; lateral edge chipping; polish }\end{array}$ \\
\hline $52^{*}$ & 064 & C31, 4 & $\begin{array}{l}\text { ruminant, longbone; L. } 62.0 \text {; B.13.5; Th.8.0; Wt.4.6; broken at base, snapped; } \\
\text { polish/rounding; ?split longitudinally through the bevel then reused; AA- } \\
\text { 29314: } 3975 \pm 50 \text { uncal BP. Illus } 35 \text { and } 51 \text {. }\end{array}$ \\
\hline 53 & 065 & C31 & $\begin{array}{l}\text { red deer, metacarpus; L.82.0; B.17.0; Th.8.5; Wt.7.5; probably complete; } \\
\text { lateral edge chipping; bevel pocked; polish/rounding; base tapered }\end{array}$ \\
\hline 54 & 066 & $\mathrm{C} 31,4$ & $\begin{array}{l}\text { ruminant, longbone; L.53.5; B.11.0; Th.5.5; Wt.1.9; possibly complete; slight } \\
\text { modern damage to one lateral edge of the bevel; weathered }\end{array}$ \\
\hline 55 & 067 & C31, 4 & $\begin{array}{l}\text { ruminant, longbone; L.45.0; B.9.0; Th.10.5; Wt.3.3; bevel broken longitudi- } \\
\text { nally; probably broken at the base }\end{array}$ \\
\hline 56 & 069 & C31 & $\begin{array}{l}\text { ruminant, longbone; L.41.0; B.13.0; Th.8.0; Wt.2.8; probably broken at the } \\
\text { base }\end{array}$ \\
\hline 57 & 070 & C31 & $\begin{array}{l}\text { ruminant, tibia; L.51.0; B.12.5; Th.9.5; Wt.3.0; probably broken at the base; } \\
\text { some rounding }\end{array}$ \\
\hline 58 & 071 & C31 & $\begin{array}{l}\text { ruminant, longbone; L.50.5; B.12.5; Th.9.5; Wt.4.0; probably complete; } \\
\text { polish/rounding; lateral edge chipping }\end{array}$ \\
\hline 59 & 072 & C31 & $\begin{array}{l}\text { red deer, metatarsus; L.39.5; B.18.0; Th.10.0; Wt.3.3; fragment } \\
\text { only; snapped medially, modern break; bevel spalled and striated; } \\
\text { polish/rounding }\end{array}$ \\
\hline 60 & 073 & C31 & $\begin{array}{l}\text { red deer, metatarsus; L. } 42.5 \text {; B.13.0; Th.9.5; Wt.2.5; possibly near complete; } \\
\text { slight damage at base; base tapered }\end{array}$ \\
\hline 61 & 074 & C31 & $\begin{array}{l}\text { ruminant, longbone; L.46.5; B.8.5; Th.7.0; Wt.1.6; fragment only; split longi- } \\
\text { tudinally through bevel and down whole length of tool }\end{array}$ \\
\hline 62 & 075 & C36, shell midden & $\begin{array}{l}\text { red deer, metatarsus; L.113.0; B.11.0; Th.10.0; Wt.8.9; ?fragment only; } \\
\text { split longitudinally through bevel and down whole length of tool, but may } \\
\text { be reused after split; possibly not a conventional bevel-ended tool; bevel } \\
\text { spalled; lateral chipping; polish }\end{array}$ \\
\hline 63 & 076 & C31 & $\begin{array}{l}\text { ruminant, longbone; L. } 66.0 ; \text { B.12.5; Th. } 6.0 ; \text { Wt.3.1; split longitudinally } \\
\text { through the bevel and down one edge; possibly intact at the base; bevel } \\
\text { spalled; weathered }\end{array}$ \\
\hline 64 & 077 & C31 & $\begin{array}{l}\text { ruminant, longbone; L. } 74.0 \text {; B.12.0; Th.8.5; Wt.4.7; possibly complete; base } \\
\text { tapered; narrow bevel; probably reused after a longitudinal split; lateral } \\
\text { edge chipped }\end{array}$ \\
\hline 65 & 078 & C31 & $\begin{array}{l}\text { ?ruminant, ?longbone (?cetacean bone); L.66.0; B.19.0; Th.9.0; Wt.3.1; } \\
\text { possibly complete, except for slight damage at base; bevel striated; heavily } \\
\text { weathered. Illus } 35 \text {. }\end{array}$ \\
\hline
\end{tabular}




\begin{tabular}{|c|c|c|c|}
\hline CAT no. & List no. & Context & Description \\
\hline 66 & 079 & $\mathrm{C} 31,4$ & $\begin{array}{l}\text { ruminant, longbone; L.72.5; B.14.5; Th.9.0; Wt.5.0; probably complete; } \\
\text { rounding; base tapered }\end{array}$ \\
\hline 67 & 080 & C31 & $\begin{array}{l}\text { ruminant, longbone; L.74.5; B.19.0; Th.8.5; Wt.5.7; possibly complete; bevel } \\
\text { heavily damaged by spalling; polish/rounding; base tapered }\end{array}$ \\
\hline 68 & 081 & $\mathrm{C} 31,4$ & $\begin{array}{l}\text { 68081C31, 4; red deer, metapodium; L.53.0; B.15.0; Th.7.0; Wt.4.1; possibly } \\
\text { complete in length; bevelled end spilt obliquely on one edge; remainder of } \\
\text { bevel heavily spalled; polish }\end{array}$ \\
\hline 69 & 103 & $\begin{array}{l}\text { C36, base: column } 1 \text {, } \\
\text { S.J.(a) }\end{array}$ & $\begin{array}{l}\text { red deer, metatarsus; L.119.5; B.39.0; Th.21.0; Wt.37.1; complete; bevel spilt } \\
\text { longitudinally then reused; base formed by an intact articular terminal; } \\
\text { polish/rounding. Illus } 36 \text {. }\end{array}$ \\
\hline $70^{*}$ & 104 & C38 & $\begin{array}{l}\text { red deer, metapodium; L.53.0; B.14.0; Th.10.0; Wt.4.5; possibly broken at } \\
\text { the base; one lateral edge of the bevel damaged by a modern spall; bevel } \\
\text { striated; polish; AA-29313: } 3660 \pm 65 \text { uncal BP. Illus } 35 \text { and } 51 \text {. }\end{array}$ \\
\hline 71 & 105 & $\begin{array}{l}\text { C36: column 1, } \\
\text { sample D }\end{array}$ & $\begin{array}{l}\text { red deer, metapodium; L.49.5; B.13.0; Th.7.5; Wt.5.5; complete; } \\
\text { polish/rounding }\end{array}$ \\
\hline 72 & 106 & $\begin{array}{l}\text { C36: column 1, } \\
\text { sample D }\end{array}$ & $\begin{array}{l}\text { red deer, metacarpus; L.67.5; B.15.0; Th.8; Wt.8.4; complete; one lateral } \\
\text { edge chipped; polish }\end{array}$ \\
\hline 73 & 107 & $\begin{array}{l}\text { C38, main midden, } \\
\text { BB5 }\end{array}$ & $\begin{array}{l}\text { ruminant, longbone; L.30.5; B.11.0; Th.5.5; Wt.1.2; ?complete; possibly split } \\
\text { longitudinally down whole implement and reused; bevel heavily spalled; } \\
\text { polish }\end{array}$ \\
\hline 74 & 228 & $\begin{array}{l}\text { C36, shell midden } \\
(6 / 7-12-1993)\end{array}$ & $\begin{array}{l}\text { ruminant, longbone; L.42.5; B.14.0; Th.7.0; Wt.1.4; fragment only, split } \\
\text { longitudinally; modern breaks at base and on one lateral edge }\end{array}$ \\
\hline 75 & 583 & $\mathrm{C} 31, \mathrm{BB} 4$ & $\begin{array}{l}\text { ruminant, longbone; L.33.0; B.15.0; Th.6.0; Wt.2.5; bevelled end only; } \\
\text { modern break; bevel heavily splintered and spalled; weathered }\end{array}$ \\
\hline $76^{*}$ & 612 & $\mathrm{C} 31, \mathrm{BB} 4$ & $\begin{array}{l}\text { red deer, metacarpus; L.89.0; B.14.0; Th.13.0; Wt.9.7; possibly complete; } \\
\text { polish/rounding; AA-29311: } 4175 \pm 60 \text { uncal BP. Illus } 35 \text { and } 51 .\end{array}$ \\
\hline 77 & 695 & $\begin{array}{l}\text { C31, main midden, } \\
\text { BB6 }\end{array}$ & $\begin{array}{l}\text { ruminant, longbone; L.50.5; B.10.5; Th.6.0; Wt.2.4; split longitudinally } \\
\text { through the bevel and down the whole tool, but possibly complete in length; } \\
\text { base heavily spalled, possibly previously bevelled; bevel spalled }\end{array}$ \\
\hline 78 & 722 & $\begin{array}{l}\mathrm{C} 31, \mathrm{BB} 1 \text { and } \\
\text { 'cleaning above } \\
\text { pavement' }\end{array}$ & $\begin{array}{l}\text { ?roe deer, metacarpus; L.50.0; B.11.5; Th.6.0; Wt.2.7; possibly broken at the } \\
\text { base; weathered }\end{array}$ \\
\hline 79 & 832 & $\mathrm{C} 31, \mathrm{BB} 6$ & $\begin{array}{l}\text { unidentified; L.43.0; B.8.0; Th.6.5; Wt.2.1; complete; stained; ?split longitu- } \\
\text { dinally then reused; polish/rounded }\end{array}$ \\
\hline
\end{tabular}


Bevel-ended tools, bevelled at both ends (all of bone)

\begin{tabular}{|c|c|c|c|}
\hline CAT no. & List no. & Context & Description \\
\hline 80 & 002 & $\begin{array}{l}\text { C36, main midden } \\
(6 / 7-12-1993)\end{array}$ & $\begin{array}{l}\text { red deer, metapodium; L.62.0; B.14.0; Th.9.5; Wt.4.5; double ended; } \\
\text { near complete; one bevel fractured longitudinally; intact bevel striated; } \\
\text { rounding; lateral edges chipped; weathered; main bevelled surfaces on } \\
\text { same face of tool. Illus } 33 \text { and } 35 \text {. }\end{array}$ \\
\hline 81 & 014 & C36, main midden & $\begin{array}{l}\text { ruminant, longbone; L.51.5; B.15.0; Th.6.0; Wt.5.9; double ended; } \\
\text { complete; bevel at narrower end spalled; pronounced polish/rounding; } \\
\text { main bevelled surfaces on same face of tool. Illus } 33 \text { and } 35 .\end{array}$ \\
\hline 82 & 028 & $\begin{array}{l}\text { C36, main midden } \\
(6 / 7-12-1993)\end{array}$ & $\begin{array}{l}\text { ruminant, longbone; L. } 47.5 \text {; B.12.0; Th.6.5; Wt.3.0; double ended; } \\
\text { complete; split longitudinally through one bevel, the other bevel } \\
\text { postdates this; dark stain; polish; the truncated bevel is striated; main } \\
\text { bevelled surfaces on same face of tool. Illus } 35 \text {. }\end{array}$ \\
\hline 83 & 032 & C36, main midden & $\begin{array}{l}\text { ruminant, longbone; L. } 48.0 \text {; B.13.5; Th.7.5; Wt.3.5; double ended; } \\
\text { complete; one bevel split longitudinally, which is postdated by the other } \\
\text { bevel; polish; lateral edge chipping; intact bevel pocked; main bevelled } \\
\text { surfaces on opposite faces of tool. Illus } 33 \text { and } 35 \text {. }\end{array}$ \\
\hline 84 & 033 & $\begin{array}{l}\text { C36, main midden } \\
(6 / 7-12-1993)\end{array}$ & $\begin{array}{l}\text { red deer, metatarsus; L.42.0; B.12.5; Th.11.0; Wt.4.3; double ended; } \\
\text { complete; one bevel heavily spalled and split longitudinally, the split } \\
\text { predates the other bevel, which is intact; polish/rounding; main bevelled } \\
\text { surfaces on opposite faces of the tool. Illus } 35 \text {. }\end{array}$ \\
\hline 85 & 036 & $\begin{array}{l}\text { C36, main midden } \\
(6 / 7-12-1993)\end{array}$ & $\begin{array}{l}\text { ruminant, longbone; L.46.0; B.9.5; Th.7.5; Wt.3.1; double ended; complete; } \\
\text { one bevel spalled and almost obscured by damage; the damaged bevel } \\
\text { is also split longitudinally, which the other bevel postdates; polish; dark } \\
\text { stain; ?BURNT; disposition of the damaged bevel uncertain. Illus } 35 \text {. }\end{array}$ \\
\hline 86 & 063 & C31 & $\begin{array}{l}\text { red deer, metatarsus; L.75.5; B.11.5; Th.9.5; Wt.4.2; double ended; } \\
\text { complete in length; one bevel split and postdated by the opposite end } \\
\text { bevel, which in turn is broken longitudinally; weathered; main bevelled } \\
\text { surfaces on same face of tool }\end{array}$ \\
\hline 87 & 083 & C31 & $\begin{array}{l}\text { ruminant, tibia; L. } 61.0 ; \text { B.13.0; Th.8.5; Wt. } 4.4 \text {; double ended; complete in } \\
\text { length; broken obliquely through the bevel at one end; the bevel at the } \\
\text { opposite end is heavily pocked/spalled; polish; main bevelled surfaces } \\
\text { probably on the same surface of the tool }\end{array}$ \\
\hline 88 & 102 & $\begin{array}{l}\text { C36: column 1, sample } \\
\text { G.(a) }\end{array}$ & $\begin{array}{l}\text { red deer, tibia; L.146.0; B.25.5; Th.11.0; Wt.37.9; double ended; complete; } \\
\text { bevels pock-marked; polish/smoothing; main bevelled surfaces on same } \\
\text { surface of the tool. Illus } 36 \text {. }\end{array}$ \\
\hline
\end{tabular}

Tools with combined bevel-end and intentional point (all of bone)

\begin{tabular}{llll}
\hline CAT no. & List no. & Context & Description \\
\hline 89 & 045 & C36 & $\begin{array}{l}\text { red deer, metacarpus; L.64.0; B.16.5; Th.10.0; Wt.7.6; complete apart } \\
\text { from modern break down one lateral edge of the bevel; pronounced } \\
\text { polish. Illus } 35 \text { and } 38 .\end{array}$ \\
90 & 053 & C36 & $\begin{array}{l}\text { red deer, metacarpus; L.51.5; B.15.5; Th.8.5; Wt.3.2; complete except for } \\
\text { slight damage at the tip of the point; lateral edge chipping; polish; bevel } \\
\text { striated. Illus 35. }\end{array}$ \\
\hline
\end{tabular}


Points (tools with intentionally pointed ends) (all of bone unless otherwise stated)

\begin{tabular}{|c|c|c|c|}
\hline CAT no. & List no. & Context & Description \\
\hline 91 & 091 & C36 & $\begin{array}{l}\text { red deer, metatarsus; L.109.5; B.12.5; Th.8.0; Wt.8.4; complete; fine } \\
\text { point; polish; polished facet at non-pointed terminal possibly relates to a } \\
\text { previous use. Illus } 36 \text { and } 39 .\end{array}$ \\
\hline 92 & 092 & C36 & $\begin{array}{l}\text { roe deer; metacarpus; L.65.0; B.11.0; Th.5.5; Wt.2.7; point broken, old } \\
\text { break; opposite terminal broken, modern break; polish }\end{array}$ \\
\hline 93 & 093 & C36 & $\begin{array}{l}\text { ruminant, longbone; L.85.0; B.12.0; Th.10.0; Wt. 5.0; old break at the tip } \\
\text { of the point; dark mark near tip of point; polish. Illus } 36 \text { and } 39 .\end{array}$ \\
\hline 94 & 094 & C36 & $\begin{array}{l}\text { ruminant, longbone; L.91.0; B.8.5; Th.6.0; Wt.3.7; slight break or use } \\
\text { damage at tip of point; opposite terminal possibly broken; polish. Illus } \\
35 \text {. }\end{array}$ \\
\hline 95 & 095 & C36 & $\begin{array}{l}\text { ruminant, rib; L.58.0; B.6.5; Th.2.5; Wt.0.9; on narrow splinter; point } \\
\text { slightly broken; possibly broken at opposite terminal; polish }\end{array}$ \\
\hline 96 & 096 & C36 & $\begin{array}{l}\text { ruminant, tibia; L.88.5; B.18.0; Th.7.0; Wt.4.5; complete; polish. Illus } 36 \\
\text { and } 39 .\end{array}$ \\
\hline 97 & 097 & C36 & $\begin{array}{l}\text { roe deer; metacarpus; L. } 43.0 ; \text { B.9.0; Th.4.5; Wt.0.7; slight break at the } \\
\text { tip of the point; broken at the opposite terminal; polish }\end{array}$ \\
\hline 98 & 098 & C31 & $\begin{array}{l}\text { red deer, ANTLER; L.29.5; B.8.5; Th.6.5; Wt.0.8; tip only; modern break } \\
\text { at opposite terminal; polish }\end{array}$ \\
\hline 99 & 099 & C36 & $\begin{array}{l}\text { ruminant, longbone; L.68.0; B.9.5; Th.5.5; Wt.2.1; narrow tip; modern } \\
\text { break at the opposite terminal; polish. Illus } 36 \text { and } 39 .\end{array}$ \\
\hline 100 & 100 & C36 & $\begin{array}{l}\text { ?roe deer, metatarsus; L.85.0; B.6.0; Th.4.5; Wt.2.1; pointed at both } \\
\text { terminals; narrower end complete; slight damage at opposite, slightly } \\
\text { thicker tip; polish. Illus } 36 \text { and } 39 .\end{array}$ \\
\hline 101 & 101 & C36 (7-12-1993) & $\begin{array}{l}\text { ruminant, longbone; L.37.0; B.9.5; Th.5.0; Wt.1.3; broken at the point; } \\
\text { modern break at opposite terminal; polish }\end{array}$ \\
\hline $102 *$ & 108 & $\begin{array}{l}\text { C36: column 1, sample } \\
\mathrm{H}\end{array}$ & $\begin{array}{l}\text { roe deer, tibia; L.104.5; B.21.0; Th.16.5; Wt.12.0; complete; obliquely split } \\
\text { shaft type of bone point; non-pointed end is the epiphyseal terminal of } \\
\text { the bone; smooth, waxy feel; very well-preserved; AA-29312: } 2045 \pm 60 \\
\text { uncal BP. Illus } 36 \text {. }\end{array}$ \\
\hline 103 & 634 & $\mathrm{C} 31, \mathrm{BB} 4$ & $\begin{array}{l}\text { ruminant, longbone; L.50.5; B.22.0; Th.15.0; Wt.5.1; old break at the tip } \\
\text { of the point; opposite terminal intact and articular }\end{array}$ \\
\hline
\end{tabular}


Miscellaneous/unclassified worked pieces (all of bone unless otherwise stated)

\begin{tabular}{|c|c|c|c|}
\hline CAT no. & List no. & Context & Description \\
\hline 104 & 037 & $\begin{array}{l}\text { C36, main midden } \\
(6 / 7-12-1993)\end{array}$ & $\begin{array}{l}\text { suid, fibula; L. } 49.5 \text {; B.8.0; Th.3.5; Wt.1.1; probably a point, but broken at } \\
\text { the tip; the base is semi-bevelled; polish }\end{array}$ \\
\hline 105 & 056 & $\begin{array}{l}\text { C36, main midden } \\
(7-12-1993)\end{array}$ & $\begin{array}{l}\text { ruminant, longbone; L.98.5; B.15.5; Th.5.5; Wt.10.4; part of polished } \\
\text { tool - ?spatula type; one end intact and worn smooth; other end absent, } \\
\text { ancient break. Illus } 36 .\end{array}$ \\
\hline 106 & 068 & $\begin{array}{l}\text { C36, main midden } \\
(7-12-1993)\end{array}$ & $\begin{array}{l}\text { ruminant, longbone; L.50.0; B.6.5; Th.6.0; Wt.1.1; ?fragment only; split off } \\
\text { longitudinally through the modified area; possibly part of a bevel-ended } \\
\text { tool }\end{array}$ \\
\hline 107 & 082 & $\begin{array}{l}\text { C36, main midden } \\
(7-12-1993)\end{array}$ & $\begin{array}{l}\text { ruminant, longbone; L.58.0; B.10.5; Th.7.0; Wt.3.4; probably complete; } \\
\text { possibly a bevel-ended tool, but the putative bevel almost wholly obscured } \\
\text { by spalling; slight break and spalling at the narrow, opposite end; polish }\end{array}$ \\
\hline 108 & 084 & C36 & $\begin{array}{l}\text { ruminant, longbone; L.6.5; B.12.5; Th.7.0; Wt.1.4; fragment only, snapped; } \\
\text { spalled terminal is thin and carefully shaped; ?base of a spatula-type tool; } \\
\text { polish }\end{array}$ \\
\hline 109 & 085 & $\mathrm{C} 31,4$ & $\begin{array}{l}\text { red deer, metacarpus; L.94.5; B.14.0; Th.8.5; Wt. } 6.3 \text {; bevel-like worn } \\
\text { surface at articular end of the bone; opposite end fortuitously pointed and } \\
\text { possibly utilised }\end{array}$ \\
\hline 110 & 086 & $\begin{array}{l}\text { C36, main midden } \\
(7-12-1993)\end{array}$ & $\begin{array}{l}\text { unidentified; L.15.5; B.12.0; Th.3.5; Wt.0.5; spall only; with bevel-type wear } \\
\text { and cutmarks }\end{array}$ \\
\hline 111 & 088 & $\begin{array}{l}\text { C36, main midden } \\
(7-12-1993)\end{array}$ & $\begin{array}{l}\text { ruminant, longbone; L.34.5; B.9.5; Th.5.5; Wt.1.7; fragment with one } \\
\text { spalled and splintered terminal; possibly from a bevel-ended tool; polish }\end{array}$ \\
\hline 112 & $089 / 212$ & $\begin{array}{l}\text { C36, main midden/ } \\
\text { shell midden } \\
(6 / 7-12-1993)\end{array}$ & $\begin{array}{l}\text { ruminant, longbone; L.59.5; B.24.0; Th.14.0; Wt.8.8; two joining fragments, } \\
\text { modern break; medial segment of longbone, broken at both ends; one end } \\
\text { is modified and worn, being flat and spatula-like }\end{array}$ \\
\hline 113 & 090 & C31 & $\begin{array}{l}\text { red deer, ANTLER, tine-tip; L.81.0; B.23.5; Th.17.5; Wt.6.5; slight modern } \\
\text { damage at tip of tine; possibly used/smoothed }\end{array}$ \\
\hline 114 & 180 & $\begin{array}{l}\text { C36, shell midden } \\
(6 / 7-12-1993)\end{array}$ & $\begin{array}{l}\text { ruminant, longbone; L.83.0; B.22.0; Th.15.0; Wt.11.7; medial, longitudinally } \\
\text { split fragment, with a notch or half of a perforation on one of the lateral } \\
\text { edges; modern break at one end }\end{array}$ \\
\hline 115 & 408 & $\begin{array}{l}\text { C36, main midden } \\
(7-12-1993)\end{array}$ & $\begin{array}{l}\text { ruminant, longbone; L.56.5; B.19.0; Th.7.5; Wt.8.1; one end is smoothed/ } \\
\text { polished on a curve; the opposite end is broken }\end{array}$ \\
\hline 116 & 780 & C39 & $\begin{array}{l}\text { ruminant, longbone; L.20.0; B.14.5; Th.4.5; Wt.1.1; fragment only; spalled } \\
\text { bevelled terminal of thin, smoothed object }\end{array}$ \\
\hline
\end{tabular}

